\title{
The National Osteoporosis Foundation's position statement on peak bone mass development and lifestyle factors: a systematic review and implementation recommendations
}

\author{
C. M. Weaver ${ }^{1}$ - C. M. Gordon ${ }^{2,3}$ • K. F. Janz ${ }^{4}$ - H. J. Kalkwarf ${ }^{5}$ - J. M. Lappe ${ }^{6}$. \\ R. Lewis ${ }^{7}$ - M. O'Karma ${ }^{8}$ - T. C. Wallace ${ }^{9,10,13}$ • B. S. Zemel ${ }^{11,12}$
}

Received: 20 October 2015 / Accepted: 10 November 2015 / Published online: 8 February 2016

(C) The Author(s) 2016. This article is published with open access at Springerlink.com

\begin{abstract}
Lifestyle choices influence $20-40 \%$ of adult peak bone mass. Therefore, optimization of lifestyle factors known to influence peak bone mass and strength is an important strategy aimed at reducing risk of osteoporosis or low bone mass later in life. The National Osteoporosis Foundation has issued this scientific statement to provide evidence-based guidance and a national implementation strategy for the purpose of helping individuals achieve maximal peak bone mass early in life. In this scientific statement, we (1) report the results of an evidence-based review of the literature since 2000 on factors that influence achieving the full genetic potential for skeletal mass; (2) recommend lifestyle choices that
\end{abstract}

Author names for PubMed indexing Weaver CM, Gordon CM, Janz KF, Kalkwarf HJ, Lappe JM, Lewis R, O'Karma M, Wallace TC, Zemel BS

T. C. Wallace

taylor.wallace@me.com

1 Department of Nutritional Sciences, Women's Global Health Institute, Purdue University, $700 \mathrm{~W}$. State Street, West Lafayette, IN 47907, USA

2 Division of Adolescent and Transition Medicine, Cincinnati Children's Hospital, 3333 Burnet Avenue, MLC 4000, Cincinnati, OH 45229, USA

3 Department of Pediatrics, University of Cincinnati College of Medicine, 3230 Eden Ave, Cincinnati, OH 45267, USA

4 Departments of Health and Human Physiology and Epidemiology, University of Iowa, 130 E FH, Iowa City, IA 52242, USA

5 Division of Gastroenterology, Hepatology and Nutrition, Cincinnati Children's Hospital Medical Center, 3333 Burnet Avenue, MLC 7035, Cincinnati, OH 45229, USA

6 Schools of Nursing and Medicine, Creighton University, 601 N. 30th Street, Omaha, NE 68131, USA promote maximal bone health throughout the lifespan; (3) outline a research agenda to address current gaps; and (4) identify implementation strategies. We conducted a systematic review of the role of individual nutrients, food patterns, special issues, contraceptives, and physical activity on bone mass and strength development in youth. An evidence grading system was applied to describe the strength of available evidence on these individual modifiable lifestyle factors that may (or may not) influence the development of peak bone mass (Table 1). A summary of the grades for each of these factors is given below. We describe the underpinning biology of these relationships as well as other factors for which a systematic

7 Department of Foods and Nutrition, University of Georgia, Dawson Hall, Athens, GA 30602, USA

8 The Children's Hospital of Philadelphia Research Institute, 3535 Market Street, Room 1560, Philadelphia, PA 19104, USA

9 Department of Nutrition and Food Studies, George Mason University, MS 1 F8, 10340 Democracy Lane, Fairfax, VA 22030, USA

10 National Osteoporosis Foundation, 1150 17th Street NW, Suite 850, Washington, DC 20036, USA

11 University of Pennsylvania Perelman School of Medicine, 3535 Market Street, Room 1560, Philadelphia, PA 19104, USA

12 Division of Gastroenterology, Hepatology, and Nutrition, The Children's Hospital of Philadelphia, 3535 Market Street, Room 1560, Philadelphia, PA 19104, USA

13 National Osteoporosis Foundation, 251 18th Street South, Suite 630, Arlington, VA 22202, USA 
review approach was not possible. Articles published since 2000, all of which followed the report by Heaney et al. [1] published in that year, were considered for this scientific statement. This current review is a systematic update of the previous review conducted by the National Osteoporosis Foundation [1].

\begin{tabular}{|c|c|}
\hline Lifestyle Factor & Grade \\
\hline \multicolumn{2}{|l|}{ Macronutrients } \\
\hline Fat & $\mathrm{D}$ \\
\hline Protein & $\mathrm{C}$ \\
\hline \multicolumn{2}{|l|}{ Micronutrients } \\
\hline Calcium & A \\
\hline Vitamin D & $\mathrm{B}$ \\
\hline Micronutrients other than calcium and vitamin D & $\mathrm{D}$ \\
\hline \multicolumn{2}{|l|}{ Food Patterns } \\
\hline Dairy & $\mathrm{B}$ \\
\hline Fiber & $\mathrm{C}$ \\
\hline Fruits and vegetables & $\mathrm{C}$ \\
\hline Detriment of cola and caffeinated beverages & $\mathrm{C}$ \\
\hline \multicolumn{2}{|l|}{ Infant Nutrition } \\
\hline Duration of breastfeeding & $\mathrm{D}$ \\
\hline Breastfeeding versus formula feeding & $\mathrm{D}$ \\
\hline Enriched formula feeding & $\mathrm{D}$ \\
\hline \multicolumn{2}{|l|}{ Adolescent Special Issues } \\
\hline Detriment of oral contraceptives & $\mathrm{D}$ \\
\hline Detriment of DMPA injections & $\mathrm{B}$ \\
\hline Detriment of alcohol & $\mathrm{D}$ \\
\hline Detriment of smoking & $\mathrm{C}$ \\
\hline \multicolumn{2}{|l|}{ Physical Activity and Exercise } \\
\hline Effect on bone mass and density & A \\
\hline Effect on bone structural outcomes & B \\
\hline
\end{tabular}

Considering the evidence-based literature review, we recommend lifestyle choices that promote maximal bone health from childhood through young to late adolescence and outline a research agenda to address current gaps in knowledge. The best evidence (grade A) is available for positive effects of calcium intake and physical activity, especially during the late childhood and peripubertal years - a critical period for bone accretion. Good evidence is also available for a role of vitamin D and dairy consumption and a detriment of DMPA injections. However, more rigorous trial data on many other lifestyle choices are needed and this need is outlined in our research agenda. Implementation strategies for lifestyle modifications to promote development of peak bone mass and strength within one's genetic potential require a multisectored (i.e., family, schools, healthcare systems) approach.

Keywords Bone mineral content · Diet · Nutrition · Peak bone mass $\cdot$ Physical activity

\section{Abbreviations}

\%ucOC Percentage of undercarboxylated osteocalcin $95 \%$ CI $\quad 95 \%$ Confidence interval

aBMD Areal bone mineral density

BMC Bone mineral content

CDC US Centers for Disease Control and Prevention

CSA Cross-sectional area

CSMI Cross-sectional moment of inertia

CT Computed tomography

DEQAS Vitamin D External Quality Assessment Scheme

DMPA Depot medroxyprogesterone acetate

DONALD Dortmund Nutritional and Anthropometric

Longitudinally Designed

DXA Dual-energy x-ray absorptiometry

HHS US Department of Health and Human Services

HRpQCT High-resolution peripheral quantitative computed tomography

HSA Hip structural analysis

IGF Insulin-like growth factor

IOM Institute of Medicine

NHANES National Health and Nutrition Examination

Survey

OC Oral contraceptive

OR Odds ratio

pQCT Peripheral quantitative computed tomography

PRAL Potential renal acid load

QCT Quantitative computed tomography

RCT Randomized controlled trial

RDA Recommended dietary allowance

SSI Stress-strain index

UHT Ultra-heat-treated

uN Urinary nitrogen

USDA US Department of Agriculture

vBMD Volumetric bone mineral density

\section{Introduction}

\section{Bone accretion}

During growth and development, skeletal growth proceeds through the coordinated action of bone deposition and resorption to allow bones to expand (periosteal apposition of cortical bone) and lengthen (endochondral ossification) into their adult form [2]. This process of bone modeling begins during fetal growth and continues until epiphyseal fusion, usually by the end of the second decade of life [1]. Bone modeling is sensitive to mechanical loading, emphasizing the importance of physical activity throughout growth [2]. Some skeletal characteristics, such as cortical density and structural strength, determined by bone dimensions and thickness, continue to increase after epiphyseal fusion and into the third decade of life. Quantitatively, the amount of bone mineral acquired from 
Table 1 Evidence grading system

\begin{tabular}{|c|c|}
\hline $\begin{array}{l}\text { Level of } \\
\text { evidence }^{\mathrm{a}}\end{array}$ & Description \\
\hline \multirow[t]{3}{*}{ A: Strong } & $\begin{array}{l}\text { Clear evidence from at least one large, well-conducted, } \\
\text { generalizable RCT that is adequately powered with a } \\
\text { large effect size and is free of bias or other concerns }\end{array}$ \\
\hline & OR \\
\hline & $\begin{array}{l}\text { Clear evidence from multiple RCTs or many controlled } \\
\text { trials that may have few limitations related to } \\
\text { bias,measurement imprecision, inconsistent results, or } \\
\text { other concerns }\end{array}$ \\
\hline B: Moderate & $\begin{array}{l}\text { Evidence obtained from multiple, well-designed, } \\
\text { conducted, and controlled prospective cohort studies } \\
\text { that have used adequate and relevant measurements } \\
\text { and that gave similar results from different } \\
\text { populations }\end{array}$ \\
\hline & OR \\
\hline
\end{tabular}

Evidence obtained from a well-conducted meta-analysis of prospective cohort studies from different populations

C: Limited Evidence obtained from multiple prospective cohort studies from diverse populations that have limitations related to bias, measurement imprecision, or inconsistent results or have other concerns

OR

Evidence from only one well-designed prospective study with few limitations

OR

Evidence from multiple well-designed and conducted cross-sectional or case-controlled studies that have very few limitations that could invalidate the results from diverse populations

OR

Evidence from a meta-analysis that has design limitations

D: Inadequate Evidence from studies that have one or more major methodological flaws or many minor methodological flaws that result in low confidence in the effect estimate

OR

Insufficient data to support a hypothesis

OR

Evidence derived from clinical experience, historical studies (before and after), or uncontrolled descriptive studies or case reports

$R C T$ randomized controlled trial

${ }^{\text {a }}$ Refers to the body of evidence

birth to adulthood follows distinct age- and sex-specific patterns (Fig. 1). Bone mass is acquired relatively slowly throughout childhood. With the onset of puberty and the adolescent growth spurt in height, bone mineral accretion is rapid, reaching a peak shortly after peak height gain (Fig. 2). For total body bone mineral, the peak bone mineral accretion rate occurs at $12.5 \pm 0.90$ years in girls and $14.1 \pm 0.95$ years in boys of European ancestry [3]. During the 4 years surrounding

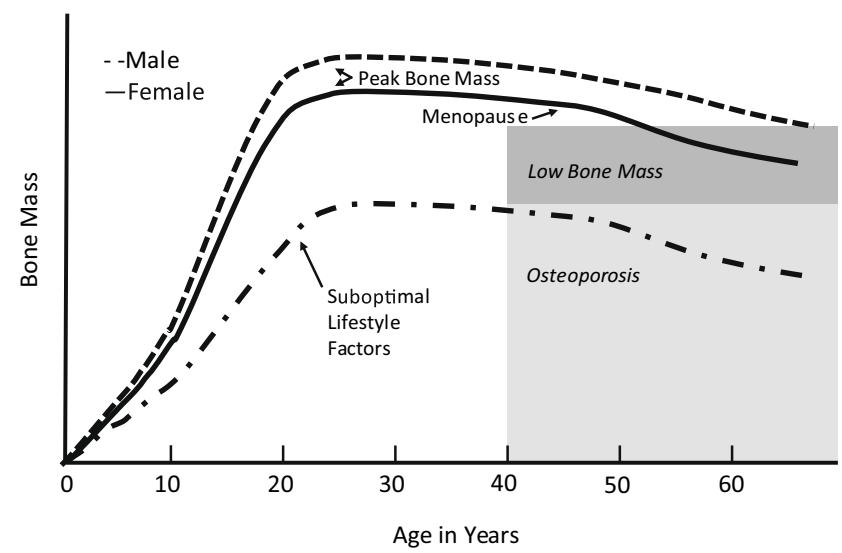

Fig. 1 Bone mass across the lifespan with optimal and suboptimal lifestyle choices

the peak in bone accretion, $39 \%$ of total body bone mineral is acquired; by 4 years following the peak, $95 \%$ of adult bone mass has been achieved [4]. Within a population, the distribution of bone mass becomes more variable, in part due to differences in height and other skeletal dimensions as adult size is attained, the timing and magnitude of peak bone mineral accrual, the cessation of bone accretion, and lifestyle factors. This period of rapid accretion may be a time of both opportunity and vulnerability for optimizing peak bone mass.

Changes in the structure (size and shape) and composition (amount of cartilage, cortical, and trabecular bone) of bone also occur with progression through puberty and thereby influence bone strength (Fig. 3). Cortical bone is the compact bone that forms the outer shell protecting bone marrow and trabecular bone. Trabecular bone is composed of rods and plates in a sponge-like structure, adding to the structural strength of bone. Cortical and trabecular bone differ in their responsiveness to disease effects, medications, muscle-loading and impact-loading physical activity, and hormonal changes. The relative importance of cortical versus trabecular bone in optimizing peak bone mass and strength and in minimizing fracture risk has not been firmly established in either childhood or adulthood. Distinct increases in trabecular bone of the spine and long bones occur between sexual maturity stages 3 and 4 [5-7]. The density of cortical bone is lower among children and adolescents than among adults, and it may even go through a transient period of increased porosity, particularly for boys [7, 8]. The density of cortical bone increases more rapidly as epiphyseal fusion occurs and continues into the third decade of life [9]. Both the inner and outer dimensions of long bones increase as growth proceeds, providing greater structural strength. The accumulation of bone mineral and changes in density and structural strength of bone may also continue into the third decade of life, depending on the bone compartment and skeletal site under consideration (Fig. 1). 
Fig. 2 Peak BMC gain and peak height velocity in boys and girls from longitudinal DXA analysis. Adapted from Bailey et al. [3]

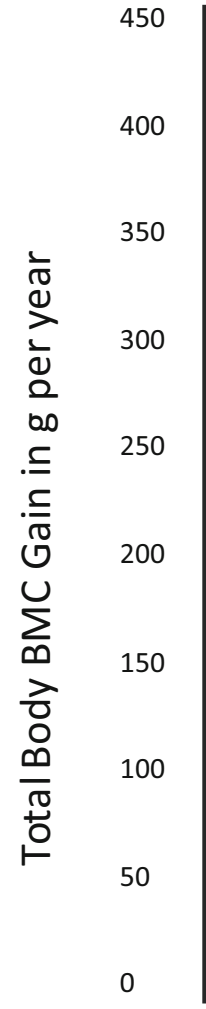

40

00

50

300

200

150

100

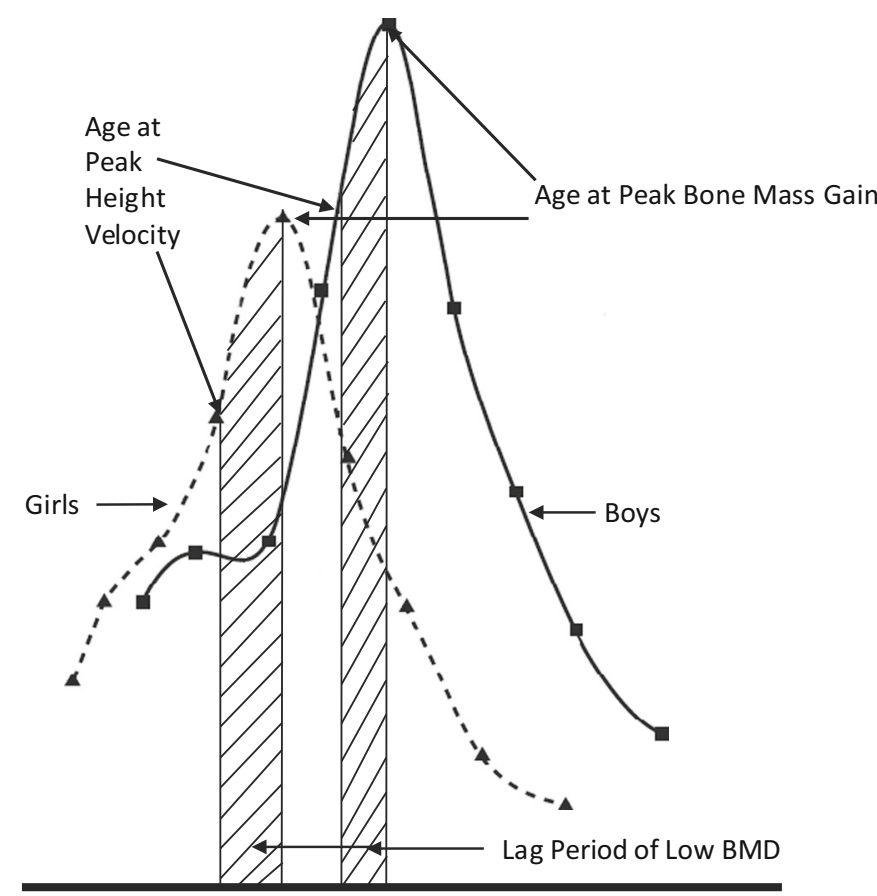

$\begin{array}{lllllllllll}9 & 10 & 11 & 12 & 13 & 14 & 15 & 16 & 17 & 18 & 19\end{array}$
Age in Years

\section{Definition of peak bone mass}

Peak bone mass is generally thought of as the amount of bone gained by the time a stable skeletal state has been attained during young adulthood. The concept of peak bone mass more broadly captures peak bone strength, which is characterized

\section{Growth and Bone}

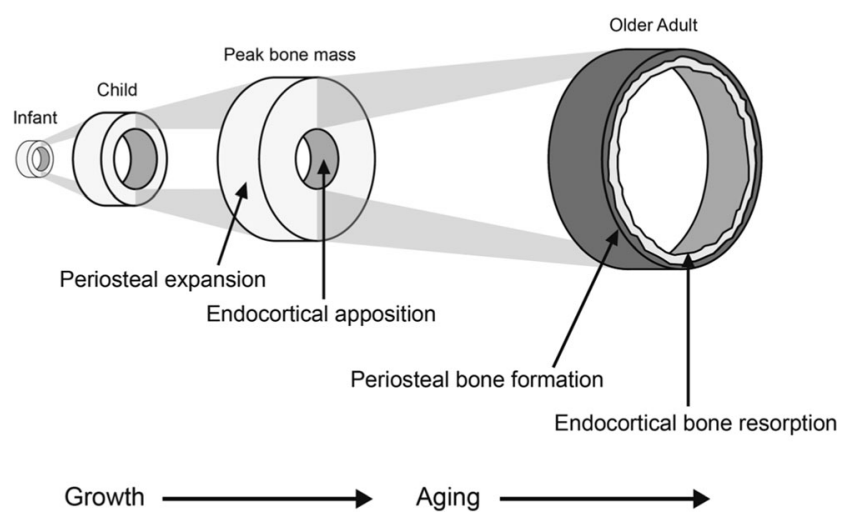

Fig. 3 Changes in structural composition of bone throughout the lifespan by mass, density, microarchitecture, microrepair mechanisms, and the geometric properties that provide structural strength.

There are several nuances to this concept that deserve recognition. The concept of peak bone mass is different when applied to an individual as opposed to a population. For an individual, peak bone mass may refer to the maximum amount of bone accrued during young adulthood. Alternatively, the concept of peak bone mass may refer to an individual's maximal or genetic potential for bone strength (i.e., bone mineral content (BMC), areal bone mineral density (aBMD), or other measures of bone strength). At the population level, peak bone mass is attained when age-related changes in a bone outcome are no longer positive and have attained a plateau or maximum value [10].

\section{Importance of peak bone mass}

\section{Fracture}

Optimizing bone accrual during growth may be of greatest significance in preventing current or future fractures, as measures of bone mass, density, and structural strength are associated with fracture in children and adults [11-13]. The frequency of fractures is higher among children compared to 
young and middle-aged adults [14], reflecting the vulnerability of the growing skeleton prior to peak bone mass. Among healthy children, as many as one half of boys and one third of girls will sustain a fracture by age 18 years, with one fifth sustaining two or more fractures $[15,16]$. Children who sustain a fracture before age 4 years are especially vulnerable to a subsequent fracture [17]. Thirty to $50 \%$ of childhood fractures involve the forearm $[14,15,18-20]$ and result from falls to an outstretched arm. There is a positive relationship between fracture frequency and level of physical activity due to the increased risk of falls during physical activity [21]. Thus, although physical activity is critical for bone modeling, children with higher levels of physical activity are more likely to have fractures [3, 22-28].

There is a developmental period during the rapid growth of late childhood and early adolescence when the skeleton is particularly vulnerable to fracture (Fig. 4) [29]. Recently, high-resolution peripheral quantitative computed tomography (HRpQCT) has been used to explain the microarchitectural basis for the observation of increased fracture frequency among young adolescents [7]. The combination of thinner cortical bone, lower total volumetric bone mineral density (vBMD), and increased cortical porosity, particularly in boys, suggests that linear bone growth outpaces bone mineralization, resulting in transient bone fragility.

Understanding factors that affect bone strength early in life is important because low bone strength is associated with fracture risk in later life, independent of fall incidence and physical activity [30]. Childhood bone mass is predictive of fracture risk during childhood, with an $89 \%$ increase in fracture risk per SD decrease in size-adjusted bone mass [31]. Moreover, among children who experience similar forearm injuries, those with greater bone density have been shown to be less likely to fracture [32]. Preterm children have low bone mass during late childhood [33], and birth weight is related to bone mass in later adult life (age $\geq 60$ years) [34].

Recent work using HRpQCT suggests that microarchitectural changes underlie increased bone fragility in children who sustain a distal forearm fracture following mild trauma compared to nonfracture controls [35]. Differences such as cortical thinning are seen at both the distal radius and distal tibia in children presenting with a forearm fracture in which the degree of trauma is mild (e.g., fall from standing height), but not in those where the trauma is moderate (e.g., fall while riding a bicycle). Further analysis, including microfinite element analysis of HRpQCT data, showed that the mild trauma distal forearm fracture cases had reduced bone strength (i.e., failure load) compared to children without a fracture history. Moderate trauma is sufficient to break healthy bones that are not otherwise inherently at increased risk of fracture. Clark et al. [21] have shown that, irrespective of bone mass, fracture risk rises as the amount of vigorous activity increases. Additional studies have shown that a forearm fracture in a child is associated with lower areal and vBMD, cortical area, and bone strength using peripheral quantitative computed tomography (pQCT) and dual-energy x-ray absorptiometry (DXA) [11]. Cohort studies in the USA and South Africa show that boys and girls of European descent have a greater fracture risk than children of African descent [36, 37], a finding that parallels patterns of osteoporosis and hip fracture in elderly adults [38, 39].

In childhood and adolescence, stress fractures exhibit a different pattern from typical long bone fractures. The lifetime prevalence of stress fracture among the general population is below $4 \%$ [40], and stress fractures are more common among women than among men [41]. In studies of military populations, where stress fractures are most common, the rate ratio
Fig. 4 Incidence of fractures of the distal forearm from birth through young adulthood. Adapted from Khosla et al. [29]

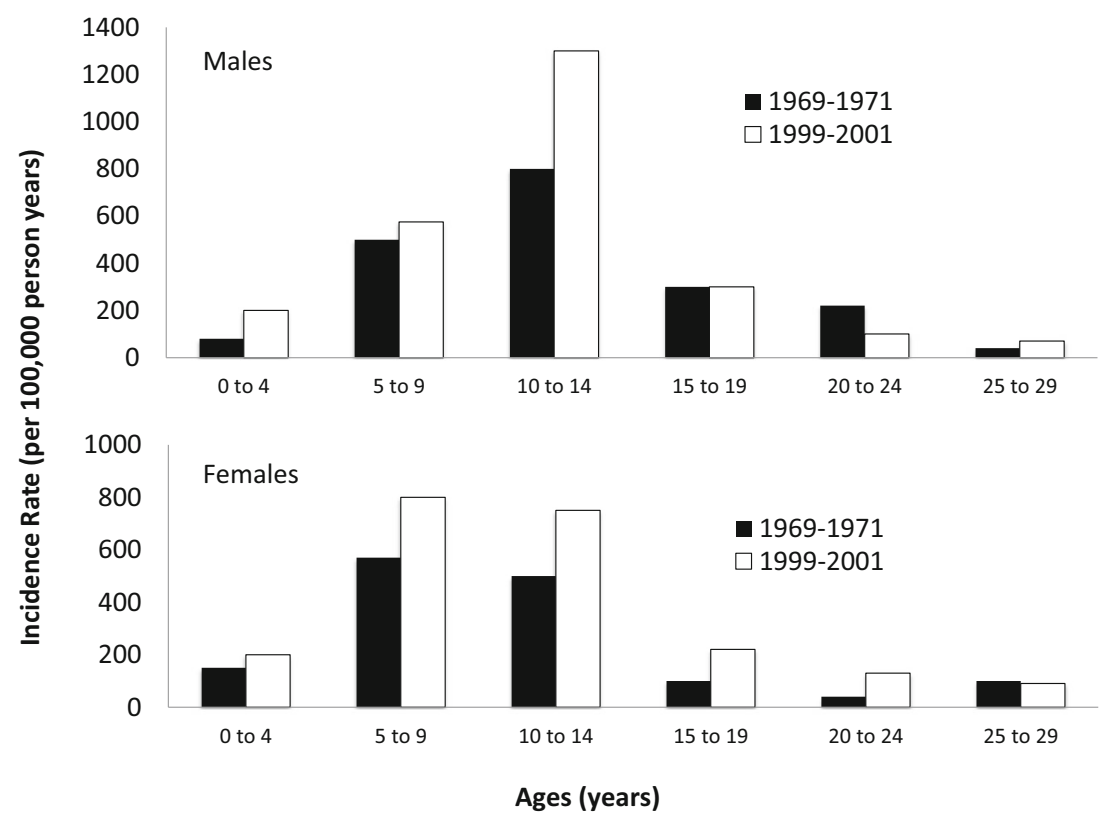


may be 10:1 [42-47], with up to $20 \%$ of female recruits in basic training reported to have sustained a stress fracture [44-48] (note: military studies include young adults aged $\geq 18$ years). Risk factors for stress fractures among recruits include low quantitative ultrasound values, smoking, history of being sedentary [49], and volume of training [40, 44, 50]. White race and a reported family history of osteoporosis or osteopenia may also represent significant risk factors [51, 52].

\section{Tracking}

Tracking refers to the stability of a trait over time. The degree to which indicators of bone strength track from childhood to peak bone mass and beyond is of paramount importance to optimizing peak bone mass for lifelong skeletal health. If bone "status" (i.e., bone mass, density, or structural strength relative to one's peers of the same age and sex) at any given time point were not associated with its future status, then concerns would only be relevant to prevention of childhood fractures, not osteoporosis later in life. In fact, numerous prospective studies have demonstrated that measures of bone density track quite strongly from childhood through adolescence, with tracking correlations ranging from 0.5 to 0.9 depending on the skeletal site, trait, and duration of follow-up, with most estimates falling in the range of 0.6 to 0.7 [32, 53-57]. Tracking correlations decline during adolescence and then rebound, a phenomenon that is likely due to variability in the timing of puberty and peak bone accrual. Adjustment for height status largely eliminates this transient decline in tracking [32, 57]. One study of children aged 8-16 years $(n=183)$ examined the factors associated with tracking deviation. Positive deviation (i.e., improvement in spine and hip aBMD tertile) was associated with having been breast-fed, gains in lean mass, aerobic fitness, and sports participation. Gains in adiposity were associated with negative deviations in tracking [55]. These findings provide strong evidence that bone status during childhood, when peak bone mass is accumulated, is indicative of bone status in young adulthood. However, the fact that tracking correlations are far from unity suggests that lifestyle factors can alter bone status in both positive and negative directions.

\section{Timing of peak bone mass}

If the magnitude of peak bone mass attained in young adulthood is an important predictor of osteoporosis later in life, then the timing of peak bone mass is also important because it defines the lifecycle phase during which peak bone mass can be optimized. Regardless of whether one is referring to peak bone mass of an individual or a population, the timing of peak bone mass varies by skeletal site. Estimates based on longitudinal studies are preferred over cross-sectional population studies for identifying the timing of peak bone mass because they capture the process of bone accretion. For example, using longitudinal observations and the plateau method, the Canadian Multicentre Osteoporosis Study identified the ages of peak bone mass for women; for lumbar spine aBMD, it was between the ages of 33 and 40 years, whereas ages of peak bone mass for total hip BMD were between 16 and 19 years [10].

Estimates of the timing of peak bone mass further depend on the parameters of bone (i.e., mass, density, geometry, microarchitecture) under consideration. Using quantitative computed tomography (QCT), Riggs et al. [9] showed that women aged $20-29$ years $(n=15)$ were losing trabecular bone at a rate of $1-1.75 \%$ per year at the distal radius and lumbar spine, but they were gaining cortical bone at a rate of $0.25 \%$ per year in the tibia. By contrast, men $(n=8)$ in this age range did not exhibit significant changes in these outcomes [9]. Cross-sectional data on >1000 men, aged 18.0-20.9 years, in the Gothenburg Osteoporosis and Obesity Determinants Study suggest that aBMD of the lumbar spine, femoral neck, and total body did not increase with age, but positive agerelated associations were observed for aBMD of the radius, cortical, and trabecular vBMD, and cortical thickness of the radius and tibia as measured by DXA and pQCT [58]. The positive association with cortical thickness was attributed to a smaller medullary diameter, and not to periosteal expansion.

Because the timing of peak bone mass and strength varies by skeletal site and bone compartment, it is important to establish and retain behaviors that contribute to skeletal health, including region-specific changes (e.g., hip, spine). Moreover, until the lifelong importance of peak bone mass is fully understood [52], it is prudent to assume that these behaviors are needed to sustain skeletal health through the life cycle.

\section{Methods for measuring peak bone mass}

Insights into the development of peak bone mass are based on studies using DXA and QCT. These measurement techniques characterize different aspects of bone strength; DXA primarily measures bone mass (or bone mineral content $[\mathrm{BMC}]$ ) and aBMD, which are integrated measures of cortical and trabecular bone.QCT can provide distinct measures of cortical and trabecular vBMD, bone geometry (e.g., periosteal and endosteal circumference and structural strength) and, in some cases, microarchitecture.

\section{Dual-energy $x$-ray absorptiometry}

The vast majority of studies on peak bone mass have utilized DXA, a low-dose $\mathrm{x}$-ray technology that measures the attenuation of $\mathrm{X}$-ray beams as they pass through tissues of varying density. DXA is a two-dimensional imaging technique that uses a planar image to estimate bone area. This technology is ideal for use in children because it is rapid, safe, widely available, and precise, with effective dose ranges from 0.03 
to $15.2 \mu \mathrm{SV}$ [59]. Because of the smaller bone size and lower density of bones in growing children, special software has been developed by the major DXA manufacturers to measure aBMD and BMC in children. DXA does not measure vBMD but instead provides what is referred to as aBMD. Since DXA does not capture the depth of bone, it systematically underestimates vBMD in children with poor growth. For this reason, adjusting DXA measures of BMC and aBMD for stature is recommended $[60,61]$. This adjustment serves to distinguish between gains in BMC or aBMD that are independent of gains in stature. In addition, cortical and trabecular bone are superimposed in the DXA image, thus providing a composite estimate of the mass and density of these two bone compartments.

Lack of agreement exists regarding whether BMC or aBMD should be the outcome of interest in bone accretion studies in children. BMC is determined, in large part, by bone size because it reflects the mineral content of one region or the entire skeleton; aBMD only partly adjusts for bone size and a size-related artifact remains [61]. Using spine QCT measures as a reference method, Wren and colleagues have shown that DXA BMC was a better measure to use in children (ages 617 years), particularly in prepubertal children, than aBMD [62]. We agree with those who argue that, to account for size in studies of children, it is best to use BMC adjusted for bone area [63, 64], height-for-age Z-score [61], lean mass [65, 66], or other combinations of anthropometric variables [64, 67, 68] or to use calculated bone mineral apparent density [69], because these provide a more accurate reflection of a child's bone health.

DXA measures have also been used to estimate structural strength of the proximal femur using the hip structural analysis (HSA) algorithm [70]. HSA estimates subperiosteal width, cross-sectional area (CSA), and section modulus in the narrow neck, intertrochanteric region, and shaft of the proximal femur. These outcomes are associated with treatment effects in adults as well as disease and exercise effects in children and adolescents [71-73].

\section{Peripheral quantitative computed tomography}

DXA only partly describes bone strength, which is the broader concern for understanding peak bone mass. Other modalities are used to more directly measure vBMD, microarchitecture, and geometry. Many of these characteristics can easily be measured in children with relatively low radiation exposure (0.59-1.09 mSv) [74]. QCT and pQCT are three-dimensional techniques that also use attenuation of $\mathrm{x}$-ray beams to construct bone images. Cortical and trabecular bone compartments vary in density, and the differential attenuation of $\mathrm{x}$ ray beams in the three-dimensional reconstruction allows for separate determination of trabecular and cortical vBMD, as well as numerous other measures of bone geometry (e.g., total bone area, periosteal and endosteal circumference) and structural strength in compression, bending, and torsion (e.g., section modulus, strain-strength index). Full-sized computed tomography (CT) scanners are used to measure the spine and other sites, and dedicated $\mathrm{pQCT}$ scanners measure the radius, tibia, or distal femur. Newer HRpQCT scanners achieve sufficient resolution for building microstructural finite element models of whole bone failure load, a surrogate measure of bone's resistance to fracture, as well as cortical porosity, and trabecular plate and rod microstructure [74].

\section{Mechanical loading}

Physical activity comprises any body movement produced by muscle contraction resulting in energy expenditure above a resting level [75]. Exercise is a more restrictive concept and is defined by planned, organized, and repetitive physical activity aimed at maintaining or enhancing one or more components of physical fitness or a specific health outcome, such as bone strength [68]. The randomized controlled trials (RCTs) reviewed in this scientific statement used targeted exercise as an intervention to improve bone strength, whereas most of the longitudinal studies measured physical activity, including active transportation and activities of everyday life [76]. Physical activity has long been regarded as behavior likely to influence bone health $[77,78]$. Epidemiological and clinical trial research dating back more than two decades confirms the positive impact of regular physical activity on bone $[3,27$, 78-81]. However, we are only beginning to quantify the specific dimensions, dose, and timing of physical activity needed for maximal bone strength. What is known, primarily from animal studies, is that increased mechanical loads placed on bone through both impact and muscle forces cause deformation (strains) of whole bone $[82,83]$. These strains activate mechanosensitive cells (i.e., osteocytes), embedded within the bone, which signal molecules to activate osteoblasts and osteoclasts. The signaling begins the process of bone adaptation to changes in physical activity, as well as other mechanical loads (e.g., an increase in body weight). To initiate an osteogenic response, bone must be subjected to a strain magnitude that surpasses a threshold determined by the habitual strain range in the predominant loading direction. The threshold varies between individuals (and also bone sites) according to physical activity habits and other factors (e.g., maturity status). Thus, children and adolescents may respond differently to similar mechanical loading conditions. Inactive children may respond to low-impact loading and improve bone mass or structure, while more active children will need a higher mechanical load to promote a skeletal response [84].

The skeleton needs to be strong for load bearing and light for mobility. A manner of minimizing the amount of bone mass needed in a cross-section without decreasing strength is to modify the distribution of bone mass and therefore 
changing bone structure. Throughout life, but mainly during growth, periosteal apposition increases the diameter of long bones and endocortical resorption enlarges the marrow cavity. Cortical thickness is determined by the net changes occurring at the periosteal and endosteal surface of bone. However, even without an increase in cortical thickness, the displacement of the cortex increases bending strength because resistance to bending is proportional to the fourth power of the distance from the neutral axis. In addition to the independent effect of physical activity on mass and density, increased mechanical loading via physical activity may influence structural changes in bone to increase strength in response to the new loading condition $[25,73,85]$.

Bone is most responsive to physical activities that are dynamic, moderate to high in load magnitude, short in load duration, odd or nonrepetitive in load direction, and applied quickly [84]. The load magnitude is produced by impact with the ground (e.g., tumbling or jumping), impact with an object (racquet sports), or muscle power moves such as the lift phase in jumping and vaulting. On the other hand, due to desensitization of the osteocytes, static loads and repetitive lowmagnitude loads are not osteogenic [86-88]. Although physical activity is a modifiable factor that contributes to peak bone mass and strength, our understanding of how to quantify the dimensions of physical activity that are osteogenic (including frequency, intensity, time, and type) is incomplete.

\section{Body composition}

It is widely recognized that lean body mass is among the strongest correlates of bone mass, density, and structural strength during childhood [89-92]. During adolescence, the peak in total body lean mass accretion occurs just prior to peak bone mineral accretion [2, 93], although at specific sites, peak increases in lean mass and bone strength may be coordinated [94]. In the latter phase of the adolescent growth spurt, following the peak, continued gains in lean mass are strong predictors of increases in BMC [95].

A major challenge in understanding the relationship between lean mass and bone is that both lean mass and bone mass have a strong heritable component. A study of young adult twins (aged 23-31 years) found that additive genetic factors accounted for $87 \%$ of the variation in total body $\mathrm{BMD}, 81 \%$ of the variation in lean mass, and $69-88 \%$ of the covariance between lean mass and BMD depending on the skeletal site. Population differences also provide evidence of genetic determinants of lean and bone mass. Cardel et al. [96] compared groups of African or European ancestry $(n=301$, aged $7-12$ years) using ancestry informative DNA markers and found that a greater amount of African admixture was associated with greater lean mass and BMC after adjusting for socioeconomic status, sex, age, height, race/ethnicity, and pubertal status.
The effect of fat mass on bone mineral accretion and attainment of peak bone mass is far more controversial. Generally, greater body weight increases the effects of weight-bearing activity on bone. As children grow and increase in weight, both lean and fat mass increase. To reduce the likelihood of confounding from the bone loading effects of lean mass, it is important to first account for the effect of lean mass on bone in order to determine the effects of fat mass.

The source of adipose tissue may be important in considering the effects of body composition on bone outcomes. Visceral adipose tissue has different metabolic effects compared to subcutaneous fat, and it may be deleterious to bone by reducing bone quality. Adipose infiltrations of muscle and bone marrow associated with excess adiposity also have adverse effects on bone. Muscle density measured by pQCT is lower when the fat content within muscle is increased.

\section{Nonmodifiable factors}

\section{Genetics}

An estimated $60-80 \%$ of the variability in bone mass and osteoporosis risk is explained by heritable factors. aBMD is lower among daughters of women with osteoporosis [97] and in men and women with first-degree relatives who have osteoporosis [98]. The familial resemblance of BMC is expressed prior to puberty $[99,100]$. Genome-wide association studies have identified more than 70 loci associated with adult bone density or fractures [101, 102]. However, only a few such studies have been conducted in children [1,103-106]. Twin studies also suggest that genetic predisposition determines up to $80 \%$ of peak bone mass; the remaining $20 \%$ is modulated by environmental factors and sex hormone levels during puberty [107].

\section{Population ancestry}

In North America, ethnic differences in vBMD and aBMD have been reported in children [5, 108, 109]. Among individuals aged 9-25 years, aBMD was consistently greater at all sites for African Americans compared to other groups, whereas Caucasians had greater values than Asians and Hispanics. In studies comparing children of Asian, European, and Hispanic ancestry, group differences in BMC were attributable to differences in bone size [110-112]. Ethnic differences in the rate of BMD gain have also been observed [109]. Differences between Caucasians, Asians, and Hispanics are smaller than between blacks and other groups; thus, pediatric reference ranges for $\mathrm{BMC}$ and $\mathrm{aBMD}$ are presented for African Americans and non-African Americans, and the International Society for Clinical Densitometry recommends using race-specific reference ranges in childhood because they reflect genetic potential for bone accretion $[60,111]$. Studies 
using QCT provide insights into the population ancestry differences in DXA measures by describing cortical bone dimensions and trabecular density [5, 113-115]. As noted earlier, trabecular density increases during puberty. The magnitude of the pubertal increase in trabecular density is greater in African-American individuals than in Caucasians, and African-American children have greater total femoral bone in cross-sectional analyses $[5,6,115]$.

\section{Sex}

Among children and adolescents, males have greater BMC and aBMD than females. These differences become more pronounced with the onset and progression through puberty or at the ages that correspond to these maturational changes [108, 109, 116-118]. The exact age at which these differences emerge is unclear. Earlier studies of infants (aged $\leq 12$ months) did not find sex differences in total body BMD [119, 120] or spine BMC and aBMD [121, 122]; however, males (aged 118 months) had greater total body BMC than females [123]. A recent study of infants and toddlers aged 1-36 months confirmed the absence of sex differences in aBMD in very young children but found greater BMC in males than in females. Sex differences in the body size of infants and toddlers may account for BMC differences and the absence of aBMD differences. By about 5 years of age, girls have lower values for spine and hip aBMD than boys, a finding that persists when adjusted for age, height, and weight [124].

Studies of bone strength by pQCT reveal a more complex pattern of sex differences. In a study of 665 healthy individuals aged 5-35 years, cortical BMC, periosteal circumference, and section modulus were lower in the $38 \%$ site of the tibia for females compared with males across all stages of puberty. However, cortical vBMD was greater and endosteal circumference was lower in peripubertal and postpubertal females compared to males. These differences were not attributable to differences in muscle mass or bone size [115]. In a 20month longitudinal study of 128 children across puberty, boys exhibited a $10 \%$ greater increase in total area and cortical area compared to girls, but the increase in the size of the marrow cavity was significantly less for girls than for boys [125]. Further evaluation showed that sex differences in bone strength are primarily due to the 4-6\% greater bone area in boys, which is evident in prepubertal children [126]. HRpQCT studies of the radius show that girls have higher cortical vBMD in midpuberty and postpuberty (9.4 and $7.4 \%$, respectively) and lower cortical porosity than boys ( -118 and $-56 \%$, respectively) [127].

\section{Maturation}

Advancement through puberty is associated with increases in $\mathrm{BMC}$ and $\mathrm{aBMD}$, as well as cortical and trabecular vBMD.
Moreover, several studies suggest that the timing of maturation may affect peak bone mass, particularly in girls. For example, Gilsanz et al. [128] showed that earlier age of pubertal onset was associated with greater DXA BMC and aBMD at skeletal maturity in both boys and girls, independent of prepubertal BMC and aBMD values and duration of puberty. Chevalley et al. [129] found that girls who attained menarche earlier had higher aBMD at multiple skeletal sites prior to, during, and after puberty. A Canadian longitudinal study (depicted in Fig. 2) found that girls who mature early had 3 $4 \%$ more total body BMC at age 20 years than girls who matured at an average age. However, maturational effects were only observed at the total body and not at other sites; no maturational timing effects were observed in males [130]. The absence of a maturation timing effect on $\mathrm{BBMD}$ and $\mathrm{BMC}$ of the lumbar spine, femoral neck, and total body was confirmed in a study of Swedish military recruits in which young men were followed until age 24 years. However, as with girls, later puberty in boys was associated with lower radius aBMD $(-4.2 \%$, by DXA), as well as lower cortical $(-0.7 \%)$ and trabecular vBMD $(-4.8 \%$, by pQCT) [131]. The long-term consequences of the effect of pubertal timing on peak bone mass remain to be determined.

\section{Modifiable factors}

Diet and physical activity are the primary modifiable factors associated with bone health, although other lifestyle and environmental factors may also be at play. Here, we review these factors and their contribution to peak bone mass.

Although we separately address the contribution of physical activity to peak bone mass and strength, we address nutrient interactions with physical activity and their effects on bone in the respective nutrient discussions. Several narrative and meta-analysis review articles were recently published that also address the strength of the evidence for physical activity and bone development [132-137].

\section{Scientific statement aims}

In this scientific statement, we (1) report the results of an evidence-based review of the literature since 2000 on factors that influence achieving the full genetic potential for skeletal mass, (2) recommend lifestyle choices that promote maximal bone health throughout the lifespan, (3) outline a research agenda to address current gaps, and (4) identify implementation strategies.

\section{Methods}

We performed a comprehensive PubMed (http://www.ncbi. nlm.nih.gov/pubmed) search of the scientific literature for 
articles published from January 2000 through December 2014. For all search terms, the following search strategy was used: ((((search term[Title/Abstract]) AND bone[Title/ Abstract]) AND child*[Title/Abstract]) AND adolescen*[Title/Abstract]) NOT review[Publication Type]. Language, date, and species filters were then applied to the list of search results to eliminate articles not in English, articles published outside the 2000-2014 window, and animal studies. Searches for some of the topics required less restrictive searching in order to yield viable results, such as removal of the terms "child*" and/or "adolescen*," or by expanding searches to scan terms found in "All Fields" rather than just "Title/Abstract." MeSH terms were also utilized in some instances. Studies that contained subjects aged $\leq 21$ years were included, except in the alcohol and smoking literature, in which studies that contained subjects aged $\leq 22$ years were accepted due to lack of data in younger populations. Figure 5 represents the flow diagram of the systematic review for peak bone mass that includes search topics and the number of search returns.

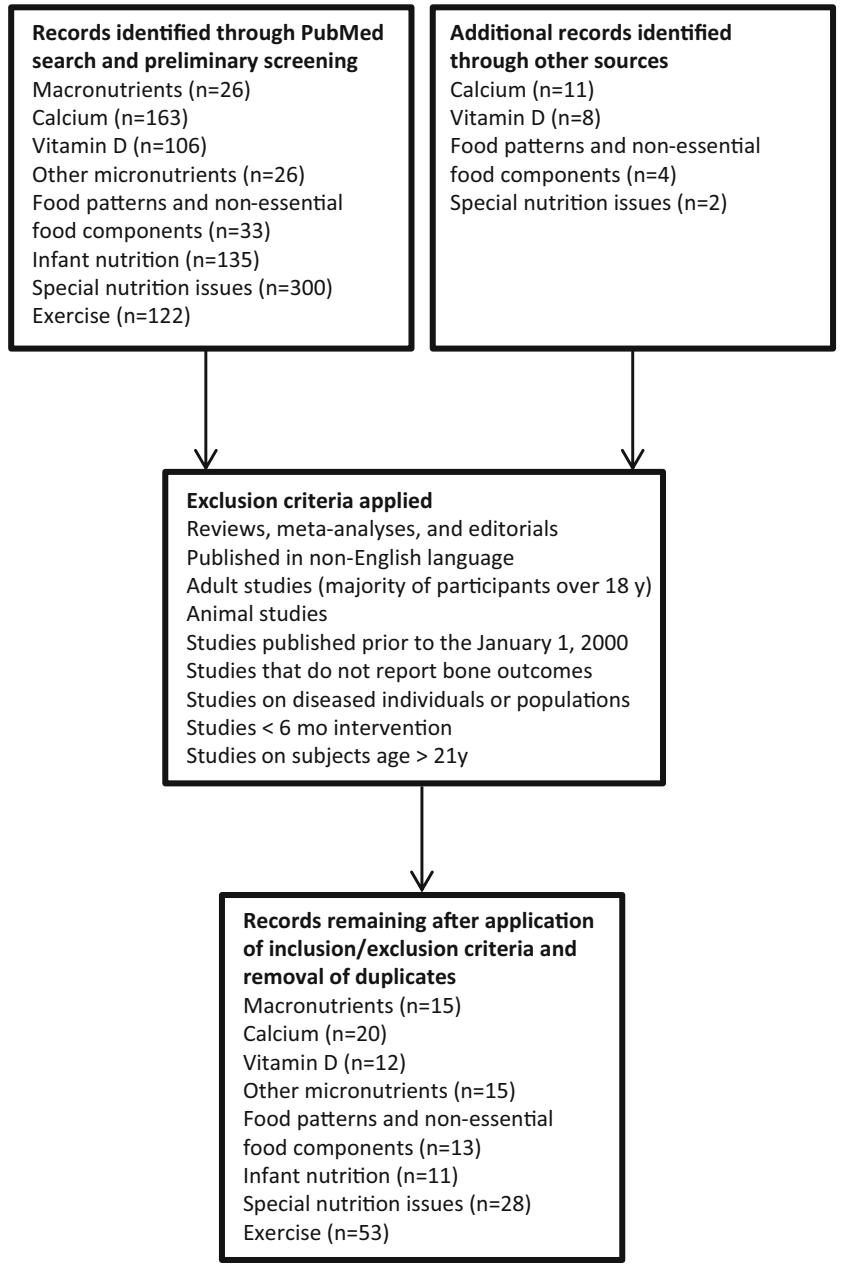

Fig. 5 Flow diagram of the systematic review on peak bone mass
To further narrow the search results for the broader topics (e.g., calcium, vitamin D, physical activity), we assigned authors to subcommittees based on their expertise and these subcommittees then reviewed the resultant abstracts. We excluded any articles that were not describing RCTs or observational studies, any studies that did not examine bone outcomes, and any interventions that were $<6$ months in duration. Studies and drug trials addressing disease states, with the exceptions of eating disorders and obesity, were likewise excluded. The articles that remained after the applications of these criteria were then rated based on the extent of scientific evidence as outlined in Table 1. This evidence grading system has previously been utilized by prominent organizations such as American Society for Nutrition [138] and the American Diabetes Association [139] and is recommended by other experts [140]. The assigned grade reflects the strength of available evidence on individual modifiable lifestyle factors that may (or may not) influence the development of peak bone mass. We assigned evidence grades after we achieved consensus among the writing group.

Tables 1, 2, 3, 4, 5, 6, 7, 8, 9, 10, 11, 12, and 13

summarize the articles that were chosen for inclusion in the current review, and these include additional articles located via review articles, meta-analyses, and expert knowledge of the literature.

\section{Results}

Nutrition and peak bone mass

\section{Macronutrients}

Fat (Table 2) The search for fat identified no RCTs, 1 prospective study, and 1 cross-sectional study published since 2000, encompassing 163 individuals (Table 2). Data from the prospective study demonstrated that changes in aBMD of the spine in males between ages 16 and 22 years were positively associated with serum levels of arachidonic acid and all omega-3 fatty acids, including DHA [141]. The cross-sectional study by Eriksson et al. [142] showed positive correlations between total body BMC and serum nervonic acid and arachidonic acid as well as negative associations with $\alpha$-linolenic acid.

Our evidence grade for fat was based on findings from one prospective study with methodological limitations and one cross-sectional study.

Grade: Level of evidence D was assigned for evidence for the benefit of fat on bone. 


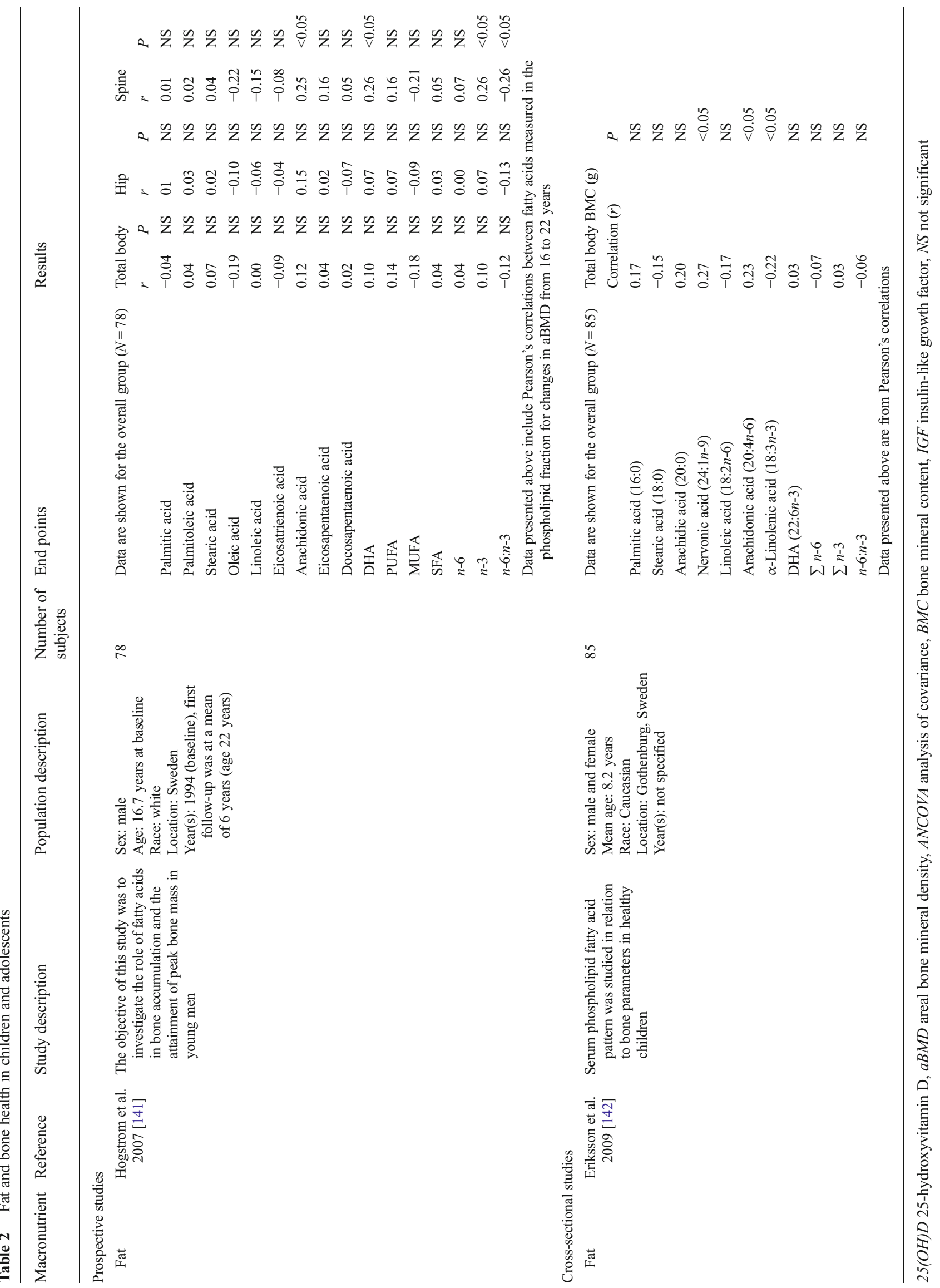




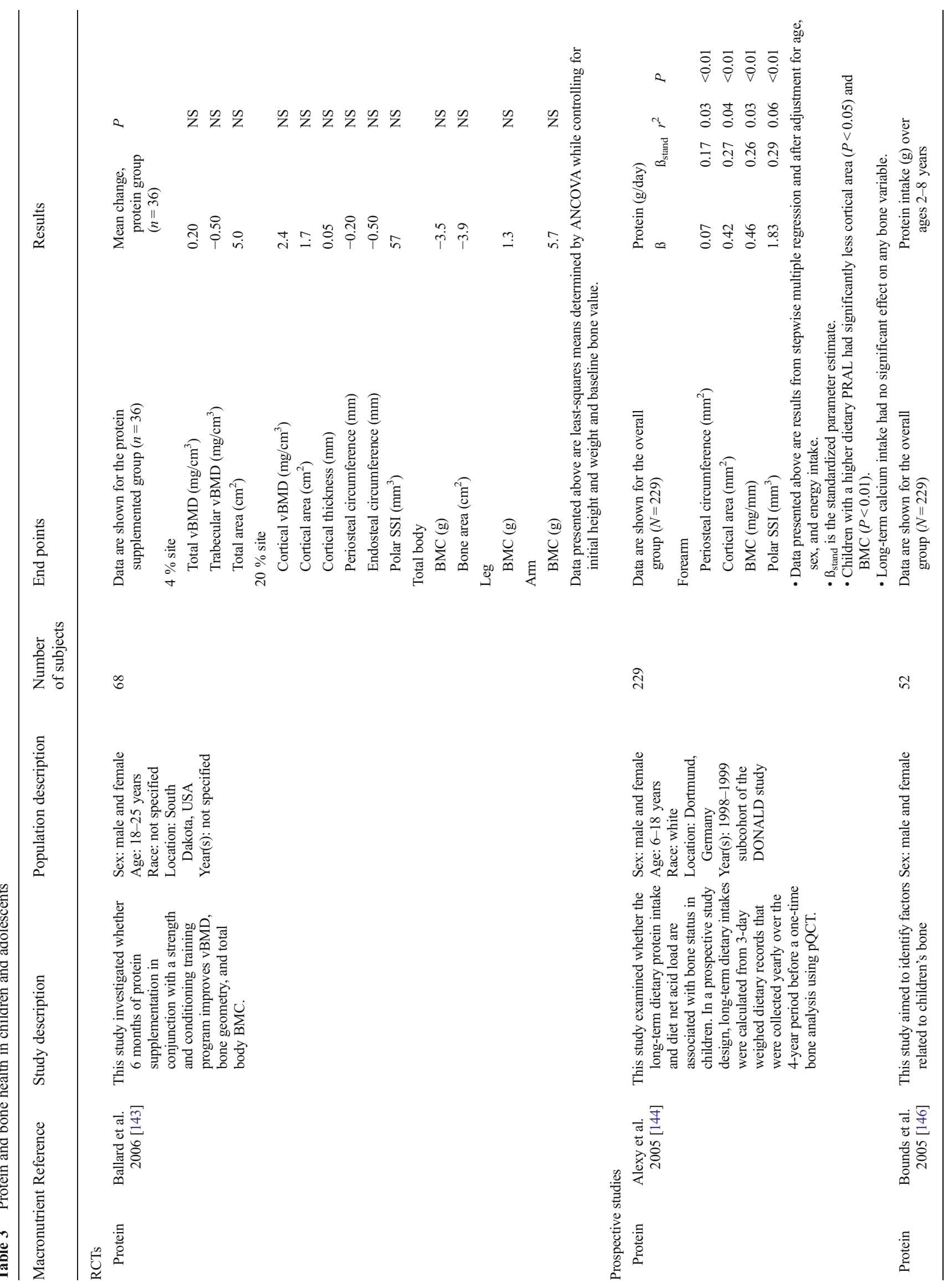




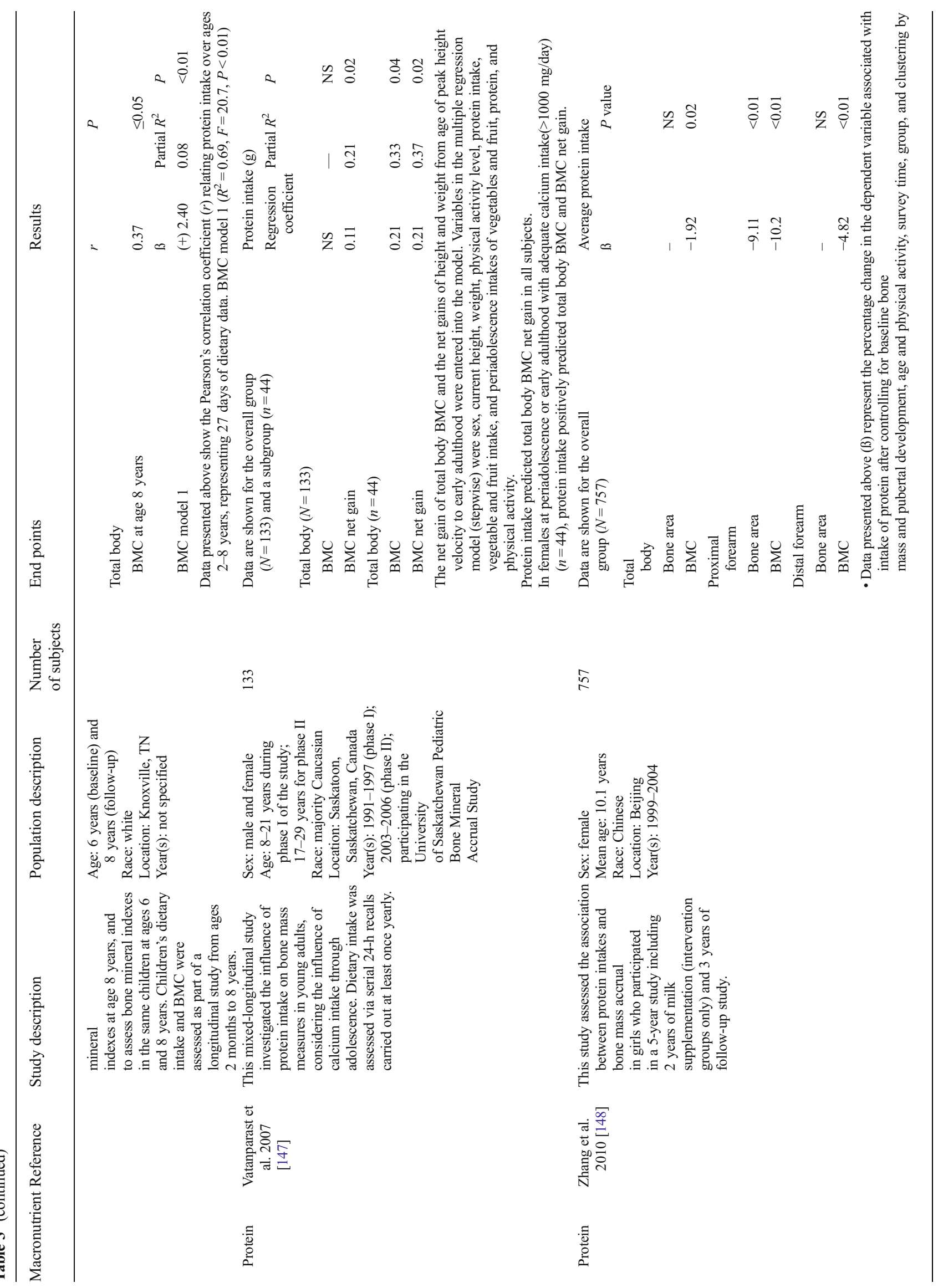




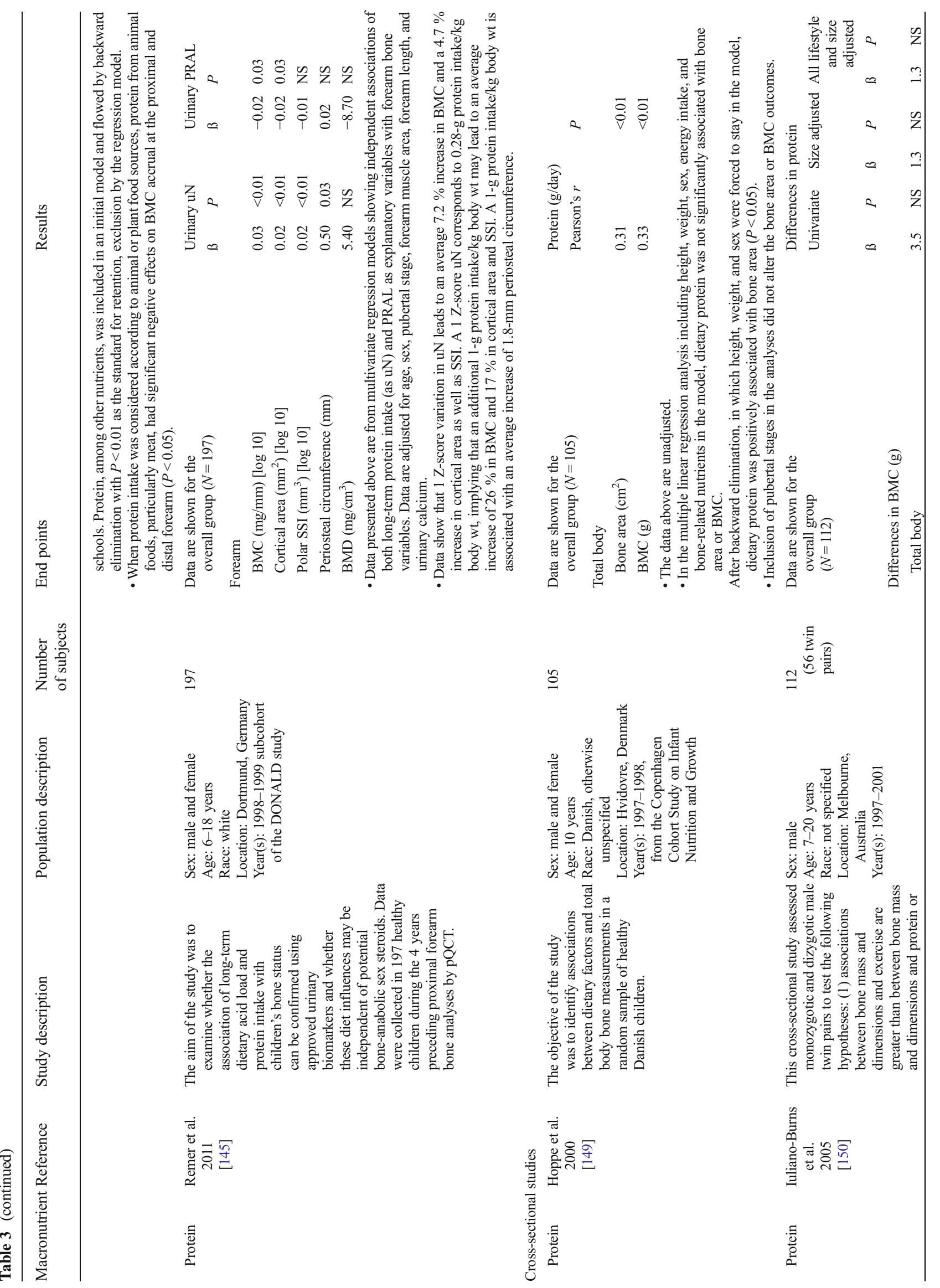




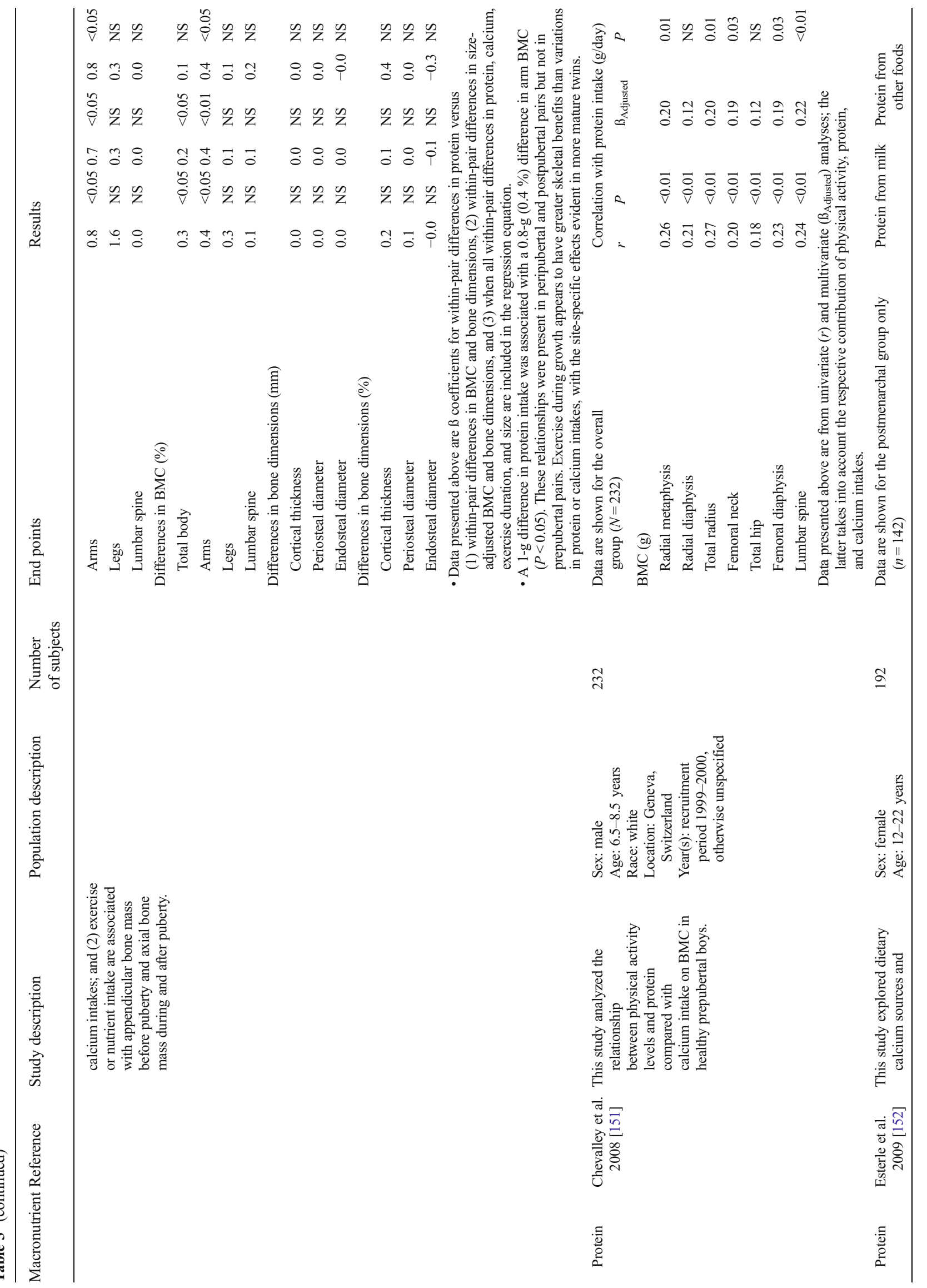




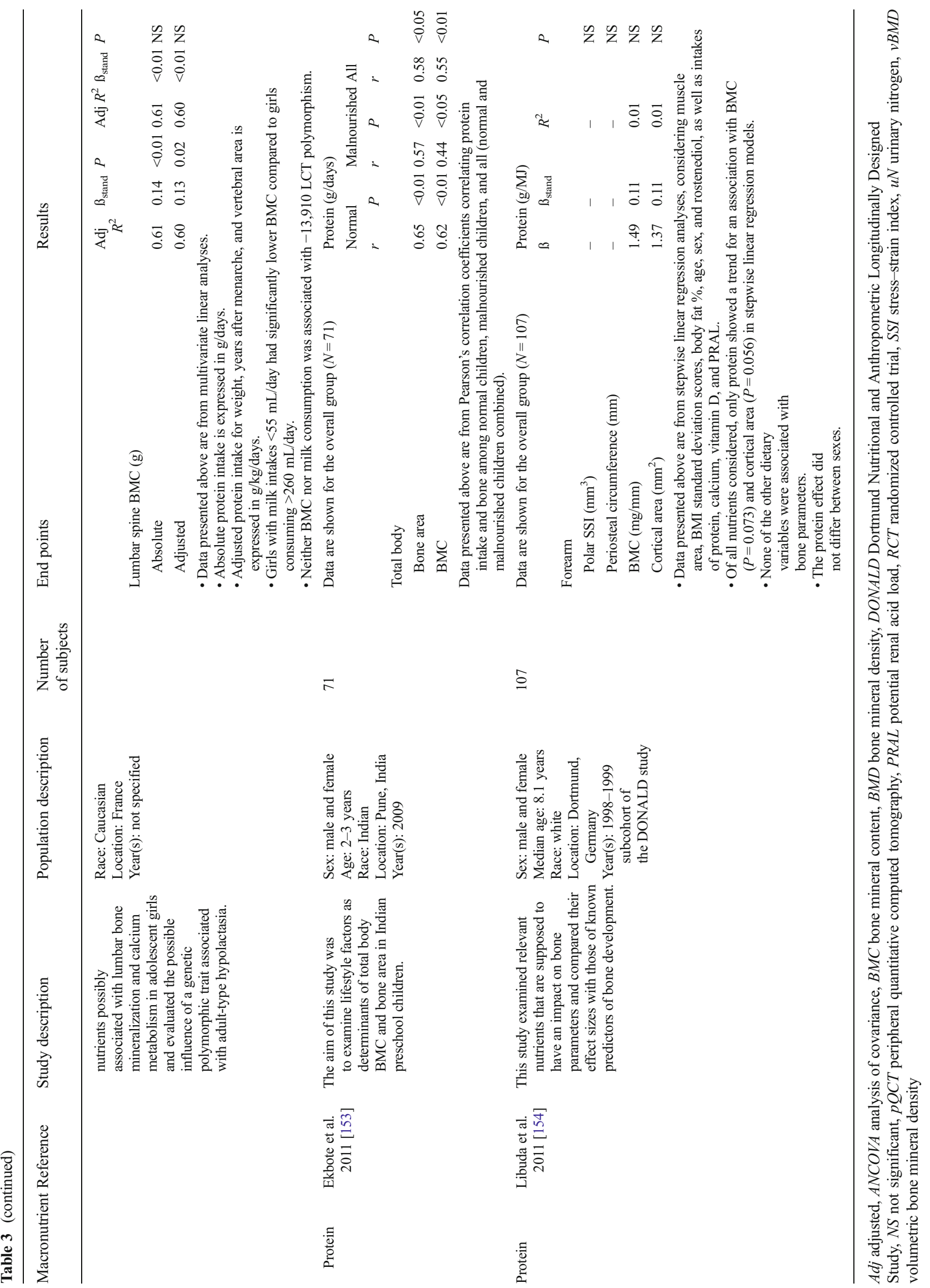




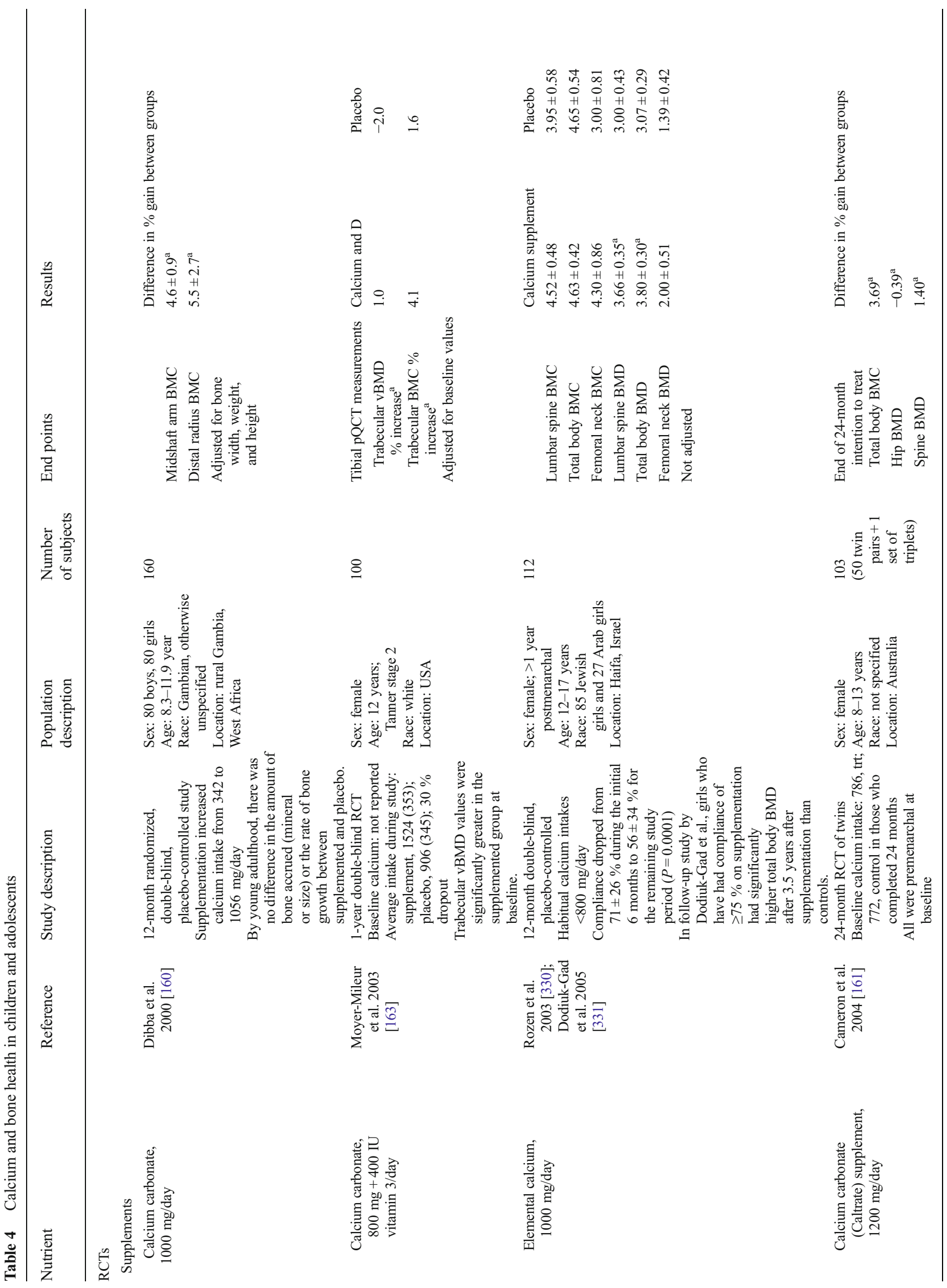




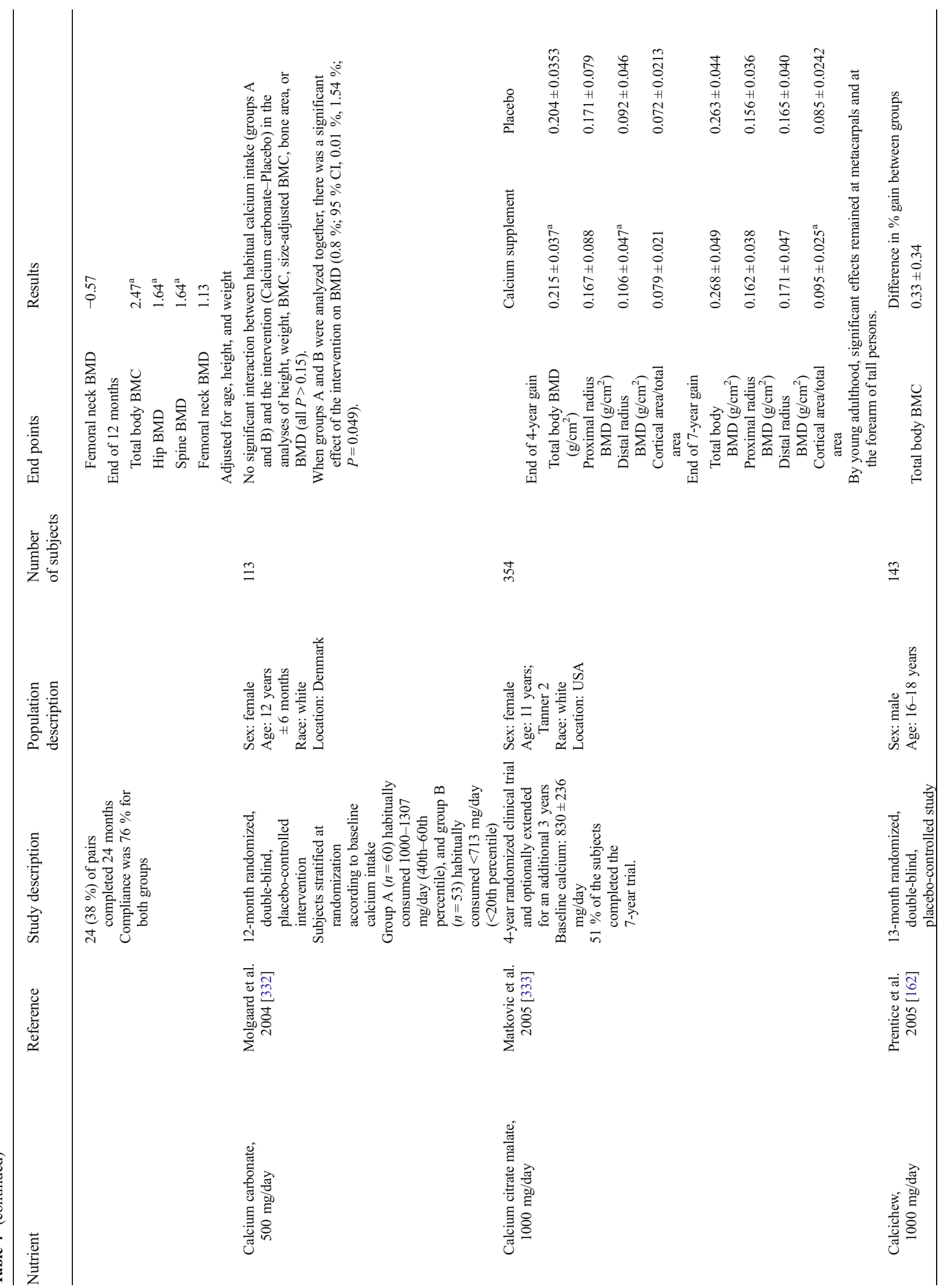




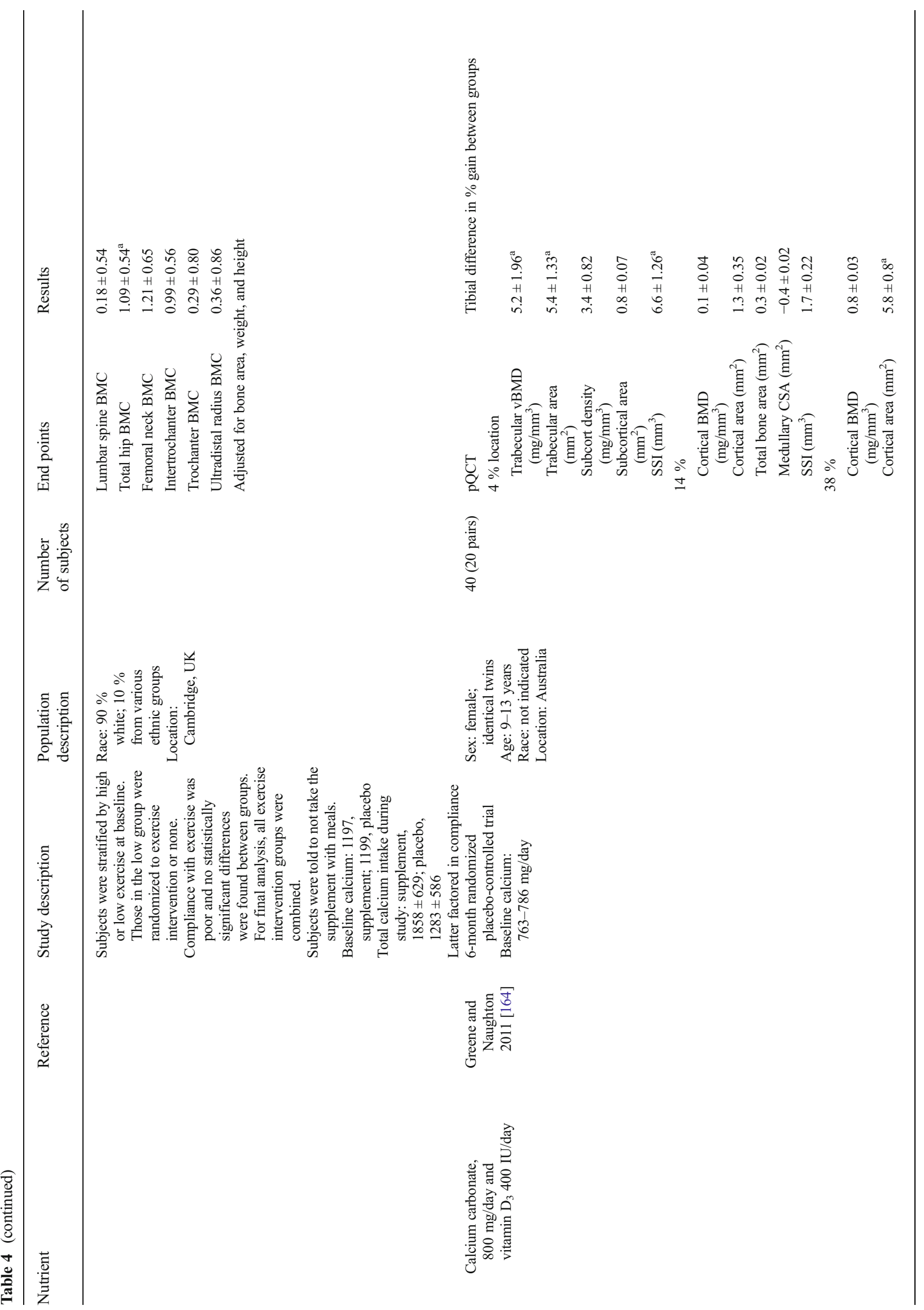




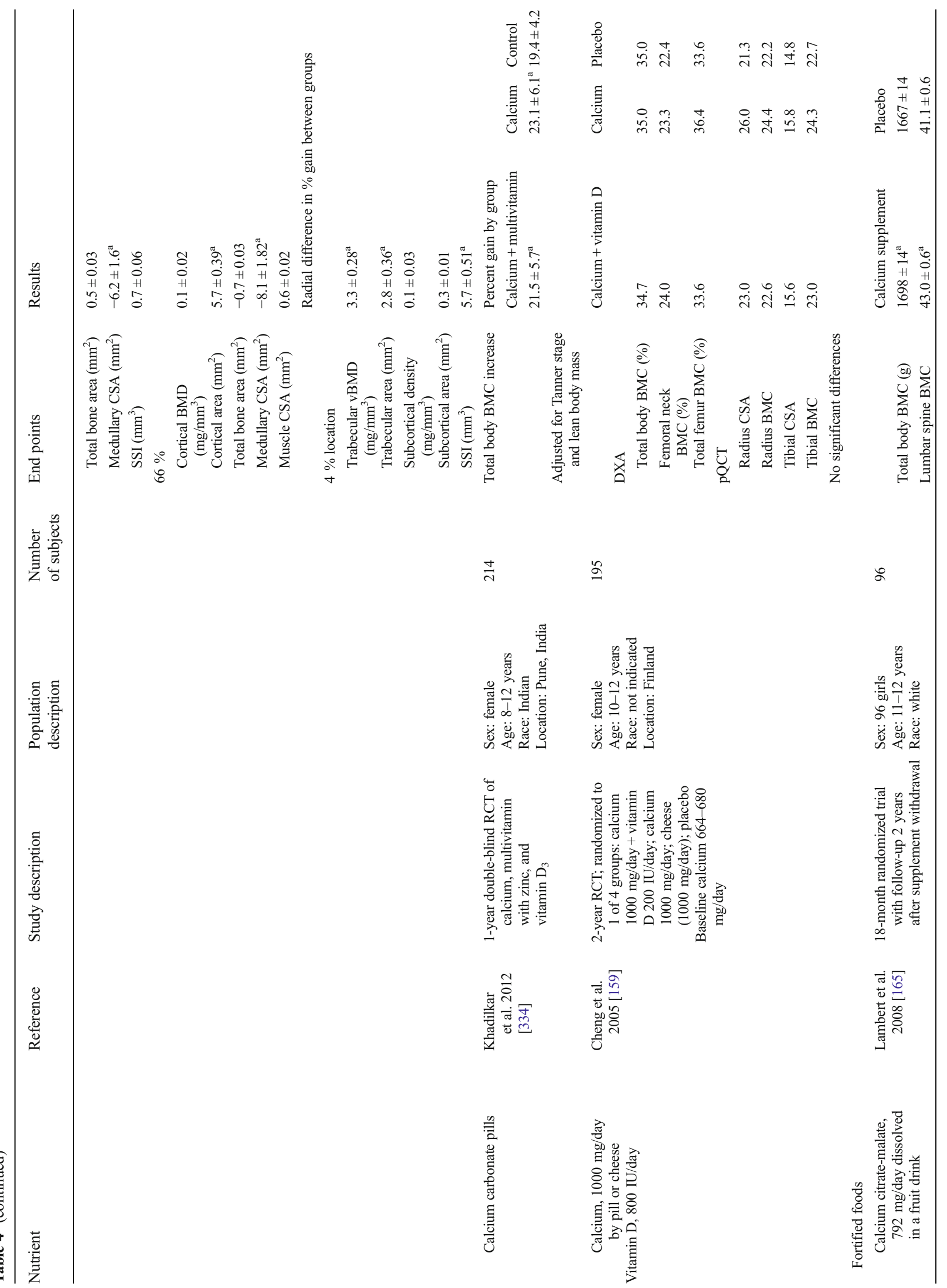




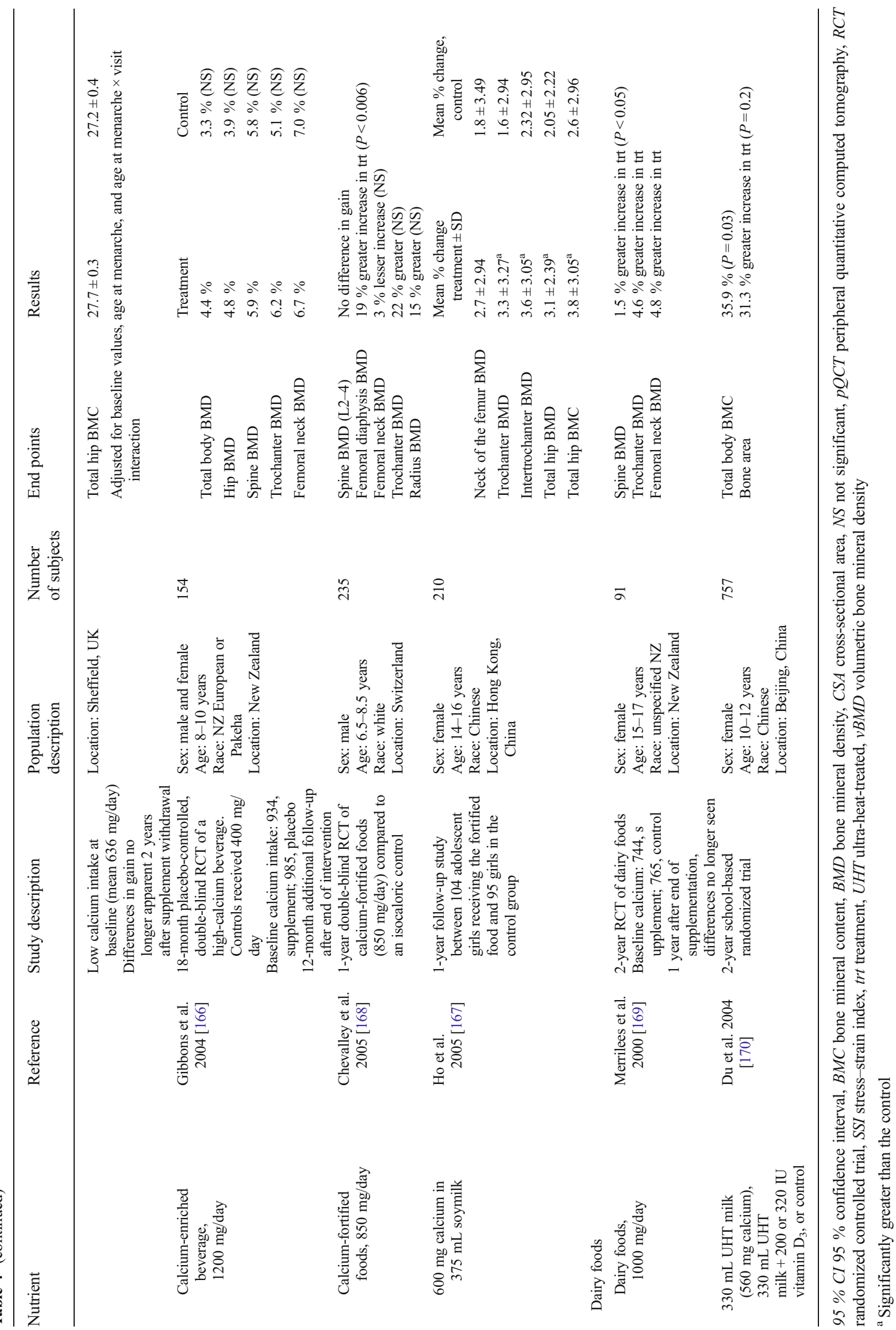




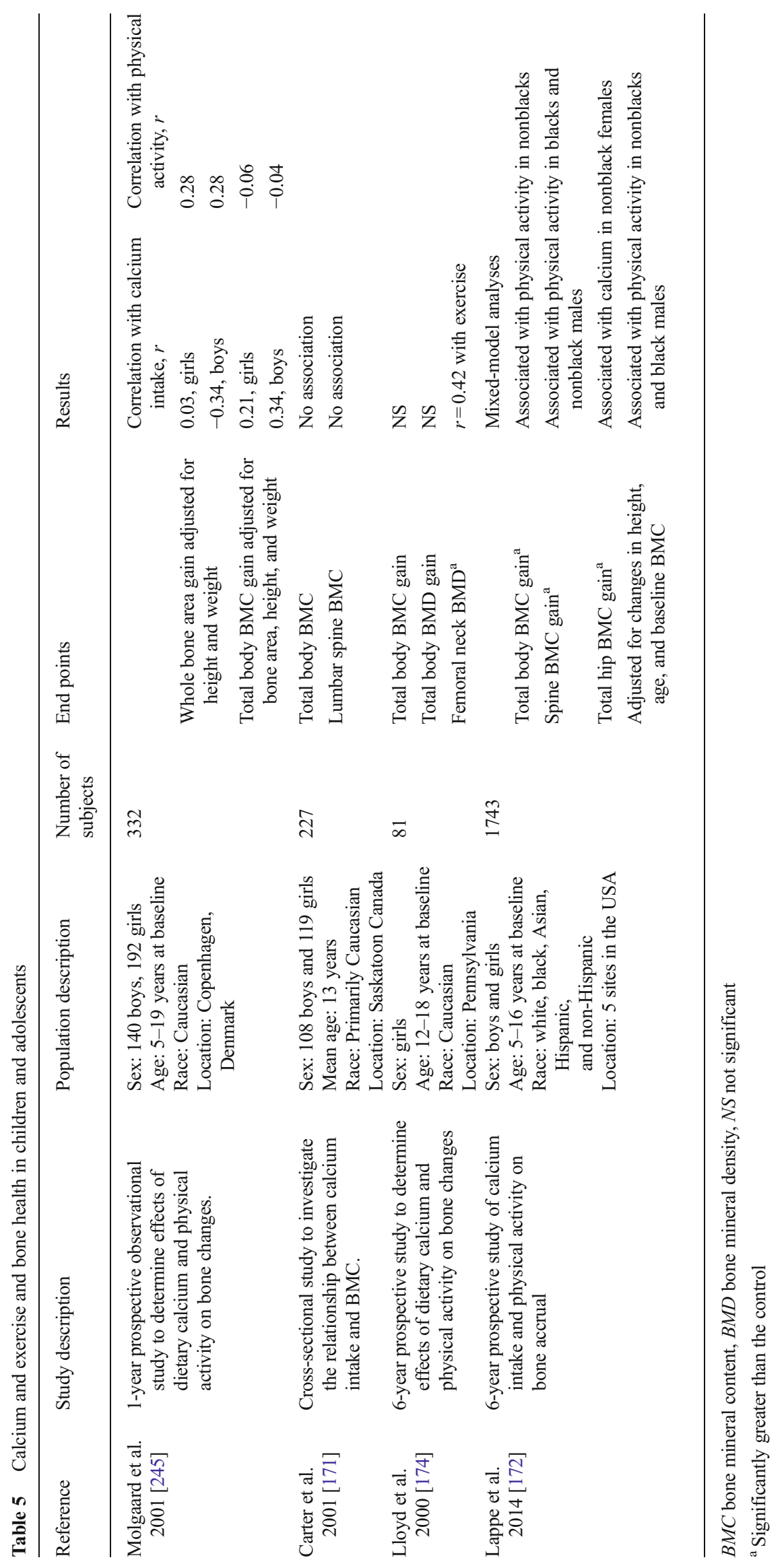




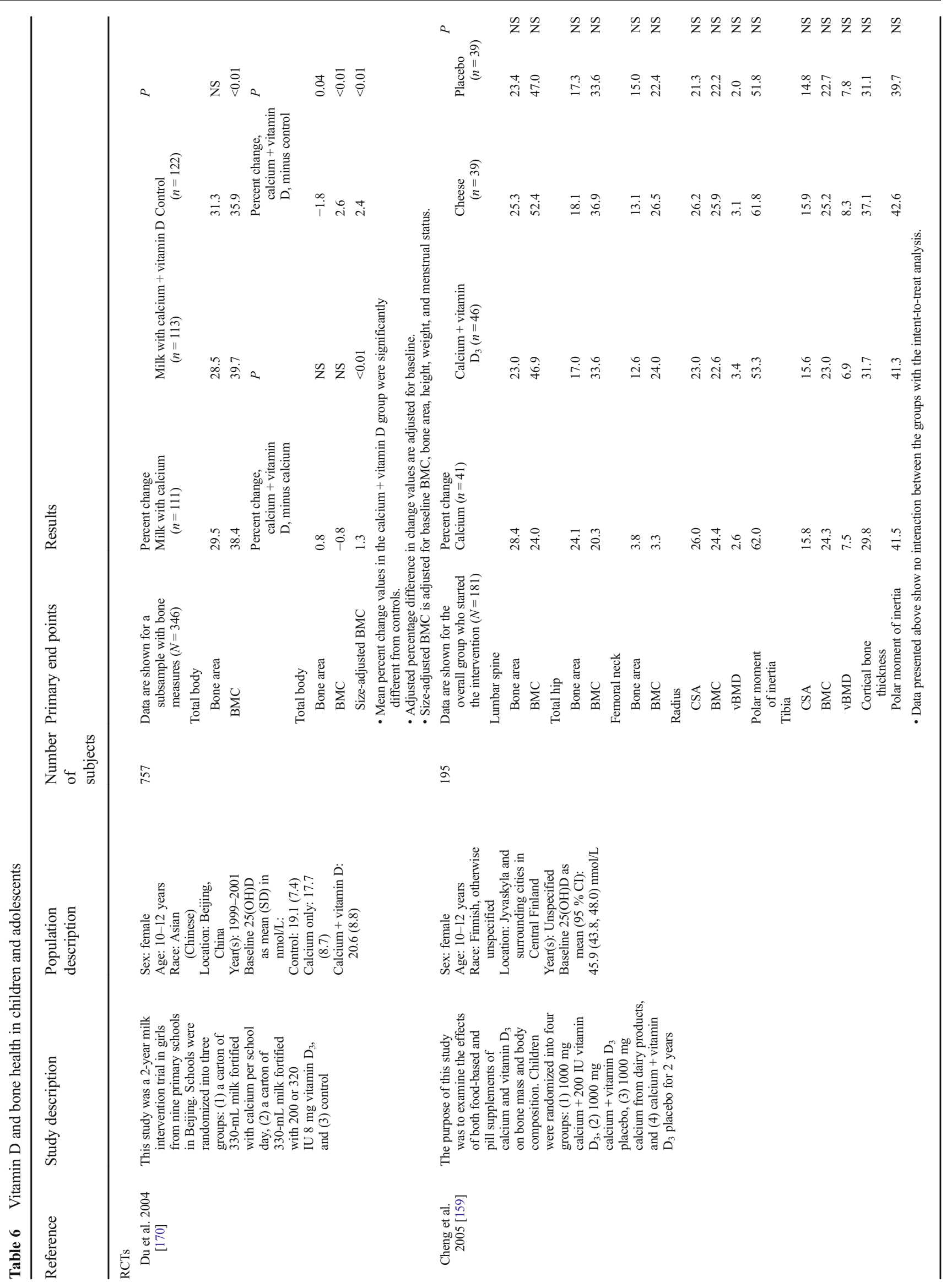




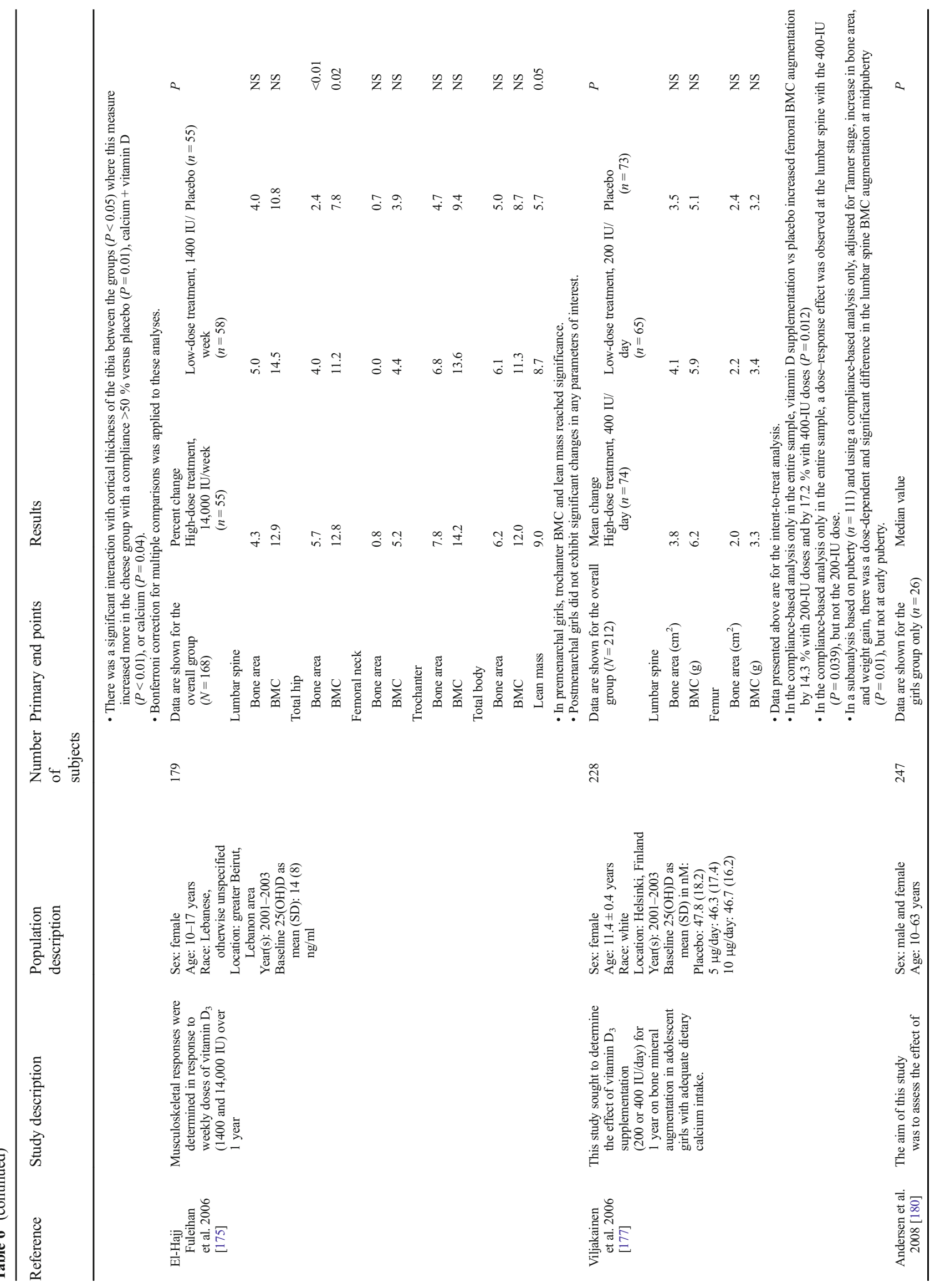




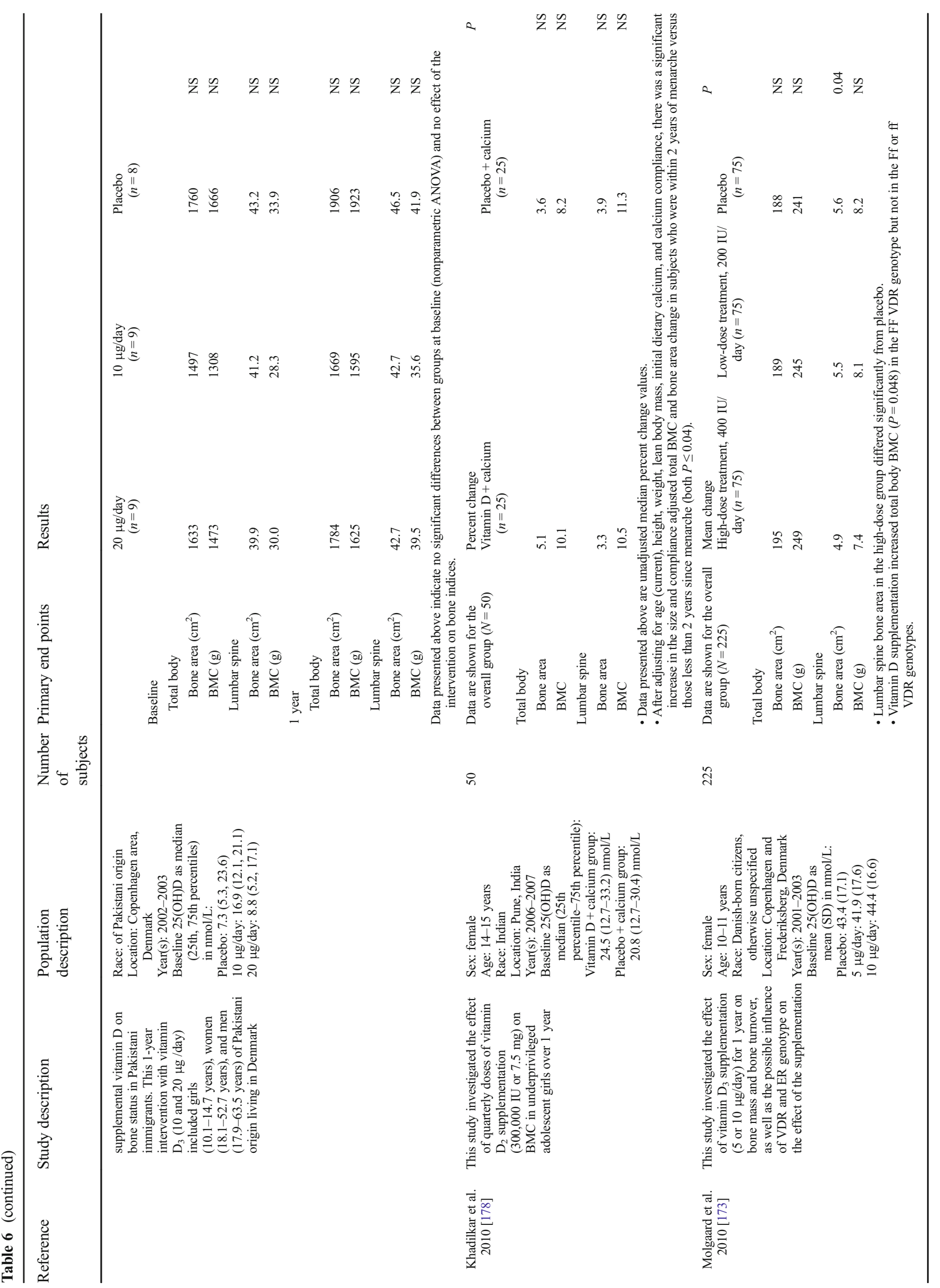




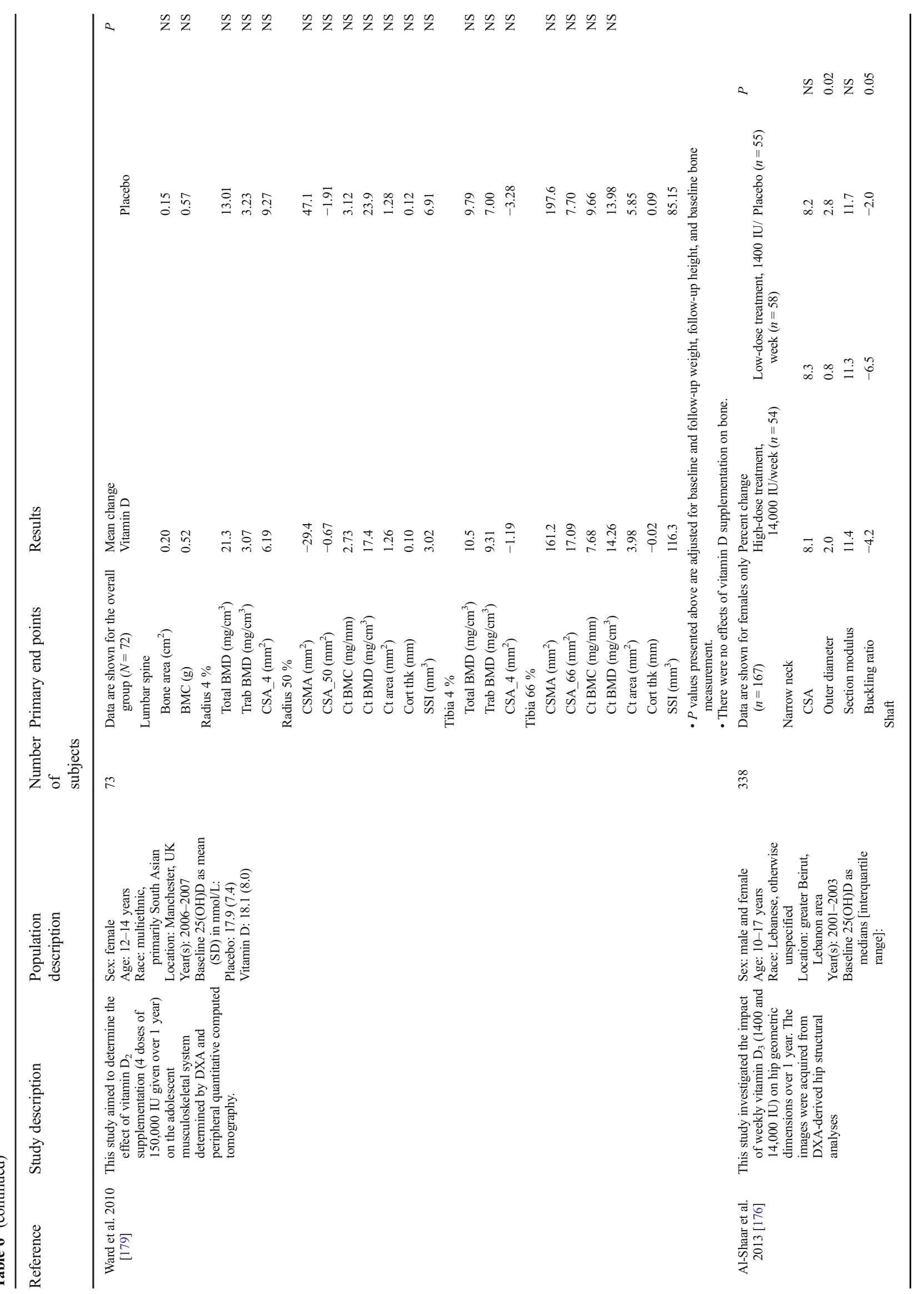




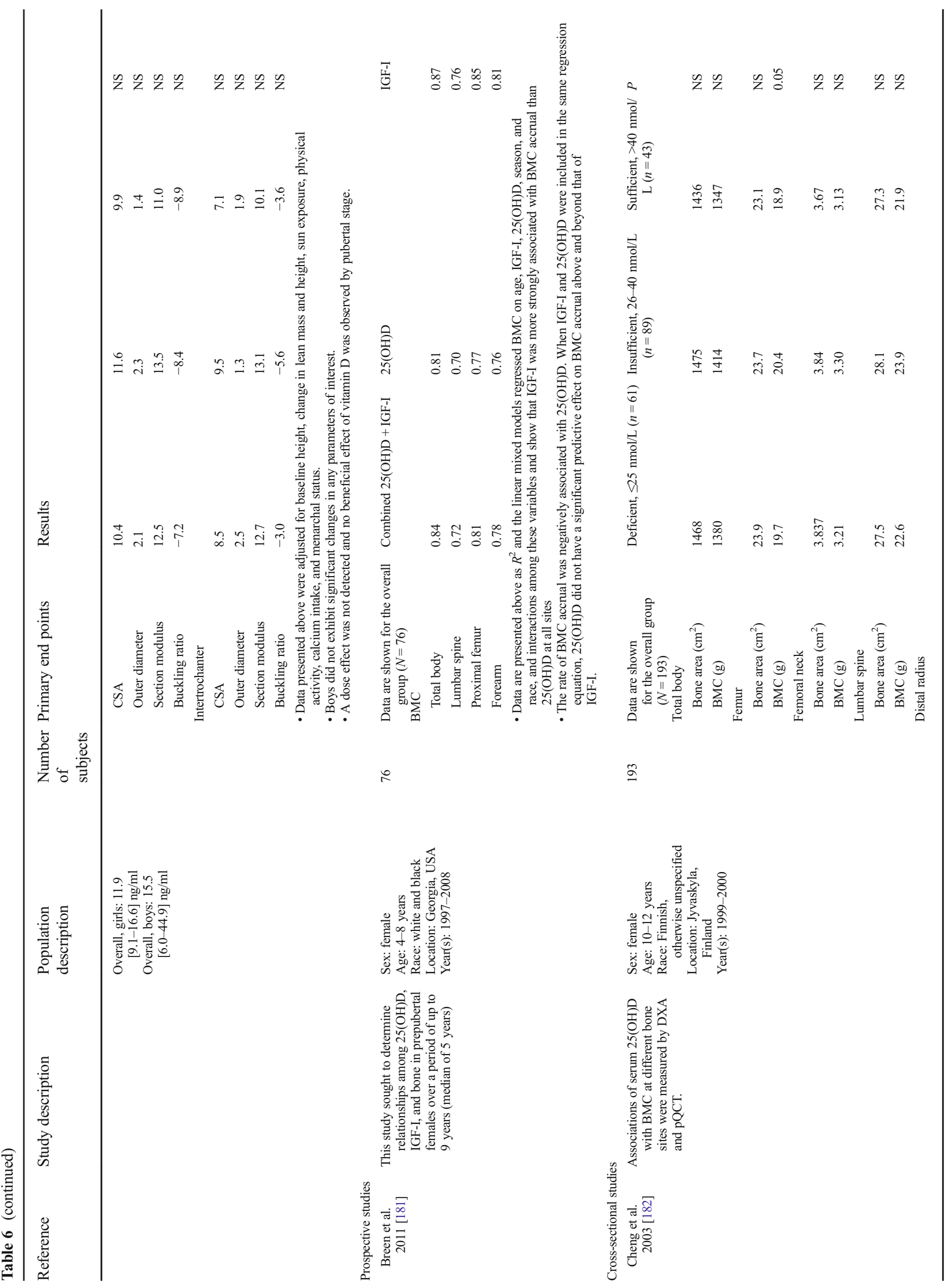




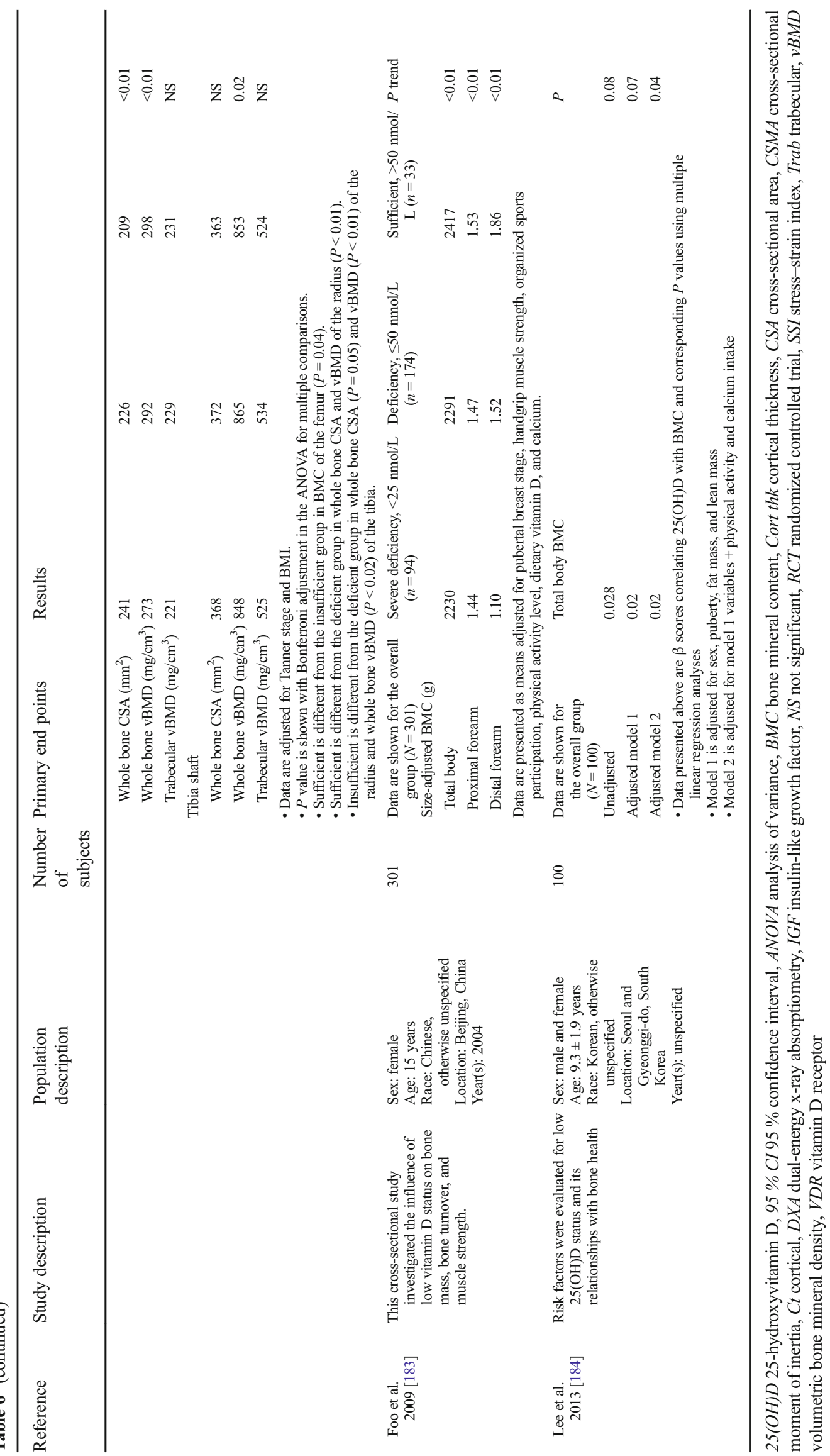




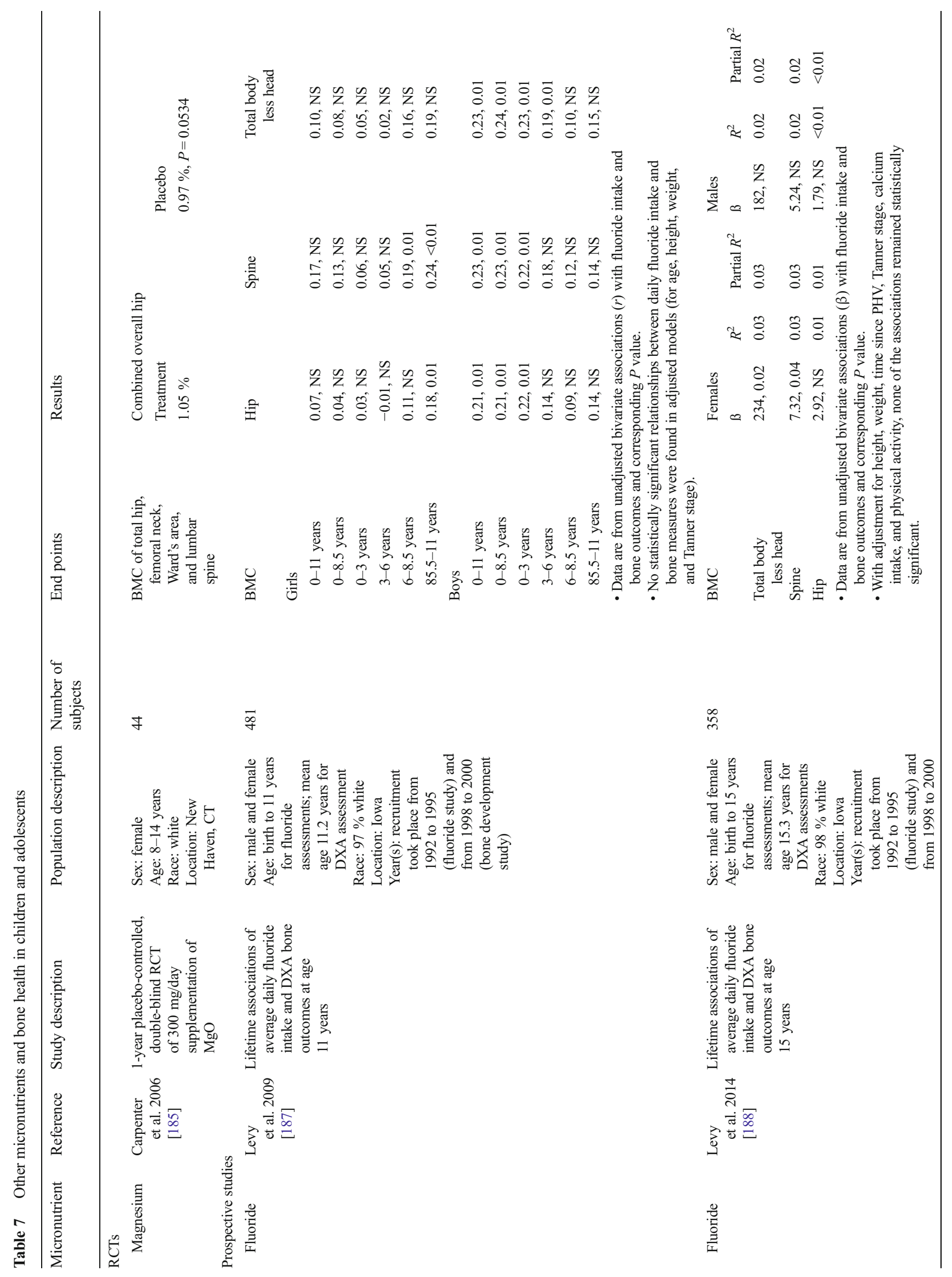




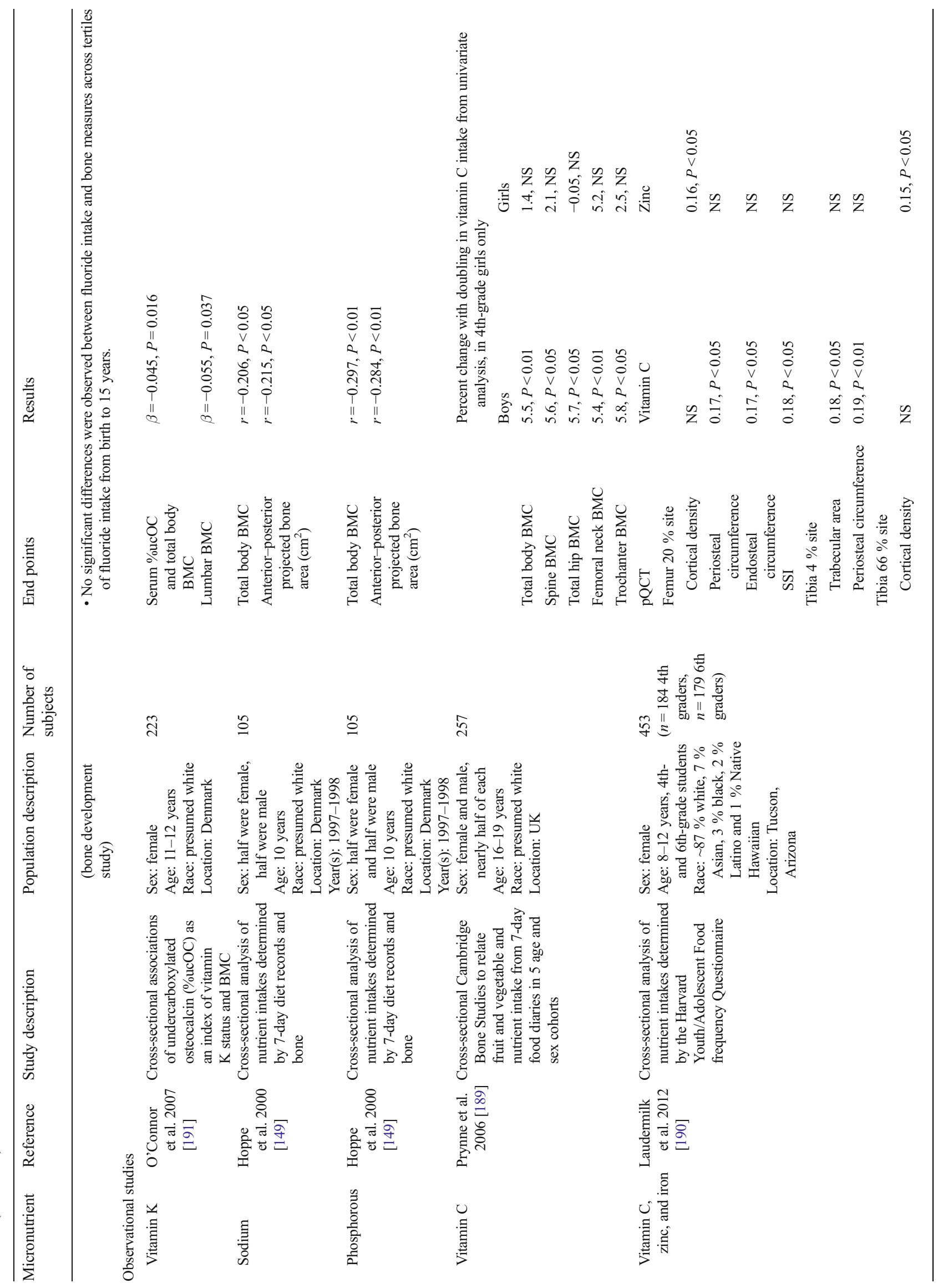




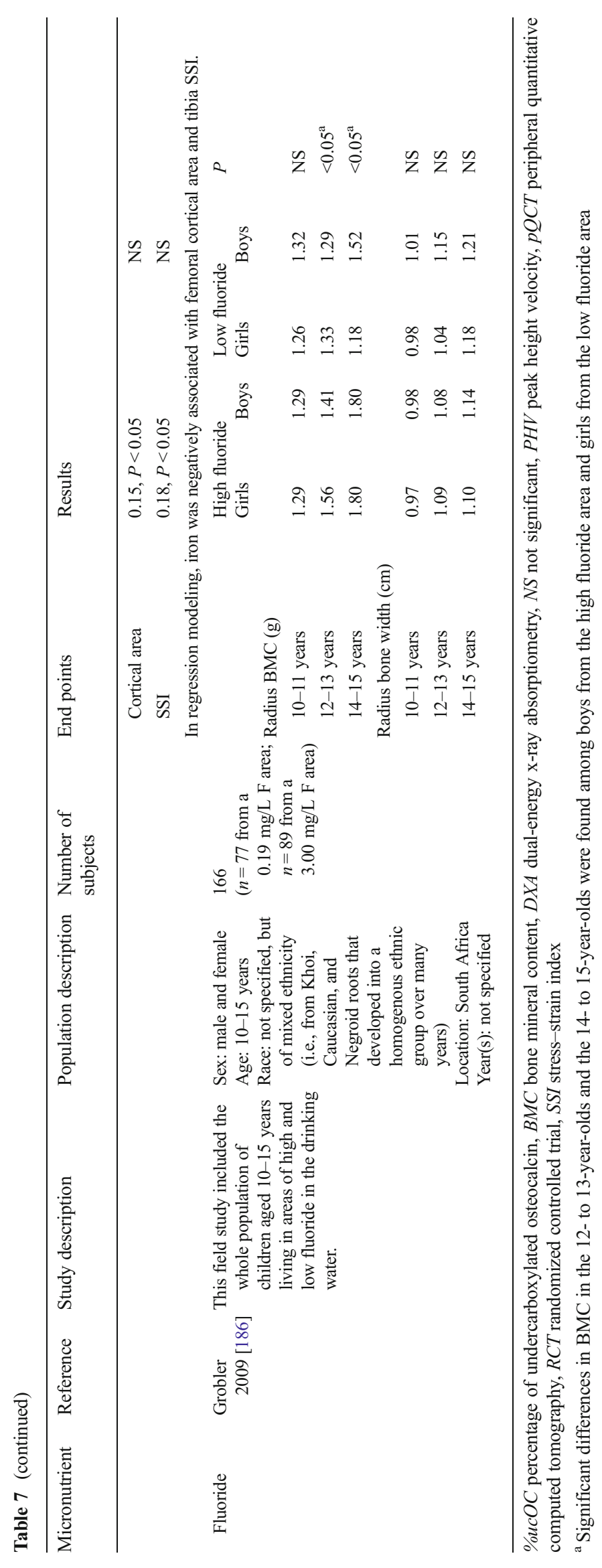


Protein (Table 3) The search for protein identified 1 RCT, 5 prospective studies, and 6 cross-sectional studies published since 2000, encompassing 2255 individuals (Table 3). In the one RCT, there was no effect of supplementing $42 \mathrm{~g}$ protein over 6 months on changes in tibia trabecular or cortical bone measures at the 4 or $20 \%$ sites, respectively, measured from the distal tibia metaphysis, or on changes in total body BMC [143]. Alexy et al. [144] demonstrated in a cohort of German children that protein intakes over 4 years were positively associated with, and were predictors of, forearm periosteal circumference, cortical area, BMC, and stress-strain index (SSI). The investigators also showed that long-term dietary potential renal acid load (PRAL) was negatively associated with forearm BMC and cortical area. PRAL is increased by sulfur amino acid content of the diet and is decreased by alkaline salts as occurs in plant foods. In the same cohort studied over 4 years, Remer et al. [145] reported that urinary nitrogen $(\mathrm{uN})$ was positively associated with forearm periosteal circumference, cortical area, BMC, and SSI, and urinary PRAL was negatively associated with forearm BMC and cortical area. Protein intakes in males and females between the ages of 2 months and 8 years were positively associated with total body BMC [146]. Using a mixed-longitudinal design, protein intakes were shown to positively predict total body BMC net gain in males and females between ages 8 and 21 years [147]. Moreover, protein intakes in periadolescent females were positively associated with total body BMC and total body BMC net gains, but only in those with calcium intakes $>1000 \mathrm{mg} /$ day. Over a period of 5 years, protein intakes in children with low calcium intakes were negatively associated with distal and proximal forearm BMC and total body BMC [148].

Hoppe et al. [149] reported that protein intakes among Danish children were positively related to total body bone area, but not BMC, when adjusted for height, weight, and sex. Differences in arm BMC between twins were partially explained by protein intakes, such that a $1-\mathrm{g}$ difference in protein intake resulted in a $0.4 \%$ difference in arm BMC [150]. Chevalley et al. [151] reported that protein intakes in prepubertal males were positively related to BMC of the radial metaphysis, total radius, femoral neck, femoral diaphysis, and the lumbar spine when controlling for physical activity and calcium intakes. Absolute or adjusted (for body weight, years after menarche, and vertebral area) protein intake from milk, but not from other foods, was positively associated with lumbar spine BMC [152]. In a group of healthy and malnourished Indian children aged 2-3 years, protein intake was positively related to total body BMC and bone area [153]. However, energy-adjusted protein intakes were not significantly associated with forearm geometrical measures in another group of children [154].

Our evidence grade for protein was based on findings from four prospective studies indicating positive findings and one null RCT.
Grade: Level of evidence C was assigned for the benefit of protein on bone.

\section{Micronutrients}

Calcium (Tables 4 and 5) The search for calcium identified 16 RCTs published since 2000, encompassing 3077 individuals (Table 4). In addition, five studies that used both calcium and physical activity interventions were evaluated for main and interaction effects [81, 155-158]. Four observational studies published since 2000, encompassing 2383 individuals, looked at calcium and physical activity interactions on bone (Table 5). When categorized according to the type of calcium intervention, nine studies included supplementation with pills/ chews, four used calcium-fortified foods, two used dairy foods, and one used a combination of dairy and pills. Most of the studies included primarily white subjects. A variety of skeletal variables were used as study outcomes. Most studies evaluated the effects of calcium intake on DXA outcomes, including BMC, aBMD, and bone area of the total body, lumbar spine, total hip, femoral neck, intertrochanteric and trochanteric areas of the hip, and distal and ultradistal areas of the forearm. Very few studies reported all possible DXA outcomes, and specific outcomes varied among studies. Three RCTs assessed bone mass and structure using pQCT.

All but one [159] of the nine RCTs using supplement pills found a small, but consistent, positive effect on aBMD and/or BMC accrual as measured by DXA. The benefit to the supplemented group compared to the placebo group ranged from 0.57 to $5.80 \%$. None of the studies found a significant effect at all (i.e., hip, spine, and radius) of the usual DXA skeletal sites, and the specific sites that benefited varied among the studies. Only three of the RCTs with DXA reported adjusting for body size [160-162], which is important because longitudinal growth confounds interpretation of changes in aBMD and BMC. The difference in height-adjusted BMC accrual between supplemented and placebo groups in these four studies ranged from 0.80 to $4.60 \%$.

One of the best-designed studies was a single-blind co-twin study of girls aged 8-13 years given calcium carbonate $1200 \mathrm{mg} /$ day or placebo for 24 months [161]. Baseline calcium intake was $786 \mathrm{mg} /$ day (calcium) and $772 \mathrm{mg} /$ day (control; not significant), values considerably lower than the recommended dietary allowance (RDA) $(1000 \mathrm{mg}$ /day for ages 4-8 years and $1300 \mathrm{mg}$ /day for ages 9-18 years). Of 64 twin pairs enrolled, 24 pairs completed the study. Compliance with supplementation was $76 \%$ for both groups (calcium and placebo). At the end of study, the calcium group had gained $3.69 \%$ more total body BMC (adjusted for age, height, and weight) than the control group. There were no significant differences in change in BMD at the total hip, spine, or femoral neck. In post hoc analyses, significant differences in gain were 


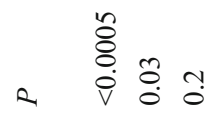

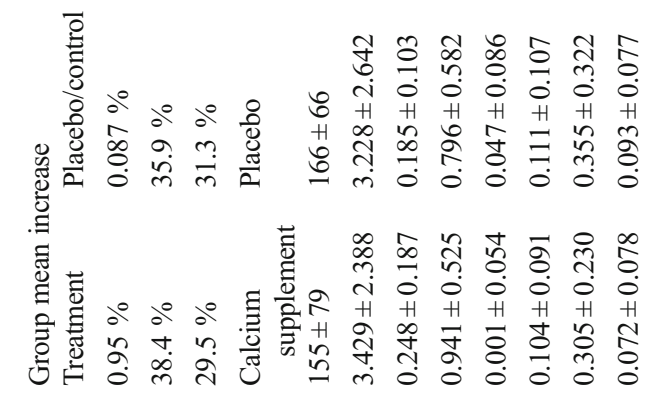

$\sum_{\infty}^{U} \sum_{\infty}^{U} \sum_{m}^{U} \sum_{\infty}^{U} \sum_{\infty}^{U} \sum_{m}^{U} \sum_{\infty}^{U} \sum_{\infty}^{U}$

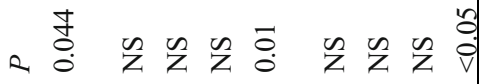

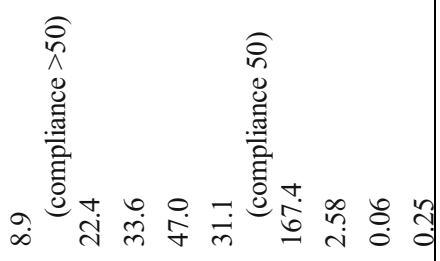

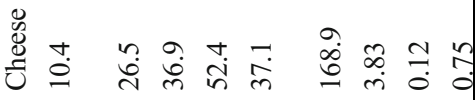

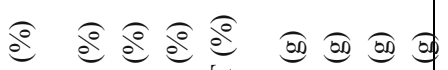
$\sum_{m} \sum_{m}^{U} \sum_{m}^{U} \sum_{m}^{U} \frac{U}{\sigma} \sum_{m}^{U} \sum_{m}^{U} \sum_{m}^{U} \sum_{m}^{U}$

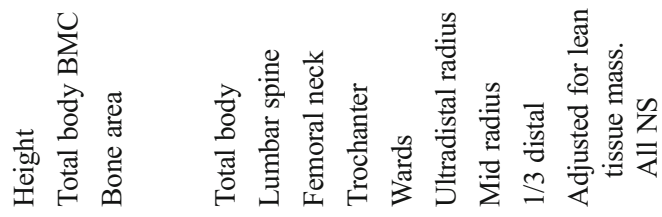

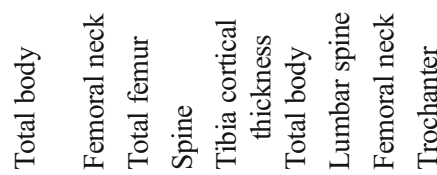

i $\quad$ 구

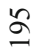

$\bar{a}$

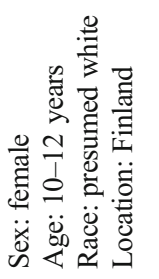

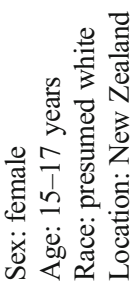

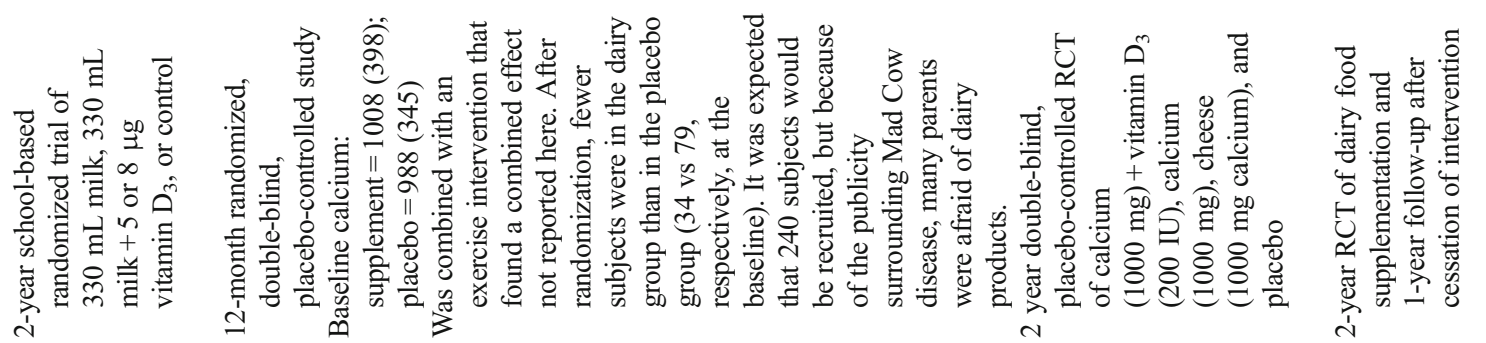

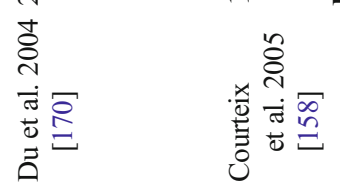
ज完

อ๊ है

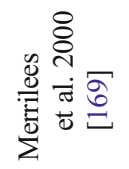

角

言 


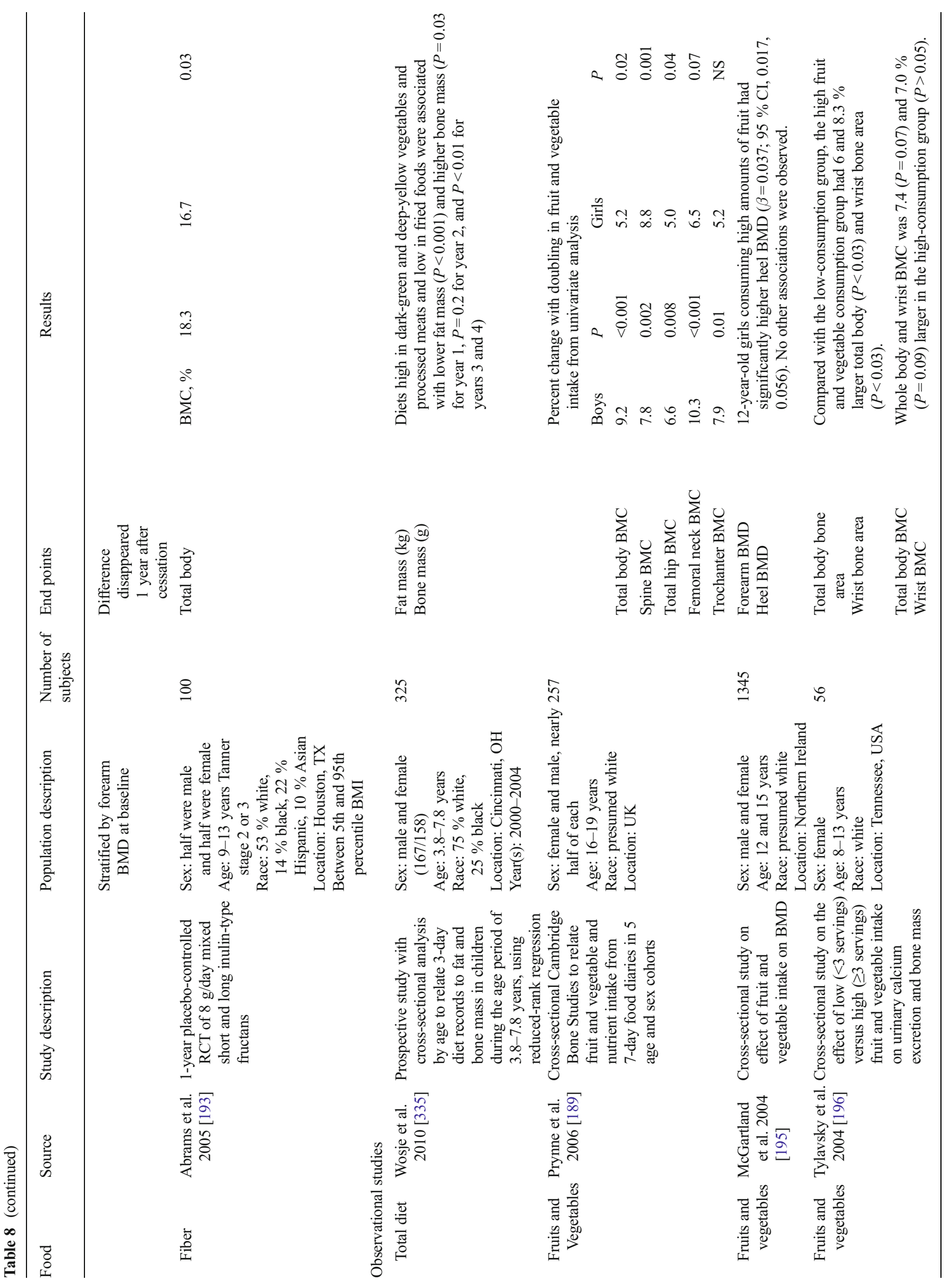




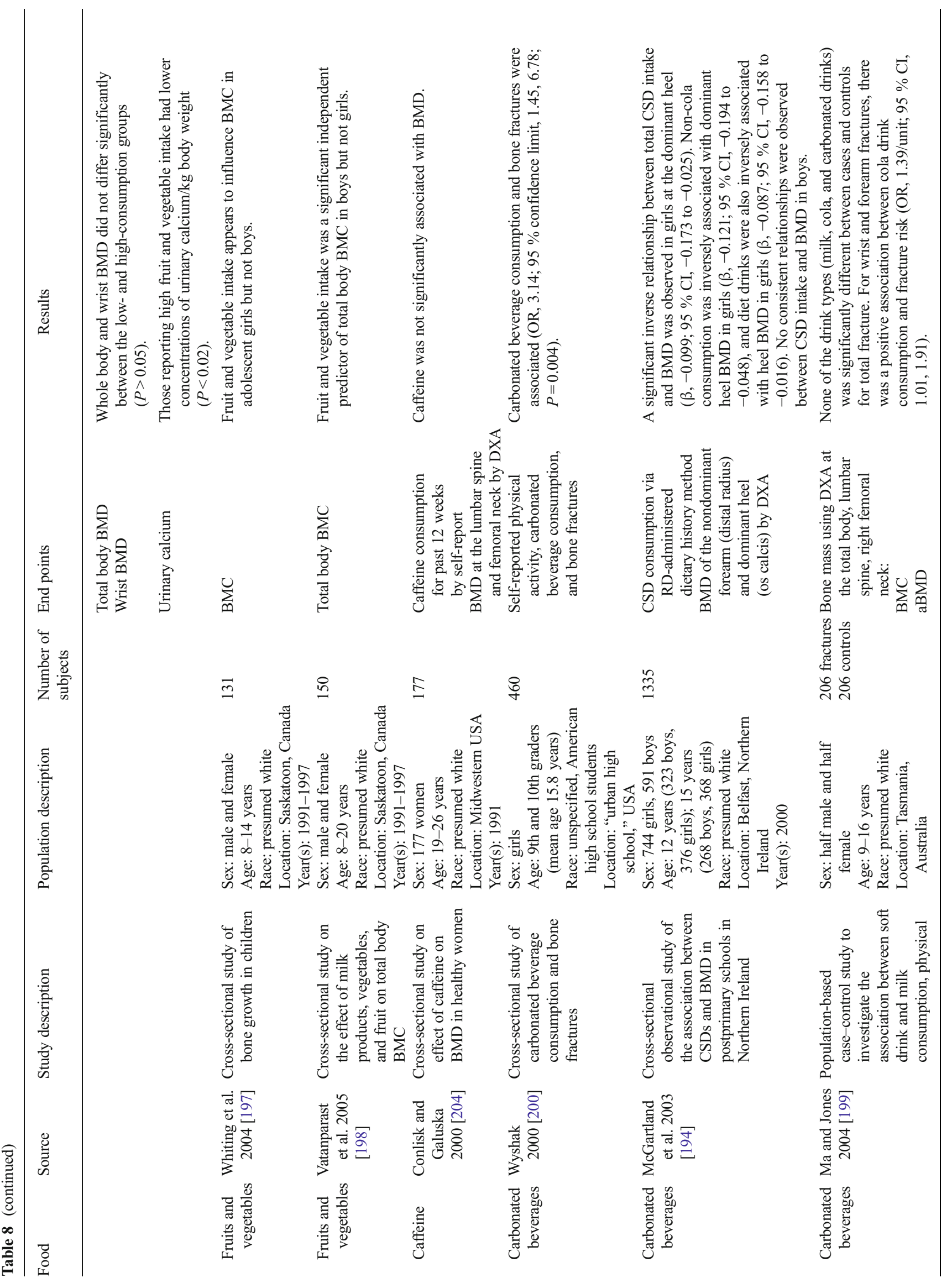




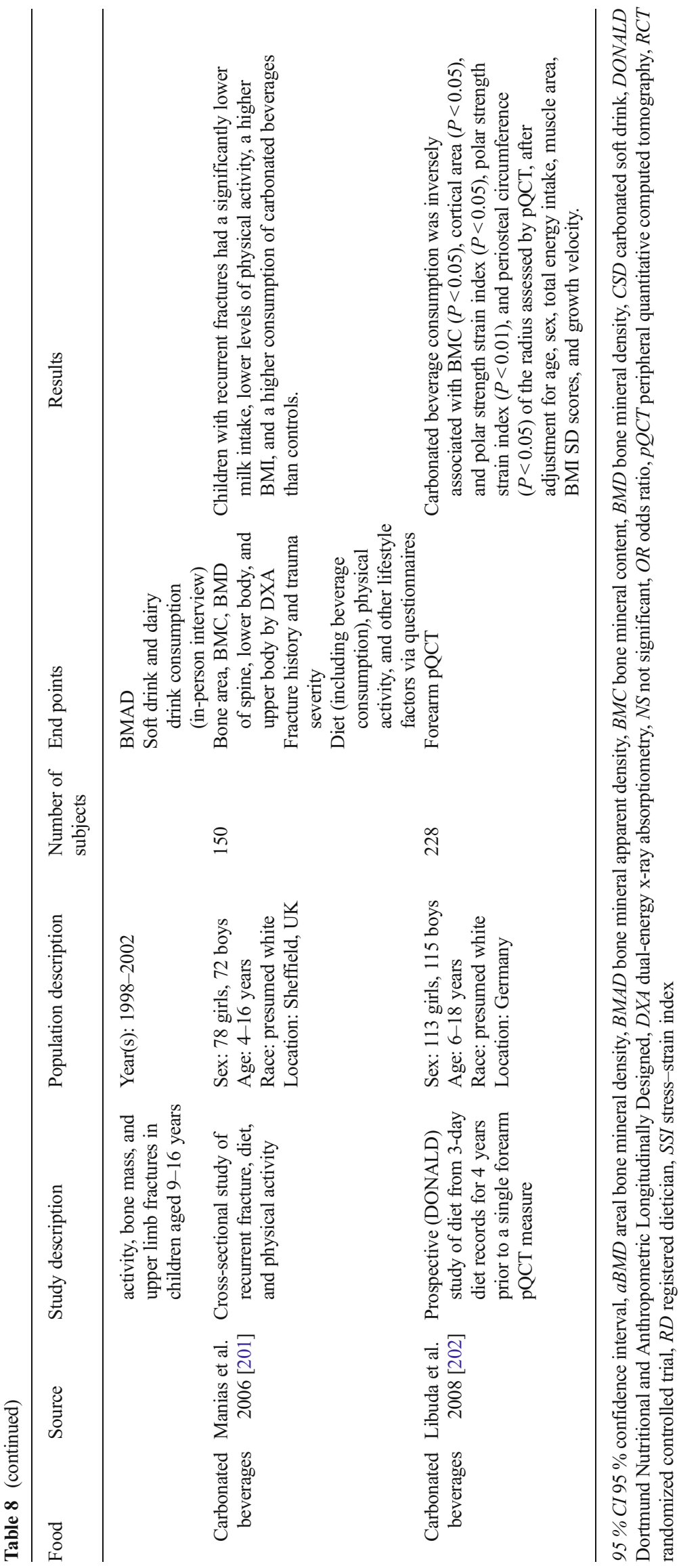




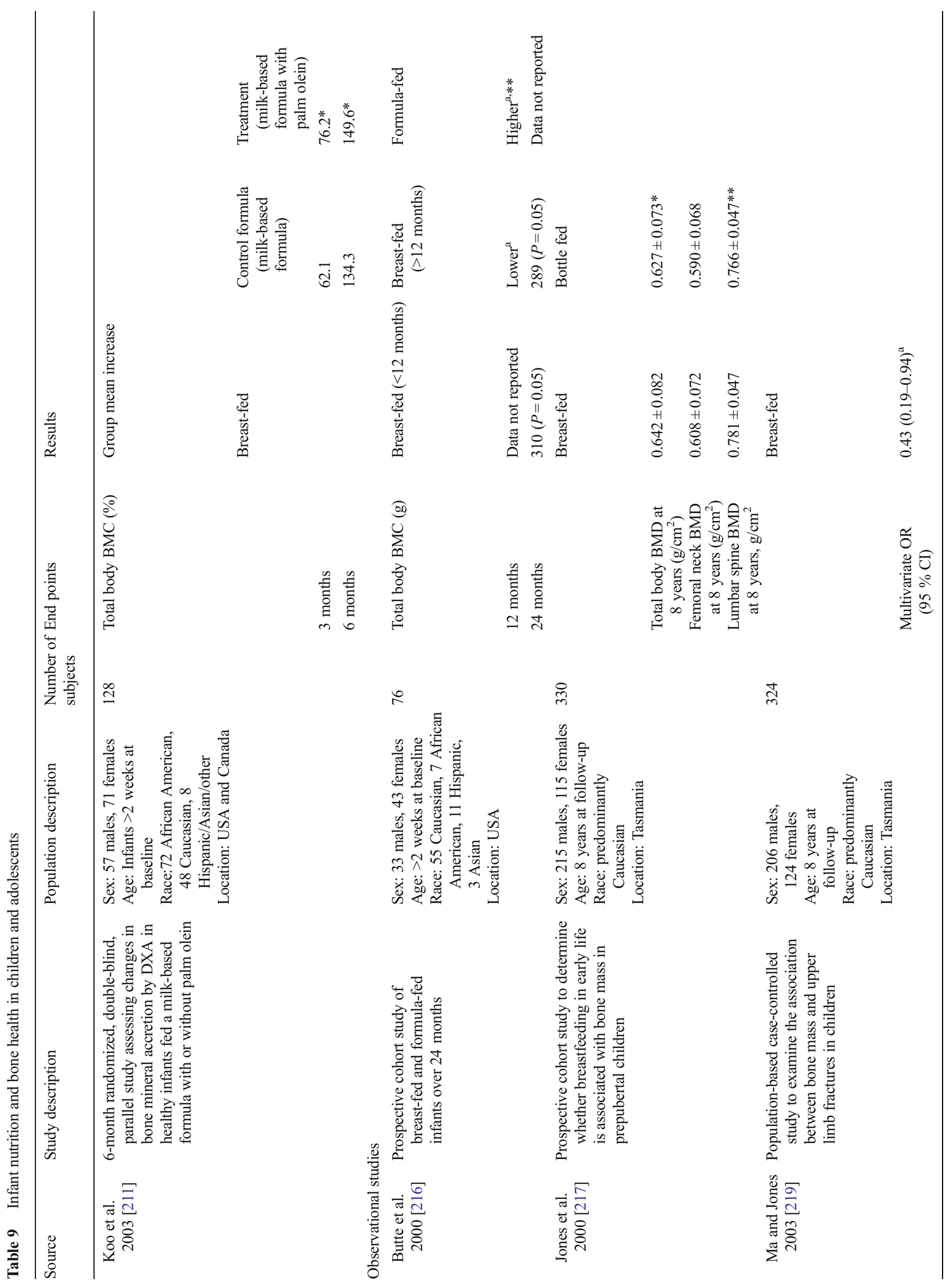




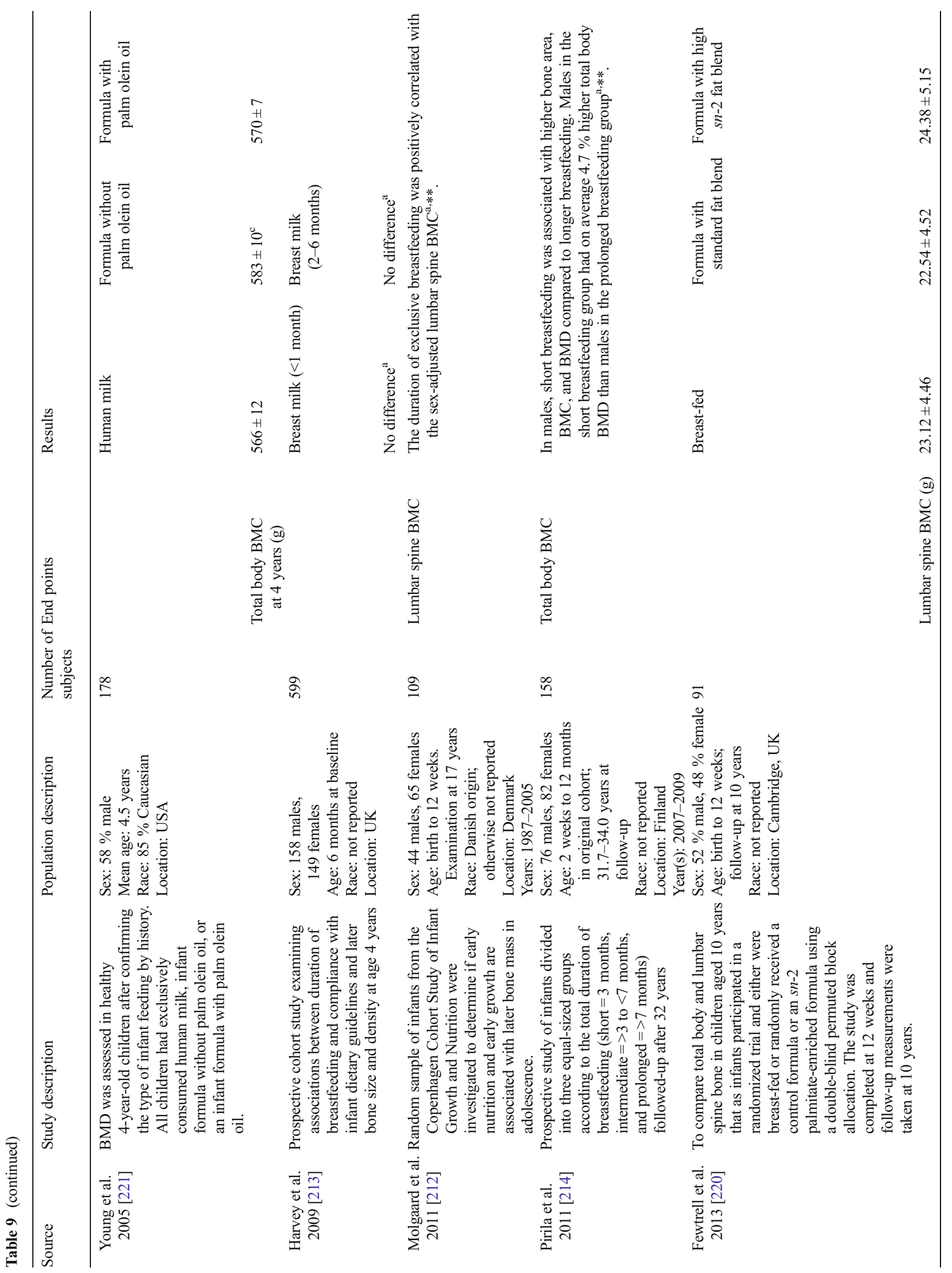




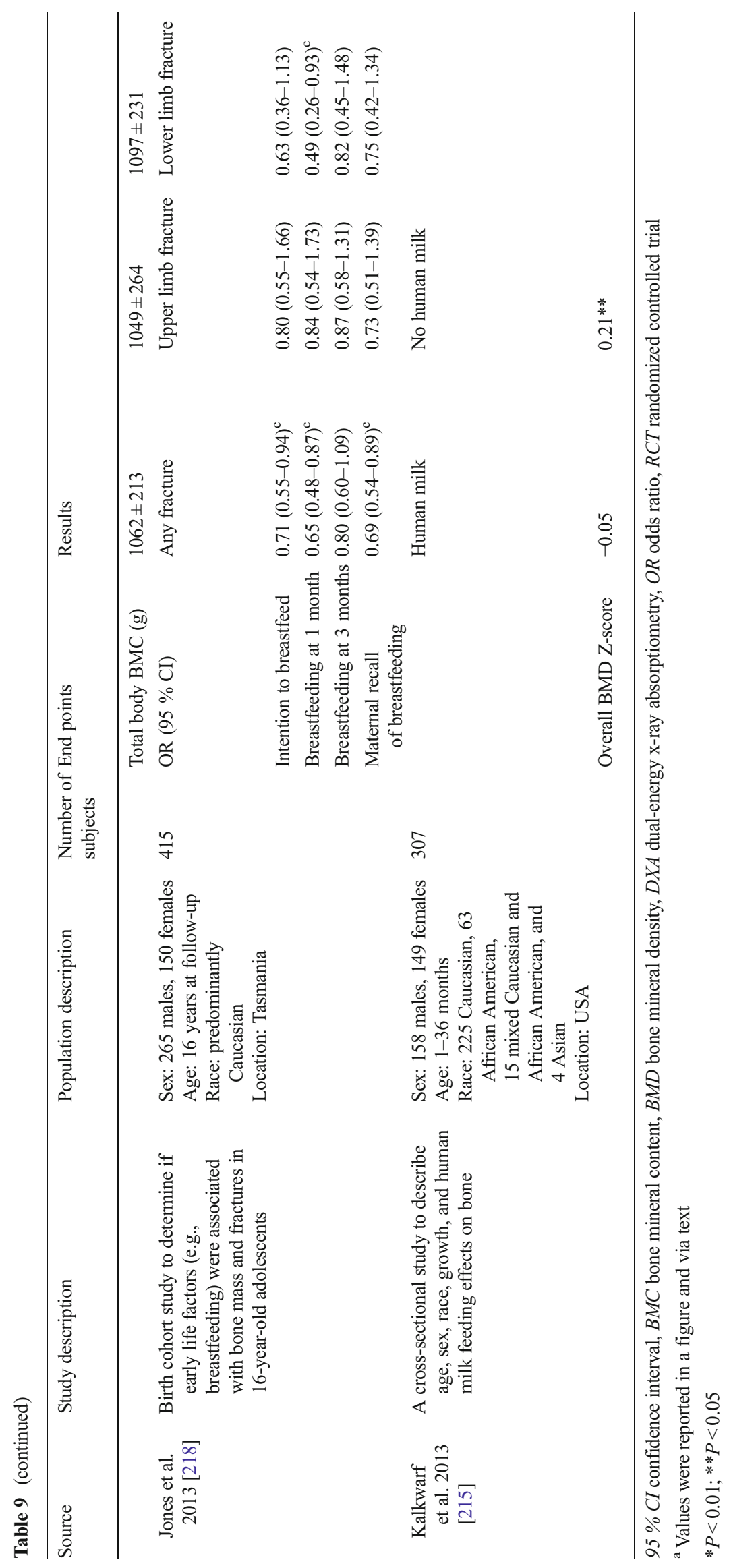




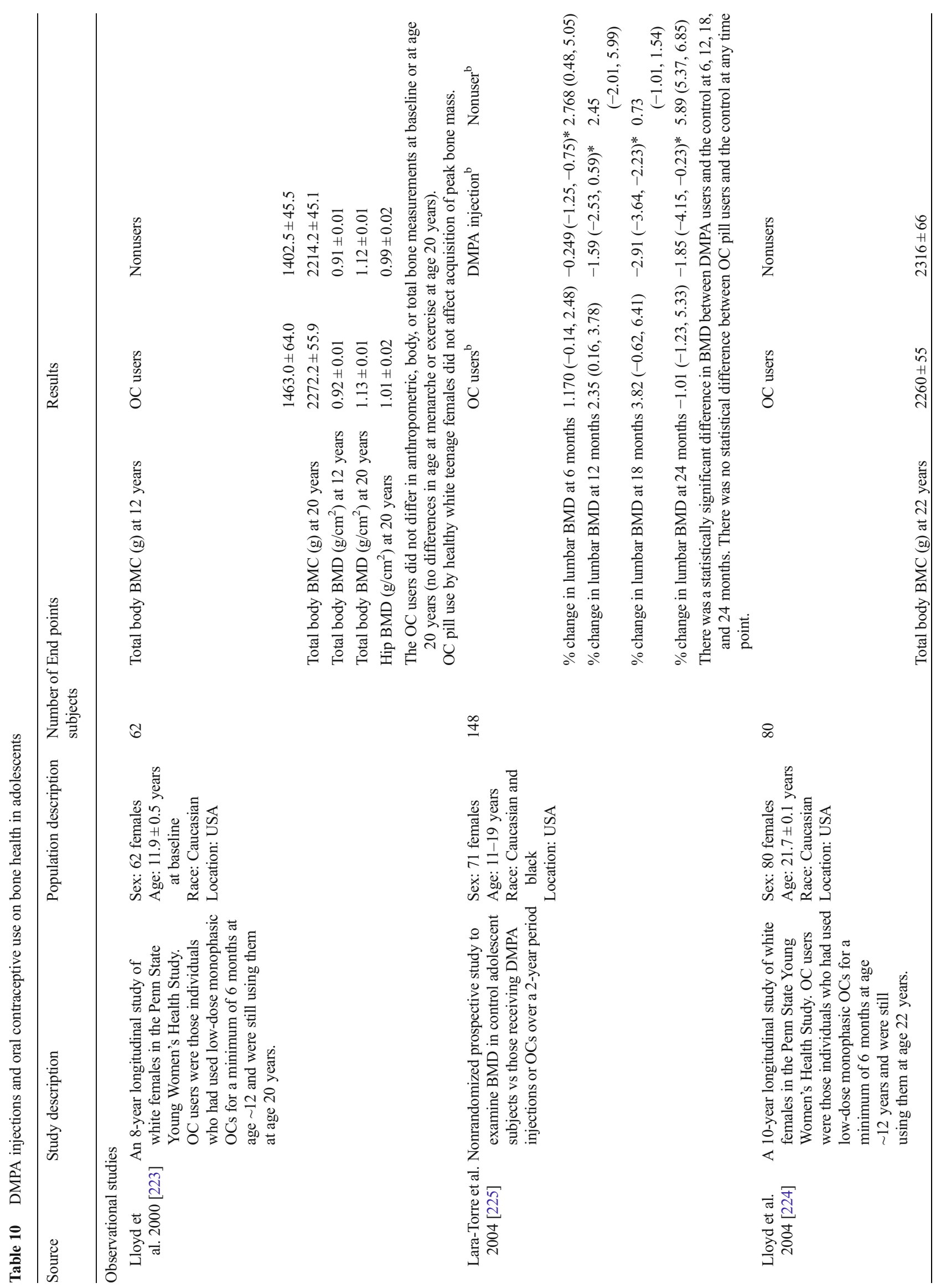




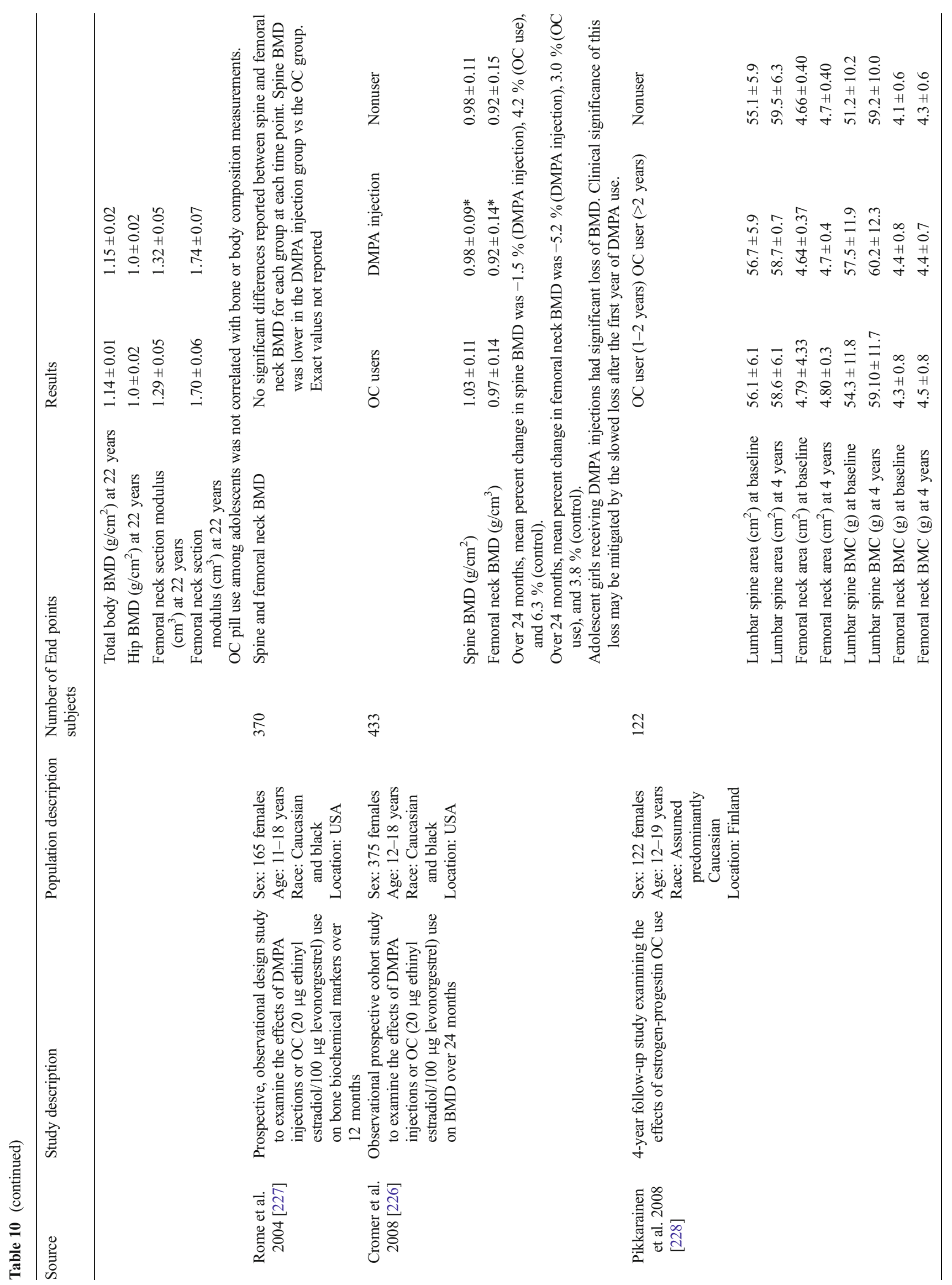




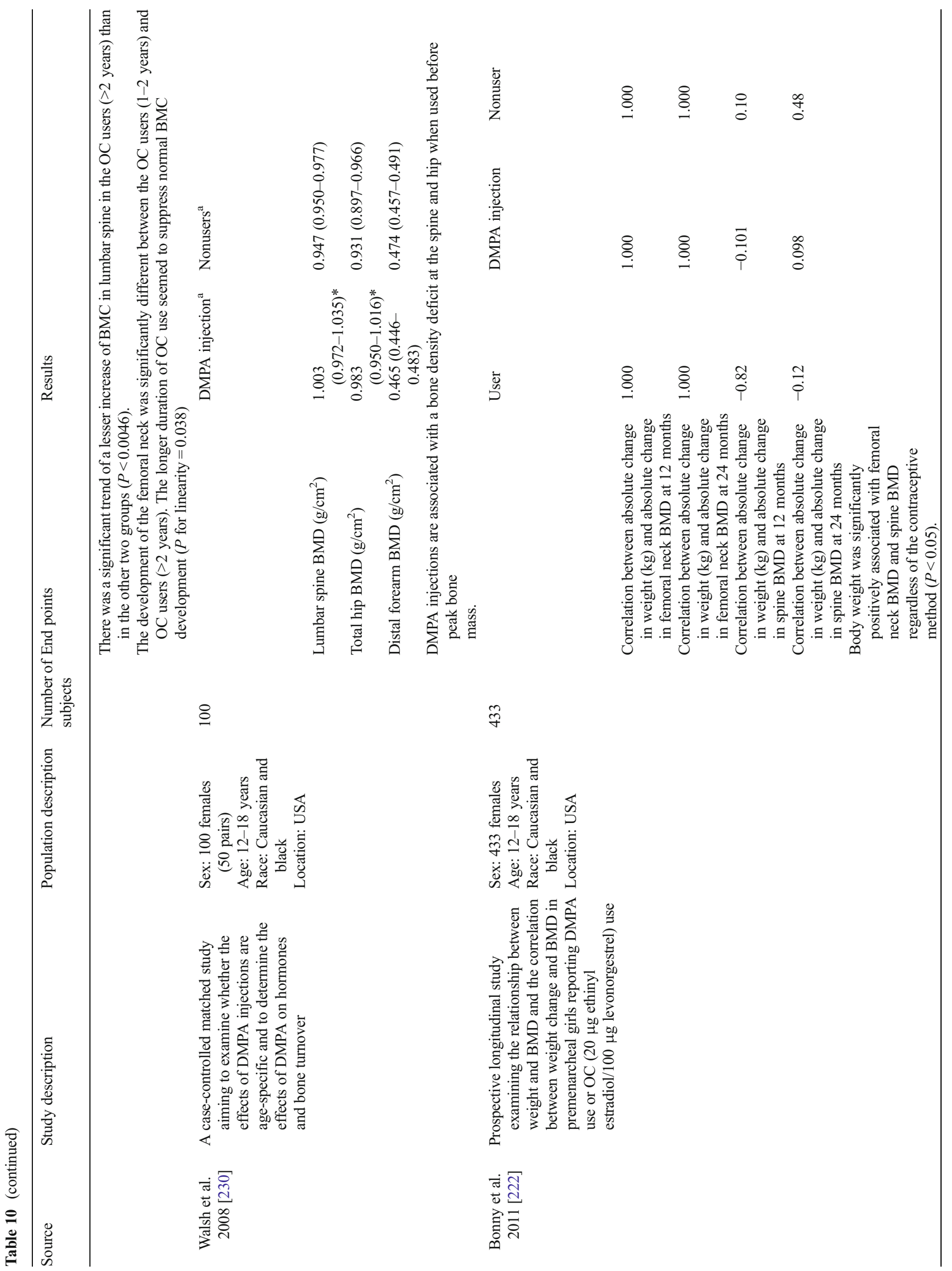




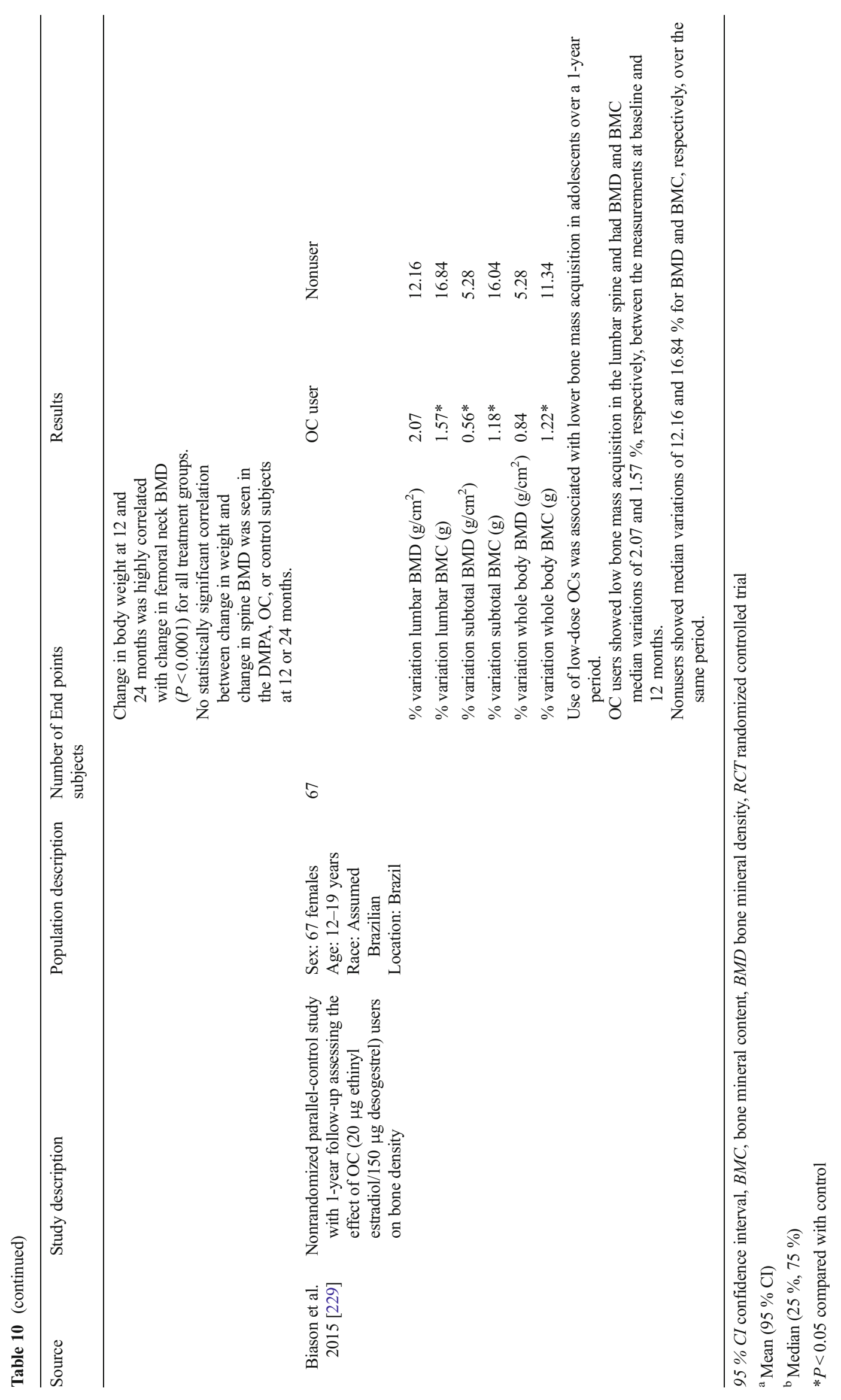




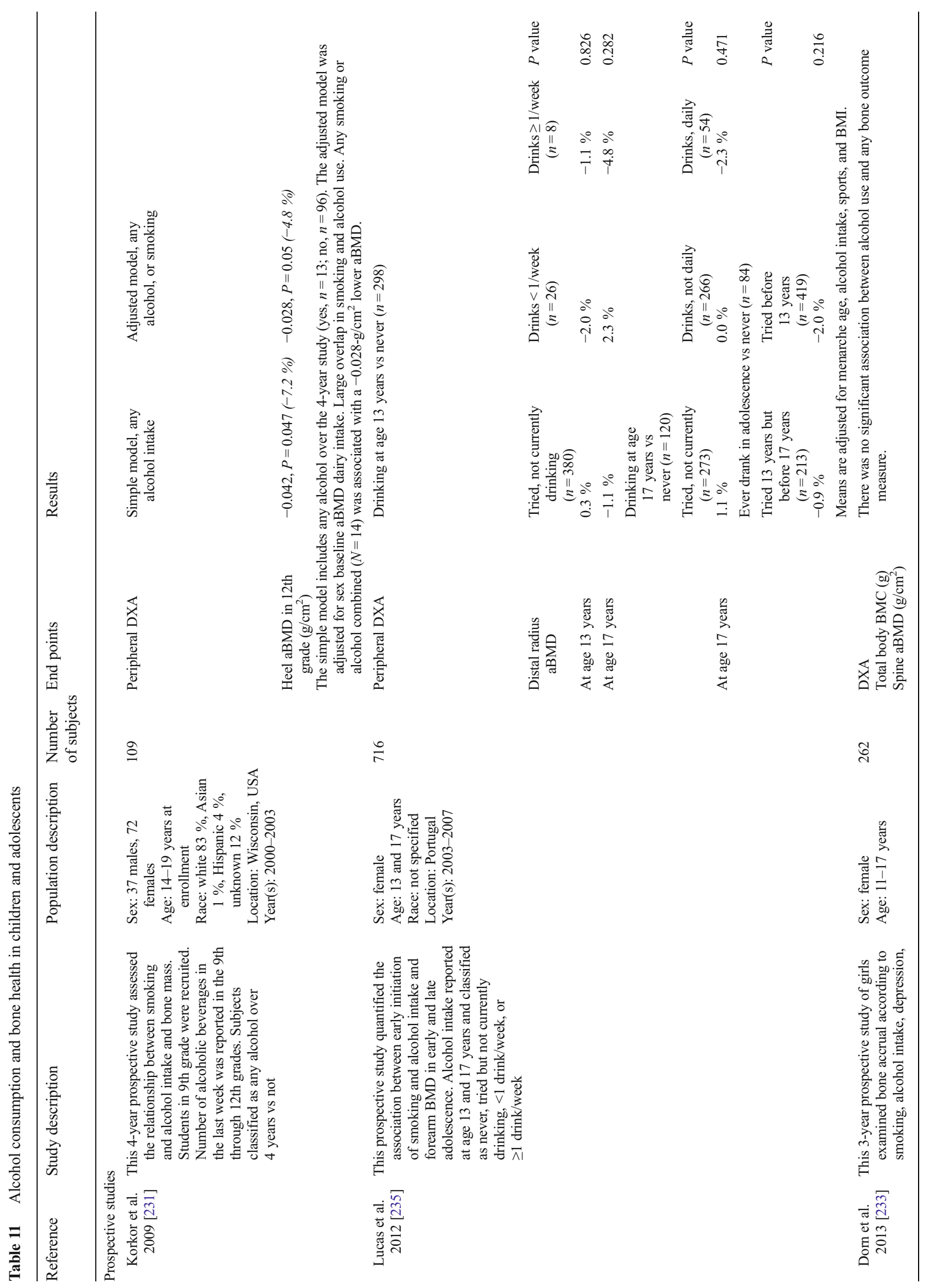




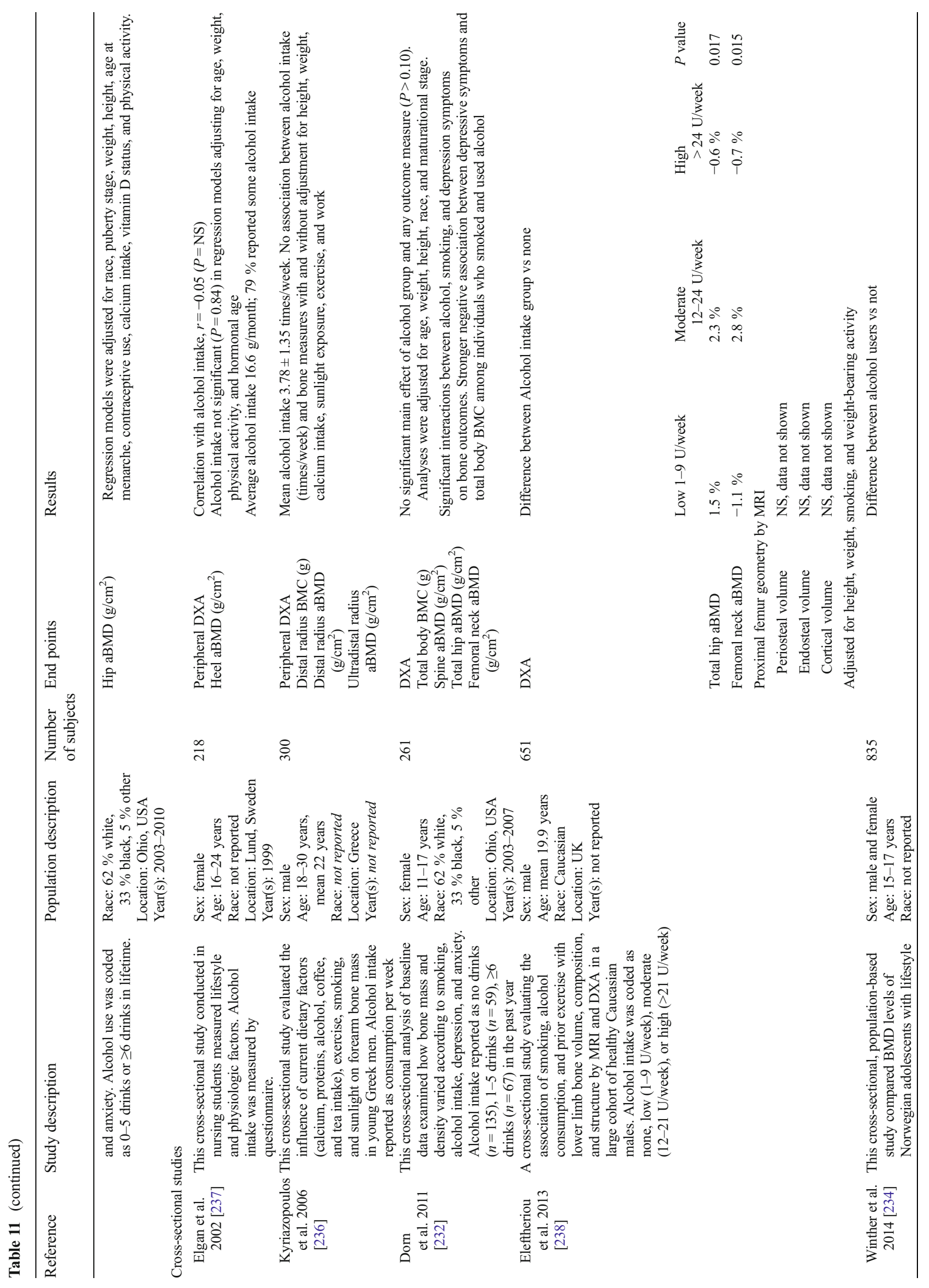




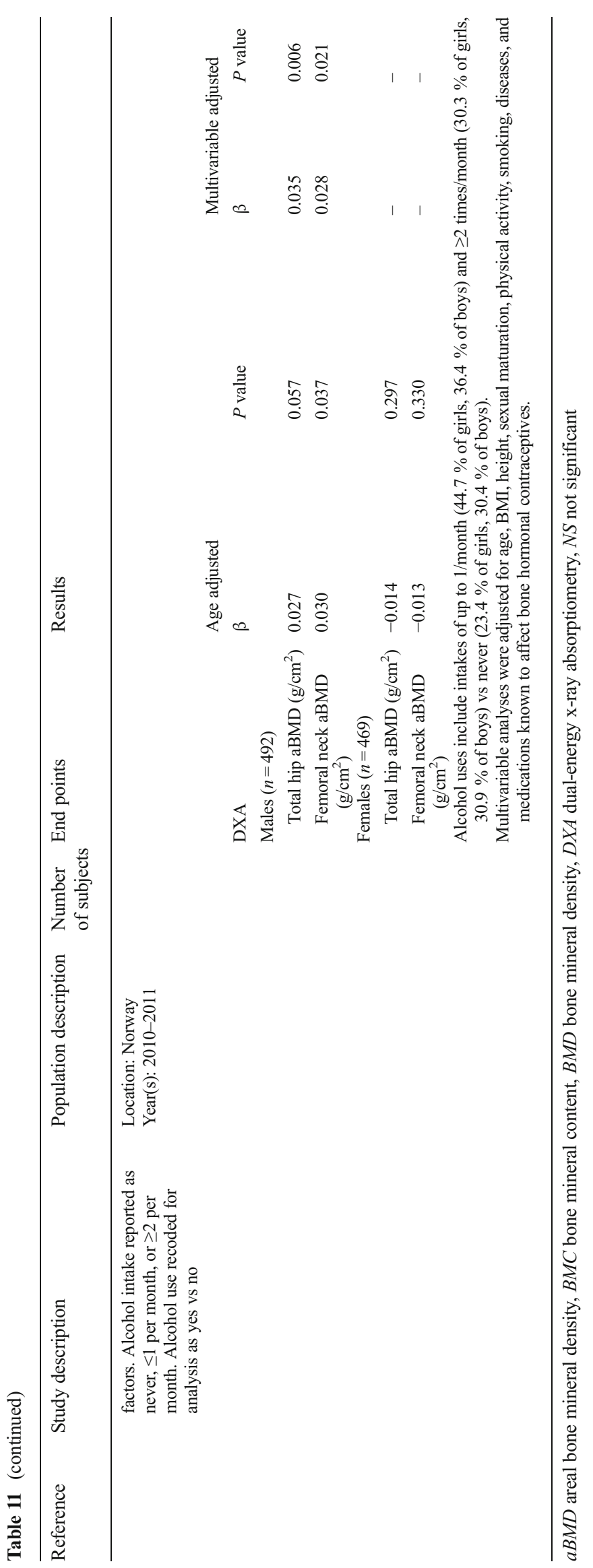




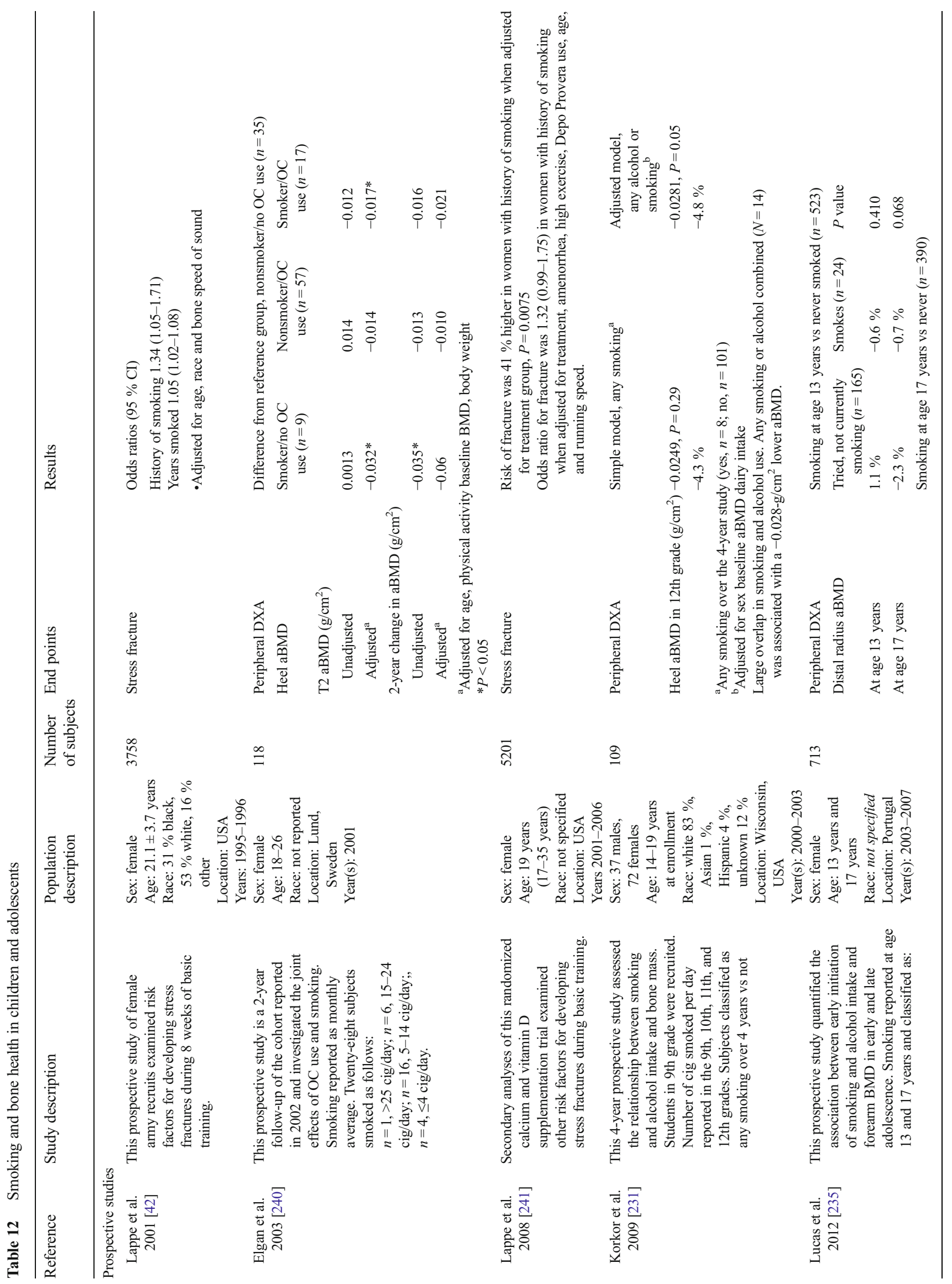




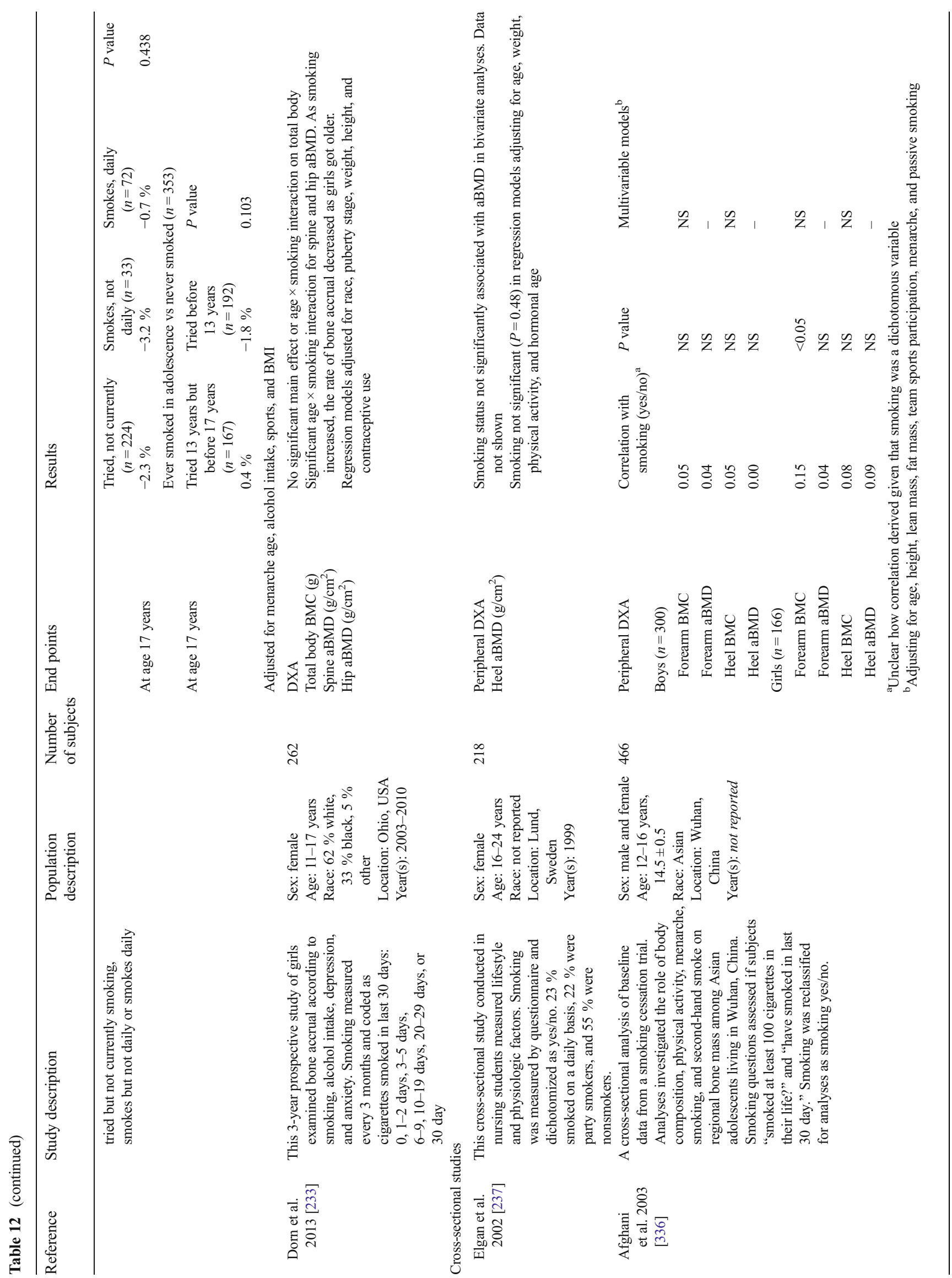




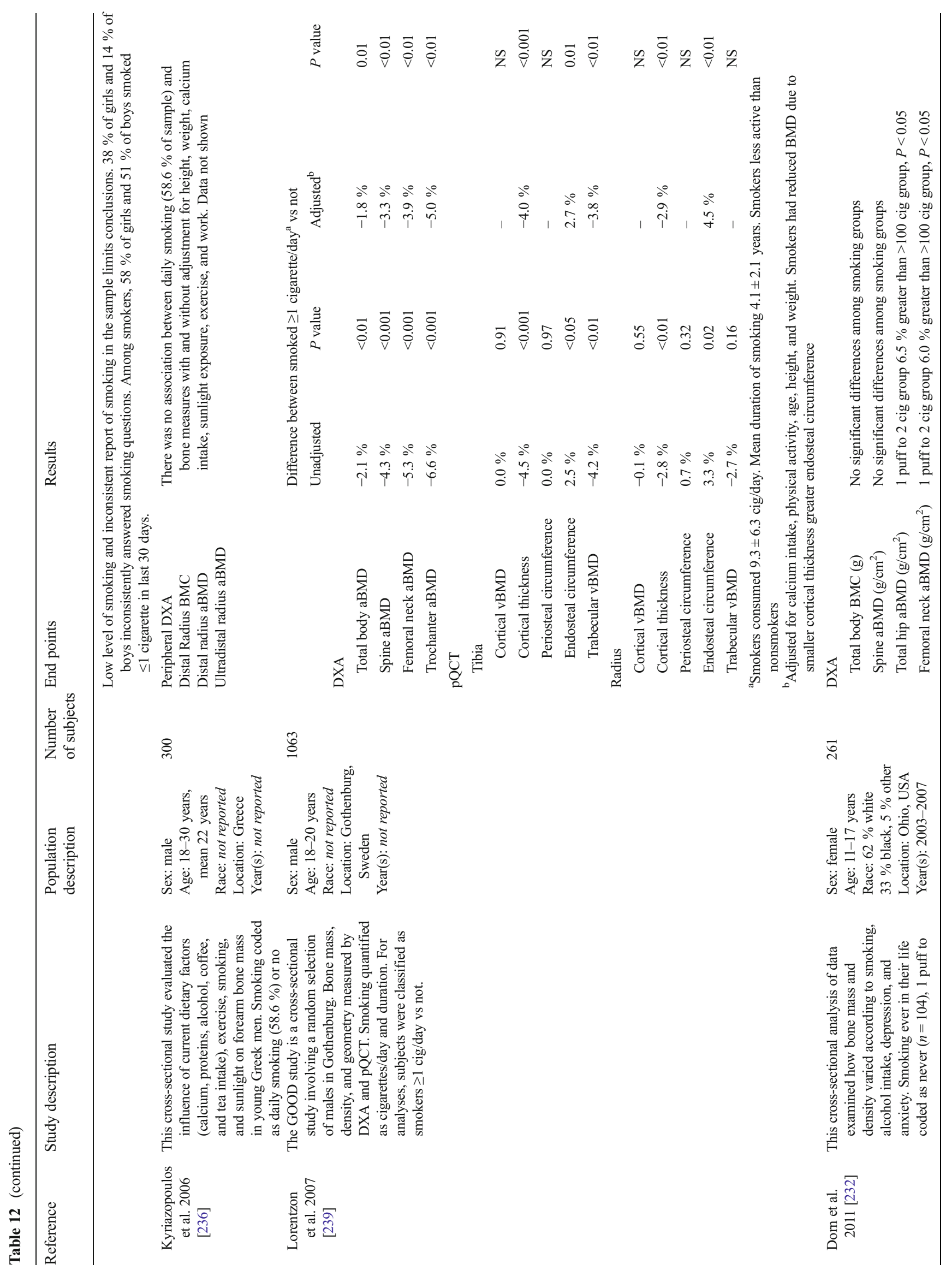




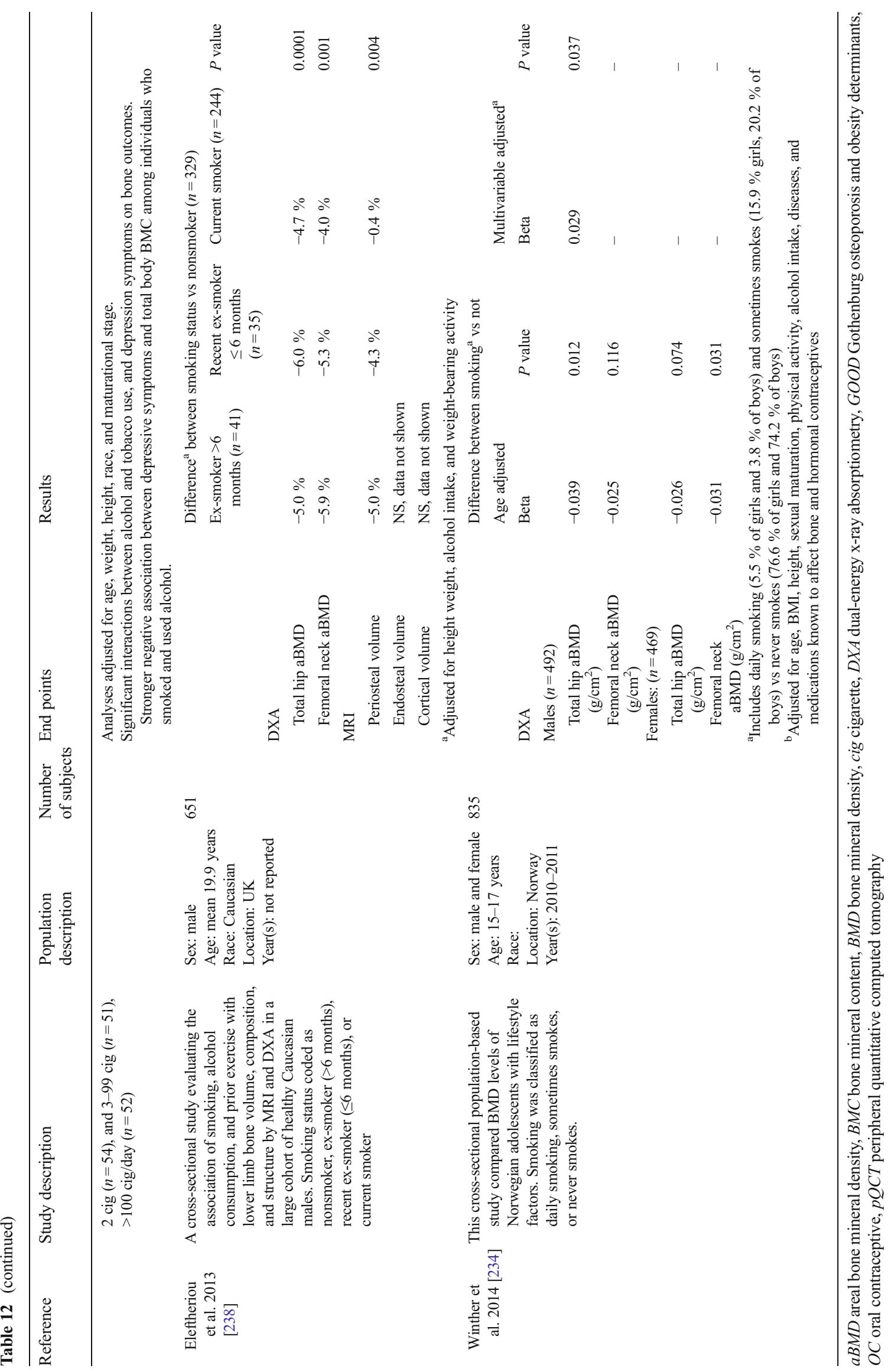




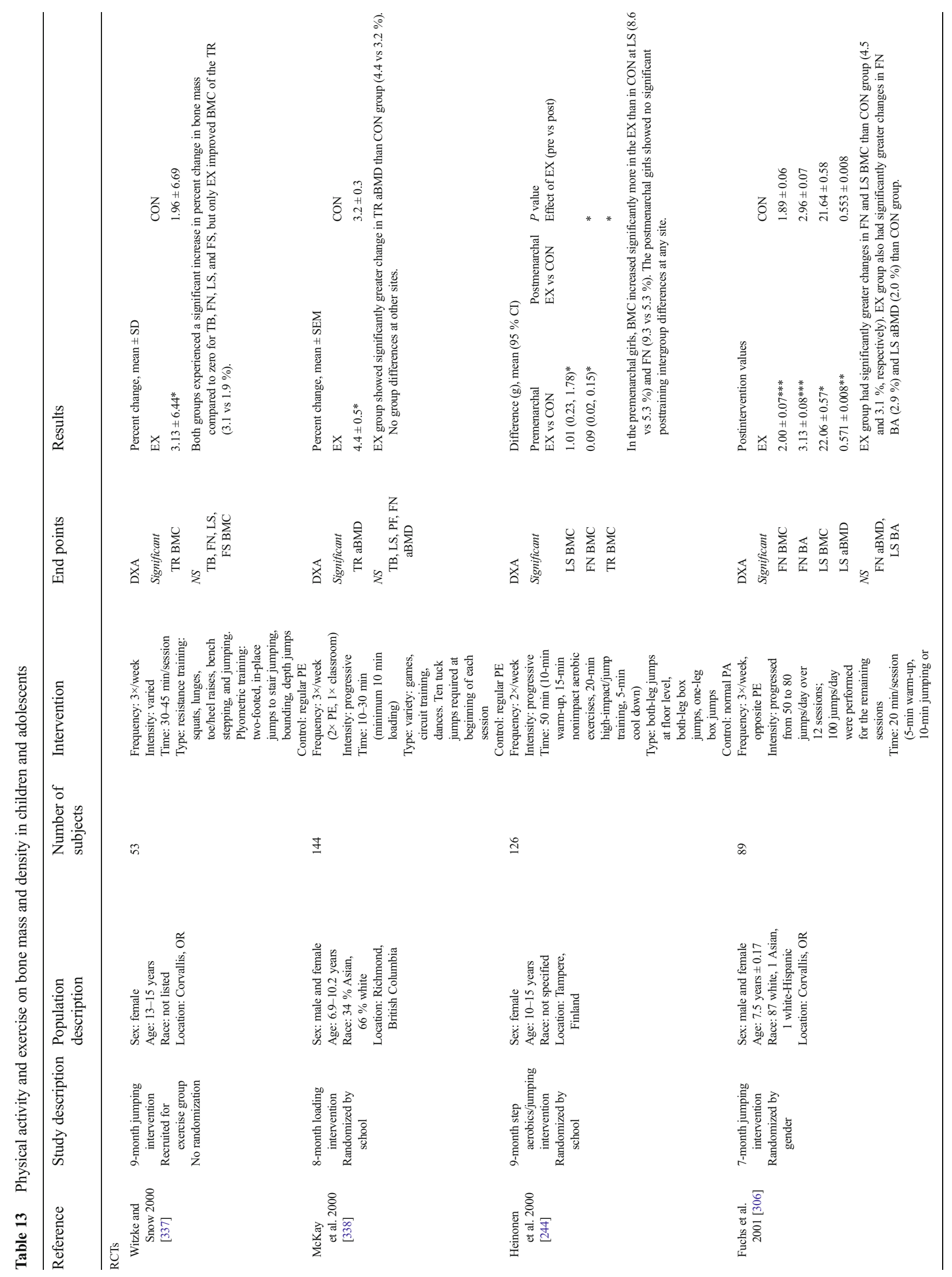




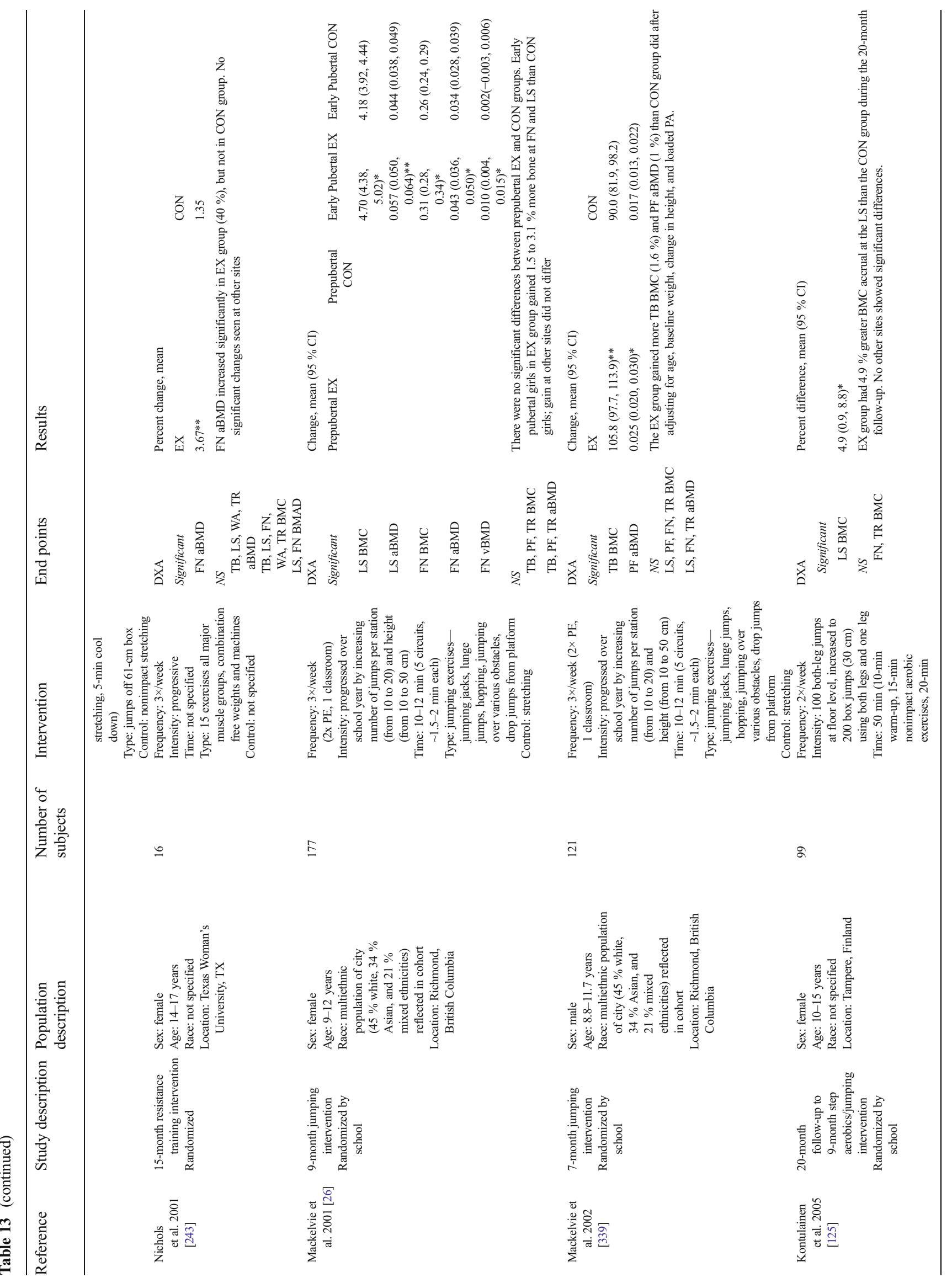




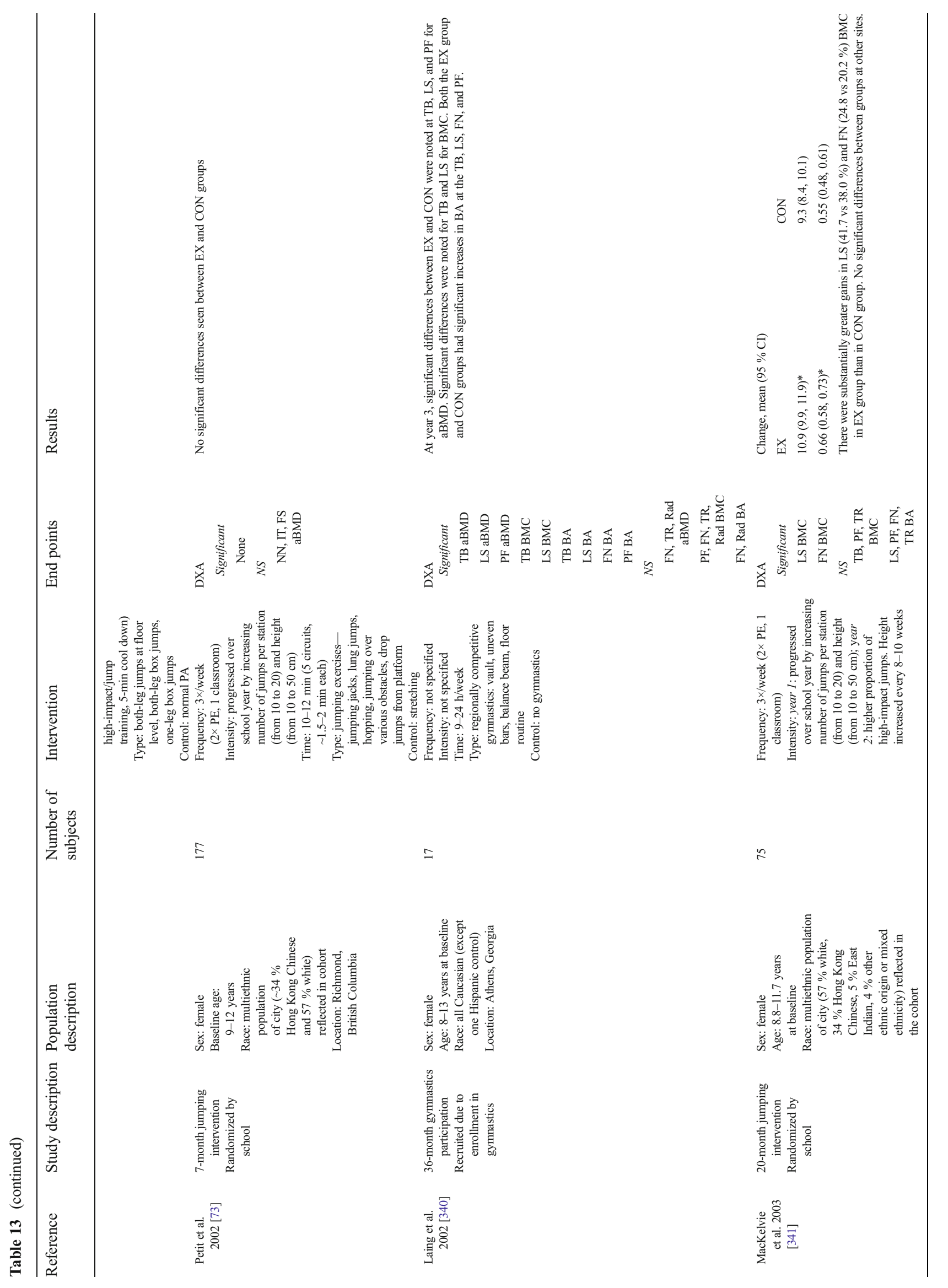




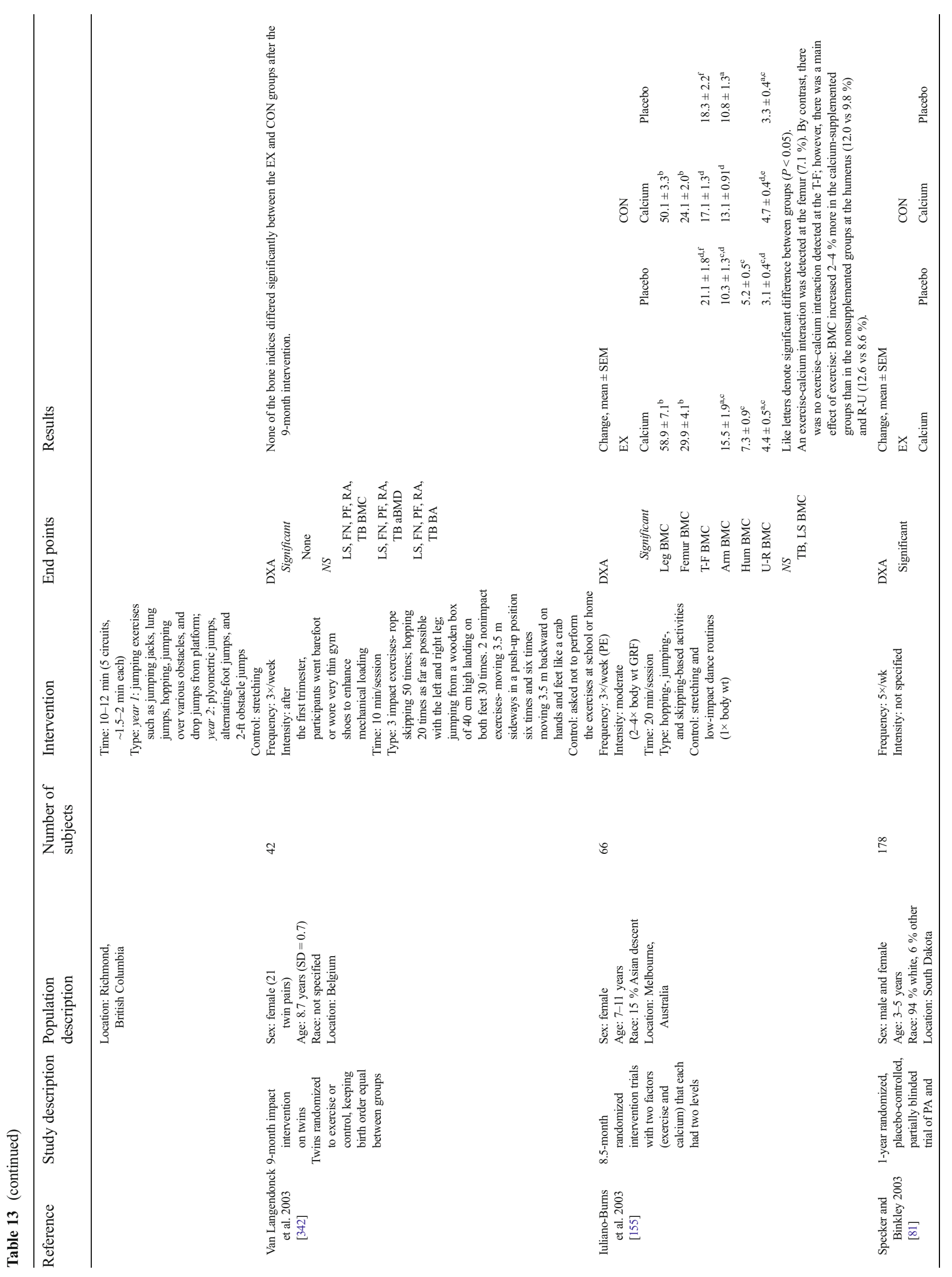




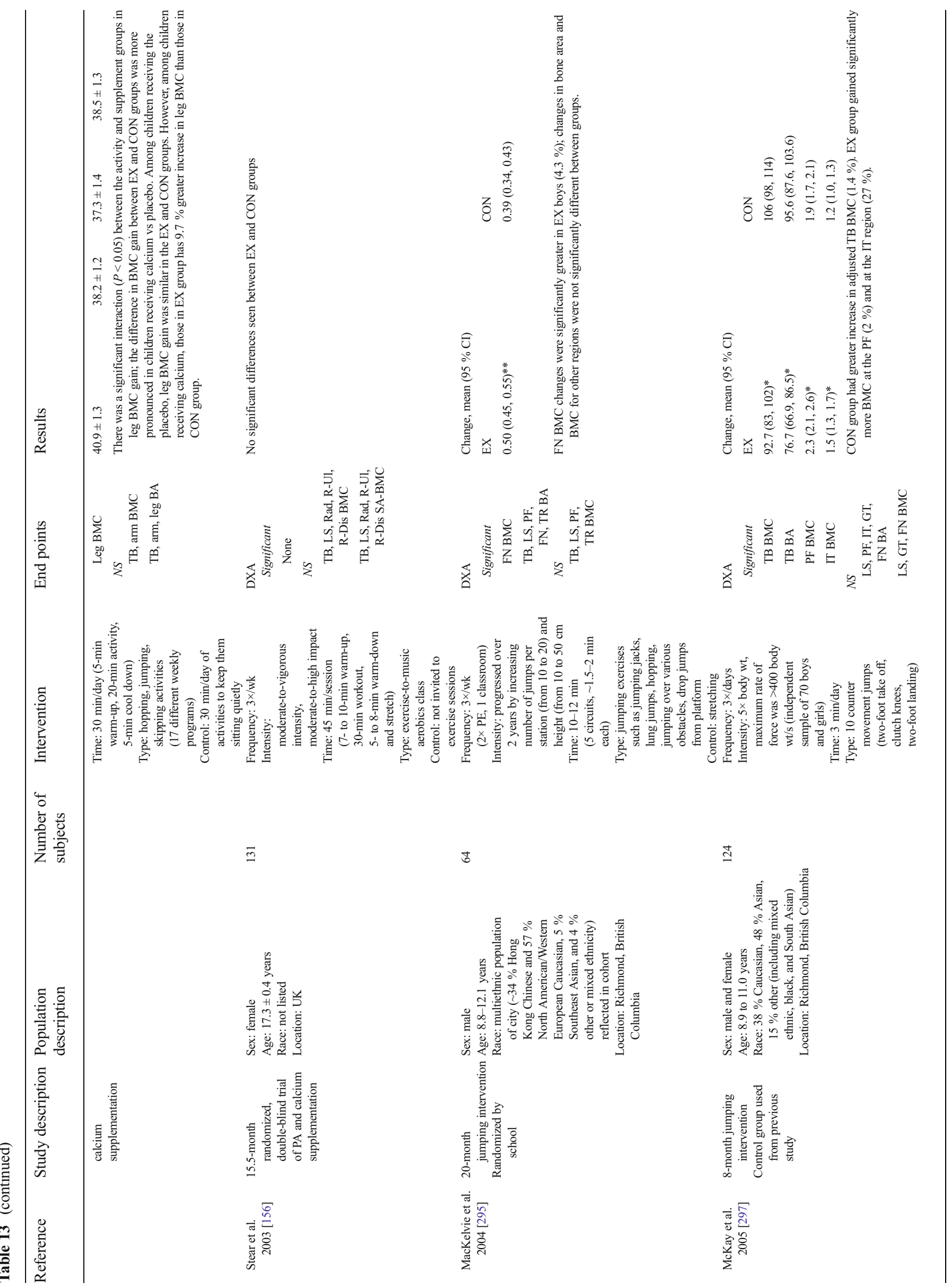




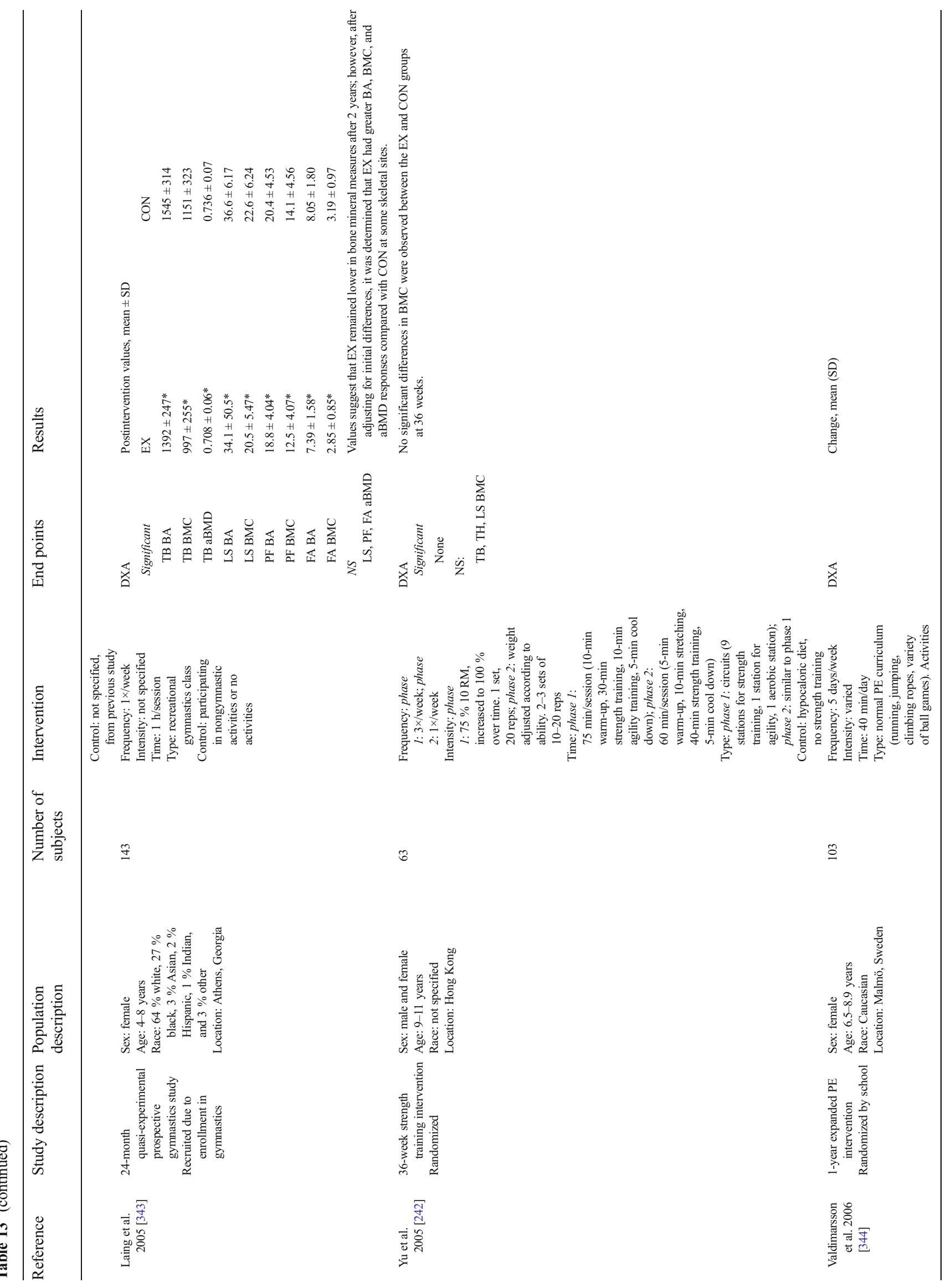




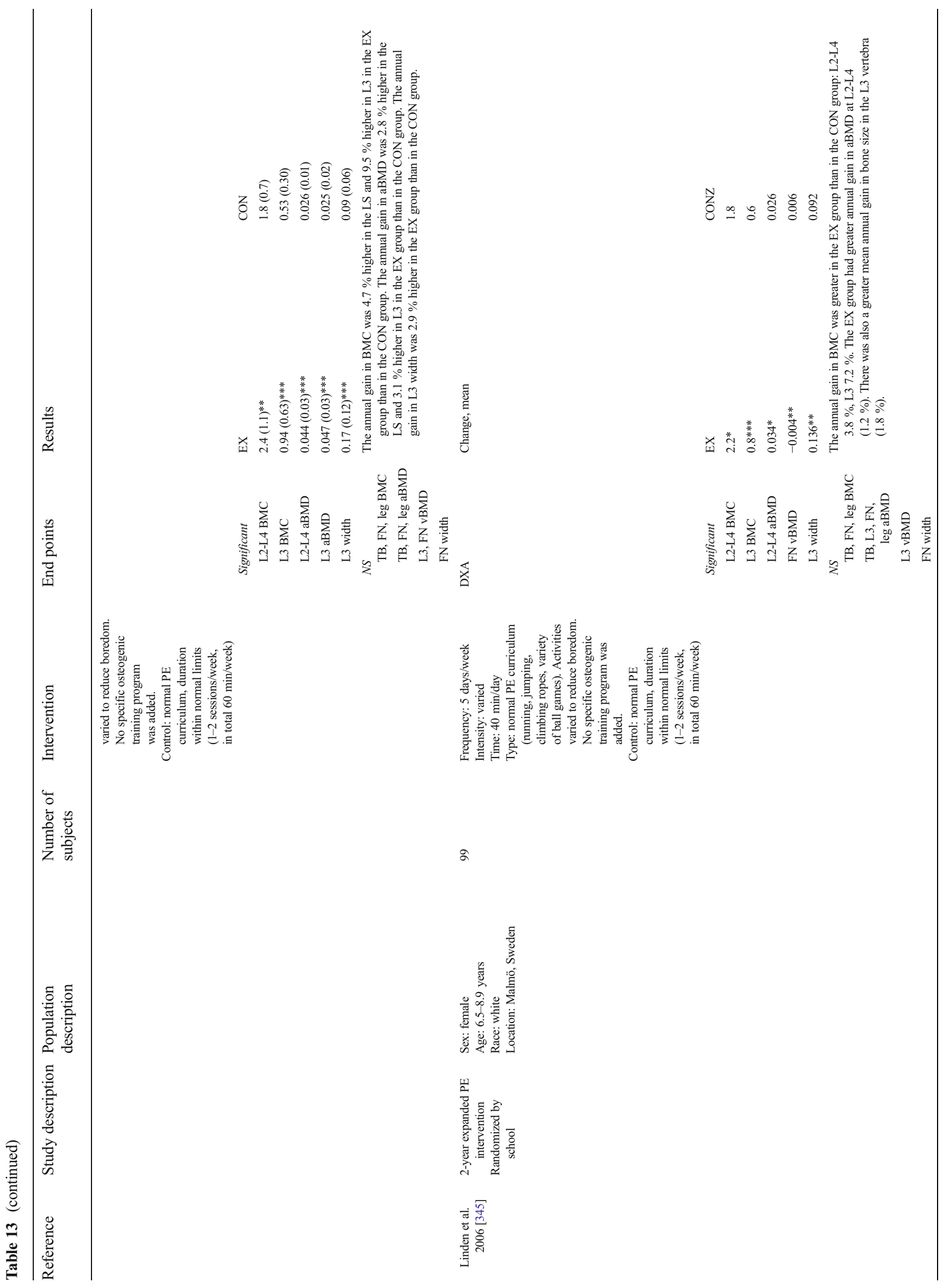




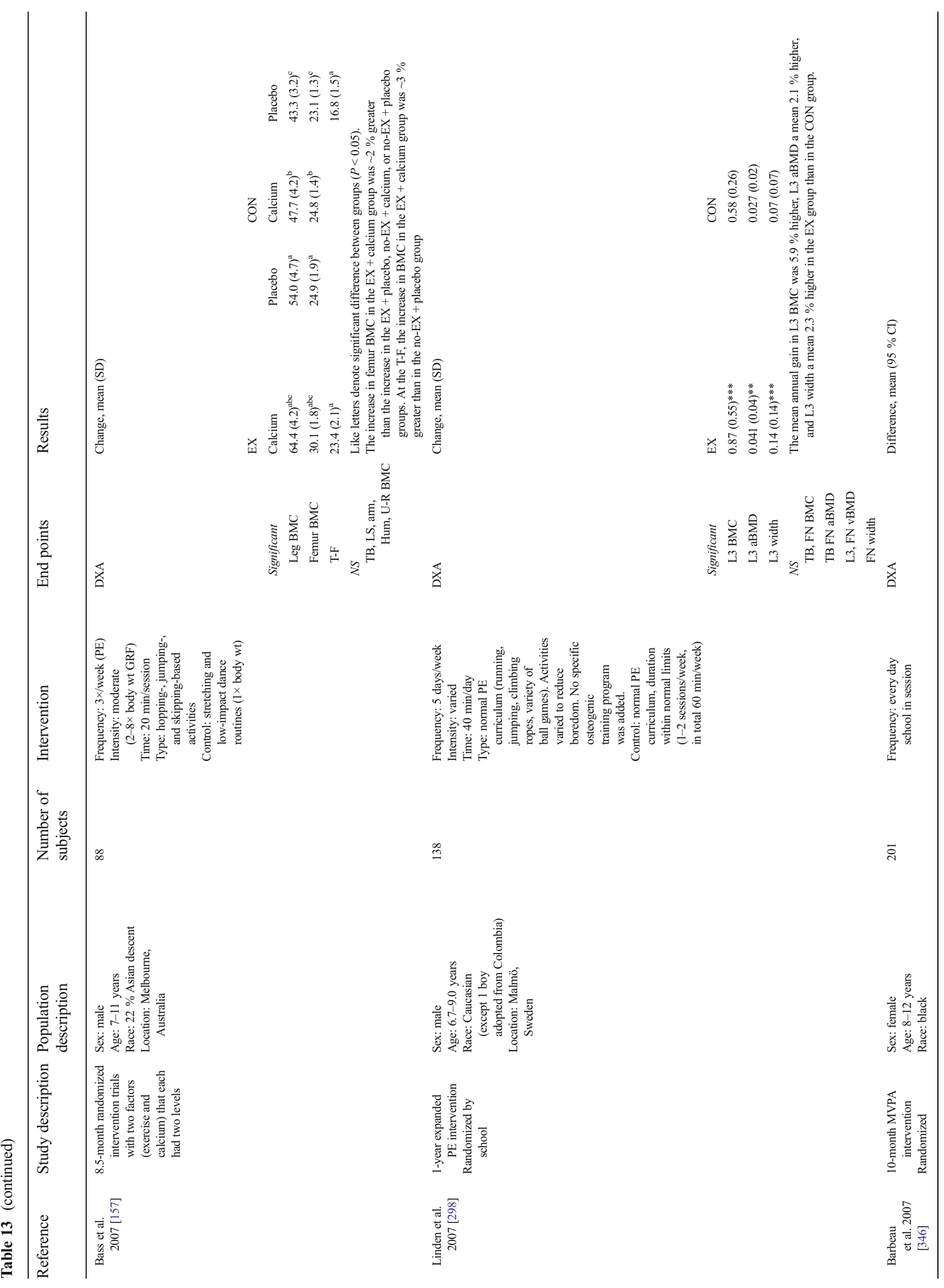




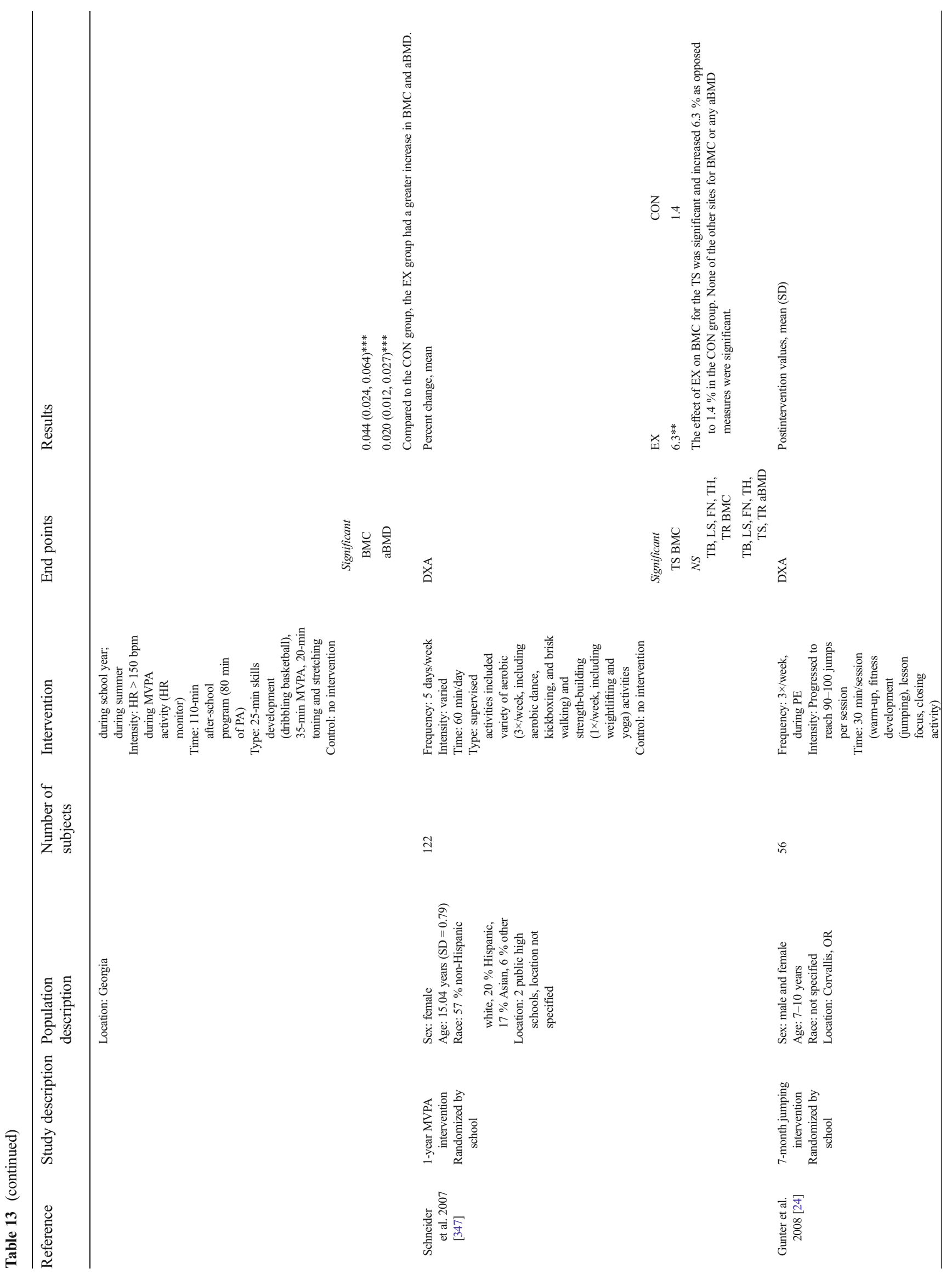




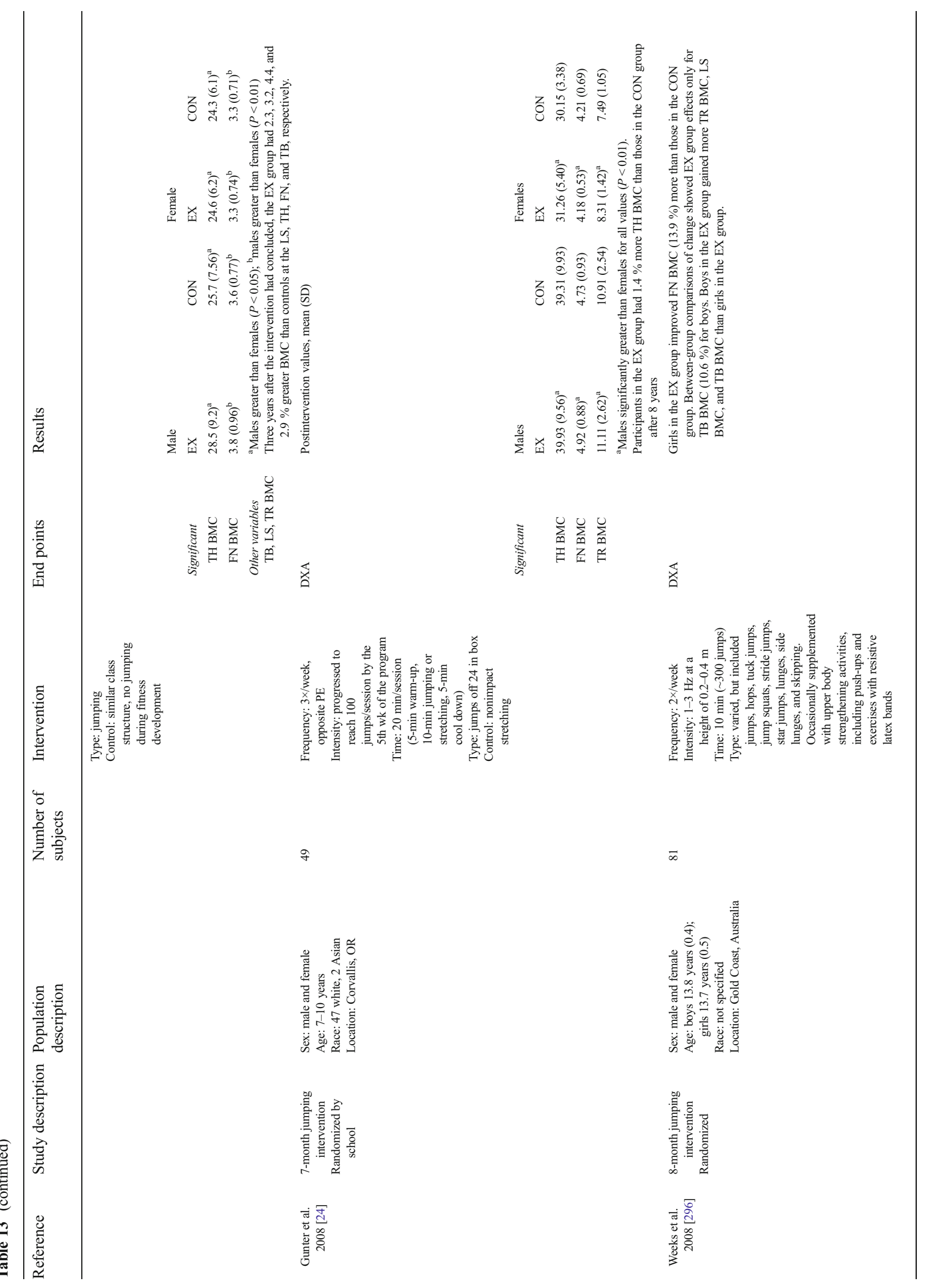




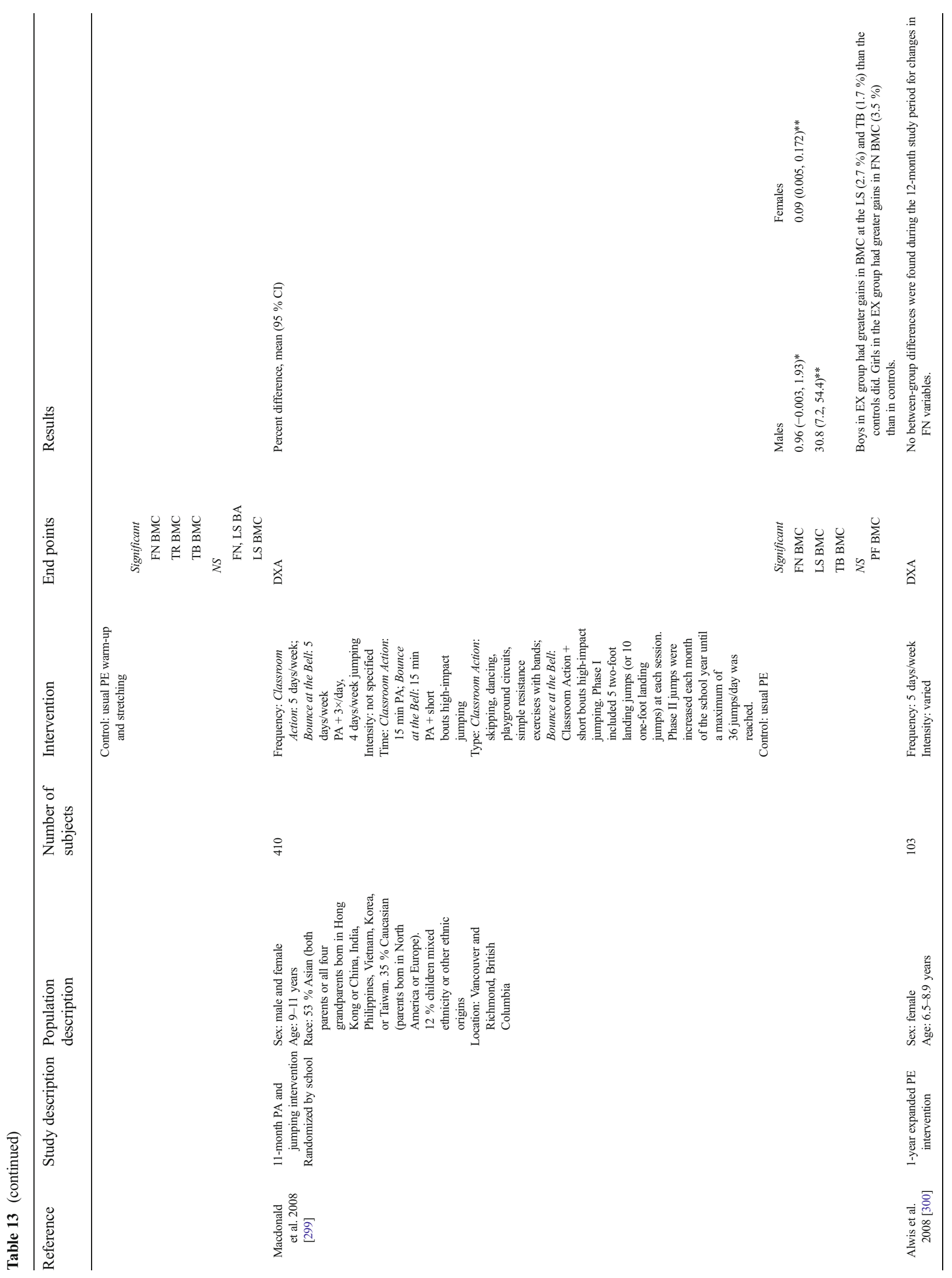




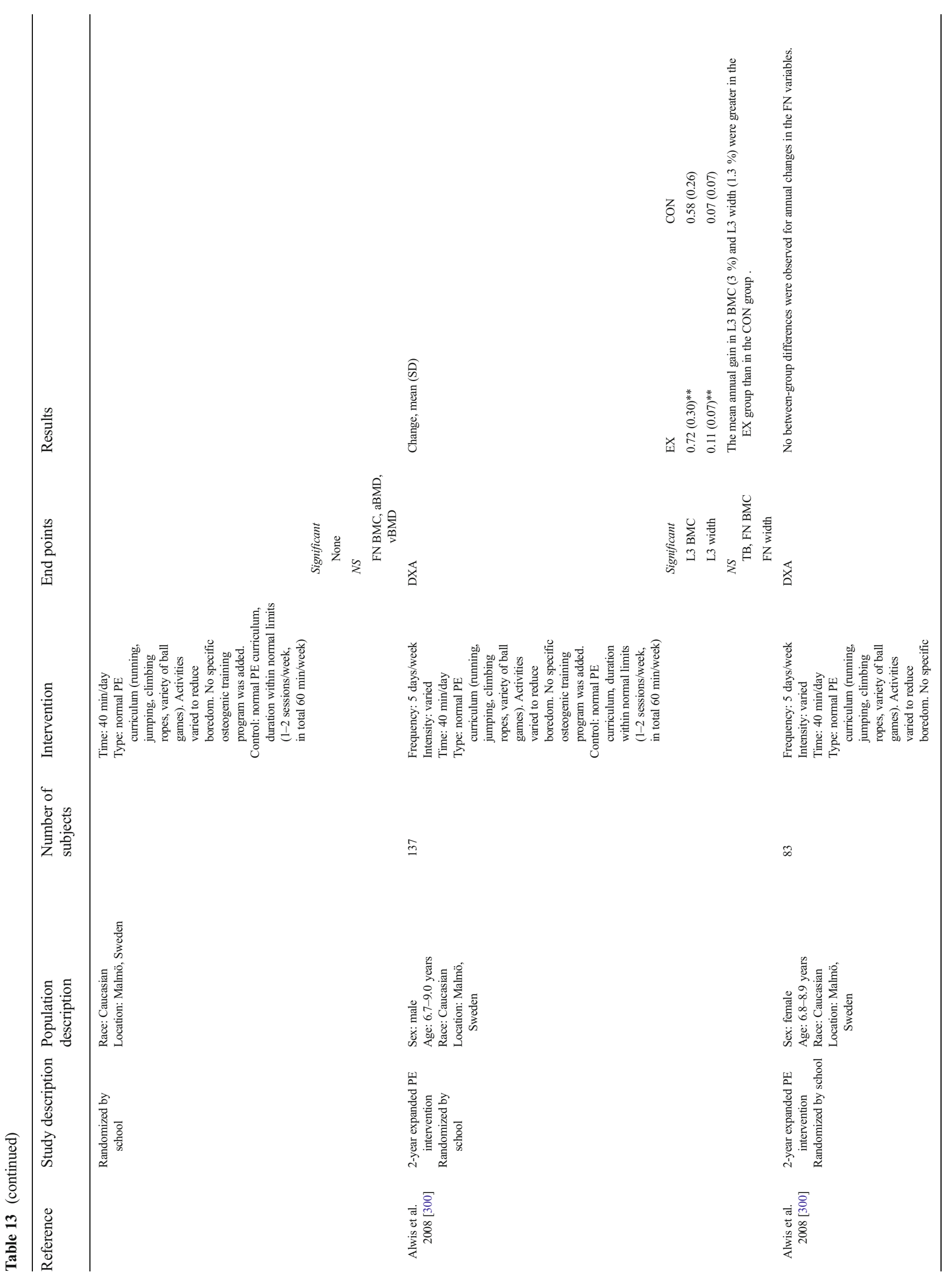




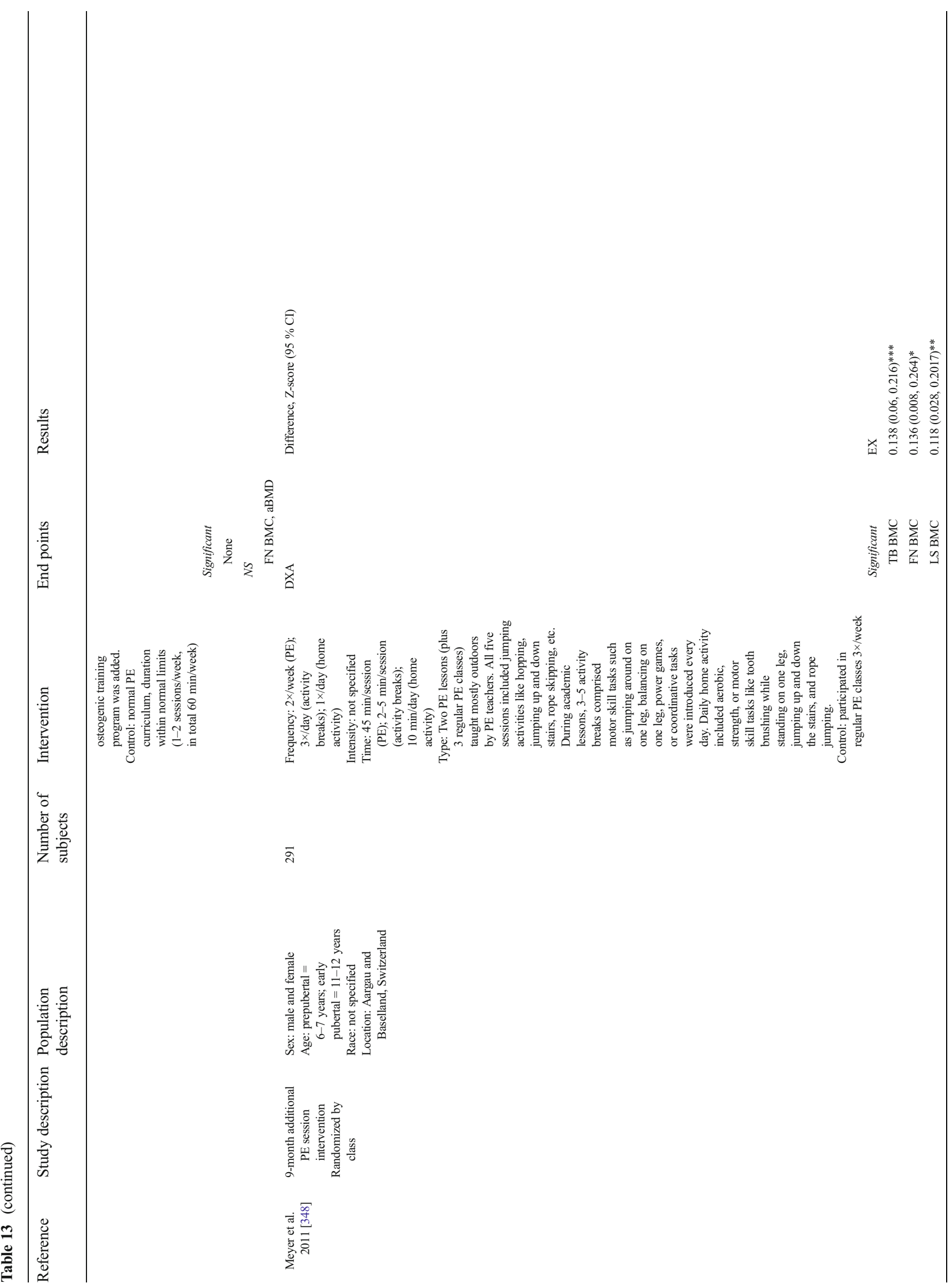




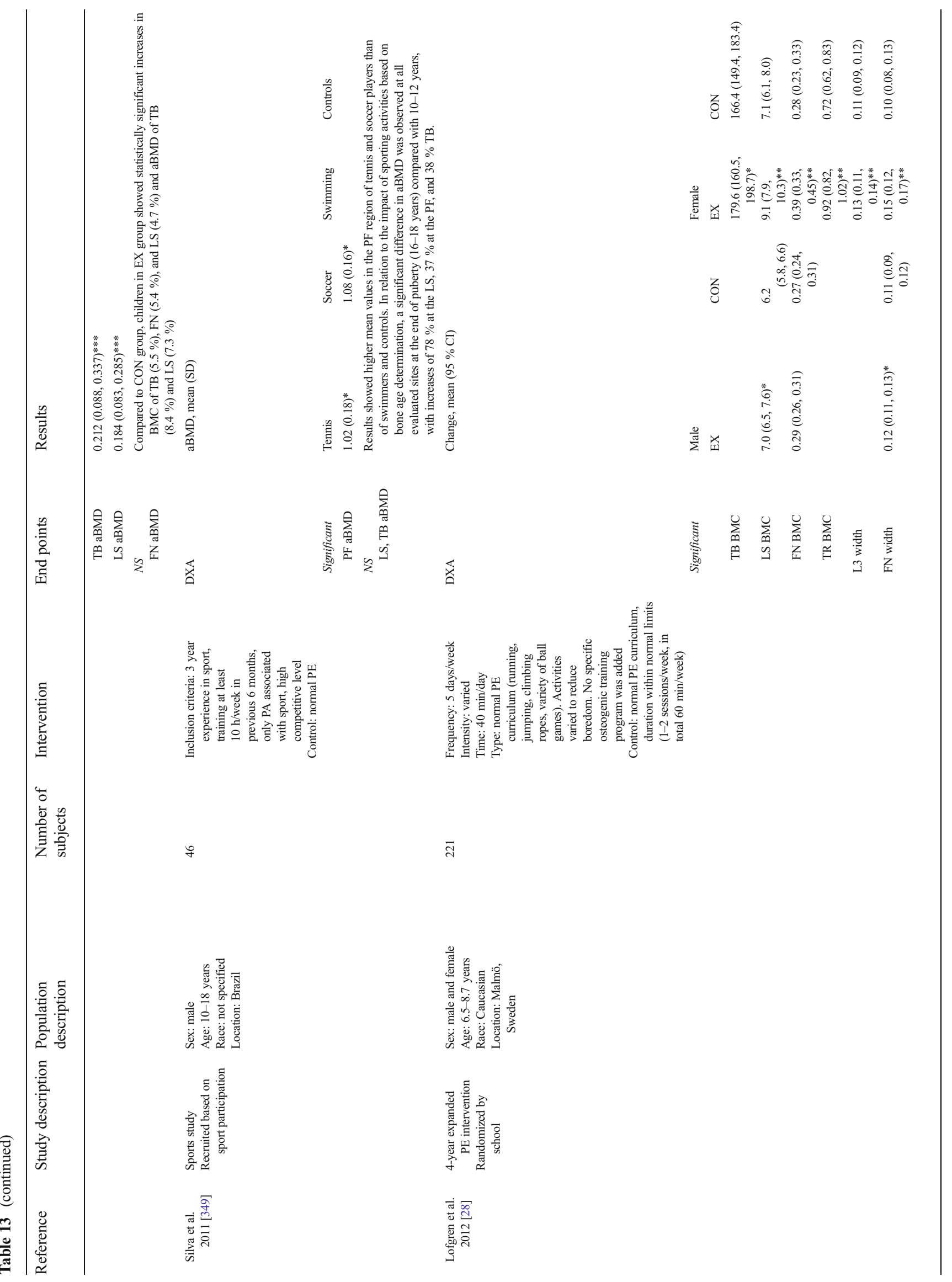




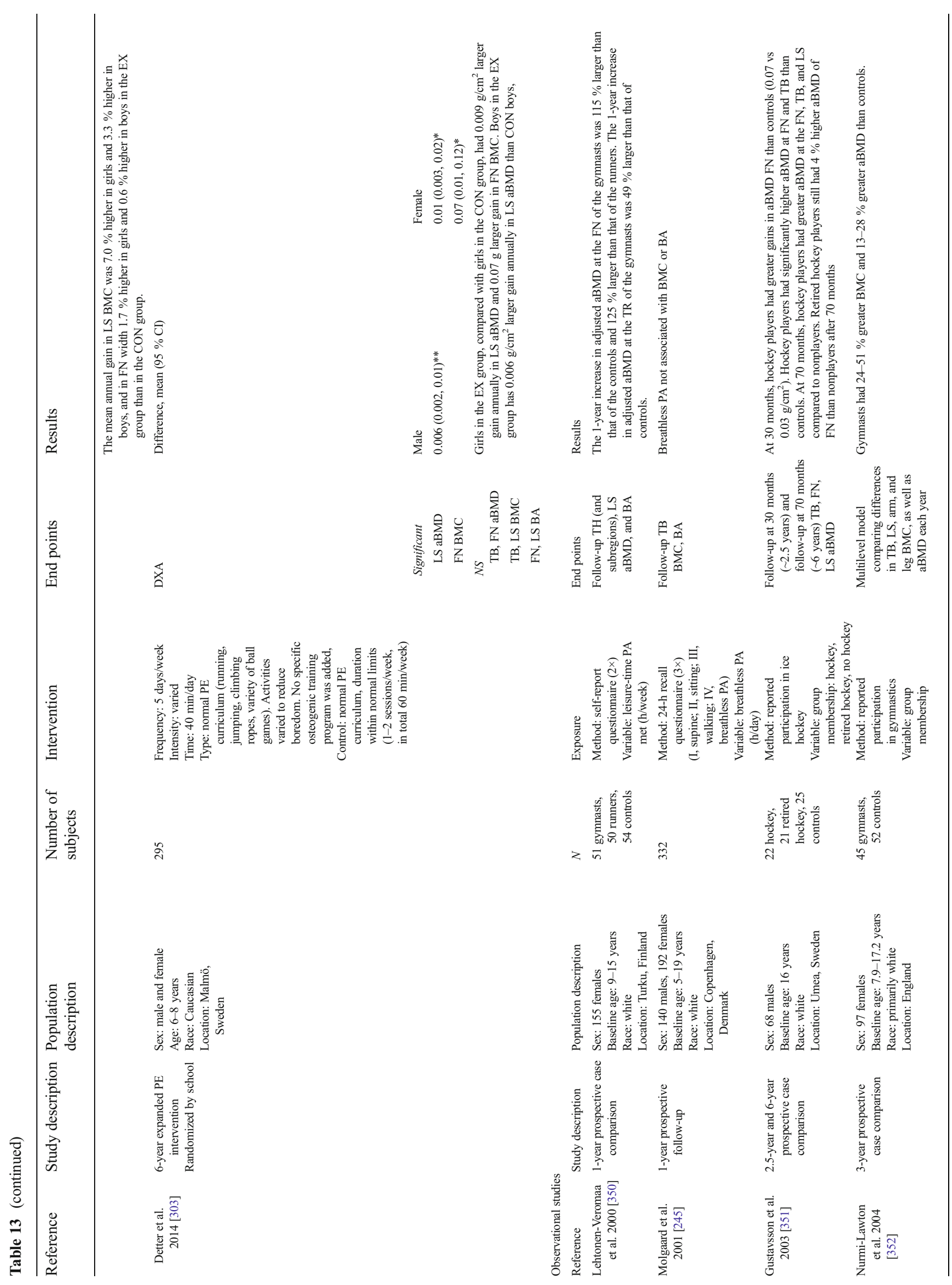




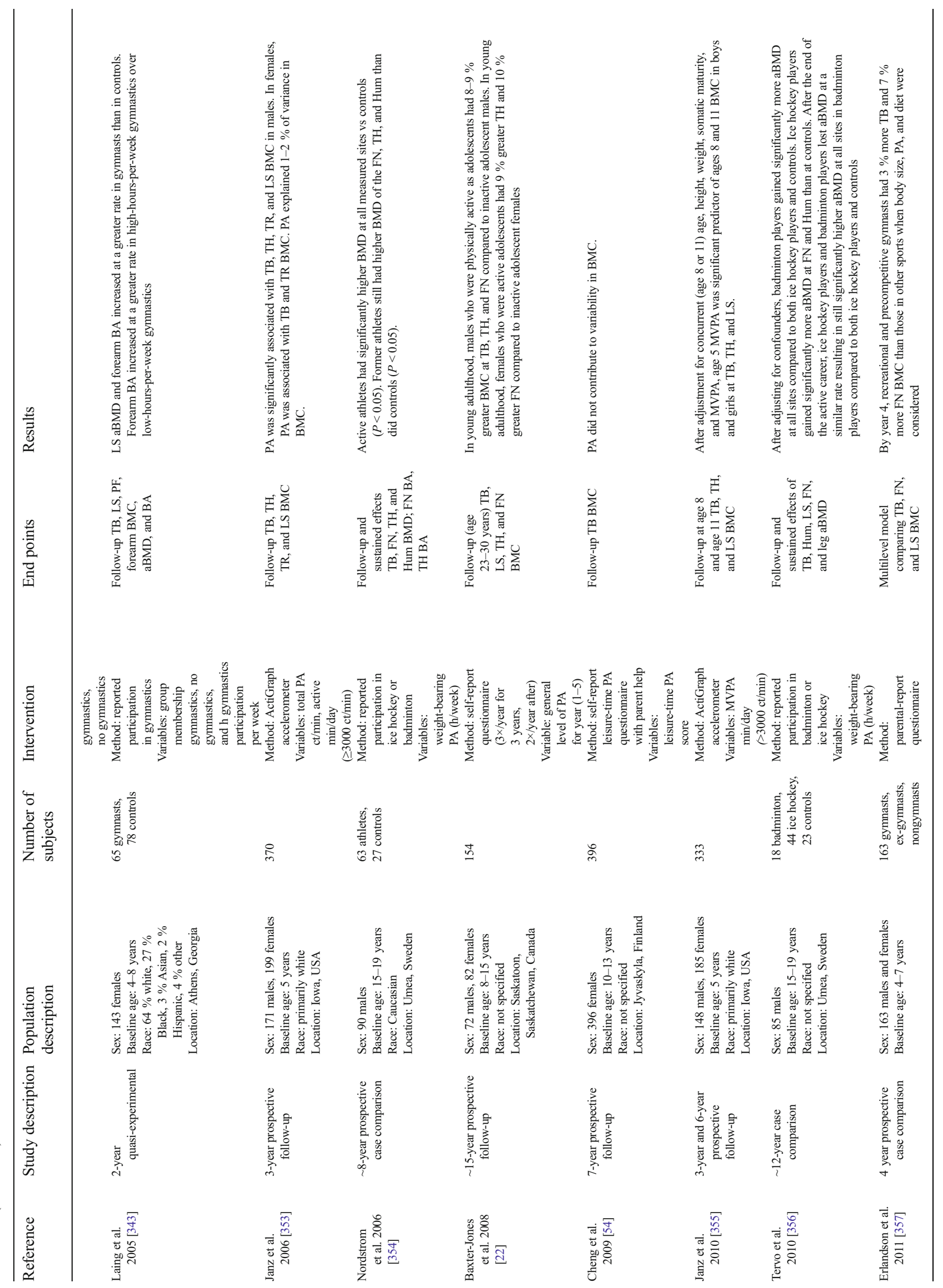




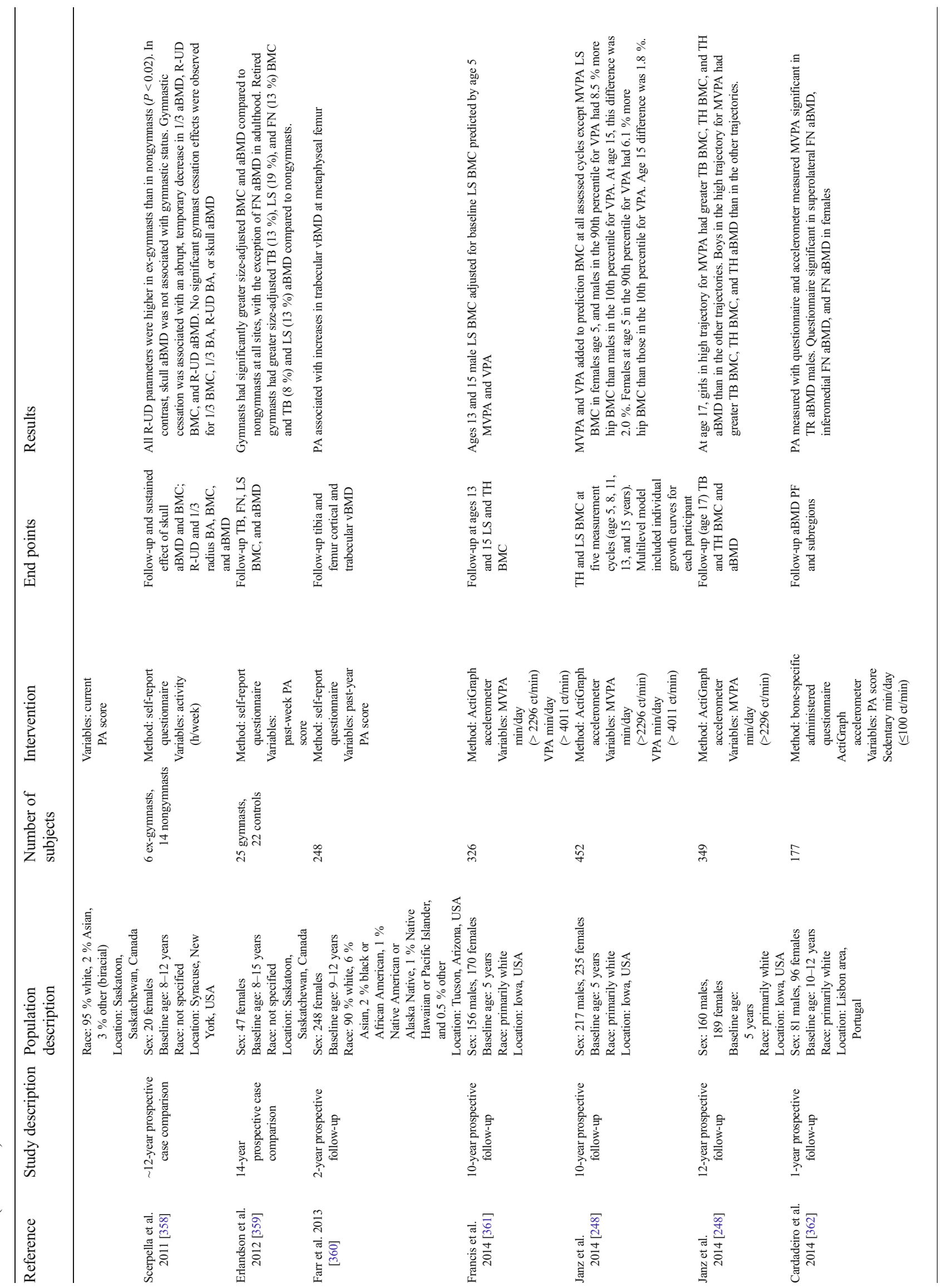




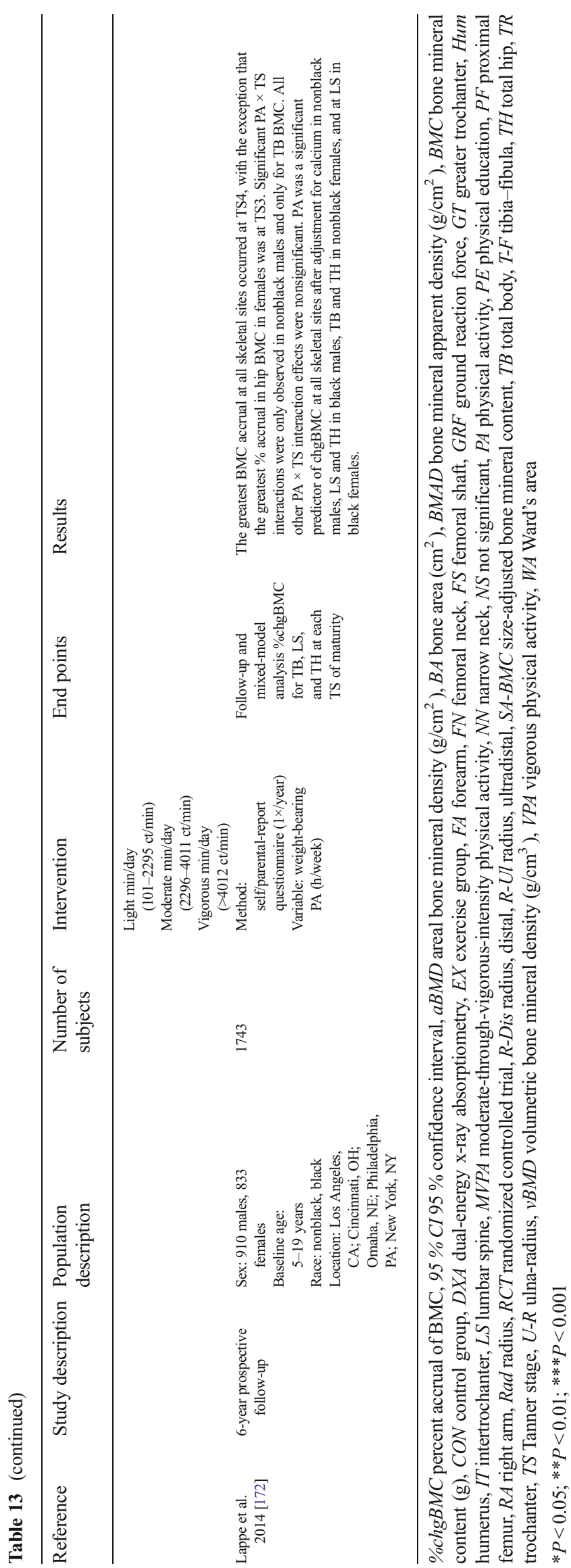


seen in total body BMC (2.47 \%), hip BMD (1.64 \%), and spine BMD (1.64 \%) in the calcium group after 12 months of supplementation. Confidence in the findings at 24 months is lessened due to the high rate of attrition (63\%). Another confounder is that the girls studied were peripubertal and thus varied in their estrogen status. At baseline, all subjects were premenarchal, whereas by the end of the study, 13 of the 48 subjects were postmenarchal (five concordant and three discordant pairs.)

Dibba et al. [160] tested the effects of calcium carbonate $1000 \mathrm{mg}$ /day on radius BMC and BMD accrual in a 12-month RCT of prepubertal Gambian children who had low baseline calcium intake (342 mg/day). Supplementation resulted in a higher size-adjusted BMC in the midshaft radius $(4.6 \pm 0.9 \%$; $P<0.0001)$ and in the distal radius $(5.5 \pm 2.7 \% ; P=0.042)$. This study showed a greater difference in gain between groups than the study by Cameron et al. [161], which supports the premise that children more deficient in a nutrient are likely to have greater benefit from supplementation. Prentice et al. [162] conducted a 13-month RCT of calcium carbonate $1000 \mathrm{mg} /$ day in older adolescent males in Great Britain. Baseline and study calcium intakes were high, even in the placebo group, which was meeting the RDA. Nonetheless, calcium supplementation resulted in an approximately $1 \%$ greater increase in total hip BMC after adjustment for bone area, weight, and height. The calcium intervention also resulted in greater height.

Three RCTs evaluated the effect of both calcium and vitamin D supplement pills on gain in tibial trabecular vBMD as measured by $\mathrm{pQCT}$ measurement on the distal tibia. MoyerMileur et al. [163] found a significant difference in gain at the $10 \%$ skeletal measurement site on the distal tibia, whereas Greene and Naughton [164] found a significant 5.2 \% difference in gain at the $4 \%$ distal tibia site. Both the 10 and $4 \%$ tibia sites represent primarily trabecular bone. Cheng et al. [159] found no effects. Only Greene and Naughton [164] reported adjusting for body size (limb length). However, the vitamin D doses (200 and $400 \mathrm{IU} /$ day) were below the RDA of $600 \mathrm{IU} /$ day, which raises doubt as to whether vitamin D status was optimized in these subjects.

Of the four RCTs using calcium fortification of food or beverages [165-168], all but one [166] found a significant supplement effect on skeletal gain, which ranged from 3.2 to $19.0 \%$. In the study showing no effect [166], the average dietary calcium intake of the placebo group was $1395 \mathrm{mg} /$ day, which was above the threshold and likely accounts for the lack of effect of a calcium supplement.

Two RCTs were identified that supplemented with dairy foods. One study [169] found that $1000 \mathrm{mg}$ of dairy resulted in a $1.5 \%$ greater gain in spine BMD compared to controls. In the study by Du et al. [170], 10-year-old girls were randomized to one of three groups: group 1 consumed $330 \mathrm{~mL} /$ day of ultra-heat-treated (UHT) milk fortified with a calcium salt containing 560-mg calcium, group 2 consumed $330 \mathrm{~mL} /$ day of UHT and 200-320 $\mu \mathrm{g}$ of vitamin D, and a control group followed their usual diet. The calcium salt also contained phosphorus and protein, both of which affect bone. Baseline calcium intake was about one third of the RDA among the three groups. After 24 months, groups 1 and 2 gained significantly greater size-adjusted total body BMC than the controls, and group 2 with vitamin $\mathrm{D}$ supplementation gained more than group $1(P=0.006)$. Cheng et al. [159] supplemented with both pills and cheese, and the authors found an effect with cheese only.

Three of the four RCTs of calcium and exercise combined $[81,155,157]$ found that the combined intervention had a significantly greater effect on bone accrual as assessed by DXA than either exercise or calcium alone. Specker and Binkley [81] also found an interaction effect on cortical thickness and area as measured by pQCT.

Only four observational studies of calcium intake and bone accrual were found [171-174]. Three found no association between calcium intake and accrual, whereas one prospective study [172] found a significant association between calcium intake and spine BMC adjusted for height change only in nonblack girls.

Our evidence grade for calcium was based on positive findings from $90 \%$ of the RCTs using supplement pills, which found a small, biologically, and statistically significant positive effect on aBMD and/or BMC accrual. The bone accrual in the supplemented group compared to the placebo group was largest in children who had the lowest intakes at baseline. This supports the premise of a threshold nutrient such as calcium (i.e., if usual intake of calcium exceeds requirements, then it is unlikely that any benefit of the intervention will be detected). Thus, on the basis of this review, we conclude that dietary intake guidelines for calcium are not being met by all children and adolescents.

Grade: Level of evidence A was assigned for the benefit of calcium on bone.

Vitamin D (Table 6) The search for vitamin D identified nine publications from 8 RCTs, 1 prospective study, and 3 crosssectional studies published since 2000, encompassing 2962 individuals (Table 6). Four of the eight RCTs provide evidence for a beneficial effect of vitamin D supplementation on bone accrual. El-Hajj Fuleihan et al. [175] found that Lebanese children receiving weekly doses of 14,000 IU vitamin $\mathrm{D}_{3}$ over 1 year had improved hip BMC and bone area (using conventional DXA) and narrow neck outer diameter and buckling ratio (using the HSA program) [176]. Furthermore, trochanter BMC improved in premenarchal, but not postmenarchal, females [175]. There were no significant effects of supplementation observed in boys. Viljakainen 
et al. [177] showed that Finnish females assigned to placebo or 200 or $400 \mathrm{IU}$ vitamin $\mathrm{D}_{3}$ over 1 year exhibited no differences in BMC gains at the lumbar spine or femur. A compliancebased analysis was conducted, which included only those subjects with $>80 \%$ compliance. After adjusting for bone area, weight gain, and changes in maturation, greater increases in lumbar spine BMC were observed with $400 \mathrm{IU}$ vitamin $\mathrm{D}_{3}$ and in femur BMC with either 200 or $400 \mathrm{IU} \mathrm{D}_{3}$ [177]. The increase in lumbar spine BMC in this study was identified in perimenarchal, but not premenarchal, females. Du et al. [170] demonstrated that the addition of $200-320 \mathrm{IU}$ of vitamin $\mathrm{D}_{3}$ to calcium-fortified milk significantly increased size-adjusted total body BMC over 2 years compared to controls. When analyzing the data by menarchal status, the significant increase in size-adjusted total body BMC was observed only in females that had experienced menarche versus premenarche. Khadilkar et al. [178] found that supplementing vitamin Ddeficient girls (girls with mean baseline serum $25(\mathrm{OH}) \mathrm{D}$ concentrations $20-25 \mathrm{nmol} / \mathrm{L}$ ) with quarterly doses of $300,000 \mathrm{IU}$ vitamin $\mathrm{D}_{2}$ along with daily supplementation of $250 \mathrm{mg}$ elemental calcium over 1 year improved adjusted total body $\mathrm{BMC}$ and bone area more compared with girls who were supplemented with calcium alone. These positive findings were observed in the compliance-based analyses only and in females within 2 years of starting their menstrual cycle, adjusting for multiple factors including fat-free mass.

Four of the eight RCTs showed no effect of vitamin D supplementation on bone. Ward et al. [179] reported that quarterly supplementation with 150,000 IU vitamin $\mathrm{D}_{2}$ versus placebo in vitamin D-deficient adolescent females did not improve DXA- and pQCT-derived bone outcomes over 1 year, including measures of tibia and radius trabecular or cortical bone. Molgaard et al. [173] reported that supplementation with 200 or 400 IU vitamin D in 10- to 11-year-old females over 1 year had no effect on changes in total body or lumbar spine BMC or in bone area. Similarly, supplementation with either 400 or $800 \mathrm{IU}$ to vitamin D-deficient females over 1 year had no effect on unadjusted total body BMC gains compared to placebo [180]. Finally, supplements containing $200 \mathrm{IU}$ with 1000-mg calcium had no effect on total body, lumbar spine, femoral neck, or total femur BMC gains over 2 years compared to placebo, calcium alone $(1000 \mathrm{mg})$, or a cheesesupplemented group [159].

A prospective study in prepubertal girls conducted over a 5-year period found that as serum 25(OH)D concentrations declined with age, there were significant increases in BMC at multiple skeletal sites [181]. This study showed that serum $25(\mathrm{OH}) \mathrm{D}$ did not have a predictive effect on BMC accrual above and beyond that of insulin-like growth factor (IGF)-I [181]. In a cross-sectional study of females aged 10-12 years, those with deficient serum $25(\mathrm{OH}) \mathrm{D} \leq 25 \mathrm{nmol} / \mathrm{L}$ had lower cortical vBMD at the distal radius than those with values $\geq 26 \mathrm{nmol} / \mathrm{L}$, and they also had lower cortical vBMD at the tibial shaft compared to subjects with values between 26 and $40 \mathrm{nmol} / \mathrm{L}$ [182]. Moreover, Foo et al. [183] found that 15year-old Chinese females with vitamin D deficiency (i.e., $<25 \mathrm{nmol} / \mathrm{L}$ ) had lower size-adjusted total body and forearm $\mathrm{BMC}$ than females with sufficient values $(>50 \mathrm{nmol} / \mathrm{L})$. In a study of 9-year-old Korean children, serum 25(OH)D was positively associated with total body BMC after adjusting for multiple variables, which included physical activity and calcium intake [184].

The evidence grade for vitamin $\mathrm{D}$ was based on the point that four of eight RCTs showed improvements in BMC accrual. Furthermore, one of the positive RCTs was well designed, used an intent-to-treat analysis, was adequately powered, and employed a wide range of supplement doses. The evidence grade B reflects the lack of generalizability across the RCTs, which included primarily female subjects with little diversity in population ancestry.

Grade: Level of evidence B was assigned for the benefit of vitamin $\mathrm{D}$ on bone.

\section{Micronutrients other than calcium and vitamin D} (Table 7) The search for other micronutrients identified 1 RCT, 2 prospective studies, and 6 cross-sectional studies published since 2000, encompassing 2192 individuals (Table 7). Only one RCT was identified and that was for magnesium [185]. Magnesium supplementation at $300 \mathrm{mg} /$ day for 1 year was significantly associated with a $\sim 3 \%$ increase in overall hip measures of BMC and a borderline significant increase in lumbar spine BMC among white girls. In prospective studies, fluoride was not related to BMC in adjusted models [186-188]. Cross-sectional studies report that a positive association of vitamin $\mathrm{C}$ intake and BMC was observed only in boys [189], and positive associations of vitamin $C$ and zinc intakes with bone size and strength were observed in fourthgrade, but not sixth-grade, girls [190]. By contrast, negative associations between high intakes of sodium and phosphorus and total body BMC and bone area in white boys and girls were observed [149]. Iron intake was negatively associated with femoral cortical area [190].

Cross-sectional studies also showed advantages of a biomarker of vitamin K status only in white females [191]. In their study of 245 healthy girls in the USA aged 3-16 years, Kalkwarf et al. [192] reported that better vitamin K status (assessed by plasma phylloquinone and serum percentage of undercarboxylated osteocalcin [\%ucOC]) was associated with decreased bone turnover, but it was not associated with baseline BMC. Serum \%ucOC was not associated with changes in BMC of the hip, total body, or total body minus the head, but it was surprisingly associated with positive changes in lumbar spine BMC [192]. In contrast with this study, a more recent association study of 223 healthy peripubertal Danish girls 
found that better vitamin $\mathrm{K}$ status was associated with increased total body and lumbar spine BMC, but not with bone turnover [191].

Our evidence grade for other micronutrients was based on one RCT of magnesium supplementation, two prospective studies of fluoride intake, two cross-sectional studies assessing vitamin $\mathrm{C}$ and vitamin $\mathrm{K}$ intake, and one crosssectional study assessing intakes of zinc, iron sodium, and phosphorus.

Grade: Level of evidence D was assigned for the benefit of micronutrients other than calcium and vitamin $\mathrm{D}$ on bone.

\section{Food patterns (Table 8)}

The search for food patterns identified 5 RCTs and 12 observational studies published since 2000, encompassing 6282 individuals (Table 8).

\section{Dairy}

Three 2-year RCTs showed increased gains in some bone sites with dairy food consumption $[159,169,170]$. The study by Cheng et al. [159] found an increase with cheese consumption in bone quality assessed by tibia cortical thickness using pQCT in addition to total body BMD, but only in those participants who were at least $50 \%$ compliant. The advantage of trochanter BMC in the study with dairy supplementation disappeared 1 year after cessation [169]. These RCTs were not generalizable because they were conducted only in presumably white girls, except for the study by Du et al. [170] conducted in Asians.

\section{Fiber}

One RCT was found and the authors reported a benefit of prebiotic fibers on total body BMC gains in boys and girls over 1 year [193]. One cross-sectional study [194] showed dietary patterns that favored higher bone mass and lower fat mass including higher amounts of dark-green and deepyellow vegetables and lower amounts of fried foods.

\section{Fruits and vegetables}

The five cross-sectional studies identified consistently found some type of benefit to bone with increased and/or high intake of fruits and vegetables [189, 195-198].

\section{Detriment of cola and caffeinated beverages}

We identified six studies that examined the effects of carbonated beverages or caffeine-containing beverages and bone accrual during childhood and peak bone mass. Several crosssectional studies have shown inverse associations between cola or carbonated beverages and bone outcomes in children or young adults. In a population-based, case-control study of children who had experienced upper limb fractures, Ma and Jones [199] found that wrist and forearm fractures were significantly associated with cola drink consumption (odds ratio (OR), 1.39 per unit; $95 \%$ confidence interval (95\% CI), 1.01 , 1.91), but not after adjustment for sedentary activities (e.g., television, computer, and video watching). Wyshak [200] found that carbonated beverage consumption was associated with a history of fracture (OR, 3.14; $95 \% \mathrm{CI}, 1.45,6.78)$. The association was strongest for girls reporting higher levels of physical activity (OR, 7.00; 95 \% CI, 2.00, 24.45). Similarly, Manias et al. [201] evaluated children with a first-time fracture $(n=50)$, those who had recurrent fractures $(n=50)$, and a fracture-free group $(n=50)$. The recurrent fracture group had lower levels of milk intake and physical activity and higher BMI and carbonated beverage intake than controls; those with one or more fractures had significantly lower total body and lumbar spine BMC and aBMD. A 4-year prospective study of 228 children showed that carbonated beverage consumption increased as milk intake declined, and carbonated beverage intake was negatively associated with strength of the radius (polar SSI) even after adjusting for milk intake [202].

Lower aBMD has been found in children with higher carbonated beverage intakes [194, 201]. McGartland et al. [194] found a significant inverse relationship between total carbonated beverage intake and heel (but not forearm) BMD among girls after adjusting for age, height, weight, pubertal status, social status, alcohol intake, smoking habits, physical activity, liquid milk consumption, and calcium obtained from sources other than liquid milk. These findings suggest that aBMD in girls may be more sensitive to the effects of carbonated beverages compared with boys. McGartland et al. [194] also observed a significant inverse association between carbonated beverage intake and milk intake in both boys and girls.

Remarkably few studies have considered the potential effects of caffeinated beverages on peak bone mass. Caffeine consumption is of concern because it is associated with increased urinary excretion of calcium [203]. In a crosssectional study of young white women, aged 19-26 years ( $n=177)$, Conlisk and Galuska [204] examined the association of caffeine consumption and femoral neck BMD. Caffeine intake was estimated by self-reported consumption of coffee, decaffeinated coffee, tea, colas, chocolate products, and select medications. After adjustment for potential confounders (height, BMI, age at menarche, calcium intake, protein consumption, alcohol consumption, and tobacco use), 
caffeine consumption was not significantly associated with aBMD. These findings do not provide support for negative effects of caffeine intake in this age range.

\section{Fruits and vegetables}

To our knowledge, there are no long-term prospective studies of vegetarian children with bone outcomes. Few studies have examined the influences of vegetarian dietary patterns on bone, but there is some evidence in adults that adhering to vegan diets is associated with lower bone mass [205] and fractures [206]. It has been hypothesized that following a diet composed primarily of fruits and vegetables would provide a nutrient profile, specifically higher potassium and plant-based proteins, which would favorably influence acid-base balance and bone mass [207]. Alternatively, following a vegetarian diet may exclude certain food groups that contain essential bone-related nutrients such as calcium [208], although a recent large US study using National Health and Nutrition Examination Survey (NHANES) data found no differences in calcium intakes between strict vegetarians and nonvegetarians [209]. In an editorial, Lanham-New [210] takes the position that vegetarianism is not a serious risk factor for osteoporosis. She recognizes that the study of vegetarian dietary patterns and bone is complex because specific patterns of vegetarian diets include or exclude bone-related nutrients and lifestyle factors, serum hormone concentrations, and dietary assessment methods could confound the findings.

Our evidence grade for food patterns was based on 3 RCTs showing a positive benefit of dairy consumption to bone accrual, 1 RCT using mixed chain length fermentable fibers, and 12 observational studies, respectively.

Grade: Level of evidence B was assigned for the benefit of dairy consumption on bone. Level of evidence $\mathrm{C}$ was assigned for the benefit of certain types of fiber and fruit and vegetable intake on bone, as well as for a detrimental effect of cola and caffeinated beverages on bone.

\section{Infant nutrition (Table 9)}

The search for infant nutrition identified 1 RCT and 10 observational studies published since 2000, encompassing 2715 individuals (Table 9). In the identified RCT, Koo et al. [211] found a positive effect of infant formula enriched with palm olein on bone mineral accretion in healthy term infants compared to the control formula. Of the ten observational studies identified in the search, three compared the effects of duration of breastfeeding [212-214], three assessed later bone outcomes in breast-fed versus formula-fed infants [215-217], two assessed later bone outcomes of breast-fed infants only
[218, 219], and two compared breast-fed versus formula-fed versus enriched formula-fed infants [220, 221].

Formula-fed infants had better BMC and BMD in the first 6 months of life compared to breast-fed infants in two of the observational studies $[215,216]$; however, breastfeeding was shown to be advantageous in two observational studies assessing later bone outcomes in 8-year-old children [217, 219] and 16-year-old adolescents [218]. Mixed results were obtained for studies testing the duration of breastfeeding in infants who were exclusively breast-fed [212-214]. The addition of palm olein and $s n-2$ palmitate to infant formula was not shown to be beneficial on later total body BMC outcomes in 4.5- and 10-year-old children [220, 221]. This is contrary to the RCT by Koo et al. [211].

Our evidence grade for infant nutrition was based on the lack of RCTs, inconsistent length of follow-up observational studies, and lack of consistent results across studies.

Grade: Level of evidence D was assigned for the benefit of duration of breastfeeding on bone. Level of evidence $\mathrm{D}$ was assigned for the benefit of breastfeeding versus formula feeding on bone. Level of evidence $\mathrm{D}$ was assigned for the benefit of enriched formula feeding on bone.

\section{Adolescent special issues}

Detriment of DMPA injections and oral contraceptives (Table 10) The search for contraception identified no RCTs, 8 observational studies, and no cross-sectional studies since 2000, encompassing 1815 individuals (Table 10). Six studies reported null effects of oral contraceptives (OCs) versus a control on bone [222-227] and two studies reported suppression of bone mineral accrual and bone mass acquisition in adolescents [228, 229]. Injections of depot medroxyprogesterone acetate (DMPA) showed a consistent detrimental effect to bone in three studies [225, 226, 230], while one study found null effects [227]. An additional study suggested that the change in body weight due to DMPA injection may override the potential detrimental effect to bone [222].

Grade: Level of evidence B was assigned for the detriment of DMPA injections on bone. Level of evidence D was assigned for the detriment of OCs on bone.

Detriment of alcohol (Table 11) The search for alcohol identified no RCTs, 3 prospective studies, and 5 cross-sectional studies published since 2000, encompassing 3352 individuals (Table 11). Four studies used peripheral DXA measurements only. There was large variability among studies in the amount of alcohol consumed by study participants and the classification of alcohol intake from ever tried to number of drinks per 
day. Overall, the reported alcohol consumption by adolescents studied was relatively low. In some studies, adolescents who consumed alcohol were more likely to smoke [231-235], necessitating statistical adjustment for smoking to investigate the independent effects of alcohol intake on bone. The majority of studies found no association between alcohol intake and bone outcomes [232, 233, 235-237]. Among studies reporting a statistically significant association, the direction of the association was inconsistent. Some reported that alcohol intake was associated with lower bone density [231], whereas others reported that alcohol intake was associated with higher bone density [234, 238].

Our evidence grade for alcohol consumption was based on insufficient data to support a hypothesis, owing to no RCTs, low alcohol exposure, and multiple methodological differences among the few studies performed.

Grade: Level of evidence D was assigned for the detriment of alcohol on bone.

Detriment of smoking (Table 12) The search for smoking identified no RCTs, 6 prospective studies, and 7 crosssectional studies published since 2000, encompassing 13, 955 individuals (Table 12). Six of the studies used peripheral DXA, and two studies examined stress fractures as the bone outcome. There was large variability among studies with respect to extent of smoking in the study participants, both in terms of the proportion who had ever smoked as well as frequency of smoking (e.g., cigarettes per day). Smoking exposure was lowest in young adolescents and increased with age up to young adulthood. Classification of smoking exposure for statistical analyses was also variable across studies (e.g., 1 puff in lifetime versus daily smoking). Some studies reported that adolescents who smoked were more likely than their nonsmoking peers to engage in behaviors that also could negatively impact bone health, namely lower physical activity levels [238, 239], lower dietary calcium intake [239], and greater alcohol use [231-235], making statistical adjustment for these behaviors critical to enable the interpretation of study findings.

Results from studies examining the association between bone density and smoking during adolescence are mixed. Some find significant deficits in bone mass or aBMD at one or more skeletal sites, ranging from -1.8 (not available for all studies) to $-6.5 \%$ [232-234, 239, 240], whereas others found no difference in bone according to smoking exposure [231, 235-237]. In the prospective study of adolescent females (aged 13-19 years) by Dorn et al. [233], the effect of smoking on bone accrual became more pronounced as girls got older. Compelling data demonstrating the deleterious effects of smoking on bone come from studies of military recruits. Among male military recruits (aged 18-22 years), Lorentzon et al. [239] found that smoking $\geq 1$ cigarette/day (average 9/day) for an average of 4 years was associated with lower aBMD ranging from -1.8 to $5.0 \%$ depending on the skeletal site. Cortical thickness measured by pQCT was -2.9 to $-4.0 \%$ lower in smokers owing to greater endosteal circumference. Eleftheriou et al. [238] found that aBMD at the hip was $-4.7 \%$ lower among current smokers compared to never smokers. By contrast, the authors found that ex-smokers had a smaller $(-4.3$ to $-5.0 \%)$ periosteal circumference measured by MRI compared to never smokers, but there were no differences in bone dimensions between current smokers and never smokers. In a study of female military recruits, Lappe et al. [42] found that a history of smoking was associated with an increased risk (OR, 1.34; $95 \% \mathrm{CI}, 1.05,1.71)$ of stress fracture during 8 weeks of basic training. However, years of exercise, which was associated with a reduced risk of stress fracture, was not accounted for in these analyses and effects of smoking may have been overestimated. In a second study of female military recruits, history of smoking was similarly associated (OR, 1.32; $95 \%$ CI, 0.99, 1.75) with risk of stress fracture even when accounting for fitness (running speed) and years of prior exercise [241].

Our evidence grade for smoking was based on multiple well-designed cross-sectional studies.

Grade: Level of evidence C was assigned for the detriment of smoking on bone.

\section{Physical activity and exercise}

Effect on bone mass and density (Table 13) The search for the effects of physical activity on BMC identified 36 RCTs and 20 observational studies published since 2000, encompassing 9942 individuals (Table 13). Eighty-three percent $(n=30)$ of the RCT studies reported statistically significant $(P<0.05)$, and many were likely clinically significant ( $\sim 3 \%$ difference), differences between exercise and control groups at the completion of the intervention. With one exception [242], interventions finding no statistically significant difference between exercise and control groups used similar exercise volume, type, and length as those studies reporting significant effects. Most of the exercise intervention studies of prepubertal, early pubertal, and midpubertal children found increases ( $\sim 1-6 \%$ difference over 6 months) in the bone mineral of the total body, hip, or lumbar spine. The type of interventions varied but typically ranged from 7 to 24 months in duration, 2-5 sessions per week, 10-60 min per session, and they included sports, games, dance, or high-impact exercises (jumping, hopping). Fewer studies existed for late-pubertal and postpubertal adolescents, and the effects were less dramatic (0.3-1.9\% difference over 6 months), despite a similar intervention dose compared to interventions that focused on 
younger participants [156, 243]. For example, within the same intervention, one study found skeletal effects in premenarchal but not in postmenarchal females [244].

We reviewed 20 prospective longitudinal studies, with $90 \%$ of these studies $(n=18)$ reporting statistical differences in bone mass or density between the most physically active children and adolescents in their cohorts and those who were less active. The range in percent difference was wide, although studies that examined youth engaged in organized sports consistently reported greater differences than other study populations. Two studies [54,245] reported no differences in mass or density between the most active and less active participants. However, these studies used specific self-report measures of physical activity known to have considerable measurement error [246, 247]. By contrast, when using an objective measure of physical activity, the Iowa Bone Development Study demonstrated $10-16 \%$ greater hip BMC and $8 \%$ greater hip aBMD in participants who accumulated the greatest amount of activity from childhood through adolescence (12-year follow-up) [248]. One of the most important of the prospective observational studies, the University of Saskatchewan Paediatric Bone Mineral Accrual Study [3], used a mixedlongitudinal design to evaluate relationships between selfreported general level of physical activity and BMC in a group of healthy Canadian adolescents. The investigators reported that children and adolescents who were physically active at ages $8-15$ years had $8-10 \%$ more hip BMC as young adults (aged 23-30 years) compared to less active peers (after controlling for their adult physical activity levels and baseline bone outcomes). This study suggested the possibility of long-term sustained benefits of childhood physical activity on adult BMC [22]. In conclusion, long-term prospective observational studies of heterogeneous cohorts of youth have examined self-selected, everyday physical activity levels and $\mathrm{BMC}$, aBMD, or vBMD. These studies have convincingly and repeatedly shown that participation in high levels of physical activity is associated with greater bone mass accrual compared to less active peers.

Our evidence grade for physical activity and exercise on bone mass and density was based on consistent evidence from many RCTs and observational studies.

Grade: Level of evidence A was assigned for the benefit of physical activity and exercise on bone mass and density.

\section{Effect on bone structural outcomes (Table 14)}

The search for the effects of physical activity on bone structure/geometry identified 17 RCTs and 8 observational studies published since 2000, encompassing 4722 individuals (Table 14). Slightly more than one third $(n=6)$ reported statistically significant effects of exercise on bone structural outcomes. However, of the 11 studies that reported no statistical differences between exercisers and controls, six reports were from the same study (the Malmö Pediatric Osteoporosis Prevention Study). This study was designed to evaluate whether increasing time in physical activity in a cohort could be used as a population-based prevention strategy to improve bone outcomes. Prepubertal children were randomized by schools into a 5-day/week, 40-min/day physical education curriculum or a 1- to 2-day/week, 60-min/week curriculum. The content of the physical education curricula did not differ and specific osteogenic exercise was not prescribed. By contrast, in a 1-year RCT in young children (aged 3-5 years) randomized at the individual level, Specker and Binkley [81] used research staff to deliver (presumably) osteogenic exercise (gross motor skills such as hopping, jumping, and skipping) and reported that gross motor skill exercise increased periosteal and endosteal circumferences at the $20 \%$ site of the distal tibia compared to fine motor skill exercise. The effect of gross motor exercise ( $2 \%$ difference) persisted 1 year after followup; however, the intervention group was also more physically active at least 6 months after the intervention (raising the possibility that the sustained effect was due to continued high levels of physical activity) [249]. Using a 7-month, 3-day/ week, $\sim 12$-min/day jumping protocol, researchers with the University of British Columbia Centre for Hip Health and Mobility [73] reported structural changes at the hip in early pubertal girls (but not prepubertal girls) compared to controls who stretched. The difference in section modulus, a measure of the strength of bone during bending, was $4 \%$. A similar University of British Columbia project by Macdonald et al. [250] used a 16-month, 5-day/wk, 15 -min/day jumping protocol and compared this intervention to usual physical education (which the intervention participants also received). A significant difference of $3 \%$ greater tibia midshaft tibia crosssectional moment of inertia (CSMI) in boys was reported. Changes in CSMI suggest a change in cross-sectional geometry due to increased periosteal apposition in one of the planes. However, other structural differences were not statistically significant in the study by Macdonald et al. [250].

We identified eight prospective observational studies that examined associations between physical activity and whole bone structure. All studies (100\%) found statistically significant, and likely clinically significant, differences between the most active and less active cohort members. The University of Saskatchewan Pediatric Bone Mineral Accrual Study found an $8-12 \%$ greater CSA and section modulus of the proximal femur in young adults who were active as adolescents (compared to peers who were less active as adolescents) [251]. In the same cohort, Duckham et al. [252] reported $13 \%$ greater polar SSI and $10 \%$ total bone CSA of the tibia in young adults who were active as adolescents compared to less active peers during adolescence. In females, differences of $10 \%$ greater cortical CSA and $12 \%$ cortical content of the tibia were found. 


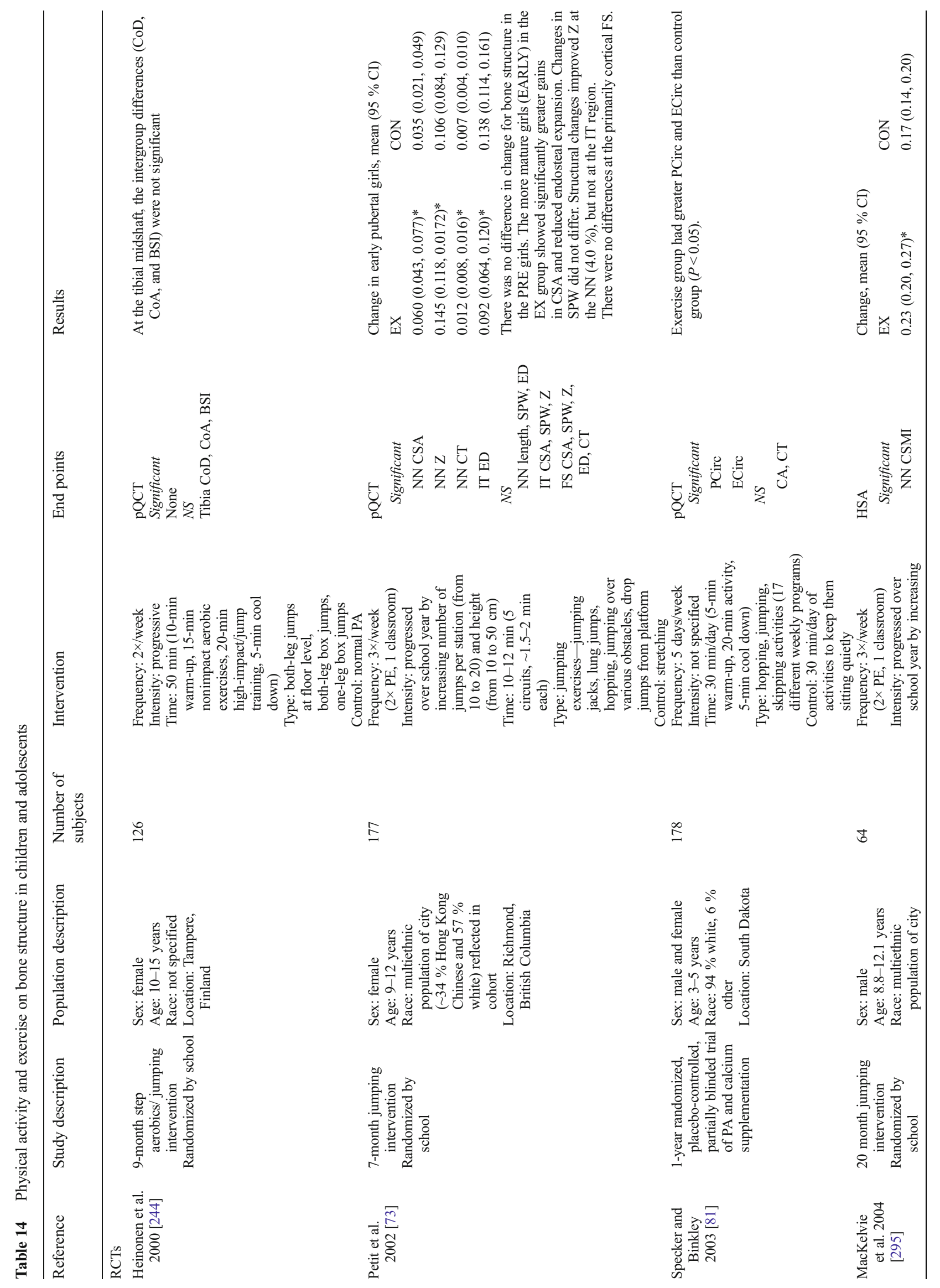




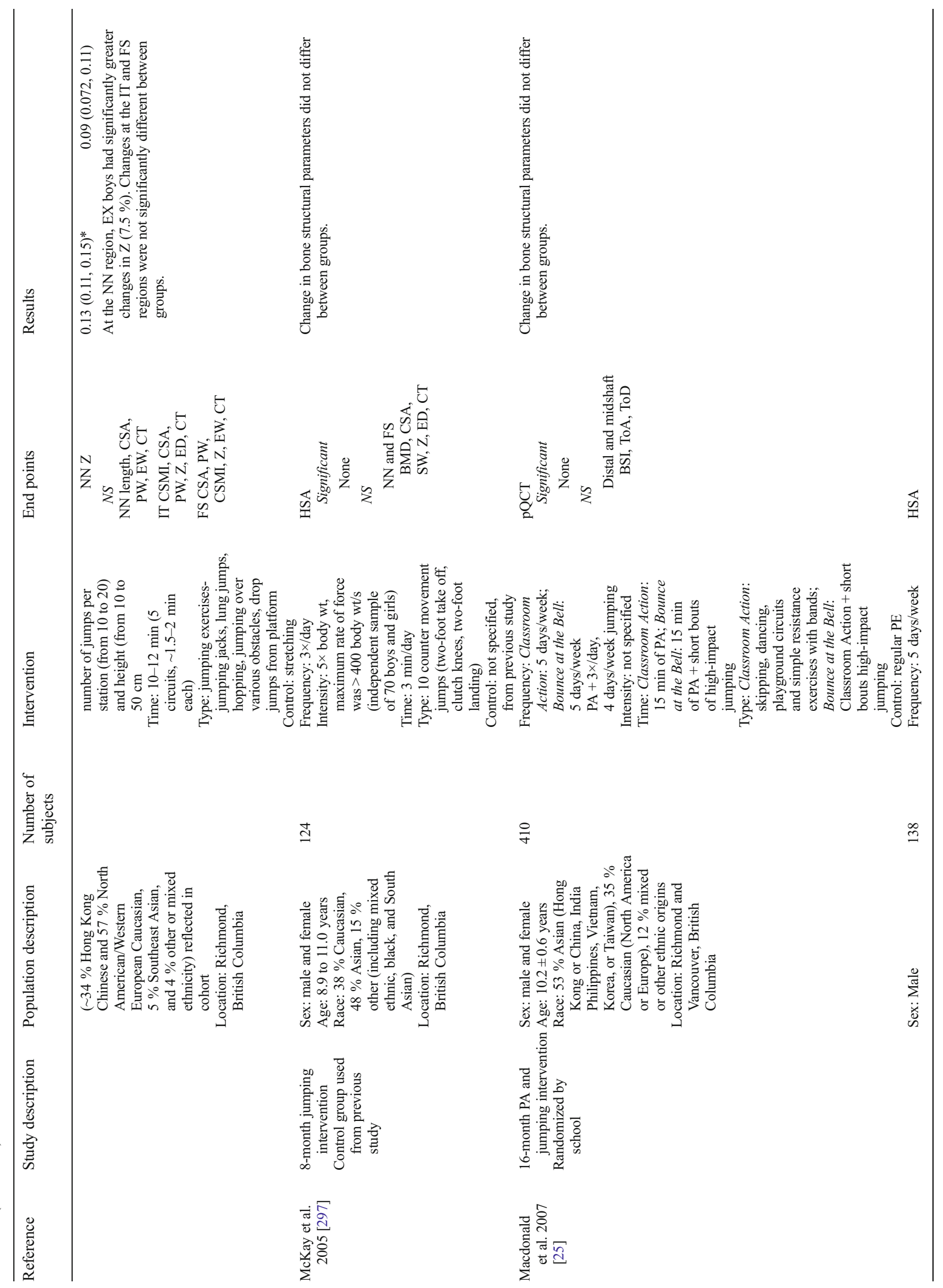




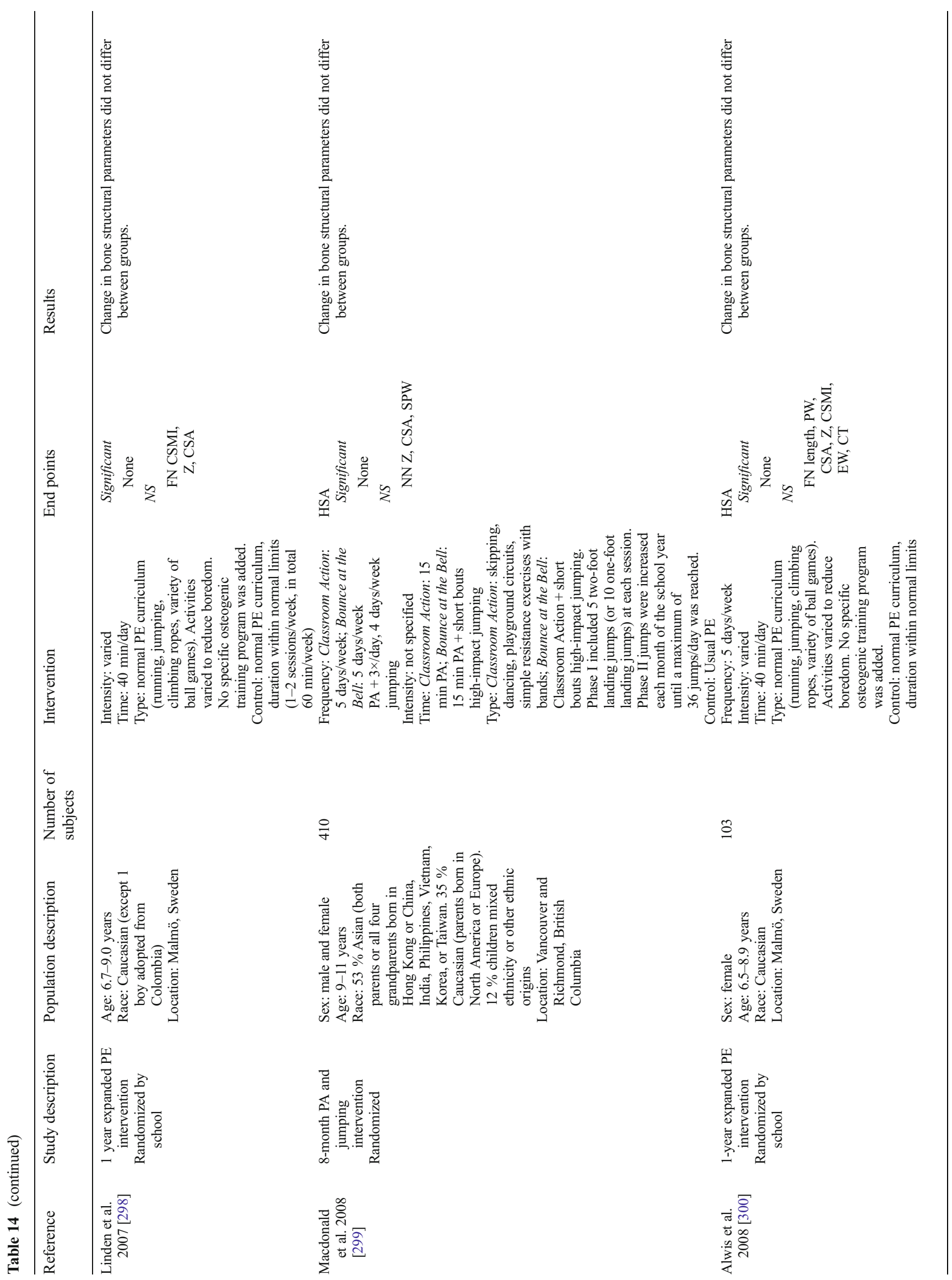




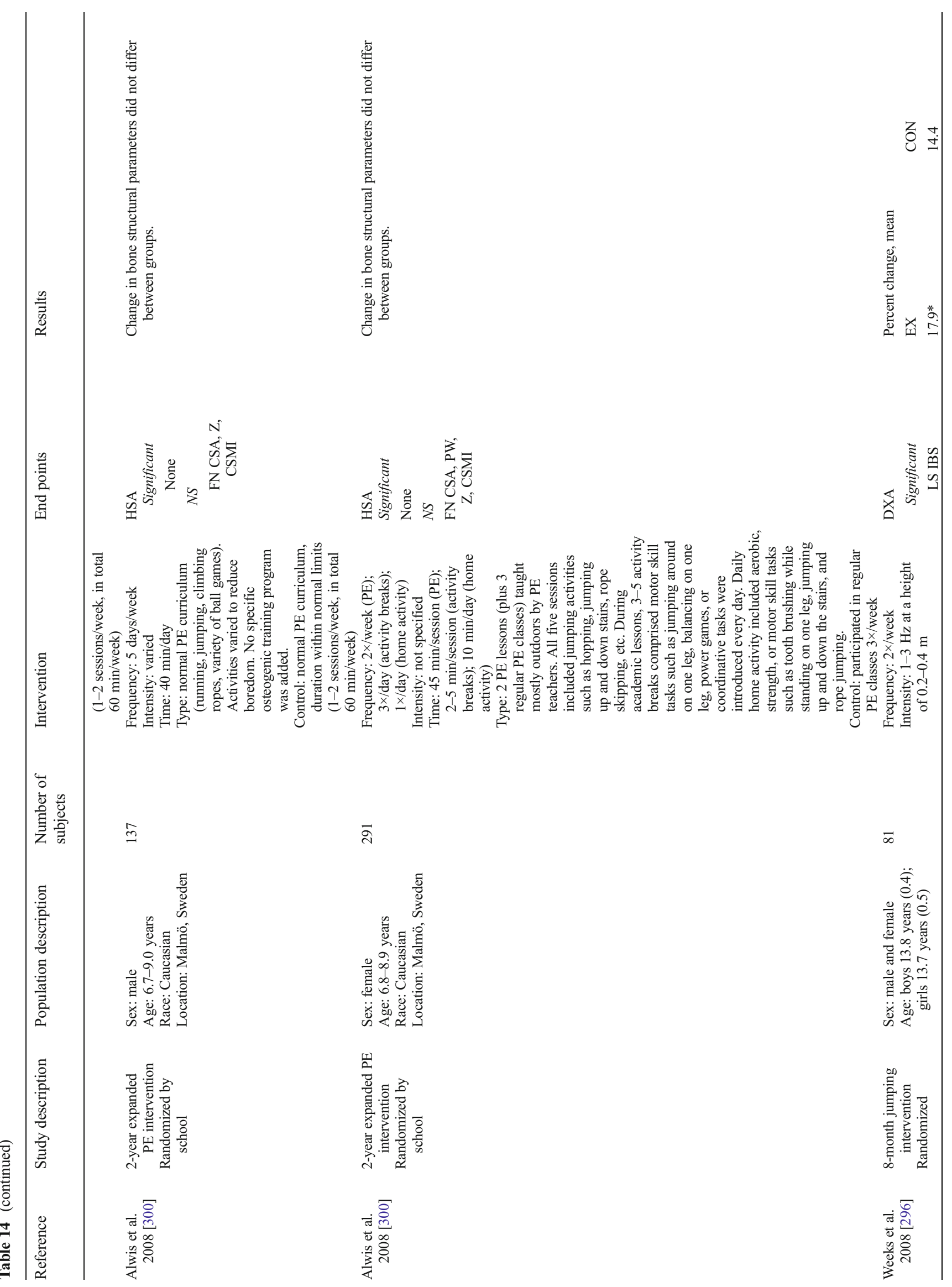




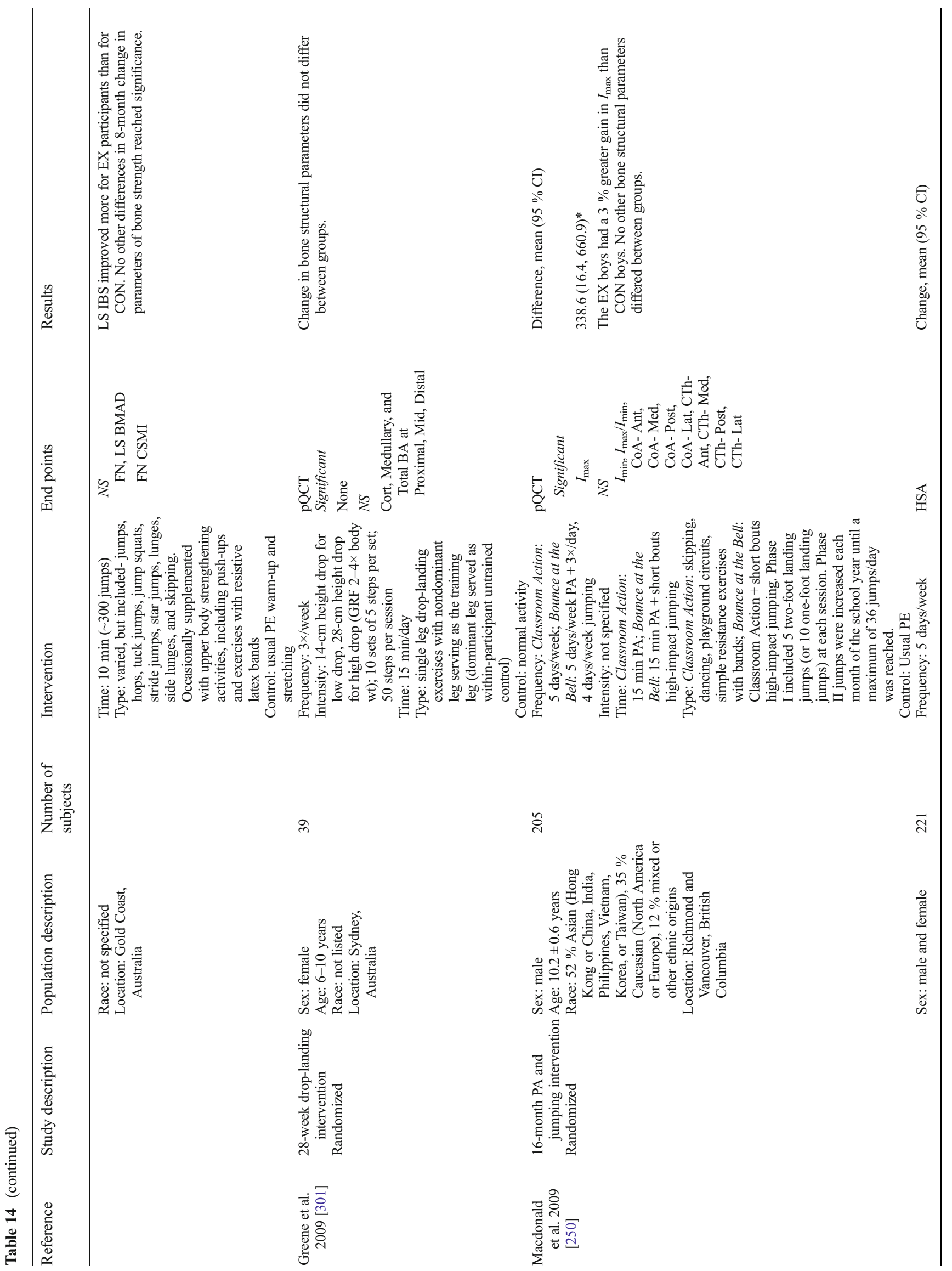




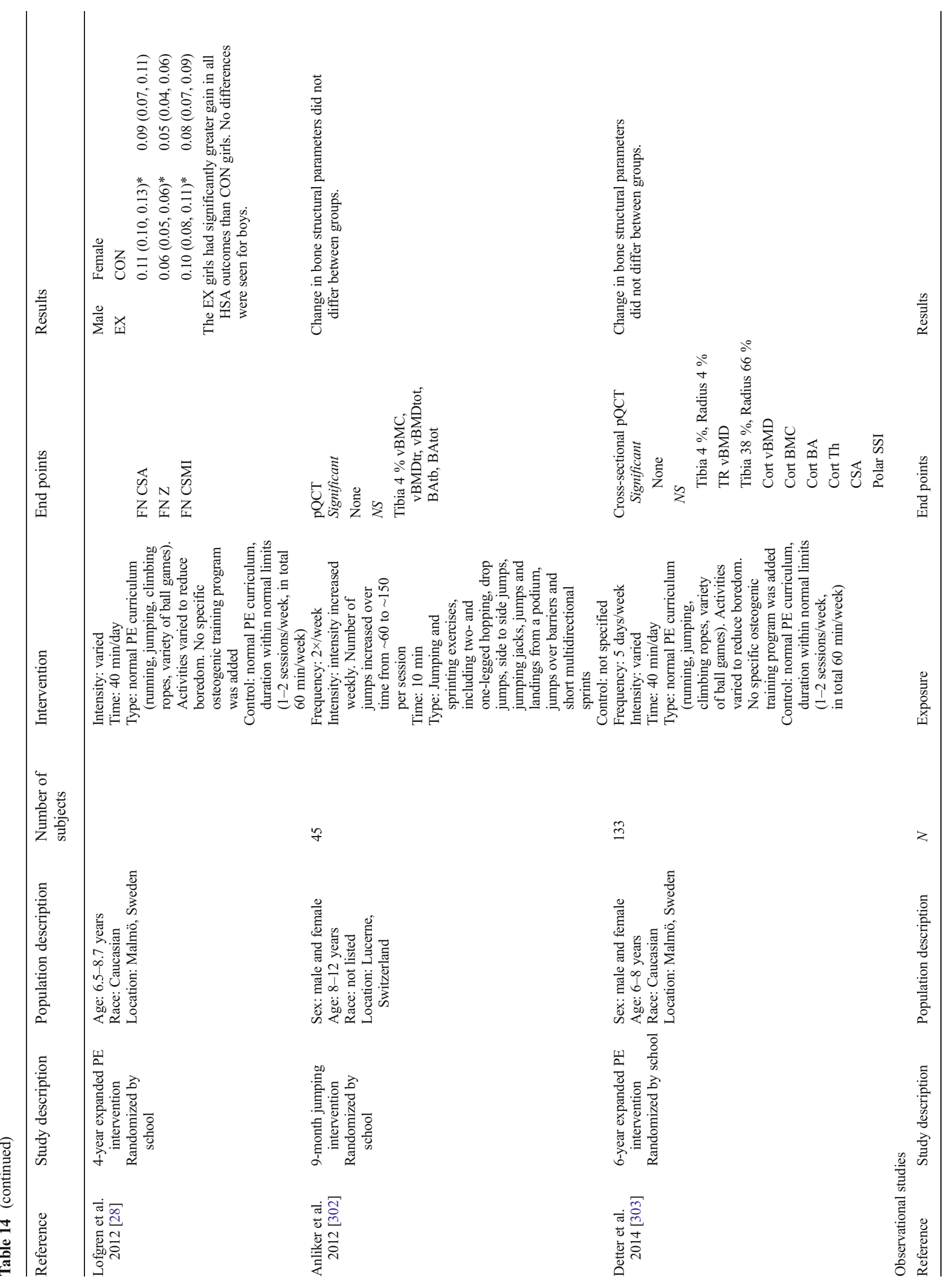




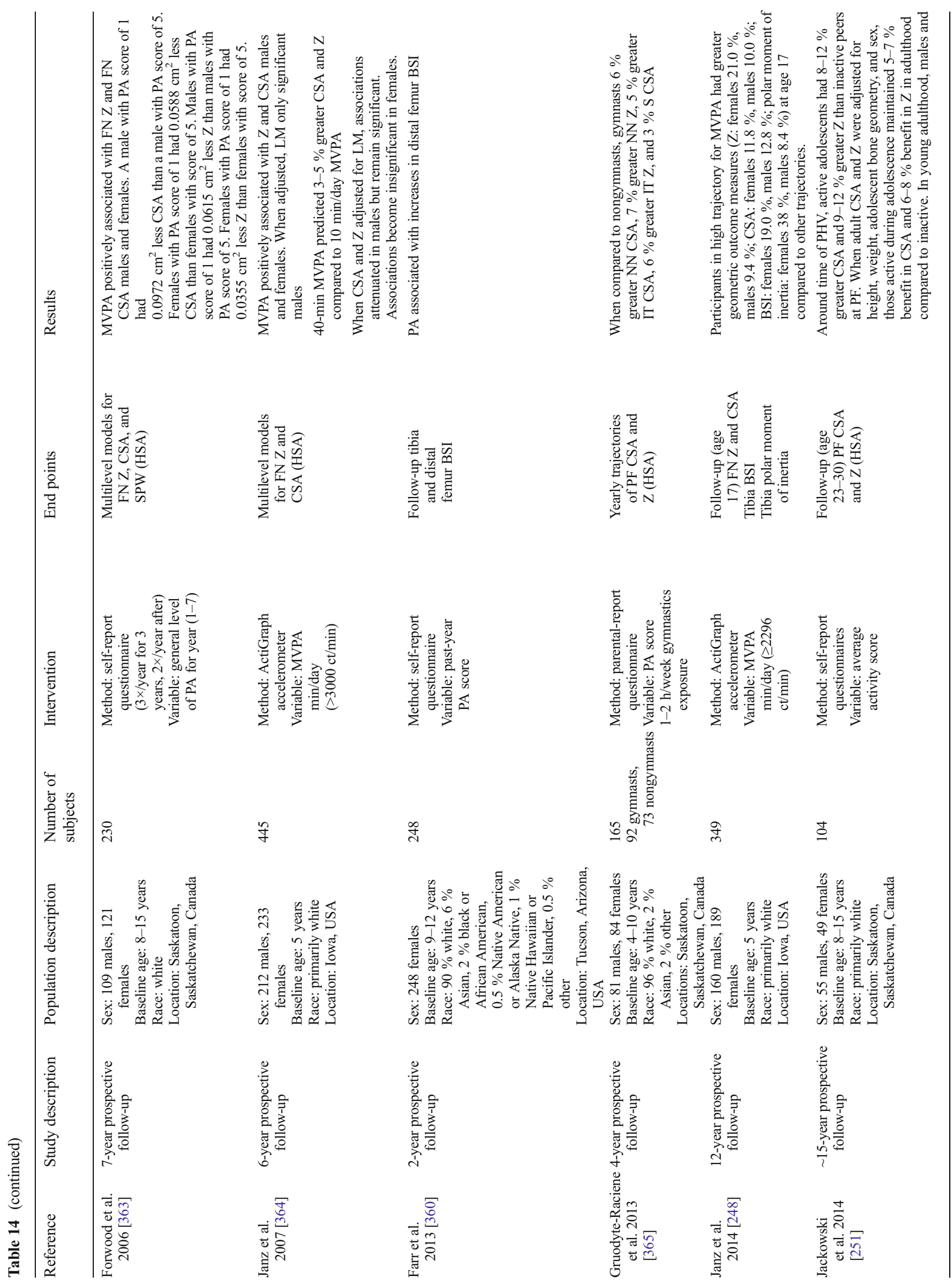




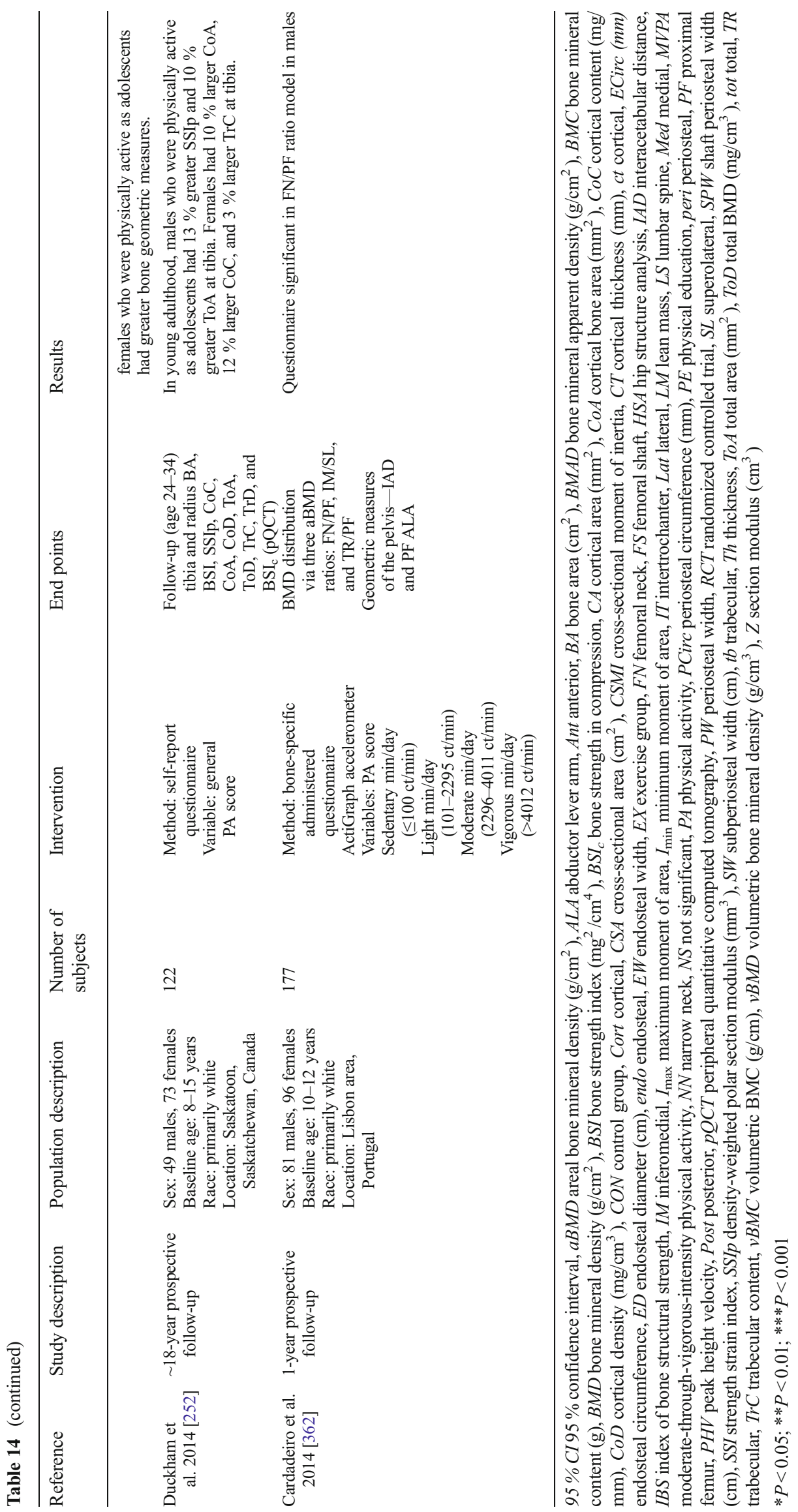


CSA and section modulus of the femoral neck as well as measures of tibial compressive and torsional strength have also been associated with physical activity in the Iowa Bone Development Study cohort. On average, the investigators reported a $14 \%$ difference in various measures between cohort members who were most active during a 12-year follow-up compared to those who were less active [248].

Our evidence grade for physical activity and exercise on bone structure was based on semi-consistent evidence from many RCTs and observational studies.

Grade: Level of evidence B was assigned for the benefit of physical activity and exercise on bone structure.

\section{Discussion}

In this scientific statement, we updated a former effort published in 2000 to summarize the lifestyle choices that influence development of peak bone mass [1]. Unlike the earlier report, our review used a systematic approach to search predictors of bone mass from publications since 2000 . We also considered our knowledge of physiological functions and biology of growth for areas for which a systematic review was not possible. Bone is a living tissue and as such requires all essential nutrients for growth and maintenance. The bony mineral tissue is composed of hydroxyapatite, a calciumphosphate compound, with magnesium and trace amounts of other minerals. The connective tissue is composed primarily of the protein, collagen. The role of many micronutrients in bone is to assist in connective tissue synthesis and maturation. Iron, zinc, magnesium, copper, manganese, and vitamin $\mathrm{K}$ are cofactors in enzymes responsible for bone metabolism, collagen synthesis, and cross-linking. Vitamin D is metabolized to a steroid-like hormone that increases calcium absorption through a saturable, facilitated diffusion pathway. Mechanical loading from physical activity is essential to stimulate bone modeling to provide the stimulus necessary to develop a strong skeleton to support growth and development. In children and adolescents, the important focus is on bone accrual, with careful monitoring of growth parameters. Unfortunately, in contrast with adults, children and adolescents have not been the focus of research in many studies relating lifestyle factors to bone density or quality.

\section{Grade A evidence}

Both physical activity and calcium intake had strong and abundant evidence to be assigned a grade A level of evidence. This level of evidence is not often attained and merits priority action for public health efforts. Regrettably, calcium intake and physical activity are not achieved in recommended levels by our youth. A large difference in the nature of the evidence between physical activity and calcium intake is apparent. The evidence for physical activity and bone mass and geometry is a global approach, whereas the evidence for calcium intake and bone mass is a reductionist approach. The research available for physical activity does not examine the effects of specific types of exercise and few studies examine the dose loading effects of any one type of exercise. Therefore, we conclude that physical activity is important for growing bone, but we do not fully understand the characteristics of physical activity that impact bone such as mode, frequency, intensity, and duration. On the other hand, studies of the effects of diet on bone usually look at a single nutrient effect; there is much less evidence for the effects of diet quality as a whole. There is opportunity for researchers in both fields to consider the approaches of the other field.

\section{Macronutrients}

\section{Fat}

There was significant interest in dietary fat and bone metabolism in the decade preceding the 2000 review by Heaney et al. [1] that centered around $\omega-3$ and $\omega-6$ fatty acids and biomarkers of inflammation, primarily in animal models. Since 2000 , the work has continued to examine the long-chain $\omega-3$ fatty acids, DHA and eicosapentaenoic acid. The majority of studies have been conducted in adults, and the findings are equivocal with respect to improvements in bone mass [253]. Only one RCT was identified in children, but it was not included in this review due to the short 16-week duration of the intervention [254]. Prospective studies and RCTs in children and adolescents are lacking, and it is premature at this time to draw conclusions regarding the influences of dietary fat on bone during growth.

\section{Protein}

During pubertal growth, BMC accrual is markedly influenced by increasing IGF-I [181], and IGF-I is impacted by energy and protein intakes. We considered studies addressing both dietary protein intakes as well as PRAL. Prior to the 2000 review on peak bone mass by Heaney et al. [1], the interest in dietary protein and bone centered on calcium/protein ratios and calcium retention in adults, although the findings of several protein and bone cross-sectional studies in adults were mixed. Other dietary factors are also of interest including the effect of specific dietary proteins with higher sulfurcontaining amino acids, which increase PRAL and may lead to lower bone quality. Much of what is known regarding dietary protein and bone quality emanates from adult studies, with limited work in children and adolescents. One short (6 months) RCT in adolescents [143] showed no benefits to 
material or geometrical properties of bone and was not generalizable because it included only late adolescents and young adults aged 18-25 years. The majority of prospective [144-147] and cross-sectional [149-151, 153] studies support a positive relationship between protein intake and bone. The Dortmund Nutritional and Anthropometric Longitudinally Designed (DONALD) Study [144, 145] demonstrated that protein intake was positively, and PRAL was negatively, associated with the geometrical properties of the forearm in a stepwise multiple regression model. Using biomarker data from that same cohort, long-term protein intake estimated by $\mathrm{uN}$ excretion and urinary PRAL were positively and negatively associated with forearm cortical BMC and area, respectively, when adjusting for age, sex, pubertal stage, forearm muscle area, forearm length, and urinary calcium. To further support a positive effect of dietary protein on bone growth, protein intake over approximately 8 years explained total body BMC net gain in the University of Saskatchewan Pediatric Bone Mineral Accrual Study [147]. In a multivariate regression model, long-term protein intake (over 2 years) positively predicted total body BMC. Collectively, the prospective studies lend support for a positive effect of protein on bone in growing children.

Only one prospective study showed negative relationships between dietary protein and bone [148]. The authors suggested that the negative relationships might have been due to low calcium intakes among the children. Consistent with this notion, Vatanparast et al. [147] reported that the positive effect of dietary protein on bone mass is most evident in those consuming adequate calcium $(>1000 \mathrm{mg} /$ day $)$. Higher dietary protein accompanied by low calcium intakes (i.e., lower calcium/protein ratio) could lead to increased urinary calcium excretion [255] and lower bone mass; however, RCTs are needed to prove this assumption.

\section{Micronutrients}

\section{Calcium}

Storage of calcium in bone serves as a functional reserve to offset dietary shortages of calcium and is tapped when needed to maintain homeostasis. More than $99 \%$ of the body's calcium is in the skeleton as a consistent proportion of bone mineral. The calcium reserve is very large relative to the cellular and extracellular metabolic pools of calcium; thus, dietary insufficiency rarely impairs calcium-dependent biochemical functions. However, long-term deficiency depletes the reserve and subsequently decreases bone mass and bone strength.

Because the human skeleton contains only about $2-3 \%$ of the total adult body calcium at birth, the dietary requirements for calcium during the first 20-30 years of life are determined primarily by skeletal growth. Extreme calcium deficiency during growth can cause rickets [256, 257]. However, even moderate deficiency has deleterious effects on the skeleton, both short term and long term.

Balance studies are useful to show the effect of a nutrient in an otherwise controlled environment because the diet is strictly controlled. These studies have shown that calcium is a threshold nutrient, implying that calcium retention increases with calcium intake until a plateau is reached. Balance studies, rather than bone density or other skeletal measures, have been used to demonstrate this phenomenon because finding the threshold requires a range of intakes, which bracket the threshold intake. This is possible in balance studies that are sufficiently short to manage controlled diets until steady state is achieved. During peak bone mass accrual, there are racial and sex differences in the plateau calcium intake and the peak maximal retention in adolescents. Black girls have a higher maximal retention than white girls, and Chinese-American girls have the lowest maximal retention rates [258-260]. The intake at which the plateau occurs is not different between white and black girls, but it is lower in Chinese-American girls (1300 versus $970 \mathrm{mg} /$ day). White boys have higher peak calcium retention rates than white girls, but the intake at which the plateau occurs is not different [261]. Chinese-American boys had both higher maximal calcium retention rates and intakes for maximal retention $(1100 \mathrm{mg} /$ day) than Chinese-American girls [260]. By contrast, MexicanAmerican boys and girls do not have different rates of calcium retention, and rates are similar to non-Hispanic white boys but are higher than for non-Hispanic white girls [262]. The intake for maximal retention for white adolescents has been established as the RDA for calcium for adolescents [263]. The recommended intakes for Chinese-American, and perhaps other Asian, adolescent girls could be lowered because maximal bone calcium accretion is achieved at lower calcium intakes than whites. However, actual calcium intakes for most Asian adolescent populations are considerably below this lower threshold intake [264]. Few balance studies have been conducted in children other than adolescents.

Numerous studies have been conducted to determine the amount/types of dietary calcium needed for development of maximal bone mass and strength and the ages/stages of development at which calcium intake might be more critical. Furthermore, efforts have been made to elucidate the relationship between calcium intake and physical activity in maximizing skeletal development.

Heaney [265] recently proposed guidelines for systematic reviews of clinical studies of nutrient effects. He proposed that all studies included in a systematic review of nutrient intake should have baseline nutrient status as an entry criterion and should start with subjects at similar baseline nutrient status values. Baseline nutrient status should be suboptimal, especially in the case of a threshold nutrient such as calcium. If subjects are calcium replete, an intervention to increase calcium intake will usually produce a null effect. Heaney also proposed that for inclusion, all studies should use similar 
doses of the nutrient intervention and that co-nutrient status should be optimized to ensure that the test nutrient is the only nutrient-related factor in the response. However, in reality, few studies meet all of Heaney's proposed guidelines. The calcium doses of studies found for this review ranged from 500 to $1200 \mathrm{mg} /$ day. Only three studies supplemented with vitamin $\mathrm{D}$, which is an important co-nutrient for bone health. Importantly, all reported baseline calcium intakes were below the Institute of Medicine (IOM) — recommended levels, ranging from 181 to $1199 \mathrm{mg} /$ day. Thus, in studies of children and adolescents whose average calcium intake is deficient, $90 \%$ of the RCTs detected a statistically and biologically significant effect on bone accrual.

In our review of applicable RCTs, we found that designs of calcium supplement studies are inconsistent with regard to baseline calcium intake, supplement dose, optimization of vitamin D, outcome variables (skeletal site, BMD versus BMC versus area), and adjustment for confounders. Nonetheless, we find that calcium supplementation, whether with pills, fortified foods, or dairy, consistently increases gain in skeletal mass and density measures in children and adolescents, usually between 1.0 and $5.0 \%$. The skeletal sites showing a calcium effect were widely varied among the studies. Some studies did not adjust for body size, which confounds the outcomes because growing children will all have increases in BMC and BMD due to elongation of the skeleton. In addition, there is some evidence that calcium supplementation also increases gain in height [162].

\section{Vitamin D}

Prior to the peak bone mass review published in 2000 [1], no vitamin D RCTs in children or adolescents had been published. Eight RCTs have been conducted since then using vitamin D doses ranging from the equivalent of $200-$ $2000 \mathrm{IU} /$ day, and these RCTs have primarily targeted female subjects between the ages of 10 and 17 years [159, 170, 173, 175-178, 180]. Two publications [175, 176] originated from the same Lebanese RCT, the only RCT to include males. Four RCTs conducted in Lebanon, Finland, China, and the United Kingdom provide moderate evidence to support vitamin D supplementation effects on childhood and adolescent bone mineral accrual. Using an intent-to-treat analysis, supplementation was shown to improve hip BMC [175] and geometrical properties of the femoral neck [176] in females, but not males. In subgroup analyses, the vitamin D effect was more pronounced in prepubertal or early pubertal versus postpubertal girls, as well as in those with lower versus higher baseline $25(\mathrm{OH}) \mathrm{D}$. Two RCTs that provided evidence demonstrating improvements in BMC gains after vitamin D supplementation only did so when analyzing results using a compliance-based analysis [177, 178]. Findings by Du et al. [170] and Khadilkar et al. [178] support the beneficial effects of vitamin D supplementation on total body BMC gains; however, unlike the other single-nutrient studies, vitamin $\mathrm{D}$ was combined with calcium. The remaining four RCTs [159, 173, 178, $180]$ did not show significant changes in BMC measures with supplementation, likely due to the use of small sample sizes or low vitamin $\mathrm{D}$ intervention doses, in some cases combined with baseline serum $25(\mathrm{OH}) \mathrm{D}$ concentrations above a threshold for demonstrating an effect.

Comparing the findings from the RCTs is complicated because of the different methodologies used to assess serum $25(\mathrm{OH}) \mathrm{D}$, including radioimmunoassay (Diasorin), enzyme immunoassay (Immunodiagnostic Systems), and high-performance liquid chromatography. More confidence in the findings is generated because all laboratories participated in the Vitamin D External Quality Assessment Scheme (DEQAS) and met the standards. Moreover, various statistical approaches were employed among RCTs. The RCT that presented the most compelling evidence for a vitamin $\mathrm{D}$ effect on bone accrual presented intentto-treat, unadjusted data [175]. In another study, positive findings were found only when taking into consideration compliance and statistically adjusting for changes in bone area, weight, and maturation [177]. The other RCTs adjusted for one or a combination of other potential confounders, including baseline bone values, bone area, age, maturation, height, weight, fat-free soft tissue, calcium intakes, sunlight exposure, and physical activity.

It is important to note that mean baseline serum $25(\mathrm{OH}) \mathrm{D}$ concentrations for all RCTs in our review were between 18 and $48 \mathrm{nmol} / \mathrm{L}$, which are lower than the 50-nmol/L cutoff used to define vitamin D sufficiency [245]. Using changes in $\mathrm{BMC}$ as the primary outcome, even in study samples with deficient-to-low serum $25(\mathrm{OH}) \mathrm{D}$, supplementation did not consistently promote gains. In a systematic review by Winzenberg et al. [266], the authors concluded that vitamin D supplementation is more likely to augment hip, forearm and lumbar spine aBMD in children with low serum $25(\mathrm{OH}) \mathrm{D}$ concentrations. To our knowledge, no RCTs with bone outcomes have been conducted in children and adolescents with serum $25(\mathrm{OH}) \mathrm{D}$ concentrations $\geq 50 \mathrm{nmol} / \mathrm{L}$ [263].

The osteogenic effects of calcitriol are attributed to its role in serum calcium homeostasis, partially through regulation of intestinal calcium absorption [267]. Calcium absorption was not assessed in the four RCTs in this review. One dose-response RCT in children entering the early stages of puberty with a mean baseline serum $25(\mathrm{OH}) \mathrm{D}$ of $70 \mathrm{nmol} / \mathrm{L}$ showed no effects of supplementation on fractional calcium absorption using vitamin D doses ranging from 400 to 4000 IU over 12 weeks [268]. These results are compatible with the aforementioned systematic review [266], which stated that the beneficial effects of vitamin $\mathrm{D}$ on bone may be less likely to occur in children with sufficient serum 25(OH)D. 
Although we ranked the evidence for a positive effect of vitamin D supplementation on bone mineral accrual in children and adolescents as moderate, several unanswered questions remain. Only one study was conducted in males, and it is therefore premature to make conclusions regarding sexual dimorphism with respect to vitamin $\mathrm{D}$ supplementation and bone. Moreover, subgroup analyses were conducted in several studies in an attempt to identify critical times during childhood and adolescence during which supplementation may be most effective on bone. The results reported for premenarche, the early stages of puberty, or the postmenarche years, however, were inconsistent. These equivocal findings deserve further investigation.

\section{Micronutrients other than calcium and vitamin $D$}

Few trials of any type have been conducted on micronutrients other than calcium and vitamin D relevant to bone health to guide recommendations. The studies on other micronutrients included in this review were not generalizable or were limited in sample size or other aspects of study design. Magnesium, phosphorus, vitamin $\mathrm{K}$, vitamin $\mathrm{C}$, zinc, and other nutrients play important structural and functional roles for bone. Only magnesium was tested in an RCT, but this benefit to BMC was only evaluated in a small group of white girls and only at one level of supplementation. Results of the two studies that found sex differences $[189,190]$ may be explained by the study group being in a period of active bone modeling. Boys experience peak bone mass accrual later than girls [3]. The benefits of vitamin C in the study by Prynne et al. [189] were not observed in girls of the same age, likely because the girls were more sexually mature. Benefits to younger girls were apparent in the study by Laudermilk et al. [190]. In cross-sectional analyses, inverse relations were observed between phosphorus and sodium intake and total body BMC and size-adjusted bone area [149]. Although phosphorus is an important component of bone mineral, it may be a marker for cola intake (see below under food patterns) or protein intake. The observed negative effect of sodium on bone mass and area may be explained by the negative effect of high dietary sodium intakes on calcium balance through greater urinary calcium excretion demonstrated in adolescent girls [269]. In that study, the negative effect of dietary sodium was more pronounced in white girls than in black girls. Calcium, magnesium, and potassium retention were all greater in black adolescent girls than in white adolescent girls [185, 269-271].

Vitamin $\mathrm{K}$ is a cofactor of vitamin K-dependent gammacarboxylase, an enzyme required for the activation (gammacarboxylation) of osteocalcin, a protein involved in bone formation and mineralization. Undercarboxylation of osteocalcin, a marker of vitamin K deficiency, was inversely associated with BMC [191]. Kalkwarf et al. [192] were the first to investigate the effects of vitamin $\mathrm{K}$ on bone mass and bone turnover in young girls and found little benefit to bone, except in the spine. It should be reemphasized that the girls in this study were aged 3-16 years, representing a broad span in terms of skeletal maturity. Even though experimental data suggest a stimulatory effect of vitamin $\mathrm{K}$ on bone formation [272], the relationship between vitamin K nutritional status and development of peak bone mass and strength in humans remains unclear.

Fluoride promotes osteoblast proliferation, increases aBMD in adults, and has been used as a therapeutic option for patients with osteoporosis [273]. The two prospective studies in children and adolescents [186, 274] suggest a possible osteogenic benefit of living in a specific location with higher fluoride concentrations in the water. Two US prospective reports from Iowa $[187,188]$, however, showed that lifetime fluoride intakes were not associated with BMC in 11- and 15 -year-old adolescents. The public health benefits of water fluoridation for dental caries prevention in children are well documented, but the available limited evidence is insufficient to draw conclusions regarding fluoride and bone during growth.

Many of these micronutrients (i.e., calcium, vitamin D, potassium, and for some subgroups, magnesium and vitamins $\mathrm{C}$ and $\mathrm{A}$ ) are shortfall nutrients compared to recommended intakes as determined by the 2015 Dietary Guidelines Advisory Committee [275].

\section{Food patterns}

The evidence since 2000 builds on earlier evidence, with additional RCTs showing a benefit to bone owing to the inclusion of dairy products in the diet. Dairy products contain colloidal calcium phosphate protein complexes in the form of casein micelles that have the minerals and nutrients needed for bone growth. Cross-sectional studies show a positive association between fruit and vegetable intake and higher bone mass. The explanation for the benefit of fruit and vegetable intake to bone is not clear. The benefit may be because of the nutrients that they provide, such as potassium, magnesium, and vitamin C [189, 276]; bioactive ingredients from specific fruits and vegetables, such as flavonoids [277]; or their alkaline ash-forming properties [189]. Studies in children on any of these hypotheses are limited. In a 4-year prospective study in German children aged 6-18 years, urinary net acid excretion, a good indicator of total body net endogenous acid load, was unrelated to bone measures [145].

Carbonated beverage and cola consumption was associated with reduced BMC, aBMD, or bone strength and higher fracture in several cross-sectional studies shown in Table 8, especially in girls. The negative effect of cola beverages and caffeine may be directly related to increased urinary calcium with caffeine or to excess phosphorus intake. To explore the potential mechanism by which carbonated beverages result in lower 
bone accretion and fracture, Kristensen et al. [278] examined biomarkers of bone turnover in a controlled crossover intervention study with 11 men (aged 22-29 years). The authors compared 10 days on a low-calcium diet with cola versus milk added to the diet. The high cola intake was associated with increased bone turnover compared to the period of high milk intake. Alternatively, the negative effect of carbonated beverage consumption on bone may be explained by associated factors including low milk intake, reduced physical activity, and higher BMI [201]. The effect of diet on bone turnover in the study by Kristensen et al. [278] could be due to calcium in milk, rather than the cola, given that dietary calcium reduces bone resorption in adolescent girls [279]. Milk displacement by soft drinks is associated with reduced intakes of calcium and other nutrients found in milk. Regardless of the mechanism, the evidence suggests that cola consumption while on a low-calcium diet can have adverse effects on bone accretion and retention.

Bioactive food components may influence human gut microbial diversity, which in turn may offer a positive impact on skeletal health. The role of the gut microbiome in regulating bone mass was recently demonstrated using a germ-free mouse model [280]. Flavonoids, found ubiquitously in nature in many plant-derived foods, may also have the potential to positively affect bone health. Although our search did not identify any RCTs that assessed the effect of any flavonoid subclass (or polyphenols in general) in children or adolescents, several animal and/or in vitro analyses have shown a biological plausibility for these compounds to affect bone turnover and markers of bone health [277]. Because of their structural similarity to estrogen, soy isoflavones are currently the main class of flavonoids studied for their role in bone health.

Total dietary fiber does not appear to be related to bone accrual, but fibers that are fermentable to short-chain fatty acids in the lower gut by the gut microbiome are associated with increased calcium absorption [281-283]. In the only intervention study of sufficient duration to examine effects on BMC accrual, a combination of short- and long-chained fructooligosaccharides showed a significant benefit [193].

\section{Infant nutrition}

Breastfeeding during the first year of life has long been suggested to be optimal for infant nutrition; however, the available scientific literature is conflicting in terms of bone and fracture outcomes. Formula feeding may have the potential to increase short-term BMC and BMD outcomes [215, 216], possibly due to higher amounts of nutrients such as calcium and vitamin $\mathrm{D}$ in most infant formulas compared with breast milk (to note, infant formula contents likely vary between and within observational studies). An older landmark RCT [284] supports this hypothesis and reported that during the first
6 months of life, bone accretion is less in infants fed human or low-mineral formula but is greater in the second 6 months of life. Data from observational studies remain inconsistent since 2000. Additional studies addressing the impact of the duration of breastfeeding on peak bone mass development are also needed because current observational data have shown inconsistent results [212-214, 251]. It is important to note potential confounding bias because mothers who breastfeed have been shown to adopt other positive health behaviors for their children that could influence the development of peak bone mass. It is important to note that the American Academy of Pediatrics has recommended that infants who are breast-fed and children and adolescents who consume less than $1 \mathrm{~L}$ of vitamin D-fortified milk per day will likely need supplementation to reach $400 \mathrm{IU}$ of vitamin D per day [285].

Data from the RCT assessing the effects of infant formula enriched with palm olein showed positive effects in relation to total body BMC at 3 and 6 months [211]. However, observational studies of children aged 4.5 and 10 years who consumed infant formula with either added palm olein or $s n-2$ palmitate during their infancy showed no significant differences in total body BMC [220, 221]. Overall, the data suggest that enrichment of infant formula with palm olein may be beneficial during the first 6 months of life.

\section{Adolescent special issues}

\section{Detriment of DMPA injections and oral contraceptives}

Data are conflicting regarding the effect of combined OCs on bone density among adolescent girls. OC pill use by healthy, white, teenage females did not affect acquisition of peak bone mass in one study [223]. However, studies that have examined the effect of low-dose estrogen OCs suggest otherwise. Some data suggest that long-term treatment with an oral monophasic contraceptive formulation (ethinylestradiol $20 \mu \mathrm{g}+$ desogestrel $0.150 \mathrm{mg}$ ) raises concerns about suboptimal achievement of peak bone mass [286], especially when initiated during the teenage years. The skeletal effects of combined OCs are of greater concern in adolescents compared to their use in adult women [287, 288]. Initiation of combined OCs within the first 3 years after menarche is of particular concern [288]. OCs suppress endogenous estradiol production by suppressing the hypothalamic-pituitary-ovarian axis. There is growing consensus that OCs containing $20 \mu \mathrm{g}$ of ethinylestradiol interfere with acquisition of peak BMD, although some studies have had inherent limitations including smoking status, small sample size, poor accounting for confounders, and so forth [289].

Contraception via injections of DMPA is associated with skeletal deficit at the spine and hip when used before peak bone mass. DMPA acts on the skeleton mainly through estrogen deficiency [230]. Pharmacological doses of DMPA may 
also possess selective glucocorticoid activity and can alter the expression of glucocorticoid receptor-regulated genes. However, weight gain on DMPA may mitigate loss of BMD among adolescent users [222]. In addition, bone loss in female adolescents receiving DMPA for contraception is partly or fully reversible following discontinuation of DMPA, with faster recovery at the spine than at the hip [290]. DMPA is still used commonly in adolescents, but with caution given the potential skeletal implications.

\section{Detriment of alcohol}

Alcohol abuse is associated with lower aBMD and increased risk of fracture among adults. However, the association between low to moderate alcohol intake and bone density in adults is inconsistent, with low to moderate intakes associated with higher aBMD than that of abstainers in some studies [291]. Likewise, there is little evidence that alcohol intake at levels currently reported in studies among adolescents to date has any effect on attainment of peak bone mass. An important limitation of published studies is the ability to identify the effects of consuming large daily amounts alcohol ( $>3$ servings/day) on bone due to its low reported prevalence in these studies.

There has been large variability among studies in the amount of alcohol consumed by study participants and the classification of alcohol intake from ever tried to number of drinks per day. Overall, the reported alcohol consumption by adolescents studied was relatively low. In some studies, adolescents who consumed alcohol were more likely to smoke [231-235], necessitating statistical adjustment for smoking to investigate the independent effects of alcohol intake on bone.

Binge drinking is an important consideration for adolescents, because about $90 \%$ of the alcohol consumed by adolescents aged $<21$ years in the USA is in the form of binge drinking [292]. We did not identify any studies that examined the association between binge drinking on bone health in adolescents.

\section{Detriment of smoking}

Despite abundant evidence that smoking has many deleterious health effects, cigarette smoking continues to be common among adolescents and adults. In 2011, $18.1 \%$ of high school students in the USA smoked $\geq 1$ cigarettes in the last 30 days and $19.0 \%$ of adults were current smokers [293].

The strength of evidence regarding the association between smoking and bone in adolescence has been limited by methodological challenges in quantifying smoke exposure and the need to disentangle the effects of smoking from other lifestyle factors such as physical activity, dietary calcium intake, and alcohol consumption. Differences in results across studies arise, in part, due to challenges in characterizing exposure and the low prevalence of regular smoking, limiting statistical power. Despite methodological challenges, results of the studies reviewed herein support the contention that smoking in adolescents may reduce peak bone mass. The large studies of young adult military recruits provide additional evidence that a history of smoking has deleterious effects on bone. Even if the effect of smoking during adolescence on bone mass is small, it may become important if the deleterious effects of smoking on aBMD compound over time. Adolescents who smoke often continue smoking in adulthood, possibly increasing their risk of osteoporosis and fracture later in life.

If the associations between active and passive smoke exposure and aBMD are causally related, curtailment of active and passive smoke exposure to children of all ages will likely facilitate maximal attainment of peak bone mass [294].

\section{Physical activity and exercise}

We judged the evidence of a positive effect of physical activity on mass and density as strong (Level A). The evidence is less clear in support of a positive effect of physical activity on structure; therefore, we judged the evidence to be moderate at this time (Level B). Similar bone structure RCT designs have resulted in positive effects [28, 81, 250, 295, 296], no effects [25, 244, 297-303], and different effects based on gender or maturity status [73]. However, despite the inconsistencies in RCT results, the evidence provided by welldesigned RCTs [81] and prospective cohort studies [252] supports a positive effect on structure, including those using objective measures of physical activity [248]. Unlike RCTs with mass and density outcomes, the multitude of structural measures, sites for measurement (distal, proximal), and inconsistencies in adjustment for bone size present a unique challenge in evaluating the quality of studies examining and interpreting exercise effects on structure. A design limitation in most of the reviewed RCT studies (mass, density, and structure) was an inability to adequately assess the following: the physical activity levels of controls, the degree of effort in the exercisers, and the activity levels of the exercisers during periods of nonintervention. In short, issues of compliance were common threats to internal validity. In addition, physical activity interventions, in general, are susceptible to compensation effects (i.e., the intervention group does less physical activity outside of the intervention session to maintain a "normal" activity routine) [304].

There is a need to more precisely deliver the exercise dose and to understand the levels of physical activity in control and intervention groups. Laboratory-based work indicates an osteogenic effect at or above mechanical loads of $4.2 \mathrm{~g}$-force [305], whereas RCTs suggest an osteogenic effect at or above 3.5 g-force $[24,306]$. RCTs also suggest 3 days/week with 100 loads per session and approximately 7 months of 
intervention are needed to detect change [24, 306, 307]. Due to the overlap in time and frequency in interventions that show change and those that do not, specific recommendations for these exercise dimensions (time and frequency) are equivocal $[25,73,295,301,302]$. At present, 100 loads per session and 3 days/week are reasonable time and frequency dimensions based on successful RCTs [24, 73, 306].

Almost all of the physical activity-related RCTs included in our review used jumping as the primary exercise type. This is a sound decision because jumping is the gross motor skill that mechanically loads the clinically important site of the hip via muscle loading during takeoff and via impact loading during landing. Animal and human studies have shown that jumping imposes a greater anabolic stimulus on bone than running or walking [306, 308], and the latter are activities commonly prescribed for metabolic health and obesity prevention. The known differences in types of physical activities for different targeted health outcomes suggest a need to promote physical activities that incorporate multiple motor skills (e.g., soccer, tumbling, tennis) or promote diverse physical activity patterns.

In addition to the RCTs and prospective longitudinal studies that we reviewed and graded, other types of research support physical activity as a causal factor for healthy bone mass, density, and structure [309]. Many of the mechanisms and pathways have been elucidated in laboratory studies [82, 308, 310] and the theoretical underpinning of why physical activity is expected to influence mass, density, and structure is clearly described in Frost's mechanostat model [77, 78], which is well respected in the greater scientific community [311-313].

\section{Research gaps}

We have identified many questions that will drive a future research agenda (Table 15). Trials should be designed to obtain at least B-level evidence. The following areas merit further investigation: differing effects of interventions depending on the life stage of growth; gene-environment interactions and how they may impact the development of peak bone mass; the need to identify and utilize biomarkers of exposure and effects; and the interaction of bone with other tissues throughout the body. It is important to recognize that the pediatric skeleton with open epiphyses differs from that of a fully grown adult who has reached his or her peak bone mass, and therefore, meaningful clinical targets and response to interventions will also differ. In addition, longitudinal studies are needed to document the relationship between growth and measures of bone fragility and fractures and to identify lifestyle interventions that may prevent fractures during this period of susceptibility.

\section{Statistical guidelines}

Analysis and interpretation of data from studies examining the effects of nutrition, dietary components, and physical activity
Table 15 Future research agenda

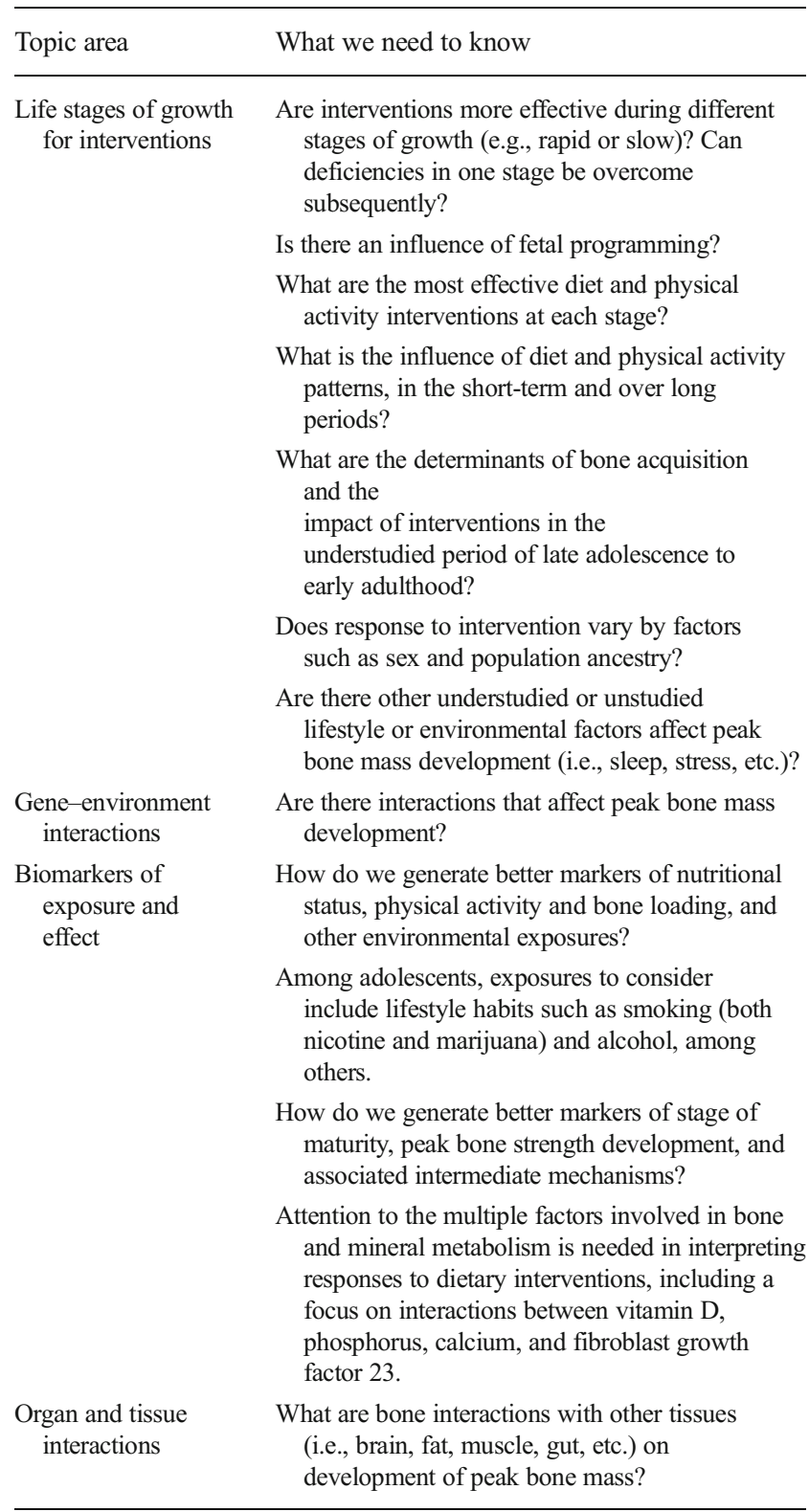

on bone mass and/or strength requires thoughtful consideration (Table 16). Foremost is the baseline of the dietary or physical activity exposure in the study population. This is particularly important for threshold nutrients or dietary components that do not have a linear association with bone measures across a broad range of intakes. Animal studies also indicate that the effects of physical activity are likely to saturate [310]. In randomized trials, it is important to select participants who are likely to benefit from additional intake and/ or exercise. For example, if usual intake of calcium exceeds requirements, then it is unlikely that any benefit of the intervention will be detected. The duration of the intervention is critical to consider in the design of intervention trials and 
Table 16 Elements to consider in the analysis and interpretation of studies examining the effects of nutrition on bone mass or density

\section{Element}

Usual intake of nutrient or dietary component, nutritional status

Duration of intervention (randomized trials)

Age

Sex

Race

Maturational stage

Body size

Physical activity

Health status and medication use

Baseline bone values (prospective studies)

should be appropriate for the bone measure under study. Changes in calcium balance may be measureable within 3 weeks, whereas measureable changes in bone mass or strength due to a dietary and/or exercise intervention may not be evident for 6-12 months.

Subject characteristics, including age, sex, race, maturational stage, and skeletal or body size, should also be considered in the design and analysis of studies examining the association between nutrition or physical activity and bone outcomes because they are strongly associated with bone measures during growth. Statistical adjustment for these characteristics can dramatically reduce residual variability in regression models and improve statistical power to identify associations among dietary intake, physical activity, and bone. In addition, statistical adjustment may compensate for imbalances in these variables across ranges (observational studies) or among intervention groups (randomized trials). Several approaches have been used to account for skeletal size, the most common being height or bone area. Several chronic medical conditions (e.g., anorexia nervosa, cystic fibrosis, etc.) [314-318] and medications (e.g., glucocorticoids, anticonvulsants) [72, 319] are known to affect bone accrual during growth, and these should be accounted for in the study design or statistical analyses. Finally, prospective studies, both randomized trials and observation studies, should consider adjustment for baseline bone values and exposures to minimize the statistical phenomenon of regression toward the mean.

\section{Implementation}

Dietary intakes and physical activity levels of most US youth during the development of peak bone mass do not support maximal bone mass accretion for genetic potential. This increases risk for fracture both during childhood and later in life. Adherence to the US Department of Agriculture (USDA)/US Department of Health and Human Services (HHS) Dietary Guidelines for Americans and HHS Physical Activity
Guidelines for Americans is an important and positive step toward ensuring healthy bone growth and/or maintenance throughout the lifecycle.

\section{Diet}

The recommended intakes of food groups and nutrients relevant to bone, their bone-related functions, and intake status are given in Tables 17 and 18. Shortfall food groups include dairy, fruits, and vegetables (Table 17). Consequently, intakes of nutrients provided by these food groups often do not meet national recommendations (Table 18). Dairy products provide most of the calcium and vitamin D in the diet as well as highquality protein and significant amounts of magnesium, potassium, and other essential nutrients. Yet, approximately $66 \%$ of boys and $83 \%$ of girls during the time of peak height velocity do not meet the recommended intakes of milk [320]. Low intakes of fruits and vegetables can lead to insufficient intakes of vitamins $\mathrm{A}, \mathrm{C}, \mathrm{E}$, and $\mathrm{K}$ and potassium. Potassium has only recently been associated with bone health [276]. Additional research is needed to confirm why higher fruit and vegetable intakes seem to contribute to pediatric bone health among cross-sectional studies. At present, continuing to advocate for children and adolescents to obtain recommended intakes of fruits and vegetables as described by the Dietary Guidelines for Americans has no downside, and may offer a potential benefit toward development of peak bone mass.

Recommended intakes of vitamin D are particularly difficult to achieve without fortified foods or supplements. Enriched and fortified foods provide almost $60 \%$ of dietary vitamin D and $30 \%$ of vitamin $\mathrm{A}$ as well as substantial amounts of B vitamins and iron [321]. Fortified foods provide most of the vitamin D in the US diet [263, 275]. Most US milk is fortified with $100 \mathrm{IU}$ of vitamin D per cup [263]. Breakfast cereals often contain added vitamin D, as do some brands of orange juice, yogurt, margarine, and soy beverages. The USA requires infant formula to contain a minimum of $40 \mathrm{IU}$ and a maximum of $100 \mathrm{IU}$ of vitamin D per $100 \mathrm{kcal}$ (21 CFR 107.100). Low-income, overweight/obese, and minority populations of children in the USA have been shown to have lower intakes of both vitamin D and calcium [209].

Very few foods naturally have vitamin D. Fatty fish (e.g., salmon, tuna, and mackerel) and fish liver oils are the best sources, whereas beef liver, cheese, and egg yolks contribute small amounts [263]. Some mushrooms naturally provide vitamin D, and mushrooms and yeast are available with enhanced levels of vitamin D from being exposed to ultraviolet light [322-324] but are scarce on the market.

There is recent growing interest in the possibility that intake of $25(\mathrm{OH}) \mathrm{D}$, the metabolized form of vitamin $\mathrm{D}$ that is also present in animal foods such as meat, poultry, and eggs, may be contributing to vitamin D status in humans [325]. 
Table 17 Recommended and actual intakes and functions of food sources involved in development of peak bone mass

\begin{tabular}{|c|c|c|c|c|c|c|c|}
\hline \multirow[t]{2}{*}{ Food source } & \multirow[t]{2}{*}{ Bone-related function } & \multicolumn{3}{|c|}{ Recommended servings $^{\mathrm{a}}$} & \multicolumn{3}{|c|}{$\begin{array}{l}\text { Percentage of population with usual intakes below } \\
\text { recommendations }\end{array}$} \\
\hline & & Children & Males & Females & Children & Males & Females \\
\hline \multirow[t]{3}{*}{ Dairy (cups) ${ }^{b}$} & \multirow{3}{*}{$\begin{array}{l}\text { Intakes correlated with } \\
\text { linear growth, bone } \\
\text { mass accrual, } \\
\text { reduced fracture }\end{array}$} & $2-3$ years: 2 & 9-13 years: 3 & 9-13 years: 3 & $2-3$ years: 41 & $9-13$ years: 8 & 9-13 years: 84 \\
\hline & & $4-8$ years: 2.5 & 14-18 years: 3 & 14-18 years: 3 & 4-8 years: 42 & $14-18$ years: 68 & 14-18 years: 92 \\
\hline & & & 19-30 years: 3 & 19-30 years: 3 & & 19-30 years: 80 & 19-30 years: 94 \\
\hline \multirow[t]{3}{*}{ Fruits (cups) ${ }^{\mathrm{c}}$} & \multirow{3}{*}{$\begin{array}{l}\text { Provide micronutrients } \\
\text { for optimal bone growth, } \\
\text { preserve bone and } \\
\text { calcium economy } \\
\text { through acid-base } \\
\text { balance }\end{array}$} & $2-3$ years: 1 & $9-13$ years: 1.5 & $9-13$ years: 1.5 & $2-3$ years: 32 & 9-13 years: 78 & $9-13$ years: 81 \\
\hline & & $4-8$ years: $1-1.5$ & $14-18$ years: 2 & $14-18$ years: 1.5 & 4-8 years: 63 & $14-18$ years: 87 & $14-18$ years: 85 \\
\hline & & & 19-30 years: 2 & 19-30 years: 2 & & $19-30$ years: 89 & 19-30 years: 93 \\
\hline \multirow{3}{*}{$\begin{array}{l}\text { Vegetables } \\
\text { (cups) }\end{array}$} & \multirow{3}{*}{$\begin{array}{l}\text { Provide micronutrients } \\
\text { for optimal bone growth, } \\
\text { preserve bone and calcium } \\
\text { economy through acid-base } \\
\text { balance }\end{array}$} & $2-3$ years: 1 & 9-13 years: 2.5 & 9-13 years: 2 & $2-3$ years: 80 & 9-13 years: 96 & 9-13 years: 95 \\
\hline & & 4-8 years: 1.5 & 14-18 years: 3 & $14-18$ years: 2.5 & $4-8$ years: 92 & 14-18 years: 97 & 14-18 years: 99 \\
\hline & & & 19-30 years: 3 & $19-30$ years: 2.5 & & 19-30 years: 93 & 19-30 years: 94 \\
\hline
\end{tabular}

\footnotetext{
${ }^{a}$ Based on the 2010 Dietary Guidelines for Americans, which may be accessed via http://www.health.gov/dietaryguidelines/dga2010/ dietaryguidelines2010.pdf (modified from: http://www.choosemyplate.gov)

${ }^{\mathrm{b}}$ Recommended servings of dairy are determined by age

${ }^{\mathrm{c}}$ Recommended servings of fruits and vegetables are determined by age, sex, and level of physical activity
}

Amounts of 25(OH)D in foods currently are not included in the USDA food tables. Studies that have reported discrepancies between estimated vitamin $\mathrm{D}$ intakes and serum levels of $25(\mathrm{OH}) \mathrm{D}$ are driving the interest in determination of $25(\mathrm{OH}) \mathrm{D}$ in foods.

\section{Physical activity}

Regular physical activity in youth promotes healthier bones throughout childhood and adolescence. As part of the federally recommended $\geq 60$ min of daily physical activity, children and adolescents should include bone-strengthening physical activity at least 3 days of the week. Bone-strengthening activities are those that are dynamic, moderate to high in load magnitude, short in load duration, odd or nonrepetitive in load direction, and applied quickly [84, 326].

Although complete data are lacking, the IOM estimates that only about one half of youth meet the current HHS Physical Activity Guidelines for Americans' recommendation for $\geq 60 \mathrm{~min}$ of daily moderate-to-vigorous intensity physical activity. The number of youth meeting this recommendation decreases with age [327] and precipitously declines in early adolescence, a time when bone appears most responsive to physical activity. Throughout childhood and adolescence, girls are less active than boys and are clearly missing opportunities to optimize bone health. The US Centers for Disease Control and Prevention (CDC) reports that as many as one third of youth report no physical activity in the preceding 5 days [328]. Regrettably, participation in bone- strengthening physical activities is not measured in the CDC Youth Risk Behavior Surveillance System. Daily opportunities for incidental physical activity have declined for both children and adolescents as a result of factors such as increased reliance on nonactive transportation, automation of activities for daily living, and greater opportunities for sedentary behavior. Disparities in opportunities for physical activity exist across racial, ethnic, and socioeconomic profiles [327].

\section{Taking action}

A multilayered approach must be applied to achieving the recommendations of the Dietary and Physical Activity Guidelines for Americans.

\section{Families}

Adults must model and participate in healthy behaviors and engage with family members during mealtime and exercise. Government resources such as MyPlate and the Youth Physical Activity Guidelines Toolkit are informative resources for parents.

\section{Schools}

Schools must continue to improve and implement optimal nutrition standards through programs such as the National School Lunch Program and the National School Breakfast Program. Specific strategies for creating an optimal 


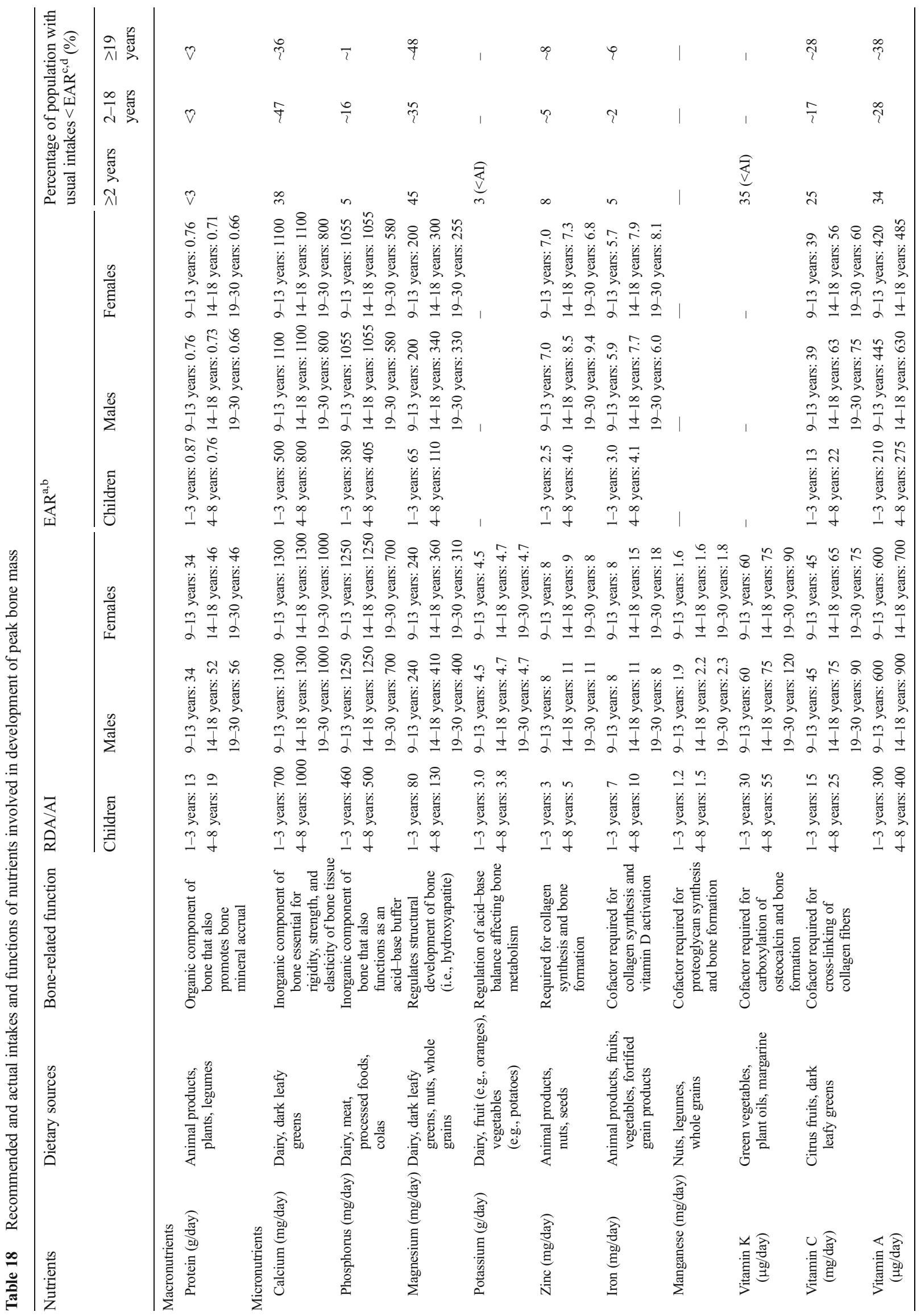




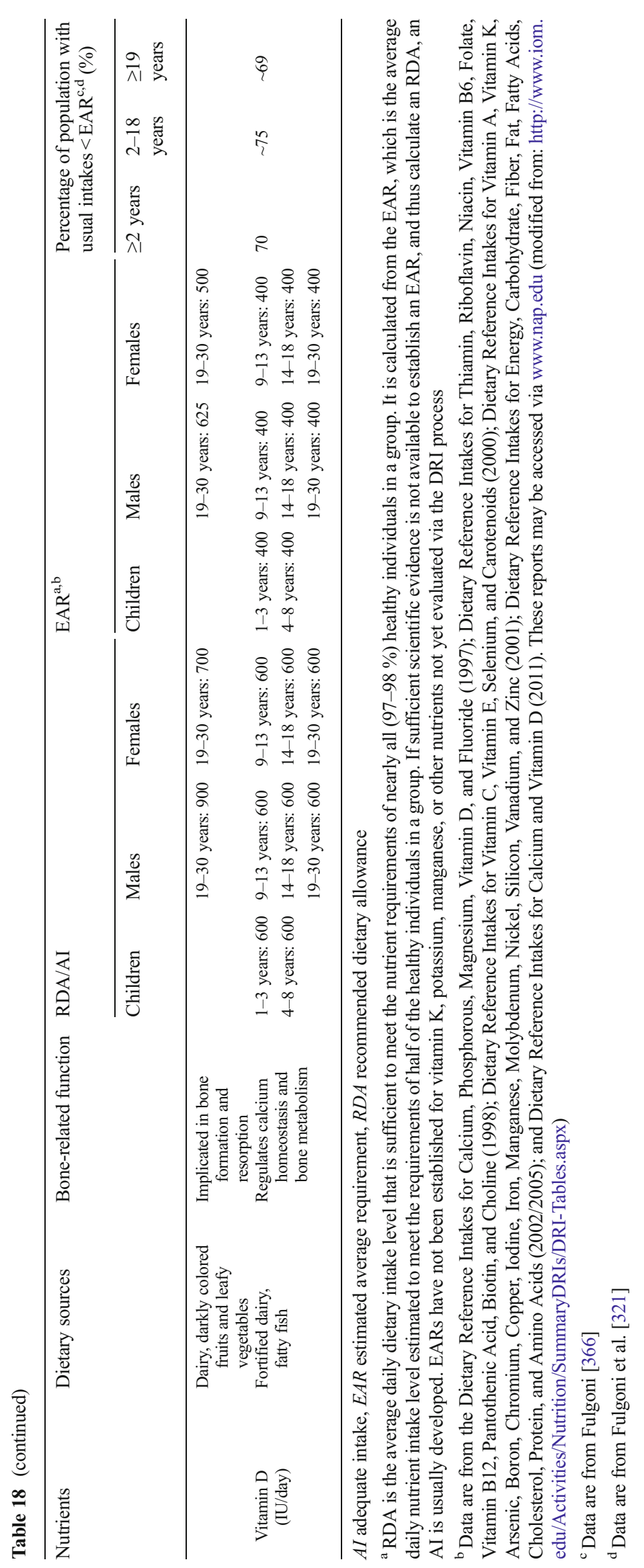


environment for inclusive physical education, extracurricular physical activities, and active classrooms are provided in the USA, most recently by the 2012 Physical Activity Guidelines for American's Midcourse Report: Strategies to Increase Physical Activity Among Youth [329] and the recent IOM report Educating the Student Body: Taking Physical Activity and Physical Education to School [327]. Early knowledge of nutrition and physical activity through consumer sciences and physical education courses should be mandatory in every $\mathrm{K}-$ 12 school. Recess should be mandatory for every K-5 school.

\section{Healthcare system}

All allied healthcare providers should be required to be proficient in both counseling for nutrition and physical activity through their required curriculum and continuing education. Scientific groups such as the National Osteoporosis Foundation, the American Society for Nutrition, the Academy of Nutrition and Dietetics, the American College of Sports Medicine, and the Society for Health and Physical Educators among others should provide tool kits and educational materials with consistent messaging on nutrition and physical activity for bone health to allied healthcare providers.

\section{Federal, state, and local policy}

Government support for healthy growth and development should reach beyond obesity to antecedents of chronic disease, including osteoporosis. Subsidizing foods for bone health through programs such as Head Start, the National School Breakfast Program, the National School Lunch Program, the Supplemental Nutrition Assistance Program, and the Special Supplemental Nutrition Program for Women, Infants, and Children helps to ensure that all children meet their nutrition requirements. Examples of how physical activity requirements are supported include the Federal Safe Routes to Schools Program and the Let's Move program, as well as public-private sector collaborations such as the NFL Play 60 Challenge and the Partnership for a Healthier America. Through zoning, incentives, and innovative cooperative agreements with businesses, local governments can help to ensure access to fresh food as well as parks and youth recreation opportunities. Expanding successful federal, state, and local nutrition and physical activity programs as well as facilitating innovative collaboration between the public and private sectors are critical to creating a society in which bone health matters.

\section{Conclusions}

There is a critical need for more research focusing on bone health in youth. Future research should consider sex, population ancestry, and maturation. When possible, standardizing

outcome measures would facilitate the pooling of data for evidence-based reviews.

The best evidence is available for positive effects of calcium intake and physical activity, especially during the late childhood and peripubertal years - a critical period for bone accretion. Good evidence is also available for a role of vitamin $\mathrm{D}$ and dairy consumption. However, more work is needed on physical activity dose response and the potential interaction between physical activity and diet quality. Weaker but physiologically plausible evidence is available and emerging for the effects of macronutrients and other micronutrients on bone among youth. It is important to address the factors most strongly linked to developing peak bone mass and strength from the current evidence through multilayered public health strategies. It is equally important to develop a research agenda to better understand other lifestyle factors that are less clearly understood for the purpose of building strong and healthy bones. Meanwhile, meeting federal guidelines for intakes of nutrients and physical activity while cautioning against harmful behaviors is a priority strategy.

\section{Glossary}

Terminology

Areal bone mineral density

Bone mineral content

Bone mineral density

Computed tomography

Cross-sectional moment of inertia

Dual-energy x-ray absorptiometry
Acronym Definition

aBMD DXA calculates BMD using area.

This is not an accurate measurement of the true bone mineral density, which is mass divided by volume. It is a reasonable estimate of BMC.

BMC DXA measures the BMC of the spine, hip, wrist, femur, or any other selected part of the skeleton. It does this by focusing an $\mathrm{x}$-ray on a body site and measuring the proportion of light rays that pass through the tissue as opposed to being blocked by minerals in the bone. Using computer software, it then divides that number by the surface area of the bone being measured to create BMD.

BMD BMD refers to the amount of mineral matter per square centimeter of bone. BMD is used as a predictor of osteoporosis and fracture risk.

CT CT is an imaging procedure that uses special x-ray equipment to create a series of detailed pictures, or scans, of areas inside the body. It is also called computerized tomography and computerized axial tomography (CAT) scanning.

CSMI CSMI is a measure of the distribution of material around a given axis. It is used to calculate bending stress.

DXA DXA is a means of measuring BMD. It is the most widely used and most 


\begin{tabular}{|c|c|c|}
\hline & & $\begin{array}{l}\text { thoroughly studied bone density } \\
\text { measurement technology. Two x- } \\
\text { ray beams with different energy } \\
\text { levels are aimed at the patient's } \\
\text { bones. When soft tissue absorption } \\
\text { is subtracted out, the BMD can be } \\
\text { determined from the absorption of } \\
\text { each beam by bone. }\end{array}$ \\
\hline Hip structural analysis & HSA & $\begin{array}{l}\text { HSA measures not only the BMD of } \\
\text { the hip bone but also structural } \\
\text { geometry of cross-sections travers- } \\
\text { ing the proximal femur at specific } \\
\text { locations. The bone mass image is } \\
\text { used directly from the DXA scan, } \\
\text { where pixel values are expressed in } \\
\text { areal mass }\left(\mathrm{g} / \mathrm{cm}^{2}\right) \text {. The method } \\
\text { employs the principle that a line of } \\
\text { pixel values across the bone axis } \\
\text { corresponds to a cut plane travers- } \\
\text { ing the bone at that location and } \\
\text { contains some of the information } \\
\text { about the cross-section. }\end{array}$ \\
\hline $\begin{array}{l}\text { Percentage of } \\
\text { undercarboxylated } \\
\text { osteocalcin }\end{array}$ & $\%$ ucOC & $\begin{array}{l}\text { \%ucOC is a measure of vitamin } \mathrm{K} \\
\text { status. Osteocalcin is a vitamin } \mathrm{K}- \\
\text { dependent protein produced by the } \\
\text { bone. The ratio of } \\
\text { undercarboxylated to carboxylated } \\
\text { or total osteocalcin has been } \\
\text { regarded as a marker of inadequate } \\
\text { vitamin K status. }\end{array}$ \\
\hline $\begin{array}{l}\text { Peripheral quantitative } \\
\text { computed } \\
\text { tomography }\end{array}$ & pQCT & $\begin{array}{l}\text { pQCT is a type of quantitative CT } \\
\text { used for making measurements of } \\
\text { the BMD in a peripheral part of the } \\
\text { body, such as the forearms or legs, } \\
\text { as opposed to CT that measures } \\
\text { BMD at the hip and spine. pQCT is } \\
\text { useful for measuring bone strength. }\end{array}$ \\
\hline Potential renal acid load & PRAL & $\begin{array}{l}\text { PRAL is a measure of the acidic or basic } \\
\text { effects that a food has on the body. }\end{array}$ \\
\hline $\begin{array}{l}\text { Quantitative computed } \\
\text { tomography }\end{array}$ & QCT & $\begin{array}{l}\text { QCT measures BMD using a standard } \\
\text { CT scanner with a calibration } \\
\text { standard to convert Hounsfield } \\
\text { units (HU) of the CT image to } \\
\text { BMD values. QCT scans are pri- } \\
\text { marily used to evaluate BMD at the } \\
\text { lumbar spine and hip. }\end{array}$ \\
\hline Stress-strain index & SSI & $\begin{array}{l}\text { The SSI of a bone is a surrogate } \\
\text { measure of bone strength } \\
\text { determined from a cross-sectional } \\
\text { scan by QCT or pQCT. The SSI is } \\
\text { used to compare the structural } \\
\text { parameters determined by analysis } \\
\text { of QCT/pQCT cross-sectional } \\
\text { scans to the results of a three-point } \\
\text { bending test. }\end{array}$ \\
\hline $\begin{array}{l}\text { Volumetric bone } \\
\text { mineral density }\end{array}$ & vBMD & $\begin{array}{l}\text { In addition to aBMD using DXA, a } \\
\text { projected posteroanterior lateral } \\
\text { vertebral scan is added to measure } \\
\text { vertebral width, height, and depth } \\
\text { to estimate vBMD. This permits } \\
\text { direct measurement of bone depth, } \\
\text { rather than estimation of projected } \\
\text { posteroanterior dimensions. }\end{array}$ \\
\hline
\end{tabular}

\section{Compliance with ethical standards}

Endorsing societies This scientific statement has been reviewed and endorsed by the following scientific societies:

American Bone Health

American College of Sports Medicine

Endocrine Society

National Osteoporosis Foundation

Society for Women's Health Research

Reviewers This scientific statement was reviewed in draft form by individuals chosen for their diverse perspectives and technical expertise. The purpose of this independent review is to provide candid and critical comments that will assist the National Osteoporosis Foundation in making this published report as sound as possible and to ensure that the report meets standards for both objectivity and evidence. We thank the following individuals for their peer review of this scientific statement:

Sue A. Shapses, PhD

Rutgers, The State University of New Jersey

Kimberly O'Brien, $\mathrm{PhD}$

Cornell University

Urszula T. Iwaniec, $\mathrm{PhD}$

Oregon State University

This scientific statement was peer reviewed by the National Osteoporosis Foundation Research Committee and Osteoporosis International. This scientific statement was approved by the National Osteoporosis Foundation Board of Directors.

Sources of financial support Funding for the manuscript was provided by the Alliance for Potato Research and the Dairy Research Institute.

Conflicts of interest TCW is employed by the National Osteoporosis Foundation. CMW, CMG, KFJ, HJK, JML, RL, MO, and BSZ have no disclosures.

Open Access This article is distributed under the terms of the Creative Commons Attribution-NonCommercial 4.0 International License (http:// creativecommons.org/licenses/by-nc/4.0/), which permits any noncommercial use, distribution, and reproduction in any medium, provided you give appropriate credit to the original author(s) and the source, provide a link to the Creative Commons license, and indicate if changes were made.

\section{References}

1. Heaney RP, Abrams S, Dawson-Hughes B, Looker A, Marcus R, Matkovic V, Weaver C (2000) Peak bone mass. Osteoporos Int 11: 985-1009

2. Parfitt AM (1994) The two faces of growth: benefits and risks to bone integrity. Osteoporos Int 4:382-398

3. Bailey DA, McKay HA, Mirwald RL, Crocker PR, Faulkner RA (1999) A six-year longitudinal study of the relationship of physical activity to bone mineral accrual in growing children: the University of Saskatchewan Bone Mineral Accrual Study. J Bone Miner Res 14:1672-1679

4. Baxter-Jones AD, Faulkner RA, Forwood MR, Mirwald RL, Bailey DA (2011) Bone mineral accrual from 8 to 30 years of age: an estimation of peak bone mass. J Bone Miner Res 26: 1729-1739 
5. Gilsanz V, Roe TF, Mora S, Costin G, Goodman WG (1991) Changes in vertebral bone density in black girls and white girls during childhood and puberty. N Engl J Med 325:1597-1600

6. Gilsanz V, Skaggs DL, Kovanlikaya A, Sayre J, Loro ML, Kaufman F, Korenman SG (1998) Differential effect of race on the axial and appendicular skeletons of children. J Clin Endocrinol Metab 83:1420-1427

7. Kirmani S, Christen D, van Lenthe GH, Fischer PR, Bouxsein ML, McCready LK, Melton LJ 3rd, Riggs BL, Amin S, Muller R, Khosla S (2009) Bone structure at the distal radius during adolescent growth. J Bone Miner Res 24:1033-1042

8. Wang Q, Wang XF, Iuliano-Burns S, Ghasem-Zadeh A, Zebaze R, Seeman E (2010) Rapid growth produces transient cortical weakness: a risk factor for metaphyseal fractures during puberty. J Bone Miner Res 25:1521-1526

9. Riggs BL, Melton LJ, Robb RA, Camp JJ, Atkinson EJ, McDaniel L, Amin S, Rouleau PA, Khosla S (2008) A population-based assessment of rates of bone loss at multiple skeletal sites: evidence for substantial trabecular bone loss in young adult women and men. J Bone Miner Res 23:205-214

10. Berger C, Goltzman D, Langsetmo L, Joseph L, Jackson S, Kreiger N, Tenenhouse A, Davison KS, Josse RG, Prior JC, Hanley DA (2010) Peak bone mass from longitudinal data: implications for the prevalence, pathophysiology, and diagnosis of osteoporosis. J Bone Miner Res 25:1948-1957

11. Kalkwarf HJ, Laor T, Bean JA (2011) Fracture risk in children with a forearm injury is associated with volumetric bone density and cortical area (by peripheral QCT) and areal bone density (by DXA). Osteoporos Int 22:607-616

12. World Health Organization (1994) Assessment of fracture risk and its application to screening for postmenopausal osteoporosis. Report Series 843. World Health Organization, Geneva

13. Holloway KL, Brennan SL, Kotowicz MA, Bucki-Smith G, Timney EN, Dobbins AG, Williams LJ, Pasco JA (2015) Prior fracture as a risk factor for future fracture in an Australian cohort. Osteoporos Int 26:629-635

14. Cooper C, Dennison EM, Leufkens HG, Bishop N, van Staa TP (2004) Epidemiology of childhood fractures in Britain: a study using the general practice research database. J Bone Miner Res 19:1976-1981

15. Landin LA (1983) Fracture patterns in children. Analysis of 8,682 fractures with special reference to incidence, etiology and secular changes in a Swedish urban population 1950-1979. Acta Orthop Scand Suppl 202:1-109

16. Mayranpaa MK, Makitie O, Kallio PE (2010) Decreasing incidence and changing pattern of childhood fractures: a populationbased study. J Bone Miner Res 25:2752-2759

17. Yeh FJ, Grant AM, Williams SM, Goulding A (2006) Children who experience their first fracture at a young age have high rates of fracture. Osteoporos Int 17:267-272

18. de Putter CE, van Beeck EF, Looman CW, Toet H, Hovius SE, Selles RW (2011) Trends in wrist fractures in children and adolescents, 1997-2009. J Hand Surg [Am] 36:1810-1815.e1812

19. Jones G, Boon P (2008) Which bone mass measures discriminate adolescents who have fractured from those who have not? Osteoporos Int 19:251-255

20. Lyons RA, Delahunty AM, Kraus D, Heaven M, McCabe M, Allen H, Nash P (1999) Children's fractures: a population based study. Inj Prev 5:129-132

21. Clark EM, Ness AR, Tobias JH (2008) Vigorous physical activity increases fracture risk in children irrespective of bone mass: a prospective study of the independent risk factors for fractures in healthy children. J Bone Miner Res 23:1012-1022

22. Baxter-Jones AD, Kontulainen SA, Faulkner RA, Bailey DA (2008) A longitudinal study of the relationship of physical activity to bone mineral accrual from adolescence to young adulthood. Bone 43:1101-1107

23. Detter FT, Rosengren BE, Dencker M, Nilsson JA, Karlsson MK (2013) A 5-year exercise program in pre- and peripubertal children improves bone mass and bone size without affecting fracture risk. Calcif Tissue Int 92:385-393

24. Gunter K, Baxter-Jones AD, Mirwald RL, Almstedt H, Fuchs RK, Durski S, Snow C (2008) Impact exercise increases BMC during growth: an 8-year longitudinal study. J Bone Miner Res 23:986993

25. Macdonald HM, Kontulainen SA, Khan KM, McKay HA (2007) Is a school-based physical activity intervention effective for increasing tibial bone strength in boys and girls? J Bone Miner Res 22:434-446

26. Mackelvie KJ, McKay HA, Khan KM, Crocker PR (2001) A school-based exercise intervention augments bone mineral accrual in early pubertal girls. J Pediatr 139:501-508

27. Slemenda CW, Miller JZ, Hui SL, Reister TK, Johnston CCJ (1991) Role of physical activity in the development of skeletal mass in children. J Bone Miner Res 6:1227-1233

28. Lofgren B, Dencker M, Nilsson JA, Karlsson MK (2012) A 4-year exercise program in children increases bone mass without increasing fracture risk. Pediatrics 129:e1468-e1476

29. Khosla S, Melton LJ 3rd, Dekutoski MB, Achenbach SJ, Oberg AL, Riggs BL (2003) Incidence of childhood distal forearm fractures over 30 years: a population-based study. JAMA 290:14791485

30. Kelsey JL, Browner WS, Seeley DG, Nevitt MC, Cummings SR (1992) Risk factors for fractures of the distal forearm and proximal humerus. The Study of Osteoporotic Fractures Research Group. Am J Epidemiol 135:477-489

31. Clark EM, Ness AR, Bishop NJ, Tobias JH (2006) Association between bone mass and fractures in children: a prospective cohort study. J Bone Miner Res 21:1489-1495

32. Kalkwarf HJ, Gilsanz V, Lappe JM, Oberfield S, Shepherd JA, Hangartner TN, Huang X, Frederick MM, Winer KK, Zemel BS (2010) Tracking of bone mass and density during childhood and adolescence. J Clin Endocrinol Metab 95:1690-1698

33. Bowden LS, Jones CJ, Ryan SW (1999) Bone mineralisation in ex-preterm infants aged 8 years. Eur J Pediatr 158:658-661

34. Dennison EM, Syddall HE, Sayer AA, Gilbody HJ, Cooper C (2005) Birth weight and weight at 1 year are independent determinants of bone mass in the seventh decade: the Hertfordshire cohort study. Pediatr Res 57:582-586

35. Farr JN, Amin S, Melton LJ 3rd, Kirmani S, McCready LK, Atkinson EJ, Muller R, Khosla S (2014) Bone strength and structural deficits in children and adolescents with a distal forearm fracture resulting from mild trauma. J Bone Miner Res 29:590599

36. Thandrayen K, Norris SA, Pettifor JM (2009) Fracture rates in urban South African children of different ethnic origins: the Birth to Twenty cohort. Osteoporos Int 20:47-52

37. Wren TA, Shepherd JA, Kalkwarf HJ, Zemel BS, Lappe JM, Oberfield S, Dorey FJ, Winer KK, Gilsanz V (2012) Racial disparity in fracture risk between white and nonwhite children in the United States. J Pediatr 161:1035-1040

38. Cauley JA, Lui LY, Ensrud KE, Zmuda JM, Stone KL, Hochberg MC, Cummings SR (2005) Bone mineral density and the risk of incident nonspinal fractures in black and white women. JAMA 293:2102-2108

39. Shin MH, Zmuda JM, Barrett-Connor E, Sheu Y, Patrick AL, Leung PC, Kwok A, Kweon SS, Nam HS, Cauley JA (2014) Race/ethnic differences in associations between bone mineral density and fracture history in older men. Osteoporos Int 25:837-845 
40. Loud KJ, Gordon CM, Micheli LJ, Field AE (2005) Correlates of stress fractures among preadolescent and adolescent girls. Pediatrics 115:e399-e406

41. Hame SL, LaFemina JM, McAllister DR, Schaadt GW, Dorey FJ (2004) Fractures in the collegiate athlete. Am J Sports Med 32: 446-451

42. Lappe JM, Stegman MR, Recker RR (2001) The impact of lifestyle factors on stress fractures in female army recruits. Osteoporos Int 12:35-42

43. Mattila VM, Niva M, Kiuru M, Pihlajamaki H (2007) Risk factors for bone stress injuries: a follow-up study of 102,515 personyears. Med Sci Sports Exerc 39:1061-1066

44. Cosman F, Ruffing J, Zion M, Uhorchak J, Ralston S, Tendy S, McGuigan FE, Lindsay R, Nieves J (2013) Determinants of stress fracture risk in United States Military Academy cadets. Bone 55: 359-366

45. Wentz L, Liu PY, Haymes E, Ilich JZ (2011) Females have a greater incidence of stress fractures than males in both military and athletic populations: a systemic review. Mil Med 176:420 430

46. Knapik J, Montain SJ, McGraw S, Grier T, Ely M, Jones BH (2012) Stress fracture risk factors in basic combat training. Int J Sports Med 33:940-946

47. Friedl KE, Evans RK, Moran DS (2008) Stress fracture and military medical readiness: bridging basic and applied research. Med Sci Sports Exerc 40:S609-S622

48. Gam A, Goldstein L, Karmon Y, Mintser I, Grotto I, Guri A, Goldberg A, Ohana N, Onn E, Levi Y, Bar-Dayan Y (2005) Comparison of stress fractures of male and female recruits during basic training in the Israeli anti-aircraft forces. Mil Med 170:710 712

49. Lappe J, Davies K, Recker R, Heaney R (2005) Quantitative ultrasound: use in screening for susceptibility to stress fractures in female army recruits. J Bone Miner Res 20:571-578

50. Field AE, Gordon CM, Pierce LM, Ramappa A, Kocher MS (2011) Prospective study of physical activity and risk of developing a stress fracture among preadolescent and adolescent girls. Arch Pediatr Adolesc Med 165:723-728

51. Loud KJ, Micheli LJ, Bristol S, Austin SB, Gordon CM (2007) Family history predicts stress fracture in active female adolescents. Pediatrics 120:e364-e372

52. Friedl KE, Nuovo JA, Patience TH, Dettori JR (1992) Factors associated with stress fracture in young army women: indications for further research. Mil Med 157:334-338

53. Budek AZ, Mark T, Michaelsen KF, Molgaard C (2010) Tracking of size-adjusted bone mineral content and bone area in boys and girls from 10 to 17 years of age. Osteoporos Int 21:179-182

54. Cheng S, Volgyi E, Tylavsky FA, Lyytikainen A, Tormakangas T, Xu L, Cheng SM, Kroger H, Alen M, Kujala UM (2009) Trait-specific tracking and determinants of body composition: a 7-year follow-up study of pubertal growth in girls. BMC Med 7:5

55. Foley S, Quinn S, Jones G (2009) Tracking of bone mass from childhood to adolescence and factors that predict deviation from tracking. Bone 44:752-757

56. Fujita Y, Iki M, Ikeda Y, Morita A, Matsukura T, Nishino H, Yamagami T, Kagamimori S, Kagawa Y, Yoneshima H (2011) Tracking of appendicular bone mineral density for 6 years including the pubertal growth spurt: Japanese population-based osteoporosis kids cohort study. J Bone Miner Metab 29:208-216

57. Wren TA, Kalkwarf HJ, Zemel BS, Lappe JM, Oberfield S, Shepherd JA, Winer KK, Gilsanz V (2014) Longitudinal tracking of dual-energy X-ray absorptiometry bone measures over 6 years in children and adolescents: persistence of low bone mass to maturity. J Pediatr 164:1280-1285.e1282
58. Lorentzon M, Mellstrom D, Ohlsson C (2005) Age of attainment of peak bone mass is site specific in Swedish men - the GOOD study. J Bone Miner Res 20:1223-1227

59. Thomas SR, Kalkwarf HJ, Buckley DD, Heubi JE (2005) Effective dose of dual-energy X-ray absorptiometry scans in children as a function of age. J Clin Densitom 8:415-422

60. Crabtree NJ, Arabi A, Bachrach LK, Fewtrell M, El-Hajj Fuleihan G, Kecskemethy HH, Jaworski M, Gordon CM (2014) Dualenergy X-ray absorptiometry interpretation and reporting in children and adolescents: the revised 2013 ISCD Pediatric Official Positions. J Clin Densitom 17:225-242

61. Zemel BS, Leonard MB, Kelly A, Lappe JM, Gilsanz V, Oberfield S, Mahboubi S, Shepherd JA, Hangartner TN, Frederick MM, Winer KK, Kalkwarf HJ (2010) Height adjustment in assessing dual energy $\mathrm{x}$-ray absorptiometry measurements of bone mass and density in children. J Clin Endocrinol Metab 95:1265-1273

62. Wren TA, Liu X, Pitukcheewanont P, Gilsanz V (2005) Bone acquisition in healthy children and adolescents: comparisons of dual-energy $\mathrm{x}$-ray absorptiometry and computed tomography measures. J Clin Endocrinol Metab 90:1925-1928

63. Prentice A, Parsons TJ, Cole TJ (1994) Uncritical use of bone mineral density in absorptiometry may lead to size-related artifacts in the identification of bone mineral determinants. Am J Clin Nutr 60:837-842

64. Molgaard C, Thomsen BL, Prentice A, Cole TJ, Michaelsen KF (1997) Whole body bone mineral content in healthy children and adolescents. Arch Dis Child 76:9-15

65. Hogler W, Briody J, Woodhead HJ, Chan A, Cowell CT (2003) Importance of lean mass in the interpretation of total body densitometry in children and adolescents. J Pediatr 143:81-88

66. Crabtree NJ, Kibirige MS, Fordham JN, Banks LM, Muntoni F, Chinn D, Boivin CM, Shaw NJ (2004) The relationship between lean body mass and bone mineral content in paediatric health and disease. Bone 35:965-972

67. Short DF, Zemel BS, Gilsanz V, Kalkwarf HJ, Lappe JM, Mahboubi S, Oberfield SE, Shepherd JA, Winer KK, Hangartner TN (2011) Fitting of bone mineral density with consideration of anthropometric parameters. Osteoporos Int 22:10471057

68. Horlick M, Wang J, Pierson RNJ, Thornton JC (2004) Prediction models for evaluation of total-body bone mass with dual-energy $\mathrm{X}$-ray absorptiometry among children and adolescents. Pediatrics 114:e33-e45

69. Crabtree NJ, Hogler W, Cooper MS, Shaw NJ (2013) Diagnostic evaluation of bone densitometric size adjustment techniques in children with and without low trauma fractures. Osteoporos Int 24:2015-2024

70. Beck TJ, Ruff CB, Warden KE, Scott WWJ, Rao GU (1990) Predicting femoral neck strength from bone mineral data. A structural approach. Invest Radiol 25:6-18

71. Beck TJ, Stone KL, Oreskovic TL, Hochberg MC, Nevitt MC, Genant HK, Cummings SR (2001) Effects of current and discontinued estrogen replacement therapy on hip structural geometry: the study of osteoporotic fractures. J Bone Miner Res 16 : 2103-2110

72. Burnham JM, Shults J, Petit MA, Semeao E, Beck TJ, Zemel BS, Leonard MB (2007) Alterations in proximal femur geometry in children treated with glucocorticoids for Crohn disease or nephrotic syndrome: impact of the underlying disease. J Bone Miner Res 22:551-559

73. Petit MA, McKay HA, MacKelvie KJ, Heinonen A, Khan KM, Beck TJ (2002) A randomized school-based jumping intervention confers site and maturity-specific benefits on bone structural properties in girls: a hip structural analysis study. J Bone Miner Res 17: 363-372 
74. Adams JE, Engelke K, Zemel BS, Ward KA (2014) Quantitative computer tomography in children and adolescents: the 2013 ISCD Pediatric Official Positions. J Clin Densitom 17:258-274

75. Caspersen CJ, Powell KE, Christenson GM (1985) Physical activity, exercise, and physical fitness: definitions and distinctions for health-related research. Public Health Rep 100:126-131

76. Bouchard C, Blair SN, Haskell W (eds) (2006) Physical activity and health. Human Kinetics, Champaign

77. Frost HM, Schonau E (2000) The "muscle-bone unit" in children and adolescents: a 2000 overview. J Pediatr Endocrinol Metab 13: $571-590$

78. Frost HM (2003) Bone's mechanostat: a 2003 update. Anat Rec A: Discov Mol Cell Evol Biol 275:1081-1101

79. Kannus P, Haapasalo H, Sankelo M, Sievanen H, Pasanen M, Heinonen A, Oja P, Vuori I (1995) Effect of starting age of physical activity on bone mass in the dominant arm of tennis and squash players. Ann Intern Med 123:27-31

80. Welten DC, Kemper HC, Post GB, Van Mechelen W, Twisk J, Lips P, Teule GJ (1994) Weight-bearing activity during youth is a more important factor for peak bone mass than calcium intake. $\mathrm{J}$ Bone Miner Res 9:1089-1096

81. Specker B, Binkley T (2003) Randomized trial of physical activity and calcium supplementation on bone mineral content in 3- to 5year-old children. J Bone Miner Res 18:885-892

82. Turner CH, Forwood MR, Rho JY, Yoshikawa T (1994) Mechanical loading thresholds for lamellar and woven bone formation. J Bone Miner Res 9:87-97

83. Forwood MR, Turner CH (1995) Skeletal adaptations to mechanical usage: results from tibial loading studies in rats. Bone 17: 197S-205S

84. Turner CH, Robling AG (2003) Designing exercise regimens to increase bone strength. Exerc Sport Sci Rev 31:45-50

85. Baptista F, Janz K (2012) Physical activity, bone growth, and development in children and adolescents: a public health perspective. In: Preedy VR (ed) Handbook of growth and growth monitoring in health and disease. Springer, New York, pp 2395-2411

86. Khan K, McKay HA, Haapasalo H, Bennell KL, Forwood MR, Kannus P, Wark JD (2000) Does childhood and adolescence provide a unique opportunity for exercise to strengthen the skeleton? J Sci Med Sport 3:150-164

87. Duncan RL, Turner CH (1995) Mechanotransduction and the functional response of bone to mechanical strain. Calcif Tissue Int 57:344-358

88. Robling AG, Hinant FM, Burr DB, Turner CH (2002) Improved bone structure and strength after long-term mechanical loading is greatest if loading is separated into short bouts. J Bone Miner Res 17:1545-1554

89. Ackerman A, Thornton JC, Wang J, Pierson RNJ, Horlick M (2006) Sex difference in the effect of puberty on the relationship between fat mass and bone mass in 926 healthy subjects, 6 to 18 years old. Obesity (Silver Spring) 14:819-825

90. Arabi A, Tamim H, Nabulsi M, Maalouf J, Khalife H, Choucair M, Vieth R, El-Hajj Fuleihan G (2004) Sex differences in the effect of body-composition variables on bone mass in healthy children and adolescents. Am J Clin Nutr 80:1428-1435

91. Ausili E, Rigante D, Salvaggio E, Focarelli B, Rendeli C, Ansuini V, Paolucci V, Triarico S, Martini L, Caradonna P (2012) Determinants of bone mineral density, bone mineral content, and body composition in a cohort of healthy children: influence of sex, age, puberty, and physical activity. Rheumatol Int 32:2737-2743

92. Pietrobelli A, Faith MS, Wang J, Brambilla P, Chiumello G, Heymsfield SB (2002) Association of lean tissue and fat mass with bone mineral content in children and adolescents. Obes Res 10:56-60

93. Jackowski SA, Faulkner RA, Farthing JP, Kontulainen SA, Beck TJ, Baxter-Jones AD (2009) Peak lean tissue mass accrual precedes changes in bone strength indices at the proximal femur during the pubertal growth spurt. Bone 44:1186-1190

94. Xu L, Nicholson P, Wang Q, Alen M, Cheng S (2009) Bone and muscle development during puberty in girls: a seven-year longitudinal study. J Bone Miner Res 24:1693-1698

95. Ashby RL, Adams JE, Roberts SA, Mughal MZ, Ward KA (2011) The muscle-bone unit of peripheral and central skeletal sites in children and young adults. Osteoporos Int 22:121-132

96. Cardel M, Higgins PB, Willig AL, Keita AD, Casazza K, Gower BA, Fernandez JR (2011) African genetic admixture is associated with body composition and fat distribution in a cross-sectional study of children. Int J Obes (Lond) 35:60-65

97. Seeman E, Hopper JL, Bach LA, Cooper ME, Parkinson E, McKay J, Jerums G (1989) Reduced bone mass in daughters of women with osteoporosis. N Engl J Med 320:554-558

98. Soroko SB, Barrett-Connor E, Edelstein SL, Kritz-Silverstein D (1994) Family history of osteoporosis and bone mineral density at the axial skeleton: the Rancho Bernardo Study. J Bone Miner Res 9:761-769

99. Ferrari S, Rizzoli R, Slosman D, Bonjour JP (1998) Familial resemblance for bone mineral mass is expressed before puberty. $\mathrm{J}$ Clin Endocrinol Metab 83:358-361

100. Duren DL, Sherwood RJ, Choh AC, Czerwinski SA, Chumlea WC, Lee M, Sun SS, Demerath EW, Siervogel RM, Towne B (2007) Quantitative genetics of cortical bone mass in healthy 10year-old children from the Fels Longitudinal Study. Bone 40:464 470

101. Estrada K, Styrkarsdottir U, Evangelou E, Hsu YH, Duncan EL, Ntzani EE, Oei L, Albagha OM, Amin N, Kemp JP, Koller DL, Li G, Liu CT, Minster RL, Moayyeri A, Vandenput L, Willner D, Xiao SM, Yerges-Armstrong LM, Zheng HF, Alonso N, Eriksson J, Kammerer CM, Kaptoge SK, Leo PJ, Thorleifsson G, Wilson SG, Wilson JF, Aalto V, Alen M, Aragaki AK, Aspelund T, Center JR, Dailiana Z, Duggan DJ, Garcia M, Garcia-Giralt N, Giroux S, Hallmans G, Hocking LJ, Husted LB, Jameson KA, Khusainova R, Kim GS, Kooperberg C, Koromila T, Kruk M, Laaksonen M, Lacroix AZ, Lee SH, Leung PC, Lewis JR, Masi L, MencejBedrac S, Nguyen TV, Nogues X, Patel MS, Prezelj J, Rose LM, Scollen S, Siggeirsdottir K, Smith AV, Svensson O, Trompet S, Trummer O, van Schoor NM, Woo J, Zhu K, Balcells S, Brandi ML, Buckley BM, Cheng S, Christiansen C, Cooper C, Dedoussis G, Ford I, Frost M, Goltzman D, Gonzalez-Macias J, Kahonen M, Karlsson M, Khusnutdinova E, Koh JM, Kollia P, Langdahl BL, Leslie WD, Lips P, Ljunggren O, Lorenc RS, Marc J, Mellstrom D, Obermayer-Pietsch B, Olmos JM, Pettersson-Kymmer U, Reid DM, Riancho JA, Ridker PM, Rousseau F, Slagboom PE, Tang NL, Urreizti R, Van Hul W, Viikari J, Zarrabeitia MT, Aulchenko YS, Castano-Betancourt M, Grundberg E, Herrera L, Ingvarsson T, Johannsdottir H, Kwan T, Li R, Luben R, Medina-Gomez C, Palsson ST, Reppe S, Rotter JI, Sigurdsson G, van Meurs JB, Verlaan D, Williams FM, Wood AR, Zhou Y, Gautvik KM, Pastinen T, Raychaudhuri S, Cauley JA, Chasman DI, Clark GR, Cummings SR, Danoy P, Dennison EM, Eastell R, Eisman JA, Gudnason V, Hofman A, Jackson RD, Jones G, Jukema JW, Khaw KT, Lehtimaki T, Liu Y, Lorentzon M, McCloskey E, Mitchell BD, Nandakumar K, Nicholson GC, Oostra BA, Peacock M, Pols HA, Prince RL, Raitakari O, Reid IR, Robbins J, Sambrook PN, Sham PC, Shuldiner AR, Tylavsky FA, van Duijn CM, Wareham NJ, Cupples LA, Econs MJ, Evans DM, Harris TB, Kung AW, Psaty BM, Reeve J, Spector TD, Streeten EA, Zillikens MC, Thorsteinsdottir U, Ohlsson C, Karasik D, Richards JB, Brown MA, Stefansson K, Uitterlinden AG, Ralston SH, Ioannidis JP, Kiel DP, Rivadeneira F (2012) Genome-wide meta-analysis identifies 56 bone mineral density loci and reveals 14 loci associated with risk of fracture. Nat Genet 44:491-501 
102. Zheng HF, Tobias JH, Duncan E, Evans DM, Eriksson J, Paternoster L, Yerges-Armstrong LM, Lehtimaki T, Bergstrom U, Kahonen M, Leo PJ, Raitakari O, Laaksonen M, Nicholson GC, Viikari J, Ladouceur M, Lyytikainen LP, Medina-Gomez C, Rivadeneira F, Prince RL, Sievanen H, Leslie WD, Mellstrom D, Eisman JA, Moverare-Skrtic S, Goltzman D, Hanley DA, Jones G, St Pourcain B, Xiao Y, Timpson NJ, Smith GD, Reid IR, Ring SM, Sambrook PN, Karlsson M, Dennison EM, Kemp JP, Danoy P, Sayers A, Wilson SG, Nethander M, McCloskey E, Vandenput L, Eastell R, Liu J, Spector T, Mitchell BD, Streeten EA, Brommage R, Pettersson-Kymmer U, Brown MA, Ohlsson C, Richards JB, Lorentzon M (2012) WNT16 influences bone mineral density, cortical bone thickness, bone strength, and osteoporotic fracture risk. PLoS Genet 8:e1002745

103. Mora S, Gilsanz V (2003) Establishment of peak bone mass. Endocrinol Metab Clin North Am 32:39-63

104. Krall EA, Dawson-Hughes B (1993) Heritable and life-style determinants of bone mineral density. J Bone Miner Res 8:1-9

105. Chevalley T, Rizzoli R, Hans D, Ferrari S, Bonjour JP (2005) Interaction between calcium intake and menarcheal age on bone mass gain: an eight-year follow-up study from prepuberty to postmenarche. J Clin Endocrinol Metab 90:44-51

106. Timpson NJ, Tobias JH, Richards JB, Soranzo N, Duncan EL, Sims AM, Whittaker P, Kumanduri V, Zhai G, Glaser B, Eisman J, Jones G, Nicholson G, Prince R, Seeman E, Spector TD, Brown MA, Peltonen L, Smith GD, Deloukas P, Evans DM (2009) Common variants in the region around Osterix are associated with bone mineral density and growth in childhood. Hum Mol Genet 18:1510-1517

107. Gueguen R, Jouanny P, Guillemin F, Kuntz C, Pourel J, Siest G (1995) Segregation analysis and variance components analysis of bone mineral density in healthy families. J Bone Miner Res 10: 2017-2022

108. McCormick DP, Ponder SW, Fawcett HD, Palmer JL (1991) Spinal bone mineral density in 335 normal and obese children and adolescents: evidence for ethnic and sex differences. J Bone Miner Res 6:507-513

109. Bachrach LK, Hastie T, Wang MC, Narasimhan B, Marcus R (1999) Bone mineral acquisition in healthy Asian, Hispanic, black, and Caucasian youth: a longitudinal study. J Clin Endocrinol Metab 84:4702-4712

110. Bhudhikanok GS, Wang MC, Eckert K, Matkin C, Marcus R, Bachrach LK (1996) Differences in bone mineral in young Asian and Caucasian Americans may reflect differences in bone size. J Bone Miner Res 11:1545-1556

111. Armstrong GT, Chow EJ, Sklar CA (2009) Alterations in pubertal timing following therapy for childhood malignancies. Endocr Dev 15:25-39

112. Weaver CM, McCabe LD, McCabe GP, Novotny R, Van Loan M, Going S, Matkovic V, Boushey C, Savaiano DA (2007) Bone mineral and predictors of bone mass in white, Hispanic, and Asian early pubertal girls. Calcif Tissue Int 81:352-363

113. Gilsanz V, Kovanlikaya A, Costin G, Roe TF, Sayre J, Kaufman F (1997) Differential effect of gender on the sizes of the bones in the axial and appendicular skeletons. J Clin Endocrinol Metab 82: $1603-1607$

114. Gilsanz V (1998) Bone density in children: a review of the available techniques and indications. Eur J Radiol 26:177-182

115. Leonard MB, Elmi A, Mostoufi-Moab S, Shults J, Burnham JM, Thayu M, Kibe L, Wetzsteon RJ, Zemel BS (2010) Effects of sex, race, and puberty on cortical bone and the functional muscle bone unit in children, adolescents, and young adults. J Clin Endocrinol Metab 95:1681-1689

116. Ellis KJ (1997) Body composition of a young, multiethnic, male population. Am J Clin Nutr 66:1323-1331
117. Ellis KJ, Abrams SA, Wong WW (1997) Body composition of a young, muiltiethnic female population. Am J Clin Nutr 65:724 731

118. Kalkwarf HJ, Zemel BS, Gilsanz V, Lappe JM, Horlick M, Oberfield S, Mahboubi S, Fan B, Frederick MM, Winer K, Shepherd JA (2007) The bone mineral density in childhood study: bone mineral content and density according to age, sex, and race. J Clin Endocrinol Metab 92:2087-2099

119. Hammami M, Koo WW, Hockman EM (2003) Body composition of neonates from fan beam dual energy X-ray absorptiometry measurement. JPEN J Parenter Enteral Nutr 27:423-426

120. Koo WW, Bush AJ, Walters J, Carlson SE (1998) Postnatal development of bone mineral status during infancy. J Am Coll Nutr 17:65-70

121. Kurl S, Heinonen K, Jurvelin JS, Lansimies E (2002) Lumbar bone mineral content and density measured using a Lunar DPX densitometer in healthy full-term infants during the first year of life. Clin Physiol Func Imaging 22:222-225

122. Unal A, Gur E, Arvas A, Erginel A, AlikasifoAglu M, Ilter O (2000) Bone density values in healthy Turkish infants. Indian Pediatr 37:497-503

123. Rupich RC, Specker BL, Lieuw AFM, Ho M (1996) Gender and race differences in bone mass during infancy. Calcif Tissue Int 58: 395-397

124. Willing MC, Torner JC, Burns TL, Janz KF, Marshall TA, Gilmore J, Warren JJ, Levy SM (2005) Percentile distributions of bone measurements in Iowa children: the Iowa Bone Development Study. J Clin Densitom 8:39-47

125. Kontulainen SA, Macdonald HM, Khan KM, McKay HA (2005) Examining bone surfaces across puberty: a 20-month pQCT trial. J Bone Miner Res 20:1202-1207

126. Macdonald H, Kontulainen S, Petit M, Janssen P, McKay H (2006) Bone strength and its determinants in pre- and early pubertal boys and girls. Bone 39:598-608

127. Nishiyama KK, Macdonald HM, Moore SA, Fung T, Boyd SK, McKay HA (2012) Cortical porosity is higher in boys compared with girls at the distal radius and distal tibia during pubertal growth: an HR-pQCT study. J Bone Miner Res 27:273-282

128. Gilsanz V, Chalfant J, Kalkwarf H, Zemel B, Lappe J, Oberfield S, Shepherd J, Wren T, Winer K (2011) Age at onset of puberty predicts bone mass in young adulthood. J Pediatr 158:100-105, 105 e101-102

129. Chevalley T, Bonjour JP, Ferrari S, Rizzoli R (2009) The influence of pubertal timing on bone mass acquisition: a predetermined trajectory detectable five years before menarche. J Clin Endocrinol Metab 94:3424-3431

130. Jackowski SA, Erlandson MC, Mirwald RL, Faulkner RA, Bailey DA, Kontulainen SA, Cooper DM, Baxter-Jones AD (2011) Effect of maturational timing on bone mineral content accrual from childhood to adulthood: evidence from 15 years of longitudinal data. Bone 48:1178-1185

131. Darelid A, Ohlsson C, Nilsson M, Kindblom JM, Mellstrom D, Lorentzon M (2012) Catch up in bone acquisition in young adult men with late normal puberty. J Bone Miner Res 27:2198-2207

132. Nikander R, Sievanen H, Heinonen A, Daly RM, Uusi-Rasi K, Kannus P (2010) Targeted exercise against osteoporosis: a systematic review and meta-analysis for optimising bone strength throughout life. BMC Med 8:47

133. Ishikawa S, Kim Y, Kang M, Morgan DW (2013) Effects of weight-bearing exercise on bone health in girls: a meta-analysis. Sports Med 43:875-892

134. Burt LA, Greene DA, Ducher G, Naughton GA (2013) Skeletal adaptations associated with pre-pubertal gymnastics participation as determined by DXA and pQCT: a systematic review and metaanalysis. J Sci Med Sport 16:231-239 
135. Behringer M, Gruetzner S, McCourt M, Mester J (2014) Effects of weight-bearing activities on bone mineral content and density in children and adolescents: a meta-analysis. J Bone Miner Res 29: $467-478$

136. Nogueira RC, Weeks BK, Beck BR (2014) Exercise to improve pediatric bone and fat: a systematic review and meta-analysis. Med Sci Sports Exerc 46:610-621

137. Tan VP, Macdonald HM, Kim S, Nettlefold L, Gabel L, Ashe MC, McKay HA (2014) Influence of physical activity on bone strength in children and adolescents: a systematic review and narrative synthesis. J Bone Miner Res 29:2161-2181

138. Cho SS, Qi L, Fahey GCJ, Klurfeld DM (2013) Consumption of cereal fiber, mixtures of whole grains and bran, and whole grains and risk reduction in type 2 diabetes, obesity, and cardiovascular disease. Am J Clin Nutr 98:594-619

139. American Diabetes Association (2012) Introduction: the American Diabetes Association's (ADA) evidence-based practice guidelines, standards, and related recommendations and documents for diabetes care. Diabetes Care 35:S1-S2

140. Woolf SH (2006) Weighing the evidence to formulate dietary guidelines. J Am Coll Nutr 25:277S-284S

141. Hogstrom M, Nordstrom P, Nordstrom A (2007) n-3 Fatty acids are positively associated with peak bone mineral density and bone accrual in healthy men: the NO2 Study. Am J Clin Nutr 85:803807

142. Eriksson S, Mellstrom D, Strandvik B (2009) Fatty acid pattern in serum is associated with bone mineralisation in healthy 8 -year-old children. Br J Nutr 102:407-412

143. Ballard TL, Specker BL, Binkley TL, Vukovich MD (2006) Effect of protein supplementation during a 6-month strength and conditioning program on areal and volumetric bone parameters. Bone 38:898-904

144. Alexy U, Remer T, Manz F, Neu CM, Schoenau E (2005) Longterm protein intake and dietary potential renal acid load are associated with bone modeling and remodeling at the proximal radius in healthy children. Am J Clin Nutr 82:1107-1114

145. Remer T, Manz F, Alexy U, Schoenau E, Wudy SA, Shi L (2011) Long-term high urinary potential renal acid load and low nitrogen excretion predict reduced diaphyseal bone mass and bone size in children. J Clin Endocrinol Metab 96:2861-2868

146. Bounds W, Skinner J, Carruth BR, Ziegler P (2005) The relationship of dietary and lifestyle factors to bone mineral indexes in children. J Am Diet Assoc 105:735-741

147. Vatanparast H, Bailey DA, Baxter-Jones AD, Whiting SJ (2007) The effects of dietary protein on bone mineral mass in young adults may be modulated by adolescent calcium intake. J Nutr 137:2674-2679

148. Zhang Q, Ma G, Greenfield H, Zhu K, Du X, Foo LH, Hu X, Fraser DR (2010) The association between dietary protein intake and bone mass accretion in pubertal girls with low calcium intakes. Br J Nutr 103:714-723

149. Hoppe C, Molgaard C, Michaelsen KF (2000) Bone size and bone mass in 10-year-old Danish children: effect of current diet. Osteoporos Int 11:1024-1030

150. Iuliano-Burns S, Stone J, Hopper JL, Seeman E (2005) Diet and exercise during growth have site-specific skeletal effects: a cotwin control study. Osteoporos Int 16:1225-1232

151. Chevalley T, Bonjour JP, Ferrari S, Rizzoli R (2008) High-protein intake enhances the positive impact of physical activity on BMC in prepubertal boys. J Bone Miner Res 23:131-142

152. Esterle L, Sabatier JP, Guillon-Metz F, Walrant-Debray O, Guaydier-Souquieres G, Jehan F, Garabedian M (2009) Milk, rather than other foods, is associated with vertebral bone mass and circulating IGF-1 in female adolescents. Osteoporos Int 20: $567-575$
153. Ekbote VH, Khadilkar AV, Chiplonkar SA, Khadilkar VV (2011) Determinants of bone mineral content and bone area in Indian preschool children. J Bone Miner Metab 29:334-341

154. Libuda L, Wudy SA, Schoenau E, Remer T (2011) Comparison of the effects of dietary protein, androstenediol and forearm muscle area on radial bone variables in healthy prepubertal children. Br J Nutr 105:428-435

155. Iuliano-Burns S, Saxon L, Naughton G, Gibbons K, Bass SL (2003) Regional specificity of exercise and calcium during skeletal growth in girls: a randomized controlled trial. J Bone Miner Res 18:156-162

156. Stear SJ, Prentice A, Jones SC, Cole TJ (2003) Effect of a calcium and exercise intervention on the bone mineral status of 16-18-yold adolescent girls. Am J Clin Nutr 77:985-992

157. Bass SL, Naughton G, Saxon L, Iuliano-Burns S, Daly R, Briganti EM, Hume C, Nowson C (2007) Exercise and calcium combined results in a greater osteogenic effect than either factor alone: a blinded randomized placebo-controlled trial in boys. J Bone Miner Res 22:458-464

158. Courteix D, Jaffre C, Lespessailles E, Benhamou L (2005) Cumulative effects of calcium supplementation and physical activity on bone accretion in premenarchal children: a double-blind randomised placebo-controlled trial. Int J Sports Med 26:332-338

159. Cheng S, Lyytikainen A, Kroger H, Lamberg-Allardt C, Alen M, Koistinen A, Wang QJ, Suuriniemi M, Suominen H, Mahonen A, Nicholson PH, Ivaska KK, Korpela R, Ohlsson C, Vaananen KH, Tylavsky F (2005) Effects of calcium, dairy product, and vitamin D supplementation on bone mass accrual and body composition in 10-12-y-old girls: a 2-y randomized trial. Am J Clin Nutr 82: 1115-1126, quiz 1147-1118

160. Dibba B, Prentice A, Ceesay M, Stirling DM, Cole TJ, Poskitt EM (2000) Effect of calcium supplementation on bone mineral accretion in Gambian children accustomed to a low-calcium diet. Am J Clin Nutr 71:544-549

161. Cameron MA, Paton LM, Nowson CA, Margerison C, Frame M, Wark JD (2004) The effect of calcium supplementation on bone density in premenarcheal females: a co-twin approach. J Clin Endocrinol Metab 89:4916-4922

162. Prentice A, Ginty F, Stear SJ, Jones SC, Laskey MA, Cole TJ (2005) Calcium supplementation increases stature and bone mineral mass of 16- to 18-year-old boys. J Clin Endocrinol Metab 90: 3153-3161

163. Moyer-Mileur LJ, Xie B, Ball SD, Pratt T (2003) Bone mass and density response to a 12 -month trial of calcium and vitamin $\mathrm{D}$ supplement in preadolescent girls. J Musculoskelet Neuronal Interact 3:63-70

164. Greene DA, Naughton GA (2011) Calcium and vitamin-D supplementation on bone structural properties in peripubertal female identical twins: a randomised controlled trial. Osteoporos Int 22: 489-498

165. Lambert HL, Eastell R, Karnik K, Russell JM, Barker ME (2008) Calcium supplementation and bone mineral accretion in adolescent girls: an 18-mo randomized controlled trial with 2-y followup. Am J Clin Nutr 87:455-462

166. Gibbons MJ, Gilchrist NL, Frampton C, Maguire P, Reilly PH, March RL, Wall CR (2004) The effects of a high calcium dairy food on bone health in pre-pubertal children in New Zealand. Asia Pac J Clin Nutr 13:341-347

167. Ho SC, Guldan GS, Woo J, Yu R, Tse MM, Sham A, Cheng J (2005) A prospective study of the effects of 1-year calcium-fortified soy milk supplementation on dietary calcium intake and bone health in Chinese adolescent girls aged 14 to 16 . Osteoporos Int 16:1907-1916

168. Chevalley T, Bonjour JP, Ferrari S, Hans D, Rizzoli R (2005) Skeletal site selectivity in the effects of calcium supplementation on areal bone mineral density gain: a randomized, double-blind, 
placebo-controlled trial in prepubertal boys. J Clin Endocrinol Metab 90:3342-3349

169. Merrilees MJ, Smart EJ, Gilchrist NL, Frampton C, Turner JG, Hooke E, March RL, Maguire P (2000) Effects of dairy food supplements on bone mineral density in teenage girls. Eur J Nutr 39:256-262

170. Du X, Zhu K, Trube A, Zhang Q, Ma G, Hu X, Fraser DR, Greenfield H (2004) School-milk intervention trial enhances growth and bone mineral accretion in Chinese girls aged 10 12 years in Beijing. Br J Nutr 92:159-168

171. Carter LM, Whiting SJ, Drinkwater DT, Zello GA, Faulkner RA, Bailey DA (2001) Self-reported calcium intake and bone mineral content in children and adolescents. J Am Coll Nutr 20:502-509

172. Lappe JM, Watson P, Gilsanz V, Hangartner T, Kalkwarf HJ, Oberfield S, Shepherd J, Winer KK, Zemel B (2015) The longitudinal effects of physical activity and dietary calcium on bone mass accrual across stages of pubertal development. J Bone Miner Res 30:156-164

173. Molgaard C, Larnkjaer A, Cashman KD, Lamberg-Allardt C, Jakobsen J, Michaelsen KF (2010) Does vitamin D supplementation of healthy Danish Caucasian girls affect bone turnover and bone mineralization? Bone 46:432-439

174. Lloyd T, Chinchilli VM, Johnson-Rollings N, Kieselhorst K, Eggli DF, Marcus R (2000) Adult female hip bone density reflects teenage sports-exercise patterns but not teenage calcium intake. Pediatrics 106:40-44

175. El-Hajj Fuleihan G, Nabulsi M, Tamim H, Maalouf J, Salamoun M, Khalife H, Choucair M, Arabi A, Vieth R (2006) Effect of vitamin $\mathrm{D}$ replacement on musculoskeletal parameters in school children: a randomized controlled trial. J Clin Endocrinol Metab 91:405-412

176. Al-Shaar L, Nabulsi M, Maalouf J, El-Rassi R, Vieth R, Beck TJ, El-Hajj Fuleihan G (2013) Effect of vitamin D replacement on hip structural geometry in adolescents: a randomized controlled trial. Bone 56:296-303

177. Viljakainen HT, Natri AM, Karkkainen M, Huttunen MM, Palssa A, Jakobsen J, Cashman KD, Molgaard C, Lamberg-Allardt C (2006) A positive dose-response effect of vitamin D supplementation on site-specific bone mineral augmentation in adolescent girls: a double-blinded randomized placebo-controlled 1-year intervention. J Bone Miner Res 21:836-844

178. Khadilkar AV, Sayyad MG, Sanwalka NJ, Bhandari DR, Naik S, Khadilkar VV, Mughal MZ (2010) Vitamin D supplementation and bone mass accrual in underprivileged adolescent Indian girls. Asia Pac J Clin Nutr 19:465-472

179. Ward KA, Das G, Roberts SA, Berry JL, Adams JE, Rawer R, Mughal MZ (2010) A randomized, controlled trial of vitamin D supplementation upon musculoskeletal health in postmenarchal females. J Clin Endocrinol Metab 95:4643-4651

180. Andersen R, Molgaard C, Skovgaard LT, Brot C, Cashman KD, Jakobsen J, Lamberg-Allardt C, Ovesen L (2008) Effect of vitamin D supplementation on bone and vitamin D status among Pakistani immigrants in Denmark: a randomised double-blinded placebo-controlled intervention study. Br J Nutr 100:197-207

181. Breen ME, Laing EM, Hall DB, Hausman DB, Taylor RG, Isales CM, Ding KH, Pollock NK, Hamrick MW, Baile CA, Lewis RD (2011) 25-hydroxyvitamin D, insulin-like growth factor-I, and bone mineral accrual during growth. J Clin Endocrinol Metab 96:E89-E98

182. Cheng S, Tylavsky F, Kröger H, Kärkkäinen M, Lyytikäinen A, Koistinen A, Mahonen A, Alen M, Halleen J, Väänänen K, Lamberg-Allardt C (2003) Association of low 25hydroxyvitamin D concentrations with elevated parathyroid hormone concentrations and low cortical bone density in early pubertal and prepubertal Finnish girls. Am J Clin Nutr 78:485-492
183. Foo LH, Zhang Q, Zhu K, Ma G, Hu X, Greenfield H, Fraser DR (2009) Low vitamin D status has an adverse influence on bone mass, bone turnover, and muscle strength in Chinese adolescent girls. J Nutr 139:1002-1007

184. Lee YA, Kim JY, Kang MJ, Chung SJ, Shin CH, Yang SW (2013) Adequate vitamin D status and adiposity contribute to bone health in peripubertal nonobese children. J Bone Miner Metab 31:337345

185. Carpenter TO, DeLucia MC, Zhang JH, Bejnerowicz G, Tartamella L, Dziura J, Petersen KF, Befroy D, Cohen D (2006) A randomized controlled study of effects of dietary magnesium oxide supplementation on bone mineral content in healthy girls. J Clin Endocrinol Metab 91:4866-4872

186. Grobler SR, Louw AJ, Chikte UM, Rossouw RJ, van W Kotze TJ (2009) The relationships between two different drinking water fluoride levels, dental fluorosis and bone mineral density of children. Open Dent J 3:48-54

187. Levy SM, Eichenberger-Gilmore J, Warren JJ, Letuchy E, Broffitt B, Marshall TA, Burns T, Willing M, Janz K, Torner JC (2009) Associations of fluoride intake with children's bone measures at age 11. Community Dent Oral Epidemiol 37:416-426

188. Levy SM, Warren JJ, Phipps K, Letuchy E, Broffitt B, Eichenberger-Gilmore J, Burns TL, Kavand G, Janz KF, Torner JC, Pauley CA (2014) Effects of life-long fluoride intake on bone measures of adolescents: a prospective cohort study. J Dent Res 93:353-359

189. Prynne CJ, Mishra GD, O'Connell MA, Muniz G, Laskey MA, Yan L, Prentice A, Ginty F (2006) Fruit and vegetable intakes and bone mineral status: a cross sectional study in 5 age and sex cohorts. Am J Clin Nutr 83:1420-1428

190. Laudermilk M, Manore M, Thomson C, Houtkooper L, Farr J, Going S (2012) Vitamin C and zinc intakes are related to bone macroarchitectural structure and strength in prepubescent girls. Calcif Tissue Int 91:430-439

191. O'Connor E, Molgaard C, Michaelsen KF, Jakobsen J, LambergAllardt CJ, Cashman KD (2007) Serum percentage undercarboxylated osteocalcin, a sensitive measure of vitamin $\mathrm{K}$ status, and its relationship to bone health indices in Danish girls. Br J Nutr 97:661-666

192. Kalkwarf HJ, Khoury JC, Bean J, Elliot JG (2004) Vitamin K, bone turnover, and bone mass in girls. Am J Clin Nutr 80:10751080

193. Abrams SA, Griffin IJ, Hawthorne KM, Liang L, Gunn SK, Darlington G, Ellis KJ (2005) A combination of prebiotic shortand long-chain inulin-type fructans enhances calcium absorption and bone mineralization in young adolescents. Am J Clin Nutr 82: 471-476

194. McGartland C, Robson PJ, Murray L, Cran G, Savage MJ, Watkins D, Rooney M, Boreham C (2003) Carbonated soft drink consumption and bone mineral density in adolescence: the Northern Ireland Young Hearts project. J Bone Miner Res 18: 1563-1569

195. McGartland CP, Robson PJ, Murray LJ, Cran GW, Savage MJ, Watkins DC, Rooney MM, Boreham CA (2004) Fruit and vegetable consumption and bone mineral density: the Northern Ireland Young Hearts Project. Am J Clin Nutr 80:1019-1023

196. Tylavsky FA, Holliday K, Danish R, Womack C, Norwood J, Carbone L (2004) Fruit and vegetable intakes are an independent predictor of bone size in early pubertal children. Am J Clin Nutr 79:311-317

197. Whiting SJ, Vatanparast H, Baxter-Jones A, Faulkner RA, Mirwald R, Bailey DA (2004) Factors that affect bone mineral accrual in the adolescent growth spurt. J Nutr 134:696S-700S

198. Vatanparast H, Baxter-Jones A, Faulkner RA, Bailey DA, Whiting SJ (2005) Positive effects of vegetable and fruit consumption and calcium intake on bone mineral accrual in boys during growth 
from childhood to adolescence: the University of Saskatchewan Pediatric Bone Mineral Accrual Study. Am J Clin Nutr 82:700 706

199. Ma D, Jones G (2004) Soft drink and milk consumption, physical activity, bone mass, and upper limb fractures in children: a population-based case-control study. Calcif Tissue Int 75:286291

200. Wyshak G (2000) Teenaged girls, carbonated beverage consumption, and bone fractures. Arch Pediatr Adolesc Med 154:610-613

201. Manias K, McCabe D, Bishop N (2006) Fractures and recurrent fractures in children; varying effects of environmental factors as well as bone size and mass. Bone 39:652-657

202. Libuda L, Alexy U, Remer T, Stehle P, Schoenau E, Kersting M (2008) Association between long-term consumption of soft drinks and variables of bone modeling and remodeling in a sample of healthy German children and adolescents. Am J Clin Nutr 88: 1670-1677

203. Hasling C, Søndergaard K, Charles P, Mosekilde L (1992) Calcium metabolism in postmenopausal osteoporotic women is determined by dietary calcium and coffee intake. J Nutr 122 : $1119-1126$

204. Conlisk AJ, Galuska DA (2000) Is caffeine associated with bone mineral density in young adult women? Prev Med 31:562-568

205. Ho-Pham LT, Nguyen ND, Nguyen TV (2009) Effect of vegetarian diets on bone mineral density: a Bayesian meta-analysis. Am J Clin Nutr 90:943-950

206. Appleby P, Roddam A, Allen N, Key T (2007) Comparative fracture risk in vegetarians and nonvegetarians in EPIC-Oxford. Eur J Clin Nutr 61:1400-1406

207. Weaver CM, Hill KM (2013) Osteoporosis: the early years. In: Coulston AM, Boushey CJ, Ferruzzi MG (eds) Nutrition in the prevention and treatment of disease, 3rd edn. Elsevier Inc., San Diego, pp 839-858

208. Weaver CM (2010) Role of dairy beverages in the diet. Physiol Behav 100:63-66

209. Wallace TC, Reider C, Fulgoni VL 3rd (2013) Calcium and vitamin $\mathrm{D}$ disparities are related to gender, age, race, household income level, and weight classification but not vegetarian status in the United States: analysis of the NHANES 2001-2008 data set. J Am Coll Nutr 32:321-330

210. Lanham-New SA (2009) Is "vegetarianism" a serious risk factor for osteoporotic fracture? Am J Clin Nutr 90:910911

211. Koo WW, Hammami M, Margeson DP, Nwaesei C, Montalto MB, Lasekan JB (2003) Reduced bone mineralization in infants fed palm olein-containing formula: a randomized, double-blinded, prospective trial. Pediatrics 111: $1017-1023$

212. Molgaard C, Larnkjaer A, Mark AB, Michaelsen KF (2011) Are early growth and nutrition related to bone health in adolescence? The Copenhagen Cohort Study of infant nutrition and growth. Am J Clin Nutr 94:1865S-1869S

213. Harvey NC, Robinson SM, Crozier SR, Marriott LD, Gale CR, Cole ZA, Inskip HM, Godfrey KM, Cooper C (2009) Breast-feeding and adherence to infant feeding guidelines do not influence bone mass at age 4 years. Br J Nutr 102:915-920

214. Pirila S, Taskinen M, Viljakainen H, Kajosaari M, Turanlahti M, Saarinen-Pihkala UM, Makitie O (2011) Infant milk feeding influences adult bone health: a prospective study from birth to 32 years. PLoS One 6:e19068

215. Kalkwarf HJ, Zemel BS, Yolton K, Heubi JE (2013) Bone mineral content and density of the lumbar spine of infants and toddlers: influence of age, sex, race, growth, and human milk feeding. J Bone Miner Res 28:206-212
216. Butte NF, Wong WW, Hopkinson JM, Smith EO, Ellis KJ (2000) Infant feeding mode affects early growth and body composition. Pediatrics 106:1355-1366

217. Jones G, Riley M, Dwyer T (2000) Breastfeeding in early life and bone mass in prepubertal children: a longitudinal study. Osteoporos Int 11:146-152

218. Jones G, Hynes KL, Dwyer T (2013) The association between breastfeeding, maternal smoking in utero, and birth weight with bone mass and fractures in adolescents: a 16-year longitudinal study. Osteoporos Int 24:1605-1611

219. Ma D, Jones G (2003) The association between bone mineral density, metacarpal morphometry, and upper limb fractures in children: a population-based case-control study. J Clin Endocrinol Metab 88:1486-1491

220. Fewtrell MS, Kennedy K, Murgatroyd PR, Williams JE, Chomtho S, Lucas A (2013) Breast-feeding and formula feeding in healthy term infants and bone health at age 10 years. Br J Nutr 110:10611067

221. Young RJ, Antonson DL, Ferguson PW, Murray ND, Merkel K, Moore TE (2005) Neonatal and infant feeding: effect on bone density at 4 years. J Pediatr Gastroenterol Nutr 41:88-93

222. Bonny AE, Secic M, Cromer BA (2011) Relationship between weight and bone mineral density in adolescents on hormonal contraception. J Pediatr Adolesc Gynecol 24:35-38

223. Lloyd T, Taylor DS, Lin HM, Matthews AE, Eggli DF, Legro RS (2000) Oral contraceptive use by teenage women does not affect peak bone mass: a longitudinal study. Fertil Steril 74:734-738

224. Lloyd T, Petit MA, Lin HM, Beck TJ (2004) Lifestyle factors and the development of bone mass and bone strength in young women. J Pediatr 144:776-782

225. Lara-Torre E, Edwards CP, Perlman S, Hertweck SP (2004) Bone mineral density in adolescent females using depot medroxyprogesterone acetate. J Pediatr Adolesc Gynecol 17:17-21

226. Cromer BA, Bonny AE, Stager M, Lazebnik R, Rome E, Ziegler J, Camlin-Shingler K, Secic M (2008) Bone mineral density in adolescent females using injectable or oral contraceptives: a $24-$ month prospective study. Fertil Steril 90:2060-2067

227. Rome E, Ziegler J, Secic M, Bonny A, Stager M, Lazebnik R, Cromer BA (2004) Bone biochemical markers in adolescent girls using either depot medroxyprogesterone acetate or an oral contraceptive. J Pediatr Adolesc Gynecol 17:373-377

228. Pikkarainen E, Lehtonen-Veromaa M, Mottonen T, Kautiainen H, Viikari J (2008) Estrogen-progestin contraceptive use during adolescence prevents bone mass acquisition: a 4-year follow-up study. Contraception 78:226-231

229. Biason TP, Goldberg TB, Kurokawa CS, Moretto MR, Teixeira AS, Nunes HR (2015) Low-dose combined oral contraceptive use is associated with lower bone mineral content variation in adolescents over a 1-year period. BMC Endocr Disord 15:15

230. Walsh JS, Eastell R, Peel NFA (2008) Effects of Depot medroxyprogesterone acetate on bone density and bone metabolism before and after peak bone mass: a case-control study. J Clin Endocrinol Metab 93:1317-1323

231. Korkor AB, Eastwood D, Bretzmann C (2009) Effects of gender, alcohol, smoking, and dairy consumption on bone mass in Wisconsin adolescents. WMJ 108:181-188

232. Dorn LD, Pabst S, Sontag LM, Kalkwarf HJ, Hillman JB, Susman EJ (2011) Bone mass, depressive, and anxiety symptoms in adolescent girls: variation by smoking and alcohol use. J Adolesc Health 49:498-504

233. Dorn LD, Beal SJ, Kalkwarf HJ, Pabst S, Noll JG, Susman EJ (2013) Longitudinal impact of substance use and depressive symptoms on bone accrual among girls aged 11-19 years. J Adolesc Health 52:393-399

234. Winther A, Dennison E, Ahmed LA, Furberg AS, Grimnes G, Jorde R, Gjesdal CG, Emaus N (2014) The Tromso study: fit 
futures: a study of Norwegian adolescents' lifestyle and bone health. Arch Osteoporos 9:185

235. Lucas R, Fraga S, Ramos E, Barros H (2012) Early initiation of smoking and alcohol drinking as a predictor of lower forearm bone mineral density in late adolescence: a cohort study in girls. PLoS One 7:e46940

236. Kyriazopoulos P, Trovas G, Charopoulos J, Antonogiannakis E, Galanos A, Lyritis G (2006) Lifestyle factors and forearm bone density in young Greek men. Clin Endocrinol (Oxf) 65:234-238

237. Elgan C, Dykes AK, Samsioe G (2002) Bone mineral density and lifestyle among female students aged 16-24 years. Gynecol Endocrinol 16:91-98

238. Eleftheriou KI, Rawal JS, James LE, Payne JR, Loosemore M, Pennell DJ, World M, Drenos F, Haddad FS, Humphries SE, Sanders J, Montgomery HE (2013) Bone structure and geometry in young men: the influence of smoking, alcohol intake and physical activity. Bone 52:17-26

239. Lorentzon M, Mellstrom D, Haug E, Ohlsson C (2007) Smoking is associated with lower bone mineral density and reduced cortical thickness in young men. J Clin Endocrinol Metab 92:497-503

240. Elgan C, Samsioe G, Dykes AK (2003) Influence of smoking and oral contraceptives on bone mineral density and bone remodeling in young women: a 2-year study. Contraception 67:439-447

241. Lappe J, Cullen D, Haynatzki G, Recker R, Ahlf R, Thompson K (2008) Calcium and vitamin d supplementation decreases incidence of stress fractures in female navy recruits. J Bone Miner Res 23:741-749

242. Yu CC, Sung RY, So RC, Lui KC, Lau W, Lam PK, Lau EM (2005) Effects of strength training on body composition and bone mineral content in children who are obese. J Strength Cond Res 19:667-672

243. Nichols DL, Sanborn CF, Love AM (2001) Resistance training and bone mineral density in adolescent females. J Pediatr 139: 494-500

244. Heinonen A, Sievanen H, Kannus P, Oja P, Pasanen M, Vuori I (2000) High-impact exercise and bones of growing girls: a 9month controlled trial. Osteoporos Int 11:1010-1017

245. Molgaard C, Thomsen BL, Michaelsen KF (2001) The influence of calcium intake and physical activity on bone mineral content and bone size in healthy children and adolescents. Osteoporos Int 12:887-894

246. Biddle SJ, Gorely T, Pearson N, Bull FC (2011) An assessment of self-reported physical activity instruments in young people for population surveillance: Project ALPHA. Int J Behav Nutr Phys Act $8: 1$

247. Helmerhorst HJ, Brage S, Warren J, Besson H, Ekelund U (2012) A systematic review of reliability and objective criterion-related validity of physical activity questionnaires. Int J Behav Nutr Phys Act 9:103

248. Janz KF, Letuchy EM, Burns TL, Eichenberger Gilmore JM, Torner JC, Levy SM (2014) Objectively measured physical activity trajectories predict adolescent bone strength: Iowa Bone Development Study. Br J Sports Med 48:1032-1036

249. Specker B, Binkley T, Fahrenwald N (2004) Increased periosteal circumference remains present 12 months after an exercise intervention in preschool children. Bone 35:1383-1388

250. Macdonald HM, Cooper DM, McKay HA (2009) Anteriorposterior bending strength at the tibial shaft increases with physical activity in boys: evidence for non-uniform geometric adaptation. Osteoporos Int 20:61-70

251. Jackowski SA, Kontulainen SA, Cooper DM, Lanovaz JL, Beck TJ, Baxter-Jones AD (2014) Adolescent physical activity and bone strength at the proximal femurin adulthood. Med Sci Sports Exerc 46:736-744

252. Duckham RL, Baxter-Jones AD, Johnston JD, Vatanparast H, Cooper D, Kontulainen S (2014) Does physical activity in adolescence have site-specific and sex-specific benefits on young adult bone size, content, and estimated strength? J Bone Miner Res 29:479-486

253. Mangano KM, Sahni S, Kerstetter JE, Kenny AM, Hannan MT (2013) Polyunsaturated fatty acids and their relation with bone and muscle health in adults. Curr Osteoporos Rep 11:203-212

254. Damsgaard CT, Molgaard C, Matthiessen J, Gyldenlove SN, Lauritzen L (2012) The effects of n-3 long-chain polyunsaturated fatty acids on bone formation and growth factors in adolescent boys. Pediatr Res 71:713-719

255. Weaver CM, Proulx WR, Heaney R (1999) Choices for achieving adequate dietary calcium with a vegetarian diet. Am J Clin Nutr 70:543S-548S

256. Thacher TD, Fischer PR, Strand MA, Pettifor JM (2006) Nutritional rickets around the world: causes and future directions. Ann Trop Paediatr 26:1-16

257. Pettifor JM (2004) Nutritional rickets: deficiency of vitamin D, calcium, or both? Am J Clin Nutr 80:1725S-1729S

258. Braun M, Palacios C, Wigertz K, Jackman LA, Bryant RJ, McCabe LD, Martin BR, McCabe GP, Peacock M, Weaver CM (2007) Racial differences in skeletal calcium retention in adolescent girls with varied controlled calcium intakes. Am J Clin Nutr 85:1657-1663

259. Jackman LA, Millane SS, Martin BR, Wood OB, McCabe GP, Peacock M, Weaver CM (1997) Calcium retention in relation to calcium intake and postmenarcheal age in adolescent females. Am J Clin Nutr 66:327-333

260. Wu L, Martin BR, Braun MM, Wastney ME, McCabe GP, McCabe LD, DiMeglio LA, Peacock M, Weaver CM (2010) Calcium requirements and metabolism in Chinese-American boys and girls. J Bone Miner Res 25:1842-1849

261. Braun M, Martin BR, Kern M, McCabe GP, Peacock M, Jiang Z, Weaver CM (2006) Calcium retention in adolescent boys on a range of controlled calcium intakes. Am J Clin Nutr 84:414-418

262. Palacios C, Martin BR, McCabe GP, McCabe L, Peacock M, Weaver CM (2014) Dietary calcium requirements do not differ between Mexican-American boys and girls. J Nutr 144:11671173

263. Del Valle HB, Yaktine AL, Taylor CL, Ross AC (2011) Dietary reference intakes for calcium and vitamin D. National Academies Press

264. Looker AC (2006) Dietary calcium: recommendations and intakes around the world. In: Calcium in human health. Humana Press, Totowa, pp 105-127

265. Heaney RP (2014) Guidelines for optimizing design and analysis of clinical studies of nutrient effects. Nutr Rev 72:48-54

266. Winzenberg T, Powell S, Shaw KA, Jones G (2011) Effects of vitamin D supplementation on bone density in healthy children: systematic review and meta-analysis. BMJ 342:c7254

267. DeLuca HF, Sicinski RR, Tanaka Y, Stern PH, Smith CM (1988) Biological activity of 1,25-dihydroxyvitamin D2 and 24-epi-1,25dihydroxyvitamin D2. Am J Physiol 254:E402-E406

268. Lewis RD, Laing EM, Hill Gallant KM, Hall DB, McCabe GP, Hausman DB, Martin BR, Warden SJ, Peacock M, Weaver CM (2013) A randomized trial of vitamin $\mathrm{D}(3)$ supplementation in children: dose-response effects on vitamin $\mathrm{D}$ metabolites and calcium absorption. J Clin Endocrinol Metab 98:4816-4825

269. Wigertz K, Palacios C, Jackman LA, Martin BR, McCabe LD, McCabe GP, Peacock M, Pratt JH, Weaver CM (2005) Racial differences in calcium retention in response to dietary salt in adolescent girls. Am J Clin Nutr 81:845-850

270. Palacios C, Wigertz K, Braun M, Martin BR, McCabe GP, McCabe L, Pratt JH, Peacock M, Weaver CM (2013) Magnesium retention from metabolic-balance studies in female adolescents: impact of race, dietary salt, and calcium. Am J Clin Nutr 97:1014-1019 
271. Palacios C, Wigertz K, Martin BR, Braun M, Pratt JH, Peacock M, Weaver CM (2010) Racial differences in potassium homeostasis in response to differences in dietary sodium in girls. Am J Clin Nutr 91:597-603

272. Szulc P, Delmas P (1994) Is there a role for vitamin K deficiency in osteoporosis? In: Challenges of modern medicine, nutritional aspects of osteoporosis (Proceedings of the Second International Symposium on Osteoporosis, Lausanne). Serono Symposia Publications, Rome, pp 357-366

273. National Research Council (2006) Fluoride in drinking water: a scientific review of EPA's standards. The National Academies Press, Washington

274. Bratteb LE, Samuelson G, Sandhagen B, Mallmin H, Lantz H, Sjostrom L (2002) Whole-body mineral measurements in Swedish adolescents at 17 years compared to 15 years of age. Acta Paediatr 91:1031-1038

275. US Department of Agriculture (2010) Dietary guidelines for Americans, 2010, 7th edn. US Government Printing Office, Washington

276. Weaver CM (2013) Potassium and health. Adv Nutr 4:368S-377S

277. Weaver CM, Alekel DL, Ward WE, Ronis MJ (2012) Flavonoid intake and bone health. J Nutr Gerontol Geriatr 31:239-253

278. Kristensen M, Jensen M, Kudsk J, Henriksen M, Molgaard C (2005) Short-term effects on bone turnover of replacing milk with cola beverages: a 10-day interventional study in young men. Osteoporos Int 16:1803-1808

279. Wastney ME, Martin BR, Peacock M, Smith D, Jiang XY, Jackman LA, Weaver CM (2000) Changes in calcium kinetics in adolescent girls induced by high calcium intake. J Clin Endocrinol Metab 85:4470-4475

280. Sjogren K, Engdahl C, Henning P, Lerner UH, Tremaroli V, Lagerquist MK, Backhed F, Ohlsson C (2012) The gut microbiota regulates bone mass in mice. J Bone Miner Res 27:1357-1367

281. Abrams SA, Griffin IJ, Hawthorne KM (2007) Young adolescents who respond to an inulin-type fructan substantially increase total absorbed calcium and daily calcium accretion to the skeleton. J Nutr 137:2524S-2526S

282. Whisner CM, Martin BR, Nakatsu CH, McCabe GP, McCabe LD, Peacock M, Weaver CM (2014) Soluble maize fibre affects shortterm calcium absorption in adolescent boys and girls: a randomised controlled trial using dual stable isotopic tracers. $\mathrm{Br}$ J Nutr 112:446-456

283. Whisner CM, Martin BR, Schoterman MH, Nakatsu CH, McCabe LD, McCabe GP, Wastney ME, van den Heuvel EG, Weaver CM (2013) Galacto-oligosaccharides increase calcium absorption and gut bifidobacteria in young girls: a double-blind cross-over trial. Br J Nutr 110:1292-1303

284. Specker BL, Beck A, Kalkwarf H, Ho M (1997) Randomized trial of varying mineral intake on total body bone mineral accretion during the first year of life. Pediatrics 99:E12

285. Wagner CL, Greer FR (2008) Prevention of rickets and vitamin D deficiency in infants, children, and adolescents. Pediatrics 122: $1142-1152$

286. Polatti F, Perotti F, Filippa N, Gallina D, Nappi RE (1995) Bone mass and long-term monophasic oral contraceptive treatment in young women. Contraception 51:221-224

287. Warholm L, Petersen KR, Ravn P (2012) Combined oral contraceptives' influence on weight, body composition, height, and bone mineral density in girls younger than 18 years: a systematic review. Eur J Contracept Reprod Health Care 17:245-253

288. Tremollieres F (2013) Impact of oral contraceptive on bone metabolism. Best Pract Res Clin Endocrinol Metab 27:47-53

289. Ziglar S, Hunter TS (2012) The effect of hormonal oral contraception on acquisition of peak bone mineral density of adolescents and young women. J Pharm Pract 25:331-340
290. Harel Z, Johnson CC, Gold MA, Cromer B, Peterson E, Burkman R, Stager M, Brown R, Bruner A, Coupey S, Hertweck P, Bone H, Wolter K, Nelson A, Marshall S, Bachrach LK (2010) Recovery of bone mineral density in adolescents following the use of depot medroxyprogesterone acetate contraceptive injections. Contraception 81:281-291

291. Wosje KS, Kalkwarf HJ (2007) Bone density in relation to alcohol intake among men and women in the United States. Osteoporos Int 18:391-400

292. Office of Juvenile Justice and Delinquency Prevention (2005) Drinking in America: myths, reality and prevention policy. US Department of Justice, Office of Justice Programs, Office of Juvenile Justice and Delinquency Prevention, Washington

293. US Centers for Disease Control and Prevention (2013) Trends in current cigarette smoking. http://www.cdc.gov/tobacco/data statistics/tables/trends/cig_smoking/index.htm. Accessed 5 Aug 2014

294. Blum M, Harris SS, Must A, Phillips SM, Rand WM, DawsonHughes B (2002) Household tobacco smoke exposure is negatively associated with premenopausal bone mass. Osteoporos Int 13: 663-668

295. MacKelvie KJ, Petit MA, Khan KM, Beck TJ, McKay HA (2004) Bone mass and structure are enhanced following a 2-year randomized controlled trial of exercise in prepubertal boys. Bone 34:755764

296. Weeks BK, Young CM, Beck BR (2008) Eight months of regular in-school jumping improves indices of bone strength in adolescent boys and Girls: the POWER PE study. J Bone Miner Res 23: 1002-1011

297. McKay HA, MacLean L, Petit M, MacKelvie-O’Brien K, Janssen P, Beck T, Khan KM (2005) "Bounce at the Bell": a novel program of short bouts of exercise improves proximal femur bone mass in early pubertal children. Br J Sports Med 39:521-526

298. Linden C, Alwis G, Ahlborg H, Gardsell P, Valdimarsson O, Stenevi-Lundgren S, Besjakov J, Karlsson MK (2007) Exercise, bone mass and bone size in prepubertal boys: one-year data from the pediatric osteoporosis prevention study. Scand J Med Sci Sports 17:340-347

299. Macdonald HM, Kontulainen SA, Petit MA, Beck TJ, Khan KM, McKay HA (2008) Does a novel school-based physical activity model benefit femoral neck bone strength in pre- and early pubertal children? Osteoporos Int 19:1445-1456

300. Alwis G, Linden C, Stenevi-Lundgren S, Ahlborg HG, Besjakov J, Gardsell P, Karlsson MK (2008) A one-year exercise intervention program in pre-pubertal girls does not influence hip structure. BMC Musculoskelet Disord 9:9

301. Greene DA, Wiebe PN, Naughton GA (2009) Influence of droplanding exercises on bone geometry and biomechanical properties in prepubertal girls: a randomized controlled study. Calcif Tissue Int 85:94-103

302. Anliker E, Dick C, Rawer R, Toigo M (2012) Effects of jumping exercise on maximum ground reaction force and bone in 8 - to $12-$ year-old boys and girls: a 9-month randomized controlled trial. J Musculoskelet Neuronal Interact 12:56-67

303. Detter F, Rosengren BE, Dencker M, Lorentzon M, Nilsson JA, Karlsson MK (2014) A 6-year exercise program improves skeletal traits without affecting fracture risk: a prospective controlled study in 2621 children. J Bone Miner Res 29:1325-1336

304. Metcalf B, Henley W, Wilkin T (2012) Effectiveness of intervention on physical activity of children: systematic review and metaanalysis of controlled trials with objectively measured outcomes (EarlyBird 54). BMJ 345:e5888

305. Deere K, Sayers A, Rittweger J, Tobias JH (2012) Habitual levels of high, but not moderate or low, impact activity are positively related to hip BMD and geometry: results from a population-based study of adolescents. J Bone Miner Res 27:1887-1895 
306. Fuchs RK, Bauer JJ, Snow CM (2001) Jumping improves hip and lumbar spine bone mass in prepubescent children: a randomized controlled trial. J Bone Miner Res 16:148-156

307. Hind K, Burrows M (2007) Weight-bearing exercise and bone mineral accrual in children and adolescents: a review of controlled trials. Bone 40:14-27

308. Ju YI, Sone T, Ohnaru K, Tanaka K, Yamaguchi H, Fukunaga M (2014) Effects of different types of jump impact on trabecular bone mass and microarchitecture in growing rats. PLoS One 9:e107953

309. Office of the Surgeon General (2004) Bone health and osteoporosis: a report of the Surgeon General. US Department of Health and Human Services, Office of the Surgeon General, Rockville

310. Umemura Y, Ishiko T, Tsujimoto H, Miura H, Mokushi N, Suzuki $\mathrm{H}$ (1995) Effects of jump training on bone hypertrophy in young and old rats. Int J Sports Med 16:364-367

311. Hing KA (2004) Bone repair in the twenty-first century: biology, chemistry or engineering? Philos Transact A Math Phys Eng Sci 362:2821-2850

312. Westbroek I, van der Plas A, de Rooij KE, Klein-Nulend J, Nijweide PJ (2001) Expression of serotonin receptors in bone. J Biol Chem 276:28961-28968

313. Stanford CM, Brand RA (1999) Toward an understanding of implant occlusion and strain adaptive bone modeling and remodeling. J Prosthet Dent 81:553-561

314. Bachrach LK, Guido D, Katzman D, Litt IF, Marcus R (1990) Decreased bone density in adolescent girls with anorexia nervosa. Pediatrics 86:440-447

315. Soyka LA, Grinspoon S, Levitsky LL, Herzog DB, Klibanski A (1999) The effects of anorexia nervosa on bone metabolism in female adolescents. J Clin Endocrinol Metab 84:4489-4496

316. Soyka LA, Misra M, Frenchman A, Miller KK, Grinspoon S, Schoenfeld DA, Klibanski A (2002) Abnormal bone mineral accrual in adolescent girls with anorexia nervosa. J Clin Endocrinol Metab 87:4177-4185

317. Grinspoon S, Thomas E, Pitts S, Gross E, Mickley D, Miller K, Herzog D, Klibanski A (2000) Prevalence and predictive factors for regional osteopenia in women with anorexia nervosa. Ann Intern Med 133:790-794

318. Putman MS, Milliren CE, Derrico N, Uluer A, Sicilian L, Lapey A, Sawicki G, Gordon CM, Bouxsein ML, Finkelstein JS (2014) Compromised bone microarchitecture and estimated bone strength in young adults with cystic fibrosis. J Clin Endocrinol Metab 99: 3399-3407

319. Wu FJ, Sheu SY, Lin HC (2014) Osteoporosis is associated with antiepileptic drugs: a population-based study. Epileptic Disord 16: 333-342

320. Krebs-Smith SM, Guenther PM, Subar AF, Kirkpatrick SI, Dodd KW (2010) Americans do not meet federal dietary recommendations. J Nutr 140:1832-1838

321. Fulgoni VL 3rd, Keast DR, Bailey RL, Dwyer J (2011) Foods, fortificants, and supplements: where do Americans get their nutrients? J Nutr 141:1847-1854

322. Mattila PH, Piironen VI, Uusi-Rauva EJ, Koivistoinen PE (1994) Vitamin D contents in edible mushrooms. J Agric Food Chem 42: 2449-2453

323. Calvo MS, Whiting SJ, Barton CN (2004) Vitamin D fortification in the United States and Canada: current status and data needs. Am J Clin Nutr 80:1710S-1716S

324. Hohman EE, Martin BR, Lachcik PJ, Gordon DT, Fleet JC, Weaver CM (2011) Bioavailability and efficacy of vitamin D2 from UV-irradiated yeast in growing, vitamin D-deficient rats. J Agric Food Chem 59:2341-2346

325. Taylor CL, Patterson KY, Roseland JM, Wise SA, Merkel JM, Pehrsson PR, Yetley EA (2014) Including food 25hydroxyvitamin $\mathrm{D}$ in intake estimates may reduce the discrepancy between dietary and serum measures of vitamin D status. J Nutr 144:654-659

326. US Department of Health and Human Services (2008) Physical activity guidelines for Americans. US Government Printing Office, Washington

327. US Institute of Medicine (2013) Educating the student body: taking physical activity and physical education to school. National Academies Press, Washington

328. Eaton DK, Kann L, Kinchen S, Shanklin S, Flint KH, Hawkins J, Harris WA, Lowry R, McManus T, Chyen D, Whittle L, Lim C, Wechsler H (2012) Youth risk behavior surveillance-United States, 2011. MMWR Surveill Summ 61:1-162

329. Physical Activity Guidelines for Americans Midcourse Report Subcommittee of the President's Council on Fitness Sports \& Nutrition (2012) Physical activity guidelines for Americans midcourse report: strategies to increase physical activity among youth. US Department of Health and Human Services, Washington

330. Rozen GS, Rennert G, Dodiuk-Gad RP, Rennert HS, Ish-Shalom N, Diab G, Raz B, Ish-Shalom S (2003) Calcium supplementation provides an extended window of opportunity for bone mass accretion after menarche. Am J Clin Nutr 78:993-998

331. Dodiuk-Gad RP, Rozen GS, Rennert G, Rennert HS, Ish-Shalom S (2005) Sustained effect of short-term calcium supplementation on bone mass in adolescent girls with low calcium intake. Am J Clin Nutr 81:168-174

332. Molgaard C, Thomsen BL, Michaelsen KF (2004) Effect of habitual dietary calcium intake on calcium supplementation in 12-14y-old girls. Am J Clin Nutr 80:1422-1427

333. Matkovic V, Goel PK, Badenhop-Stevens NE, Landoll JD, Li B, Ilich JZ, Skugor M, Nagode LA, Mobley SL, Ha EJ, Hangartner TN, Clairmont A (2005) Calcium supplementation and bone mineral density in females from childhood to young adulthood: a randomized controlled trial. Am J Clin Nutr 81:175-188

334. Khadilkar A, Kadam N, Chiplonkar S, Fischer PR, Khadilkar V (2012) School-based calcium-vitamin D with micronutrient supplementation enhances bone mass in underprivileged Indian premenarchal girls. Bone 51:1-7

335. Wosje KS, Khoury PR, Claytor RP, Copeland KA, Hornung RW, Daniels SR, Kalkwarf HJ (2010) Dietary patterns associated with fat and bone mass in young children. Am J Clin Nutr 92:294-303

336. Afghani A, Xie B, Wiswell RA, Gong J, Li Y, Anderson Johnson C (2003) Bone mass of Asian adolescents in China: influence of physical activity and smoking. Med Sci Sports Exerc 35:720-729

337. Witzke KA, Snow CM (2000) Effects of plyometric jump training on bone mass in adolescent girls. Med Sci Sports Exerc 32:10511057

338. McKay HA, Petit MA, Schutz RW, Prior JC, Barr SI, Khan KM (2000) Augmented trochanteric bone mineral density after modified physical education classes: a randomized school-based exercise intervention study in prepubescent and early pubescent children. J Pediatr 136:156-162

339. Mackelvie KJ, McKay HA, Petit MA, Moran O, Khan KM (2002) Bone mineral response to a 7-month randomized controlled, school-based jumping intervention in 121 prepubertal boys: associations with ethnicity and body mass index. J Bone Miner Res 17: 834-844

340. Laing EM, Massoni JA, Nickols-Richardson SM, Modlesky CM, O'Connor PJ, Lewis RD (2002) A prospective study of bone mass and body composition in female adolescent gymnasts. J Pediatr 141:211-216

341. MacKelvie KJ, Khan KM, Petit MA, Janssen PA, McKay HA (2003) A school-based exercise intervention elicits substantial bone health benefits: a 2-year randomized controlled trial in girls. Pediatrics 112:e447

342. Van Langendonck L, Claessens AL, Vlietinck R, Derom C, Beunen G (2003) Influence of weight-bearing exercises on bone 
acquisition in prepubertal monozygotic female twins: a randomized controlled prospective study. Calcif Tissue Int 72:666-674

343. Laing EM, Wilson AR, Modlesky CM, O'Connor PJ, Hall DB, Lewis RD (2005) Initial years of recreational artistic gymnastics training improves lumbar spine bone mineral accrual in 4- to 8year-old females. J Bone Miner Res 20:509-519

344. Valdimarsson O, Linden C, Johnell O, Gardsell P, Karlsson MK (2006) Daily physical education in the school curriculum in prepubertal girls during 1 year is followed by an increase in bone mineral accrual and bone width - data from the prospective controlled Malmo pediatric osteoporosis prevention study. Calcif Tissue Int 78:65-71

345. Linden C, Ahlborg HG, Besjakov J, Gardsell P, Karlsson MK (2006) A school curriculum-based exercise program increases bone mineral accrual and bone size in prepubertal girls: two-year data from the Pediatric Osteoporosis Prevention (POP) study. J Bone Miner Res 21:829-835

346. Barbeau P, Johnson MH, Howe CA, Allison J, Davis CL, Gutin B, Lemmon CR (2007) Ten months of exercise improves general and visceral adiposity, bone, and fitness in black girls. Obesity (Silver Spring) 15:2077-2085

347. Schneider M, Dunton GF, Bassin S, Graham DJ, Eliakim AF, Cooper DM (2007) Impact of a school-based physical activity intervention on fitness and bone in adolescent females. J Phys Act Health 4:17-29

348. Meyer U, Romann M, Zahner L, Schindler C, Puder JJ, Kraenzlin M, Rizzoli R, Kriemler S (2011) Effect of a general school-based physical activity intervention on bone mineral content and density: a cluster-randomized controlled trial. Bone 48:792-797

349. Silva CC, Goldberg TB, Teixeira AS, Dalmas JC (2011) The impact of different types of physical activity on total and regional bone mineral density in young Brazilian athletes. J Sports Sci 29: 227-234

350. Lehtonen-Veromaa M, Mottonen T, Irjala K, Nuotio I, Leino A, Viikari J (2000) A 1-year prospective study on the relationship between physical activity, markers of bone metabolism, and bone acquisition in peripubertal girls. J Clin Endocrinol Metab 85: 3726-3732

351. Gustavsson A, Olsson T, Nordstrom P (2003) Rapid loss of bone mineral density of the femoral neck after cessation of ice hockey training: a 6-year longitudinal study in males. J Bone Miner Res 18:1964-1969

352. Nurmi-Lawton JA, Baxter-Jones AD, Mirwald RL, Bishop JA, Taylor P, Cooper C, New SA (2004) Evidence of sustained skeletal benefits from impact-loading exercise in young females: a 3year longitudinal study. J Bone Miner Res 19:314-322

353. Janz KF, Gilmore JM, Burns TL, Levy SM, Torner JC, Willing MC, Marshall TA (2006) Physical activity augments bone mineral accrual in young children: the Iowa Bone Development study. J Pediatr 148:793-799

354. Nordstrom A, Olsson T, Nordstrom P (2006) Sustained benefits from previous physical activity on bone mineral density in males. J Clin Endocrinol Metab 91:2600-2604

355. Janz KF, Letuchy EM, Eichenberger Gilmore JM, Burns TL, Torner JC, Willing MC, Levy SM (2010) Early physical activity provides sustained bone health benefits later in childhood. Med Sci Sports Exerc 42:1072-1078

356. Tervo T, Nordstrom P, Nordstrom A (2010) Effects of badminton and ice hockey on bone mass in young males: a 12-year follow-up. Bone 47:666-672

357. Erlandson MC, Kontulainen SA, Chilibeck PD, Arnold CM, Baxter-Jones AD (2011) Bone mineral accrual in 4- to 10-yearold precompetitive, recreational gymnasts: a 4-year longitudinal study. J Bone Miner Res 26:1313-1320

358. Scerpella TA, Dowthwaite JN, Rosenbaum PF (2011) Sustained skeletal benefit from childhood mechanical loading. Osteoporos Int 22:2205-2210

359. Erlandson MC, Kontulainen SA, Chilibeck PD, Arnold CM, Faulkner RA, Baxter-Jones AD (2012) Higher premenarcheal bone mass in elite gymnasts is maintained into young adulthood after long-term retirement from sport: a 14-year follow-up. J Bone Miner Res 27:104-110

360. Farr JN, Laddu DR, Blew RM, Lee VR, Going SB (2013) Effects of physical activity and muscle quality on bone development in girls. Med Sci Sports Exerc 45:2332-2340

361. Francis SL, Letuchy EM, Levy SM, Janz KF (2014) Sustained effects of physical activity on bone health: Iowa Bone Development Study. Bone 63:95-100

362. Cardadeiro G, Baptista F, Rosati N, Zymbal V, Janz KF, Sardinha LB (2014) Influence of physical activity and skeleton geometry on bone mass at the proximal femur in 10- to 12-year-old children-a longitudinal study. Osteoporos Int 25:2035-2045

363. Forwood MR, Baxter-Jones AD, Beck TJ, Mirwald RL, Howard A, Bailey DA (2006) Physical activity and strength of the femoral neck during the adolescent growth spurt: a longitudinal analysis. Bone 38:576-583

364. Janz KF, Gilmore JM, Levy SM, Letuchy EM, Burns TL, Beck TJ (2007) Physical activity and femoral neck bone strength during childhood: the Iowa Bone Development Study. Bone 41:216-222

365. Gruodyte-Raciene R, Erlandson MC, Jackowski SA, Baxter-Jones AD (2013) Structural strength development at the proximal femur in 4- to 10-year-old precompetitive gymnasts: a 4-year longitudinal hip structural analysis study. J Bone Miner Res 28:2592-2600

366. Fulgoni VL 3rd (2008) Current protein intake in America: analysis of the National Health and Nutrition Examination Survey, 20032004. Am J Clin Nutr 87:1554s-1557s 